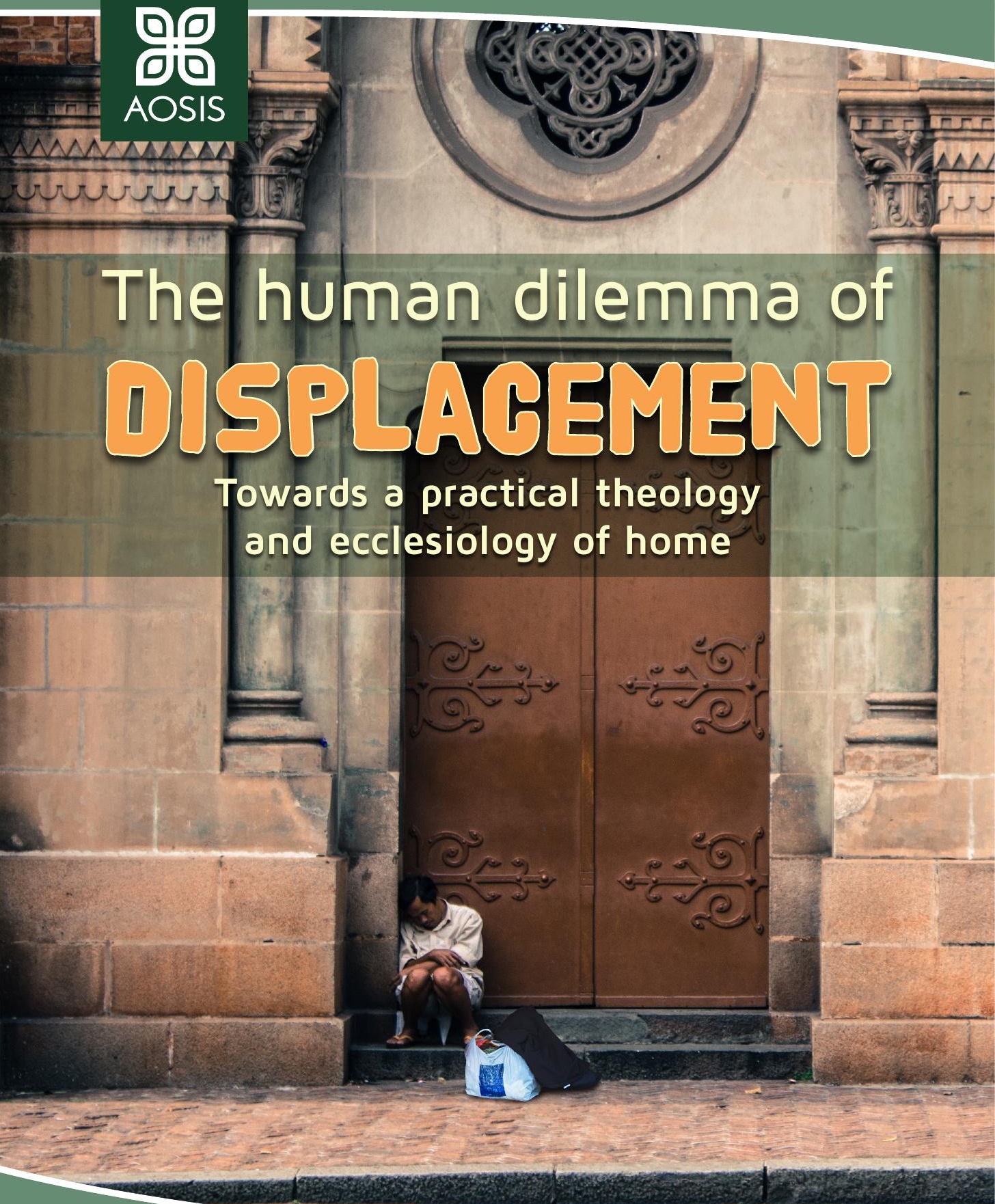

Edited by

Alfred R. Brunsdon 


\section{The human dilemma of DISPLAGEMENT \\ Towards a practical theology and ecclesiology of home}




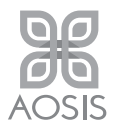

Published by AOSIS Books, an imprint of AOSIS Publishing.

\section{AOSIS Publishing}

15 Oxford Street, Durbanville 7550, Cape Town, South Africa

Postnet Suite \#110, Private Bag X19, Durbanville 7551, South Africa

Tel: +27219752602

Website: https://www.aosis.co.za

Copyright (c) Alfred R. Brunsdon (ed.). Licensee: AOSIS (Pty) Ltd

The moral right of the authors has been asserted.

Cover image: Original design created with the use of free images. Free images used https:// pxhere.com/en/photo/1394160 is released under pxhere License, and https://www.pexels. com/photo/man-sitting-beside-wall-1657935/ released under the Pexels License.

Published in 2020

Impression: 1

ISBN: 978-1-928523-31-4 (print)

ISBN: 978-1-928523-32-1 (epub)

ISBN: 978-1-928523-33-8 (pdf)

DOI: https://doi.org/10.4102/aosis.2020.BK198

How to cite this work: Brunsdon, A.R. (ed.), 2020, The human dilemma of displacement: Towards a practical theology and ecclesiology of home, pp. i-267, AOSIS, Cape Town.

\section{(c) $\frac{1}{\mathrm{BY}}(\mathbf{2})(2)$}

Printed and bound in South Africa.

Listed in OAPEN (http://www.oapen.org), DOAB (http://www.doabooks.org/) and indexed by Google Scholar. Some rights reserved.

This is an open access publication. Except where otherwise noted, this work is distributed under the terms of a Creative Commons Attribution-NonCommercial-ShareAlike 4.0 International license (CC BY-NC-SA 4.0), a copy of which is available at https:// creativecommons.org/licenses/by-nc-sa/4.0/. Enquiries outside the terms of the Creative Commons licence should be sent to the Rights Department, AOSIS, at the above address or to publishing@aosis.co.za

The publisher accepts no responsibility for any statement made or opinion expressed in this publication. Consequently, the publishers and copyright holder will not be liable for any loss or damage sustained by any reader as a result of his or her action upon any statement or opinion in this work. Links by third-party websites are provided by AOSIS in good faith and for information only. AOSIS disclaims any responsibility for the materials contained in any third-party website referenced in this work.

Every effort has been made to protect the interest of copyright holders. Should any infringement have occurred inadvertently, the publisher apologises and undertakes to amend the omission in the event of a reprint. 


\title{
The human dilemma of DISPLAGEMENT Towards a practical theology and ecclesiology of home
}

\author{
Editor
}

Alfred R. Brunsdon

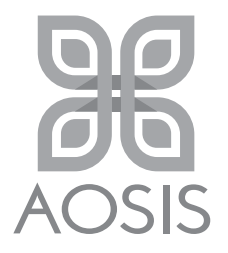




\title{
Religious Studies domain editorial board at AOSIS
}

\section{Commissioning Editor}

\author{
Andries G. van Aarde, MA, DD, PhD, D Litt, South Africa
}

\section{Board Members}

Jan Botha, Professor in the Centre for Research on Evaluation, Science and Technology, University of Stellenbosch, South Africa

Joan Hambidge, Deputy Dean at the Faculty of Humanities for the University of Cape Town and Professor for the School of Languages and Literatures, South Africa

Sakari Häkkinen, Dean of the Diocese of Kuopio, Finland

Glenna Jackson, Associate Editor, Professor Chair, Department of Religion and Philosophy, Otterbein University, Westerville, $\mathrm{OH}$, United States of America

Gregory C. Jenkins, Dean-elect, St George's College, Jerusalem, Israel

Reina-Marie Loader, Director and Filmmaker, CinémaHumain, Vienna, Austria

Babita Marthur-Helm, Senior Lecturer in Organisational Transformation and Development; Managing Diversity Gender Empowerment, University of Stellenbosch Business School, Stellenbosch, South Africa

Christopher Mbazira, Professor of Law and Coordinator of the Public Interest Law Clinic, Makerere University, Kampala, Uganda

Piet Naudé, Professor, Ethics related to politics, economics and business and Director, University of Stellenbosch Business School, Stellenbosch, South Africa

Charles Neill, Professor, Department of Business Administration, The British University in Egypt, El Sherouk, Cairo Governorate, Egypt

Cornelia Pop, Full professor at the Department of Business, Faculty of Business, BabesBolyai University, Cluj-Napoca, Romania

Michael Schratz, Professor, Institut für LehrerInnenbildung und Schulforschung, Dekan der School of Education, Leopold-Franzens-Universität Innsbruck, Austria

Johann Tempelhoff, Professor, Research Niche for Cultural Dynamics of Water (CuDyWat), School of Basic Sciences, Vaal Triangle Campus of North-West University, Vanderbijlpark, South Africa

Anthony Turton, Professor Centre for Environmental Management and Director TouchStone Resources, University of Free State, South Africa

Willie L. van der Merwe, Professor and Chair, Philosophy of Religion, Apologetics and Encyclopaedia of theology and Professor Extraordinary, Stellenbosch University, South Africa, Vrije Universiteit Amsterdam, Amsterdam, the Netherlands

Christi van der Westhuizen, Associate Professor, Department of Sociology, Faculty of Humanities, University of Pretoria, South Africa

Joke van Saane, Professor, Amsterdam Center for the Study of Lived Religion, Vrije Universiteit Amsterdam, the Netherlands

Paul van Tongeren, Professor, Department of Philosophy, Radboud University Nijmegen, the Netherlands

Robert G. Varady, Deputy Director and Research Professor of Environmental Policy, Udall Center for Studies in Public Policy, The University of Arizona, Tucson, United States of America Anné H. Verhoef, Associate Editor, Professor, Faculty of Arts: School of Philosophy, North-West University, Potchefstroom, South Africa

Xiao Yun Zheng, Professor and Assistant President of Yunnan Academy of Social Sciences (YASS) and Director International Center for Ecological Culture Studies (ICECS-YASS), Yunnan Academy of Social Sciences, Kunming City, China

\section{Peer review declaration}

The publisher (AOSIS) endorses the South African 'National Scholarly Book Publishers Forum Best Practice for Peer Review of Scholarly Books'. The manuscript was subjected to a rigorous two-step peer-review process prior to publication, with the identities of the reviewers not revealed to the author(s). The reviewers were independent of the publisher and/or authors in question. The reviewers commented positively on the scholarly merits of the manuscript and recommended that the manuscript should be published. Where the reviewers recommended revision and/or improvements to the manuscript, the authors responded adequately to such recommendations. 


\section{Research Justification}

In this book, social responsive theological research converges in order to provide practical theological and ecclesiological perspectives on the growing human dilemma of displacement. The main contribution of this collaborative work is to be sought in the practical theological and ecclesiological perspectives it provides. The book presents original and innovative research of practical theologians and missiologists whose work pertains first and foremost to the (South) African context. The book engages the critical questions of what kind of church would be relevant in today's world and what kind of care the church should provide in the face of the growing predicament of human displacement. The theological and theoretical principles uncovered in the different chapters are functional for academic exploration and use by theologians from multidisciplinary research areas focusing on communities that are challenged with the growing realities of strangers on their doorsteps and in their pews. Methodologically seen, the different fields of expertise of the contributors within the broader field of practical theology worked towards a unique compilation of themes, each relevant to the issue at stake. The majority of chapters are theoretically orientated, except where authors refer to empirical work conducted during previous research. The centre target consists of scholars in one or more of the fields of theology and religious studies. No part of the book was plagiarised from another publication or published elsewhere before.

Alfred R. Brunsdon, Department of Practical Theology, Faculty of Theology, North-West University, Mahikeng, South Africa 



\section{Contents}

Abbreviations and Figures Appearing in the Text and Notes XV List of Abbreviations $\quad X V$

List of Figures $\quad X V$

Notes on Contributors $\quad x v i i$

Acknowledgements $\quad x X V$

Preface $\quad x x v i i$

\section{Chapter 1: On becoming a 'streetwise home-church' within} the dynamics of social co-existence: Reforming 'cathedral ecclesiologies' within the migrant dilemma of human displacement

Daniël J. Louw

Abstract

Introduction

The core civil societal question in the predicament of displaced refugees and migrants: Integration or segregation? 4

The migrants and refugees: Who are they?

The predicament of human displacement: The social pathology of xenophobic alienation

The ambiguous complexity of human displacement:

The dilemma between Heimat (welcoming - sense of belongingness) and hell (experience of rejection - not being wanted)

Towards a graphic design in a diagnostic approach:

The healing of 'seeing the bigger picture' within the predicament of displacement and social polarisation

Towards a praxis of cooperative peaceful co-existence

Believing in 'some-T(t)hing': The religious and theological

dimension of peaceful co-existence

Spiritual directives within a theological interpretation of 'hospitable accompaniment': The migrating God 
On becoming a streetwise church within the complexity of social polarisation: Between xenophilia (inclusivity of hospitality) and xenophobia (exclusivity of fear or paranoia) 25 Conclusion

Chapter 2: Negotiating nostalgia: A pastoral reflection on the notion of 'home' within the context of displacement on the African continent

Alfred R. Brunsdon

Abstract

Introduction

Placing displacement

Displacement and human displacement

Expressions of human displacement: From (in-)voluntary migration to fleeing in order to survive

Quantifying displacement

Displacement on the African continent

Challenges resulting from displacement

Displacement in a pastoral and ecclesial framework

Finding a suitable paradigm for pastoral care within the context of displacement in the African context: The loss of home

Seeking the meaning of home

'Home' (oikos) within the Christian tradition

'Home' (ekhaya) within the African tradition

Seeking an outcome for pastoral care within the context of displacement (loss of home) in the African context:

Negotiating nostalgia

Conclusion

Chapter 3: Complexities of migration challenges in South Africa and a theological perspective: The Good Samaritan framework 
Abstract 51

Introduction $\quad 52$

The complexity of the challenges of migrants in South Africa

Foreign nationals face discrimination in the labour market and accusations of stealing jobs from the native people

Foreign nationals suffer exploitation in the labour market

Foreign nationals working in the formal sectors and foreign students at tertiary institutions suffer discrimination from work colleagues and fellow students

Migrants are accused of illegally owning properties

Foreign nationals are targeted by high-profile

people's reckless utterances on social media

Identifying the concepts of neighbourliness and Ubuntu in the African context

The origin and meaning of the concept of Ubuntu in the African context

Challenges associated with the concept of Ubuntu

Luke 10:25-37: Towards Jesus' extension of the definition of a neighbour as every fellow human being in need

The purpose of Luke and the immediate context of Luke 10:25-37

Discussion of Luke 10:25-37 in view of Jesus'

extension of the definition of a neighbour as

every fellow human being in need

The concept of neighbourliness in Luke 10:25-37 as a theological theory that affects how one may think and act positively in response to migrant challenges

Chapter 4: Towards understanding migrants' coping mechanisms and development of an operative ecclesiology as church care response: Home away from home migrants' church care 
$\begin{array}{ll}\text { Abstract } & 86\end{array}$

Introduction $\quad 86$

Towards a kingdom reversal and eschatological recognition framework

Conception of home amongst migrants and some coping strategies

Eschatological perspective within the notion of home amongst migrants

Reversals and eschatological home as operative ecclesiological framework

\section{Chapter 5: Evaluating 'prophecy' as a South African}

Neo-Pentecostal pastoral response to the challenges of xenophobia 103

\section{Marius Nel}

Abstract

Methodology

Xenophobia in South Africa

'Prophecy' in the Neo-Pentecostal churches in South Africa

'Prophecy' as a pastoral response to xenophobia

An evaluation of the Neo-Pentecostal pastoral

response to xenophobia

Conclusion

Synthesis

Acknowledgements

\section{Chapter 6: The plight of unaccompanied migrant} children in South Africa: Challenges en route to a practical theology and ecclesiology of home

Hannelie Yates \& Sinenhlanhla S. Chisale

Abstract

Introduction

Unaccompanied migrant children in South Africa 
Home as a safe place and a space of care, love and respect

Home as relational and communal

Challenges of finding home and 'being at home'

Xenophobia

From a culture of xenophobia to a culture of welcoming

Absence of the extended family

From living in isolation to a community of love and companionship

Cultural-spiritual dynamics

From a fragmented cultural-spiritual life to a contextualised holistic cultural-spiritual life

\section{Chapter 7: A life beyond iron bars: Creating a space of dignity and hope for the displaced father in prison}

Fazel E. Freeks

Abstract

Rationale

Introduction

The Potchefstroom remand detention facility (previously known as Potchefstroom correctional services)

The fatherhood training and equipping programme

An ideal and unique programme for convicted inmates (fathers)

Layout of the fatherhood training and equipping programme

Purpose of the fatherhood training and equipping programme

The role of Families South Africa

Who and what is Families South Africa?

The aim of Families South Africa

The dilemma of refugees, foreigners and displaced people 
The refugee and the displacement crisis in the world 162

Who is a refugee: A displaced person and a stranger? 165 God's view and his care for refugees and the displaced persons

Displaced fathers could be reintegrated in society if we restore their dignity and build spiritual resilience 168 Christian's responsibility for the displaced fathers

Chapter 8: Migrants, missio Dei and the church in South Africa

Johannes J. Knoetze \& Paul Verryn

Abstract

Introduction

Background

Application to Matthew 13:1-23

Context of the parable in the text

Application of the parable to migration

Seed along the pathways

Seed on rocky places

Seed amongst the thorn bushes

Good soil

Implications of migration for the church as kingdom community

The pathways exposing the need to create community

The rocky places exposing the need to act and serve as church

The thorn bushes expose the need to respect the ministry of clergy and laity

The good soil exposes the full potential of the church as a vibrant community 
Chapter 9: A pastoral encounter with the stranger: The basic ambivalence of hostility to hospitality inherent to the human response

Amanda L. du Plessis

Abstract

Introduction

Do not call anything that God has made clean as impure

An encounter with a stranger

Changing world

Helping without hurting: From divine definition to divine infinition

Chapter 10: Embracing compassion, hospitality, forgiveness and reconciliation: The quest for peaceful living in the human displacement crisis

Rudy A. Denton

Abstract

Introduction

The complexity of human displacement

Challenges of human displacement

Prejudice

Polarisation, separation and isolation

Xenophobia

Tolerance and hospitality

Compassion and hospitality

Biblical references to displaced people

Displacement of strangers and foreigners residing amongst God's people

Embracing forgiveness and reconciliation in the human displacement crisis 
The quest for peaceful living

Conclusion

References 


\section{Abbreviations and Figures Appearing in the Text and Notes}

\section{List of Abbreviations}

AIC African Indigenous/Initiated/Independent Churches

ATR African Traditional Religion

FAMSA Families South Africa

GEM Global Extremism Monitor

IDP Internally Displaced Person

NGO Non-governmental Organisations

NWU North-West University

RDP Reconstruction and Development Programme

SAHRC South African Human Rights Commission

UDHR Universal Declaration of Human Rights

UNHCR United Nations High Commissioner for Refugees

URM Unaccompanied Refugee Minors

WCC World Council of Churches

\section{List of Figures}

Figure 1.1: Five dynamic dispositions: Dynamics of attitudes (habitus) - different options.

Figure 1.2: Dynamics of spiritual networking: Paradigmatic framework for peaceful co-existence and a 'hospitality of accompaniment'.

Figure 1.3: Theological components in an operative, streetwise ecclesiology of home

Figure 4.1: Interactive migrant responses within an

operational ecclesiology. 



\title{
Notes on Contributors
}

\author{
Daniël J. Louw \\ Department of Practical Theology, \\ Faculty of Theology, Stellenbosch University, \\ Stellenbosch, South Africa \\ Department of Practical Theology, \\ Faculty of Theology, North-West University, \\ Potchefstroom, South Africa \\ email: djl@sun.ac.za \\ ORCID: https://orcid.org/0000-0003-4512-0180
}

Daniël J. Louw is a professor emeritus at the Faculty of Theology, University of Stellenbosch and extraordinary researcher at the Faculty of Theology, North-West University, Potchefstroom campus. His research interests include practical theology, pastoral care and counselling, healing of life, marriage and family enrichment, and clinical pastoral care in a hospital environment. He holds the following degrees: BA (Adm) cum laude, Stellenbosch (1965); BA (Hons Philosophy) cum laude, Stellenbosch (1967); BTh cum laude, Stellenbosch (1968); MA (Philosophy) cum laude, Stellenbosch (1968); Licentiate Theology cum laude, Stellenbosch (1969); DPhil, Stellenbosch (1972); DTh, Stellenbosch (1983). Professor Louw has authored a number of major academic books in practical theology and pastoral care, and published more than 85 articles in accredited national and international journals. He is involved in ongoing scholarly projects such as the migrant crisis within the framework of an ecclesiology of homecoming, practical theology as life care and healing of life and spiritual lifestyles: fides quaerens vivendi. In October 2000, he received the Totius Award for Biblical Languages and Theology from the South African Academy for Science and Arts.

\section{Alfred R. Brunsdon \\ Department of Practical Theology, \\ Faculty of Theology, North-West University, \\ Mahikeng, South Africa \\ Email: alfred.brunsdon@nwu.ac.za \\ ORCID: https://orcid.org/0000-0002-1509-4770}

Alfred R. Brunsdon is an associate professor in practical theology at the Faculty of Theology of the North-West University (Mahikeng campus). 
He holds a PhD in practical theology (2007). His areas of interest include the contextualisation of practical theology and pastoral care in the African context. He is responsible for teaching and learning as well as supervision of postgraduate students in a multicultured context. He has published his research in accredited journals and peer-reviewed books since 2003, is a member of a number of local and international academic associations, and has presented a number of academic papers at local and international conferences. Professor Brunsdon is serving as the subject chair and subgroup leader for practical theology since 2016 at the North-West University (NWU) and coordinates both teaching and learning and research within this subject group. In 2018, he was awarded the Distinguished Teaching Excellence Award by the NWU in recognition of his contribution to teaching and learning in the online open-distance environment, where he developed modules in pastoral care and homiletics. He is an ordained minister of the Dutch Reformed Church and is married to Rev Elizabeth Brunsdon. They have two adult sons and reside in Lichtenburg in the North West Province.

\section{Christopher Magezi}

Department of Practical Theology,

Faculty of Theology, North-West University,

Vaal Triangle, South Africa

Email: magezichristopher@gmail.com

ORCID: https://orcid.org/0000-0001-6097-4788

Zimbabwean born Christopher Magezi is a postdoctoral fellow at the Faculty of Theology, North-West University (Vaal Triangle campus). His PhD (2018) in practical theology focused on theological understandings of migration and its implications for church ministry. It employed a biblical redemptive historical approach to analyse the biblical text and its relevance to the impact of migration on the church. The study is located within a systematic theological reflection, with an intentional gospel ministry application in contemporary urban ministry and intercultural experience, as well as human co-existence in global ministry context, with particular focus on South Africa. He has published several articles in accredited academic journals. 


\section{Vhumani Magezi}

Department of Practical Theology,

Faculty of Theology, North-West University,

Vaal Triangle, South Africa

Email: vhumani.magezi@nwu.ac.za

ORCID: https://orcid.org/0000-0002-5858-143X

Vhumani Magezi is an associate professor in practical theology and pastoral care at the Faculty of Theology, North-West University (Vaal Triangle campus). His research focusses on public practical theology and public pastoral care, which is the intersection of church or theology with social issues. He has published in the following areas: Church and Public Ministry; Congregational (Church) Ministry Designs; Church-Driven Development (Church and Public Health; Church and Community Development); Public Pastoral Care; Pastoral Care, diagnosis and Spirituality in Africa; and Church and Civil Society Leadership. He is involved in faculty senior management as a coordinator. He is the president of the African Association for Pastoral Studies and Counselling (AAPSC), and an active member of academic and professional organisations that include the International Academy of Practical Theology (IAPT); Association of Practical Theology (APT) (USA); Society for Pastoral Theology (SPT) (USA); International Council of Pastoral Care and Counselling (ICPCC); and Society for Practical Theology of Southern Africa (SPTSA).

\section{Marius Nel}

Unit for Reformational Theology and the Development of the South African

Society,

Faculty of Theology, North-West University,

Potchefstroom, South Africa

Email: marius.nel@nwu.ac.za

ORCID: https://orcid.org/0000-0003-0304-5805

Marius $\mathrm{Nel}$ is a research professor and he occupies the Chair of Ecumenism: Pentecostalism and Neo-Pentecostalism at the Unit for Reformed Theology of the Faculty of Theology at the Potchefstroom campus of the North-West University in South Africa. He has been a pastor of the Apostolic Faith Mission of South Africa with 35 years of experience. He specialises in apocalypticism in the Old Testament and New Testament, the 
history of the Pentecostal movement and the study of its doctrine. $\mathrm{He}$ is a C2 National Research Foundation-rated researcher.

\section{Hannelie Yates}

Department of Practical Theology,

Faculty of Theology, North-West University,

Potchefstroom, South Africa

Email: hannelie.yates@nwu.ac.za

ORCID: https://orcid.org/0000-0003-0736-7924

Hannelie Yates is a senior lecturer in practical theology at the Faculty of Theology, North-West University (Potchefstroom campus). Her academic career is steered by her profound concern for children. She received her undergraduate, honours and master's qualifications in theology with specialisation in youth work at Huguenot College, and then continued to gain international exposure in Sweden and the Netherlands, focusing on the rights and agency of children in their daily living environment. She completed her PhD in practical theology at the University of Stellenbosch (2012). In recent years, her primary research interest is related to the position, role and voice of children in faith communities and relational spaces in civil society.

\section{Sinenhlanhla S. Chisale}

Department of Practical Theology,

Faculty of Theology and Religion, University of Pretoria,

Pretoria, South Africa;

Department of Religious Studies,

Faculty of Arts, Midlands State University,

Zvishavane, Zimbabwe

Email: sinengwenya@gmail.com

ORCID: https://orcid.org/0000-0001-7227-2206

Sinenhlanhla S. Chisale is a postdoctoral fellow under the mentorship of Prof. Yolanda Dreyer. Her project, 'Pastoral care in a context of gender-based violence (GBV), sexuality, migration and disability', is embedded in the broader research project titled 'Gender studies and practical theology theory formation' directed by Prof. Dreyer in Department of Practical Theology, Faculty of Theology and Religion, University of Pretoria. She is also a lecturer in the Department of Religious Studies in Midlands State University, Zvishavane, Zimbabwe. She holds a Doctorate in 
practical theology (2014, UNISA), Master of Theology and Development (2009, UKZN) and a Master of Arts degree in Sociology (cum laude) (2017, UNISA). She is ordained into ministry in the Evangelical Lutheran Church in Southern Africa (ELCSA). Her research focusses on pastoral care, decolonisation, gender, migration, disability and childhood. Her responsibilities include research and part-time teaching and learning, including supervision of postgraduate students in practical theology, pastoral care and gender studies, mainly from an African context. She has published numerous articles in accredited journals and books since 2014 and is a peer reviewer for several journals and the National Research Foundation. Professor Chisale is affiliated with local and international academic associations and has presented several academic papers at local and international conferences.

\section{Fazel E. Freeks}

Department of Practical Theology,

Faculty of Theology, North-West University,

Potchefstroom, South Africa

Email: fazel.freeks@nwu.ac.za

ORCID: https://orcid.org/O000-0002-2474-8756

Fazel E. Freeks is an associate professor and Coordinator of Community Engagement in the Faculty of Theology, North-West University (Potchefstroom campus). He holds doctorates in Education, Pastoral Studies and Missiology with the focus on values and character-building, fatherhood and father absence, community engagement and training and equipping. His responsibilities include teaching and learning as well as supervision of postgraduate students, especially in the field of fatherhood and the family context. He is also the author and co-author of numerous articles in accredited journals, has presented papers at national and international conferences, and has authored six popular books, mainly on fatherhood. He collaborates with Families South Africa (FAMSA), correctional services (Remand Detention Facility) and schools and communities. Professor Freeks is currently managing and driving the LIFEPLAN ${ }^{\circledR}$ Training and Equipping Programme in the Northern Cape farm communities and the 
fatherhood training and equipping programme with its project, 'A life beyond iron bars' in the North West Province, especially at the Potchefstroom remand detention facility. He is also a member of the South African Academy for Science and Arts.

\section{Johannes J. Knoetze}

\section{Department of Missiology,}

Faculty of Theology, North-West University,

Mahikeng, South Africa

Email: hannes.knoetze@nwu.ac.za

ORCID: https://orcid.org/0000-0002-2342-2527

Johannes J. Knoetze is an associate professor in missiology at the Faculty of Theology of the North-West University (Mahikeng campus). He holds a Doctoral Divinitatis in Missiology (2002). He serves in different management positions within the Faculty of Theology, such as faculty coordinator of Teaching and Learning and is a member of the Faculty Management Committee. He has published articles in different accredited journals as well as chapters in peer-reviewed books. His research focus is on Missional Diaconate in Africa, with specific focus on the millennial (emerging adults) population and the alleviation of poverty. He acts as an external examiner for different universities, as well as a reviewer for international academic journals in his field of research. Professor Knoetze is a member of the following associations: South African Mission Society (SAMS), SPTSA, International Association of Missiological Studies (IAMS), World Reformed Fellowship and International Society for the Research and Study of Diaconia and Christian Social Practice (ReDi). He also serves as a board member of NetACT Africa and as a member of the Moderamen of the General Synod of the Dutch Reformed Church in Southern Africa.

\section{Paul Verryn}

Methodist Church,

Soweto, South Africa

Email: paulverryn@gmail.com

ORCID: https://orcid.org/O000-0002-5716-5629

Paul Verryn is an ordained minister of the Methodist Church in South Africa and former bishop of the Central District (Gauteng). 
He became known for his ministry amongst refugees in the city centre of Johannesburg for housing, mainly Zimbabwean refugees, in the Johannesburg Central Methodist Church. Verryn is currently residing in Soweto and ministering to the poor under the auspices of the Church Unity Commission.

\section{Amanda L. du Plessis}

Department of Practical Theology,

Faculty of Theology, North-West University,

Potchefstroom, South Africa

Email: amanda.duplessis@nwu.ac.za

ORCID: https://orcid.org/O000-0002-7564-2353

Amanda L. du Plessis is a senior lecturer in practical theology at the Faculty of Theology, North-West University (Potchefstroom campus). She holds a PhD in practical theology (2008) and became a postdoctoral fellow at the North-West University Potchefstroom campus in 2011. During this period, she furthered her research in pastoral care towards inner healing from a reformed perspective. In 2015, she was appointed as a senior lecturer on the Mafikeng campus of the North-West University. Her current areas of interest include the contextualisation of practical theology and pastoral care in the African context. Her responsibilities include teaching and learning, as well as supervision of postgraduate students. She has published numerous articles in accredited journals since 2011. She is also member of a number of local and international academic associations and has presented a number of academic papers at local and international conferences.

\section{Rudy A. Denton}

Department of Practical Theology,

Faculty of Theology, North-West University,

Potchefstroom, South Africa

Email: rudydenton@outlook.com

ORCID: https://orcid.org/0000-0002-7271-4825

Rudy A. Denton is a reverend of the Netherdutch Reformed Church Student congregation in Potchefstroom and a researcher in practical theology at the Faculty of Theology of the NorthWest University (Potchefstroom campus). His research interests 
include pastoral studies with the focus on forgiveness and Christian Psychology from a reformed perspective. His research responsibilities also include supervision of postgraduate students. He has published a number of articles in accredited journals, presented academic papers at local and international conferences and contributed chapters to collective works. He is the secretary of the Society for Practical Theology in South Africa (SPTSA) and also a member of local and international academic associations. Doctor Denton is currently the chairperson of the research ethics committee of the Faculty of Theology of the North-West University (Potchefstroom campus). 


\section{Acknowledgements}

Chapter 5 represents substantial reworking (more than 50\%) and amalgamation of two published articles:

Nel, M., 2019, 'The African background of Pentecostal theology: A critical perspective', In die Skriflig / In Luce Verbi 53(4), a2418. https://doi.org/ 10.4102/ids.v53i4.2418

Nel, M., 2019, 'Prophetic witness in weakness: A response to Prof Robert Vosloo from a Pentecostal perspective', In die Skriflig/In Luce Verbi 53(4), a2419. https://doi.org/10.4102/ids. v53i4.2419

These two articles were published under the Creative Commons Attribution 4.0 International (CC BY 4.0) licence, according to which permission is granted for reworking. 



\title{
Preface
}

\author{
Alfred R. Brunsdon \\ Department of Practical Theology, \\ Faculty of Theology, North-West University, \\ Mahikeng, South Africa
}

The dilemma of human displacement is rapidly spreading across the globe. Irrespective of the angle from which this phenomenon is viewed, it remains a disaster of epic proportions. The harrowing plight of humans that find themselves at the centre of this phenomenon makes it a crisis that is difficult to ignore.

As practical theologians calling Africa their home, a need arose to contribute to the growing academic discourse surrounding human displacement. Living and working on the southern tip of Africa, there was a collective decision amongst practical theologians of the North-West University (NWU) in South Africa to reflect about displacement on the African continent. The African continent, being one of the areas globally where migration is very rife, and South Africa, in particular, being the last outpost and beacon of hope for many, invoked the collective empathy of the participants to apply their minds to this challenge and to heed the duty to be socially responsive.

The theological reflection recorded here is essentially from the paradigm the authors know best, namely, practical theology. Hence, this book represents critical theological reflection at the intersection of Christian faith and one of the direst human conditions, namely, those in transition to ultimately find themselves homeless.

The title of the book was carefully formulated through a team effort to bring into a dynamic interplay what contributors thought to be the unique challenges that relate to this phenomenon. 
As such, it attempts to contribute much needed theory to inform the praxis of faith communities in ministering to the destitute. Methodologically, the work relied on documentary studies regarding the topic and brings together the insights of both young and mature theological voices.

In Chapter 1, Daniël J. Louw challenges current ecclesiologies, 'On becoming a "streetwise home-church" within the dynamics of social co-existence: Reforming "cathedral ecclesiologies" within the migrant dilemma of human displacement'. In this chapter, he grapples with the question as to how local churches can bridge the gap between the xenophobic insiders and the displaced outsiders that comes to the fore in an age of migration. The chapter offers a grassroots and operational ecclesiology of home in order to 'home in' on the dilemma of displacement. A pastoral approach of compassionate co-existence is proposed to achieve an operational ecclesiology of home.

Alfred R. Brunsdon presents a pastoral view on the phenomenon of displacement on the African continent through the lens of nostalgia in Chapter 2. Relating the notion of nostalgia to the notion of home, this chapter attempts to understand how the idea of 'home' can both 'cause' and 'cure' nostalgia as one of the main challenges stemming from displacement. These notions are reflected upon within a pastoral framework and hope to provide some suggestions that will be of value for pastoral care within the context of displacement on the African continent.

In Chapter 3, Christopher Magezi explores the complexities of migrant challenges in South Africa from the perspective of the Good Samaritan (Lk 10:25-37). In so doing, he attempts to develop a theological theory on complex migrant challenges that foster constructive theological thinking that can result in the embracing of migrants and appropriate responses to their existential needs. This reasoning is premised on the notion that people are intricately linked together by their common humanity as the bearers of the image of God. 
Chapter 4 by Vhumani Magezi shifts the focus back to the pastoral responsibilities of the church towards migrants. The unique contribution of this chapter, 'Towards understanding migrants coping mechanisms and development of an operative ecclesiology as church care response: Home away from home migrants' church care', is found in the challenge to develop an understanding of migration that places responsibilities on both migrants and host nations in their social and ecclesial interactions. It develops a framework resting on the notion of eschatological home as an understanding that informs an inclusive approach to migrant response and integrated churches.

Chapter 5 by Marius Nel links onto the growth of the Pentecostal movement in Africa. He argues that prophecy, as one of the main characteristics of the Pentecostal movement, can be seen as a possible solution for one of the most disturbing results of displacement, namely, xenophobia. Prophecy stands in the service of Neo-Pentecostals' emphasis on salvation and healing, within the wider context of an African cosmological view of a spirit world populated by good and evil spirits, and animating the seen world. Evil spirits are supposedly responsible for the occurrence of some cases of death, barrenness, illnesses and other misfortunes; the prophet can decipher and uncover the human and spiritual causes of events and prescribe a possible way to overcome it. Neo-prophecy provides guidance for the displaced as well as for those who are challenged to accept and welcome the displaced strangers in their midst. This chapter describes the phenomenon of neo-prophecy and evaluates its benefits and shortcomings as a pastoral response to xenophobia.

In the co-authored Chapter 6, 'The plight of unaccompanied migrant children in South Africa: Challenges en route to a practical theology and ecclesiology of home', Hannelie Yates and Sinenhlanhla S. Chisale attend to vulnerable children in the framework of displacement. This chapter problematises the crisis of displacement from the perspective of migrant children in the 
construction of a practical theology of home. The primary focus is on the category of unaccompanied migrant children in the context of South Africa. Yates and Chisale apply the hermeneutics of listening to identify challenges to the construction of a practical theology of home based on the lived experiences of unaccompanied migrant children.

Fazel Freeks retains focus on the impact of displacement on families in Chapter 7. In 'A life beyond iron bars: Creating a space of dignity and hope for the displaced father in prison', Freeks engages the reality of displaced fathers who are jailed. This chapter draws on the fatherhood training and equipping programme used to guide, train and equip displaced fathers with skills and knowledge about their role. The author argues that when an effort is made to restore dignity and build resilience, displaced fathers can be reunited with their families and the society successfully.

Chapter 8 welcomes the contribution of missiologist, Hannes Knoetze and migrant-veteran, Paul Verryn. This chapter contributes further to a migrant-friendly ecclesiology from a missional perspective and suggests possible responses for the local churches in South Africa towards migrants. The parable of the sower, as found within the context of Matthew 13, is used as an analogy to discuss these responses. The personal engagement of the authors with migrants contributes to these responses.

Amanda du Plessis brings together ecclesiology and pastoral caregiving in Chapter 9. In 'A pastoral encounter with the stranger: The basic ambivalence of hostility to hospitality inherent to the human response', Du Plessis focusses on the role of the church and the pastoral caregiving ministry in helping displaced persons find the resilience, not only to cope but also to find a sense of meaning in life in helping others who suffer as a result of the same circumstances. The chapter unfolds in four parts. An exegetical study of Acts 10 provides the scriptural foundation for the calling of believers to witness and care for strangers. The focus then shifts to what a pastoral encounter with a stranger 
entails. This is followed by a discussion of the rapidly changing world of today. The chapter concludes with a view on how to help without hurting, an explanation of the paradigm shift from divine definition to divine infinition and three guidelines or principles for a pastoral encounter with the stranger.

Finally, in Chapter 10, entitled as 'Embracing compassion, hospitality, forgiveness and reconciliation: The quest for peaceful living in the human displacement crisis', Rudy Denton challenges faith communities to live in peace with migrants. At the same time, it is a challenge to move away from prejudice and discriminatory discourses in order to address feelings of resentment, panic, fear, suspicion and insecurity towards the stranger. To this end, the chapter engages the multidimensional concepts of compassion, hospitality, forgiveness and reconciliation. He argues that this is imperative if there is a collective will to replace xenophobia with xenophilia. In a world characterised by human beings in flux, the chapter posits that embracing compassion, hospitality, forgiveness and reconciliation is our only chance for peaceful living in an age, which is characterised by migration.

The realisation of this book was a team effort. I want to convey my sincere gratitude to each colleague who contributed to this project. The Faculty of Theology of the NWU and especially the Unit for Reformational Theology and the Development of the South African Society deserve mention for their ongoing support of research that is socially responsive. Their financial support of this project testifies to a true commitment to develop the South African society through responsible theological reflection. The authors are also indebted to AOSIS Books who were willing to publish the research. The efficient guidance of all of the staff involved in this project deserves special mention.

I trust that this book will contribute to pastoral-ecclesial thinking and practices that will enable us to offer a home to the strangers and the destitute that faith communities encounter on a growing basis. 



\section{Chapter 1}

\section{On becoming a 'streetwise home- church' within the dynamics of social co-existence: Reforming 'cathedral ecclesiologies' within the migrant dilemma of human displacement}

Daniël J. Louw ${ }^{\mathrm{a}, \mathrm{b}}$

aDepartment of Practical Theology, Faculty of Theology, Stellenbosch University, Stellenbosch, South Africa

${ }^{b}$ Department of Practical Theology, Faculty of Theology, North-West University,

Potchefstroom, South Africa

How to cite: Louw, D.J., 2020, "On becoming a "streetwise home-church" within the dynamics of social co-existence: Reforming "cathedral ecclesiologies" within the migrant dilemma of human displacement', in A.R. Brunsdon (ed.), The human dilemma of displacement: Towards a practical theology and ecclesiology of home, pp. 1-30, AOSIS, Cape Town. https://doi.org/10.4102/aosis.2020.BK198.01 


\section{Abstract}

Migration has become a feature of mobility in the global society. The refugee crisis stirs a new kind of global paranoia: xenophobic fear for the strange 'other' and threatening foreigner. The global migrant crisis causes a human dilemma: the complexity of interculturality. The following existential and political questions surface: separation, integration or sheer indifferentism? Governments face a gigantic national and social dilemma: foreclosure or embracement? Communities of faith wrestle with the ambivalence: the hospitality of welcoming or the comfort of unemployed and poor church members? Thus, the research questions are as follows: how does the local church bridge the gap between the xenophobic insiders and the displaced outsiders? What is meant by a public hospitality of accompaniment within cultural diversity? Should ecclesiologies be designed to keep merely denominational doctrine and clerical concerns going (cathedral ecclesiologies), or should be redesigned to feature as safe havens, shelters (xenodochia) for both fearful victims and displaced others? A grassroots and operative ecclesiology of home is designed in order to home in on the dilemma of displacement. With reference to a hermeneutical approach in caregiving, diagnostic charts are developed in order to assess both the character of the displacement crisis and what a ministerial approach entails. A pastoral approach of compassionate co-existence is proposed.

Keywords: Streetwise ecclesiology of home; Theology of compassion; Displacement crisis; Xenophobia; Co-existence; Pastoral diagnosis.

\section{Introduction}

In his response to the migrant crisis, practical theologian Emanuel Lartey pointed out that the refugee dilemma poses a gigantic challenge to the provision of care. 'Global migration has become the critical defining issue of the dawn of the 21st century' (Lartey 2018:x). 
The current refugee paranoia, and its connection to Islamophobia, creates a kind of political explosive confusion on the level of emotions. The emotional turmoil also causes a global kind of political helplessness that oscillates between two incompatible polarities: foreclosure (Abschottung) and integration (Bauman 2016). The current migration crisis is indeed ambivalent and has the capacity to end in a moral debacle - a kind of immoral indifferentism regarding the tragedy and the desperate cry of suffering, vulnerable people. On a spiritual level, we face the inflation of compassion.

On an ecclesial level, it has also the capacity to turn church polity into the exclusivity of denominationalism: maintaining merely 'our church' - the cathedral position (cathedra = throne of the bishop). 'Church' is then about clerical defensive positions and survival of the denomination by means of merely top-down strategies, rather than bottom-up approaches that are engaged in grassroots strategies; that is, to approach the displacement crisis from the viewpoint of human weakness (astheneia) and suffering. The latter option is about ecclesiologies and theological paradigms that use crises in life as a point of departure for redefining and reforming existing inappropriate ecclesial self-understandings.

The core question for a practical theological approach is posed by Kessler (2014): can the church exploit the refugee and migrant crisis of human displacement, the encounter with the predicament of the homeless foreigner along the sprawling malls and forsaken pavements of established, affluent societies in order to create new paradigmatic frameworks for theological reflection and ecclesial self-understanding (Migration als Ort der Theologie)? This challenge is underlined by Polak (2018), who states that the migrant crisis challenges the church to rethink its theological and ecclesial stance:

We therefore can consider flight and migration a locus theologicus: a place, where theology can validate itself and create new theologies on one of the most important 'signs of times'. (p. 43)

In fact, migration is not only about a new starting point for reflection on the essence of being the church within human 
displacement (reforming ecclesial thinking). Displacement is even a theological category indicating a mode of God's beingwith suffering human beings: God as both the displaced God in our human history of suffering (passio Dei) and the migrating God, Deus migrator - God the migrant journeying with displaced human beings (Phan 2016:845-868).

The quest for rethinking and redefining church polity shifts the debate on being the church from fixed decrees and axiomatic doctrine to the predicament of the homeless other within the public domain of civil societal life. The quest is an ecclesiology with 'Christian humanism' (De Gruchy 2009; Kaunda 1967)'1 as a focal point in the design of an ecclesiology of home for displaced, homeless people. Thus, my attempt is to translate the public ministry of the church into the paradigm of 'streetwise ecclesiologies'.

\section{The core civil societal question in the predicament of displaced refugees and migrants: Integration or segregation?}

Keeping the current suffering of human displacement in mind, Bauman (2016) poses the following intriguing question: is the political and social option of inclusive integration an appropriate route to take when human habitus is determined by scepticism, anxiety, hate and delimitation? The latter leads to exclusive selfmaintenance, a discriminatory ethos of 'apartheid' and stigmatising practices of xenophobia. It becomes actually an

1. The connection between humanism and a Christian approach is not necessarily acceptable to all researchers. In an article on the connection between 'Christian humanism' and social transformation, De Gruchy (2018) points out that Christian humanism is, for some, an oxymoron for the simple reason that humanism today generally refers to its secular variety, and Christianity has long been regarded as its antagonist. Within the realm of 'African thinking', it was the former president of Zambia, Kenneth Kaunda, who wrote a book in the 1960s entitled A Humanist in Africa. He advocated for a humanist approach to life (Christian humanism) because of the communal spirit within different African spiritualties (Kaunda 1967:22). 
aggressive mode of masked enculturation and social assimilation, which is 'a typical Western approach' - thus, the reaction of Bauman (2016:122) and his argument that inclusion and integration could become the strongest offensive strategies in the west.

Therefore, the very poignant research question is as follows: is integration the eventual goal of attempts to deal with the migrant crisis on a political and social level? Is integration a kind of instant political and social solution that will solve the migration crisis? (Bauman 2016:123). In his response, Bauman points out that in the history of humankind, integration and segregation always accompany one another within the unhealthy tension of we and the $m^{2}$ - the polarisation between self-defensive insiders and marginalised outsiders.

My further basic research question is: instead of integration, could the notion of co-existence perhaps help the church to start creating meaningful networking on grassroots level of societal diversity (even cultural friction) in order to overcome the social impasse of separation - integration?

\section{The migrants and refugees: Who are they?}

Human beings are constantly on the move, looking for a better place to live and to stay. In the February edition of the National Geographic Magazine (Gorney 2008), it was forecasted that the phenomenon of migration will cause a critical challenge to governments worldwide; migration has become a sign of the times (eds. Gruber \& Rettenbacher 2015) - a central, permanent and constant feature of life (eds. Padilla \& Khan 2013). That will be demonstrated in a very profound way on the border between the United States and Mexico. Migration has become a transnational phenomenon and is evoking a kind of 'transnational revolution'. It brings about a new sense of civil interconnectivity and national identity.

2. 'Wir müssen die Kunst der Integration ganz neu lernen, unter Verzicht auf das Entwederoder, wenn wir unserer Lage gerecht werden sollen' (Bauman 2016:124). 
The migrating refugees are part of a new kind of 'transnational diaspora' (Polak 2014). In this regard, Polak's research is important because very timely she pointed out that it is going to challenge core ecclesial approaches in practical theological thinking and pastoral caregiving. The fact is that Homo sapiens is at the same time a homo migrans. ${ }^{3}$ Migration is not merely about people flying from despotic political regimes; it is about a new mode of being within global forces, dictating the agenda of market-driven economies and expectations as created by the social media. There is always the utopic projection of 'beter places' elsewhere the glamour of new 'smart cities' (Castles \& Miller 2009:299).

Migrants represent the notion of homo viator; the restless human being in his or her search for a better life is migrating towards the utopia of ultimate happiness. However, between the zest for fortune and success lurks always fate, and the unpredictable reality of tragedy and inhumane suffering. The pursuit of happiness, the utopia of a happy ending elsewhere, is often merely the illusion of a fata morgana, ending most of times in disastrous disillusionment and unhappiness (Brown 2017:17).

We live in a global world of diversification within mass pluralisation. ${ }^{4}$ Smart phones wipe out all local limitations, and

3. One needs to differentiate between migrants and refugees. A migrant is a person who moves from one place to another in order to find work or better living conditions, while a refugee is someone who has been forced to flee his or her country because of persecution, war or violence. Both have one common characteristic in that they move from one place to another in search of better working conditions or more appropriate lifestyles despite cultural differences. A refugee has a well-founded fear of persecution for reasons of race, religion, nationality, political opinion or membership in a particular social group and thus has experienced life within specific national or local boundaries unbearable and dangerous. According to international law, such a person immediately has legal status or refugee status in the new country and cannot be deported without substantial reasons. They are defined and protected in international law and must not be expelled or returned to previous threatening situations.

4.'Die"Super-Diversifizierung"globalerMigrationführtzueinemnichtmehrüberschaubarenAusmaß an Pluralisierung und Mobilität. Zeitgenössische Mobilitäts- und Kommunikationsmöglichkeiten fördern "transnationale Migration" und lassen Mehrfachzugehörigkeiten entstehen, die nicht mehr in die klassischen Formate von "Heimat" und "Fremde" passen. Rund um den Globus findet eine "transnationale Revolution" statt, die Gesellschaften und Politiken neu formt' (Polak 2014:3). 
challenge our understanding of notions like national states, 'civil society', 'democracy', 'human dignity' and on being the church for the 'homeless other' and often 'threatening stranger'.

Migrants can be people who enter a country legally (with documents) or illegally (without any document or by fraud). They can also be people who are forced to leave home and then be removed to foreign places (townships and forced removals as in the time of apartheid). Migrant people can also be people who are moving from one stage in their life to another, for example, from their home to security estates or retirement villages. All of them are exposed to the phenomenon of displacement.

Refugees are people who are forced to leave their country against their will. In terms of international law, when refugees arrive in another country, they cannot be repatriated by force. Therefore, there is a necessity to understand the diaspora situation of most migrants. In the long run, migrants must become citizens of their 'new state'. On the other hand, for many generations, they want to keep up their own identity, and this is the reason why migrants cannot easily be assimilated. ${ }^{5}$

Migrants have become the challenging and even disturbing others in many developed countries. In terms of Levinas' (1968) concern, the migrant becomes the quest and source for authentic humanity, founded in the prior of a face-to-face encounter (visage) and directed by the principle of l'un-pour-l'autre [one for the other]. The threatening other is even in terms of Levinas' mystical metaphysica, an invitation to instil hope; hope is anchored in the presence of the frail and disturbing other; care is then directed by the ethical principle of 'one for the other' [I'unpour-l'autre] (Levinas 1968).

5. 'Sie assimilieren sich nicht oder nur noch oberflächlich, anders als die Einwanderer des 19. Jahrhunderts. Die Türken in Deutschland wollen lojalen Bürger in Deutschland sein, aber sie wollen auch Tüken bleiben. Warum? Sie sind alle produkte von Migration, nicht von Immigration. Doch wir fahren fort, so zu tun, als wäre Migration gleich Immigration - planbar, regulierbar, kontrollierbar duch die Regierung in Berlin, Paris oder London' (Bauman 2016:123). 
The threatening presence of the other leads to the widespread fear of the other, namely xenophobia. It also challenges a profound basic principle in Christian spirituality, namely the principle of hospitality - that is, the challenge to invite the stranger into a space called 'home'. The challenge is then to share the public space of civil society in such a way that the outsider could become an insider.

\section{The predicament of human displacement: The social pathology of xenophobic alienation}

Displacement can be called a feature of life between birth and death. ${ }^{6}$ Displacement infiltrates our understanding of place and space and underlines the quest for 'intimate dwelling' and 'trusting bonds' that can establish a sense of meaning (Bollnow 2011:261). Without the networking of trusting relationships, life experiences can be viewed as a kind of existential death; one is being amputated from the very fabric of significant existence. Displacement should, thus, be connected to our basic quest for human dignity; it is about the striving towards a better humane society (free from violence, oppression and fraud). One can even say that the 'pursuit of happiness' as institutionalised by the Constitution of the United States frames in a very subconscious way the aspirations for a 'better world' and a 'better place'. Wong (2012:19) also links the striving towards a new world order and a more cooperative and humane society as an expression of the quest for purposeful living (Klinger 2012:23).

Without any doubt, displacement is about more than a physical space and place. It embodies the striving for purposeful living.

6. Søren Kierkegaard (1962:317) connected life and death paradoxically in order to understand the aesthetics or value of life better. 'Thus, death is the briefest summary of life or life reduced to its briefest form'. Within the ambiguity of life and death, 'sunshine' and 'shadow', the beauty of life and hope emerges. 
It is essentially a spiritual category. ${ }^{7}$ If Michael Jackson's song is a plea for a better place, one can translate this plea into what can be called a kind of 'sanctification of the cosmos' (Religion als heiliger Kosmos) (Berger in Drehsen, Gräb \& Weyl 2005:262).

Displacement within this framework can be called both a religious and a spiritual phenomenon. Therefore, everyday experiences should be translated and articulated into a comprehensive cosmic system that, in its normative directive capacity, would become a 'holy cosmic network'. The current refugee crisis for the church should thus not merely be a question about integration or segregation, welcoming or foreclosure, but a question about exercising a kind of public theology of cosmic and social spiritualisation of human life, about what one can call 'a hospitality of interfaith religiosity' beyond the exclusive categories of denominationalism and 'doctrinal religiosity'. Thus, the question is, how can Christians and Turks (Muslims), insiders and outsiders cooperate in order to overcome enmity and hatred by means of respectful tolerance and human hermeneutics of socio-cultural understanding?

How can the church apply the spiritual principle of neighbourly love, even the extreme command of 'love your enemy', irrespective of whether the other is a Christian or a Muslim, in order to establish an ecclesiology of home within the realm of severe social pathology and xenophobic paranoia?

7. Steger (2012:165-175) argues that psychological well-being cannot ignore spirituality, that is, the general sense of transcendence and connection with something larger than one's self (Steger 2012:175). Spirituality is then identified and described as the pursuit of significance in that which is sacred about life (Steger 2012:175).

8. Fear for the 'foreign other' has become the most profound pathology of living in a global world shaped by instant mobility. This paranoia of xenophobic fear (Shuster 2018:28-33) is what Angela Merkel has to face in her 'welcoming politics' when asked how she is going to deal with the many Muslims in Germany in order to prevent the threat of 'Islamization', with so many Muslims entering Germany: '[f]ear has never been a good adviser, neither in our personal lives nor in our society. Cultures and societies that are shaped by fear will without doubt not get a grip on the future' (Vick, Shuster \& Simon 2015). 
Xenophobia reveals a worldwide dilemma in the refugee and migrant crisis, with a huge political challenge, ${ }^{9}$ namely how to deal with domestic resistance (anxiety and hate) and the moral emphasis of outreach, and how to address the spiritual and humane demand for acceptance (trust). The dilemma becomes even ideological: tolerance and accommodation or suspicion and resistance? And what about the threat of a negative political backlash, even conservative radicalism?

All of these questions challenge the very essence of Christian spirituality, namely the quality of compassion. Displacement and xenophobia expose compassion to gradual emotional and habitual inflation. Compassion becomes merely compulsory and formal tolerance. According to António Guterres, the UN High Commissioner for Refugees, '[t] here is definitely a battle of values, with compassion one side and fear on the other' (Vick 2015:32), thus, the danger of the inflation of compassion; '[t]he limits of compassion, coupled with wariness of Muslims, comes [sic] into remorseless focus, even in an immigrant nation' (Vick 2015:34).

\section{The ambiguous complexity of human displacement: The dilemma between Heimat (welcoming - sense of belongingness) and hell (experience of rejection - not being wanted)}

Because of complexity, it seems that for human displacement there is no instant solution and straightforward answer (Klein 2015:24). Rather than to opt for an instant solution, the challenge is to approach the crisis from a hermeneutical perspective, that is, to understand the complexity of displacement within the networking space of social interaction, existential reactions and attitudinal responses. What is most needed in a pastoral and hermeneutical approach is a different perception and new

9. 'Right-wing parties that promote nativism and xenophobia were already on the rise in France, Greece and other E.U. nations well before the latest surge of migrants' (Vick 2015:32). 
conceptualisation of the displacement predicament, offering a hermeneutics of 'migration reality' and a migrational reinterpretation of theology (eds. Gruber \& Rettenbacher 2015).

In a hermeneutical approach to the complexity of displacement, a praxis approach should differentiate between complexity and complication. In complication, the attempt is to find rational answers and practical solutions (Taleb 2010:9). In complification, ${ }^{10}$ one opts for a solution; in complexity, one faces the difficulty of decision-making without the guarantee of a necessary solution (Nilson 2007:239).

Complexity is not about a manual how to solve a problem. It is about understanding and insight on how different polar tensions and paradoxical tendencies appeal to the making of wise decisions contributing to meaning and significant engagement rather than offering quick-fix answers. To understand how opposing polarities are interconnected creates new insights about change and healing. It could eventually help people and institutions to revisit existing approaches and structures. Hermeneutics challenges all institutions to start to design alternatives (the heuristic stance).

In hermeneutics of complexification," the pointers are not positivistic solutions on the level of the cognitive. One should rather turn to the realm of disposition, attitude and aptitude (habitus). This is the reason why the sociologist and philosopher Bauman (2016:122) is convinced that the only option to deal with the crisis of displacement is the route of compassionate solidarity. ${ }^{12}$

10. 'A complicated process or phenomenon can be decomposed and reduced to solvable parts and it therefore follows that with such an ontological standpoint the positivistic paradigm prevails' (Nilson 2007:238).

11. Complexification (Morin 2008:20-21) steers away from statistics, predictability and calculated certainty. It accommodates uncertainty and only tries to 'see the bigger picture' despite the paradox of smaller entities. Complexity works with indetermination and implies the risk of engagement without a fixed plan and making choices within the awareness of possible failure.

12. Bauman (2016:122) emphatically states, 'Es gibt keinen anderen Ausweg aus die Krise, in der die Menschheit sich befindet, als Solidarität'. 
It is right at this point where the image of Angela Merkel comes into play and could be viewed as an icon of how the civil society could deal with the challenges of the migrant outsider and display social solidarity and sympathetic compassion.

To my mind, Angela Merkel ${ }^{13}$ is an exception in global politics. I want to see her visionary leadership as a kind of piety that embodies the diakonia of reformed Christian spirituality. She could even be called the Calvin and Reformer of Berlin. Living in the former Eastern Germany, she was constantly exposed to the predicament of displacement. She oscillated between her Christian tradition as a child of a pastor and the experience of estrangement under a communist and even fascist regime (Vick \& Shuster 2015b:30). However, she boldly continued to emphasise the fundamental attitudinal change. ${ }^{14}$

Very surprisingly, the influential German magazine Der Spiegel (29 August 2015) made a plea for a hermeneutical approach that promotes attitudinal change. The challenge is to understand the plight of the refugees from their perspective (Amann et al. 2015:28). The front cover page put it very boldly: Germans will have to change their attitude ('Es liegt an uns, wie wir leben werden' - Our attitude determines the how of our life). And change without sincere compassion will immediately be interpreted as merely political window dressing.

13. 'The German Democratic Republic, where Angela Merkel grew up, was neither democratic nor a republic; it was an Orwellian horror show, where the Iron Curtain found literal expression in the form of the Berlin Wall. The shy daughter of a Lutheran minister, Merkel slipped into politics as a divorced Protestant in largely Catholic party, a woman in a frat house, an Ossi in the newly unified Germany of the 1990s where easterners were still aliens' (Gibbs 2015:23).

14. Angela Merkel was elected as 'Person of the Year' by Time Magazine (Vick \& Shuster 2015a). The core of her pilgrimage from behind the Wall in Berlin to The Reichstag (parliament building in Berlin) is captured by the phrase, 'Welcoming the stranger'. Her politics implies therefore more than merely finding a political solution. She took the risk of following her heart and conscience. To my mind, she has become both an icon of being a displaced stranger (reunification of Germany), and of a welcoming host for the foreign outsider and outcast in society. 
In terms of the previous outline, one can conclude and say that the crisis and dilemma are basically a crisis of attitudes, disposition and skewed perceptions. Behind all of these lurk different inappropriate ideologies and political agendas (Manheim 1966:49). Paradigmatic frameworks determine people's reactions. Thus, there is an urgent need to provide a diagnostic tool that can help people to start 'seeing' behind the turmoil of displacement new avenues for compassionate accommodation and the humanisation of the civil space of humane interconnectedness.

\section{Towards a graphic design in a diagnostic approach: The healing of 'seeing the bigger picture' within the predicament of displacement and social polarisation}

The previous outline reveals that displacement is inevitably enclosed by an investable social and bipolar tension: the tension between distancing (kind of normal form of resistance) as an indication of the existential realism of detachment (to differentiate oneself from the other - isolation and cultural separation or segregation) (e.g. I am a South African, you are a foreigner and I am different) and hospitable welcoming (the need to create an intimate space of recognition, acknowledgement and accommodation).

In severe conflict settings of social polarisation and social friction, the danger exists that the bipolar poles become isolated from one another. They become fixed and ideological polarities lead to more social and political friction and tension (even violence):

- The threat of fixed prejudice and enmity - social segregation. In South Africa, this position leads to the ideology of judicial and discriminating apartheid.

- The irrational attempt of social assimilation. This option tends to fuel the danger of social and political totalitarianism - social 
engineering as the artificial attempt to mould diversity into a forced unity dominated by the strongest cultural and political party. In this regard, the notion of the 'strongest tribe' (political power play) eventually dictates the quality of interconnectedness (totalitarian assimilation; oppressive patronising).

In pastoral hermeneutics and diagnostic approach (Figure 1.1), the first step is to probe into the realm of social and relational polarisation by asking the following four questions:

1. What are separating human beings and how does one understand one's own unique identity? (The necessity of dealing with the phenomenon of differentiation: identity identification and detachment as creating a constructive space of distancing in order to gain perspective). The necessity of constructive distancing, detachment, can easily fuel enmity and destructive forms of discriminating prejudice.

2. What are the communal factors that can be shared in terms of mutual exchange in order to create a sense of cohesiveness, togetherness and belonging? (Creating a sense of communal togetherness - sense of belongingness and sharing within a hospitable space of sincere welcoming). Within this space always lurk the danger zones of totalitarian political assimilation and oppressive forms of patronising.

3. What are the norms, values and belief systems that direct a very specific group of people: the normative factor and ethical directive in a process of reorientation and attitudinal change (customs, cultural convictions and religious confessions)? Here lurks the danger zone of utopian ideology - the elsewhere will be a better place.

4. What are the specific needs and expectations as related to basic commitments, lifestyles and dispositions (ethos and realm of attitudes)? How appropriate are they? This area must face different levels of human aspirations and is constantly exposed to severe scepticism and, thus, possible levels of fear and disillusionment. 
Several times the notion of disposition featured in the description of the predicament of displaced human beings. In the design of a visual depiction and graphic portrayal (diagnostic tool), the space as demarcated by four quadrants (see Figure 1.1) becomes informative and decisive for the understanding of the dynamics of ethos and repositioning (habitational changes). They help to identify within the possible bipolar tensions the realm of

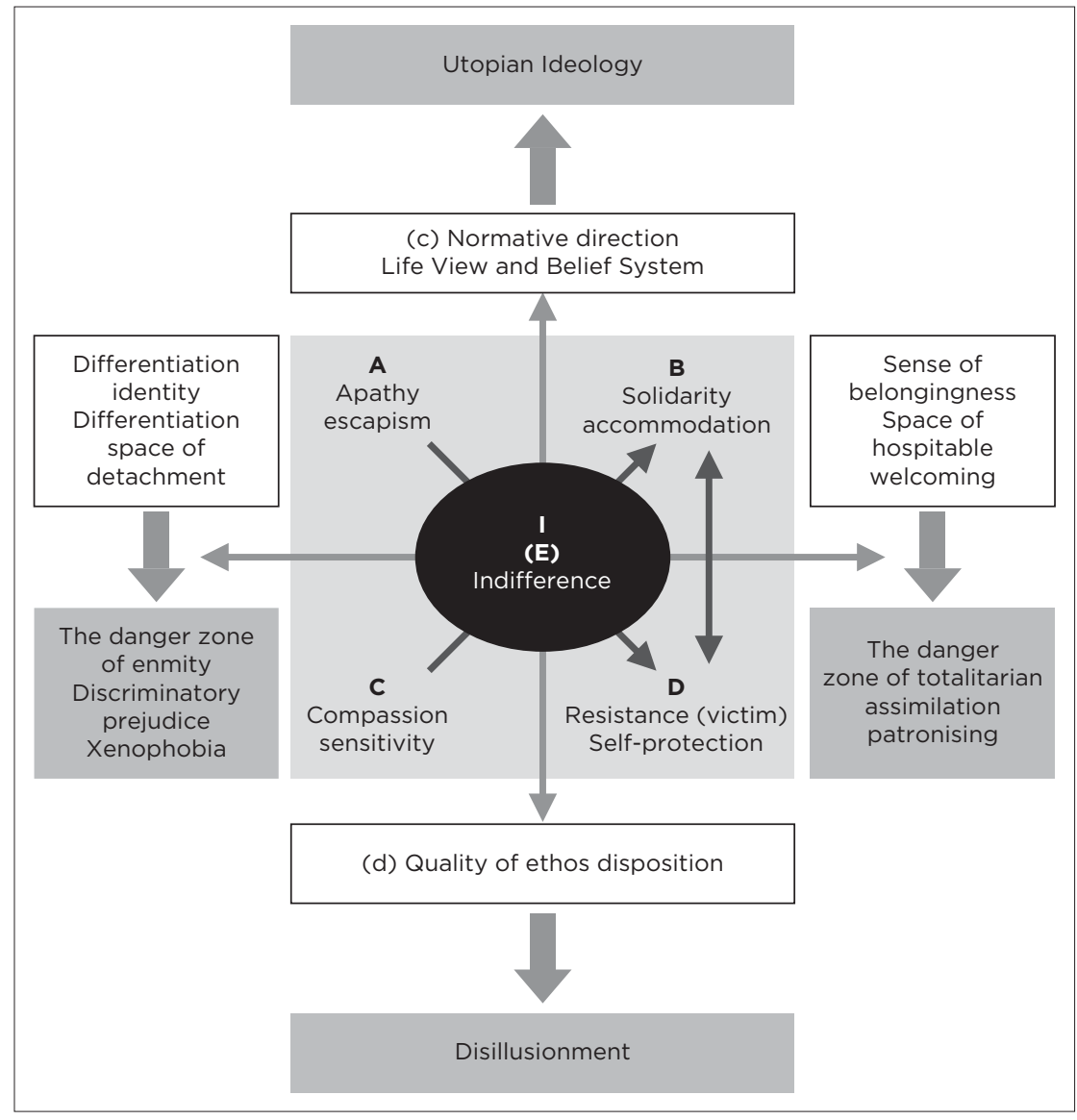

FIGURE 1.1: Five dynamic dispositions: Dynamics of attitudes (habitus) - different options. 
existential positions (habitus). Furthermore, the different positions indicate the how of attitude (quality) within interactional dynamics, especially when people from diverse cultures share the same place and space. The different positions explain how the networking dynamics of co-existence can be either promoted or being hampered.

On the one hand, it helps to discover how diversity can enrich the space of multi-pluralism and intercultural sharing. This is what Polak (2018:45) calls a learning curve, namely, learning to translate those positive experiences into organisational, institutional and juridical structures that foster living together and learning from each other. As a Muslim scholar (Kassim 2018:85) ${ }^{15}$ aptly remarks, one needs to understand that pluralism is a feature of life in the global village. On the other hand, it makes an appeal for repositioning in order to foster peaceful co-existence and an ethos of hospitable responsibility.

Figure 1.1 depicts the following four positions (the four quadrants present four different positions in the displacement crisis):

1. A position of apathy and the tendency to escape, deny and withdraw from the demands of appropriate engagement with the crisis.

2. A position of solidarity that displays one or other forms of accommodation of the foreign other.

3. A position of compassionate being-with the other because of sensitivity and the willingness to become engaged - significant participation.

4. A position of becoming a victim (fearful resistance, fear for loss) that is fuelled by xenophobic fear and the tendency to safeguard one's own position (self-protection; German: Abschottung).

15. Militant Islam can reveal also the other side of the coin: Resistance to dislocation within own local communities and a reaction to forced processes of acculturation (Kassam 2018:85). 
Despite these four positions, there is also a kind of middle position (E) which one can call a position of indifference. It represents a neutral stance that points to sheer ignorance. This position contributes to what already has been mentioned - the inflation of compassion. At stake here is the question why one does not want to become involved at all or is just not interested?

In order to put the diagram into practice and to make thorough analysis of the displacement crisis, one must reckon with the fact that all positions and bipolarities are always at the same time existent. They do not represent an 'either-or' approach. Furthermore, the different bipolarities and habitational quadrants should not be viewed from a moral perspective, that is, that left is wrong (bad) and right is the better (good). Left represents merely the shadow side of life and right the brighter side of life.

Positions in the crisis of displacement can therefore differ from time to time. Unfortunately, they can become fixed because of different emotions, contexts and local settings that are directly or indirectly related to the danger zones of enmity and totalitarian assimilation, disillusionment and utopic ideologies.

The dynamic component of change implies the constant shifting of positions (habitational change). Healing within the networking of co-existence implies the shifting of position $A$ towards the opposite quadrant $\mathrm{C}$, from apathy to compassionate solidarity; from position $D$ to the opposite quadrant $B$, from xenophobic resistance to accommodative solidarity. Positions $B$ and $\mathrm{C}$ are complimentary to each other and function in a supplementary mode.

It has already been mentioned that the core problem in the displacement crisis is the danger of radical polarisation. According to Bauman (2016), the option of integration has to do with the danger of assimilation and in the long run the cause of destructive reaction; the pathology of social separation and alienation. Rather than running the danger of totalitarian assimilation, the hospitable option of compassionate co-existence is proposed. This option implies the challenge of 
creating a platform of common interest (sense of communality). It should pose the question of identifying a common ground wherein mutual interests and values can be shared. One such common ground should be the principle of cooperative sharing and co-compassionate accompanying. At the same time, coexistence can provide space for differentiation and the maintenance of own, unique identities (the dynamics of constructive and enriching diversity: identity formation).

The option of co-existence should therefore be explored and promoted. Specifically, in the setting of the refugee crisis wherein it is not clear whether refugees will go back to their country of origin, or whether they are going to stay on long-term basis. To provide a framework for sustainable monitoring of the process, more than merely the dynamics of relational co-existence is needed. Co-existence should be directed by a comprehensive paradigm, patterns of thinking, spiritual framework of supplementing co-categories that direct peace as expression of hospitable sharing, trustworthiness (integrity) and charitable reaching out.

\section{Towards a praxis of cooperative peaceful co-existence}

Cooperative accommodation captures the true spirit of coexistence. In this regard, Ramphele's (2012:184-195) identification of supplementing categories that contribute to the dynamics of an enriched space of co-existence (the Letsema Circle Open Hand Approach) is most helpful to understand why the option for habitable and hospitable co-existence (peaceful interaction) is a more appropriate approach than unifying integration or assimilation. The following co-categories explain the praxis of accommodative and cooperative co-existence:

- Co-discover - identifying assets residing in communities that unleash energy for sustainable development and dignifying co-operation. 
- Co-invest - processes that can help communities to make decisive choices about co-existence, that is, to decide where to invest time, energy and resources towards becoming selfreliant.

- Co-create - new ways of relational building and communal networking to develop community skills, shifting mindsets from prejudice to embracement and finding appropriate cultural resources to develop community initiatives.

- Co-initiate - facilitating comprehensive frameworks of understanding; paradigmatic issues that enhance constructive life views contributing to a sense of belonging and cooperative participation; directive factors that can mobilise local communities to start sharing from their tradition and these perspectives that can contribute to a common ground of dignifying virtues and values.

- Co-inspire - solidarity with real contexts of pain and suffering so that the so-called victims can start moving from learned helplessness to participatory involvement and mutual accountability.

- Co-municate - narrating together different stories regarding displacement and the fear for rejection; and collecting stories of 'success' and radiating them to fuel constructive social development.

I want to add another co-factor that determines the character of meaningful living, namely, the dynamics of co-existence:

- The spirituality of co-suffering (compassionate being-with): of mutual exchange and the ethos of sacrificial benevolence; and seeking the benefit of the other through charity and diaconal service.

The expected outcome of an accommodative approach of cooperative co-existence is what one can call peaceful coexistence. Peace is then not a stable condition wherein tension and violence and enmity are absent; it is not about the nice and utopic space of harmony. It is about a new mode of being, namely, the sacrificial stance (habitus) of exchange and diaconal outreach 
wherein one starts to invite the strange and foreign other into the hospitable space of mutual sharing. The dynamics of this peaceful space of cooperative sharing, diaconal outreach and hospitable serving are compiled by the above-mentioned co-categories of co-discovering, co-investing, co-creating, co-initiating, co-inspiring, co-municating and co-suffering.

Peaceful co-existence is not a democratic ideal of wishful thinking (utopic stance) coming from privileged people, opportunistic politics and ideological populism. Peaceful coexistence is, in the words of Mbaku (1999:5), not about opportunistic nationalism but an exponent of the African spirit of communality and sense of belongingness (Ubuntu interconnectedness) (Mandela 2005):

The spirit of Ubuntu - that profound African sense that we are human only through the humanity of other human beings - is not a parochial phenomenon but has added globally to our common search for a better world. (p. 82)

This is what Udoga (1999:162-163) calls 'symbolic interactionism' within the realism of the culturally based 'ethnicity paradox' in South African politics.

The concept of peaceful co-existence ${ }^{16}$ should be linked to the hermeneutical realism of cultural and ethnic diversity; it is about a very forceful interactional dynamics that deals creatively with the reality of ethnic diversity and racial polarisation in South Africa. But (and this is now the intriguing question in peaceful co-existence) what is the spiritual source for such a sustainable mode of co-existence that is not merely dependent on the politics of democratisation and the goodwill of people?

16. Kunzig (2016:115) refers to the danger of discriminating separation, the notion of a 'parallel society' that eventually can become a divided society. 'In a word: Parallelgesel/schaften, or "parallel societies." "The part of cities where you wouldn't know you were in Germany" (Kunzig 2016:112)'. 


\section{Believing in 'some-T(t)hing': The religious and theological dimension of peaceful co-existence}

The further assumption is that peaceful co-existence needs the directive of an external, 'transcendent factor' that serves as a kind of centrifugal cohesive togetherness: believing in 'some-T(t) hing'. Klaus Schwab, the founder of the World Economic Forum, made a profound statement in their meeting in Davos that human beings are not merely directed by the externals of profit and business connections. Besides the human mind (brain), we are directed by the soulfulness of the heart (Duffy 2016):

But you never will replicate the heart, which is passion, compassion. And the soul, which enables us to believe. The robot will never have the ability to believe in something. So perhaps we will have at the end of this revolution - possibly, possibly - a basis for a new human renaissance. (p. 12)

Thus, there is the plea for a theological interpretation of coexistence that resides in the core of Christian spirituality - the passio Dei (Louw 2017:273-381). What is most needed is a shift from rational and cognitive instant solutions to the ethos of sacrificial sharing: the 'wisdom of the heart' as directed by a theopascitic theology of co-suffering (Louw 2017:303-312).

In Christian spirituality, compassion is a many layered concept. It varies from the psychology of empathetic listening to the sociology of interpathetic communication. Davis (2001:234) describes the different nuances from the Latin word commiseratio to the Greek word sumpatheiea and the German Mitleid (in Afrikaans medelye, meaning 'to suffer with'). In caregiving, compassion is closely connected to a kind of sympathetic mode of being. Compassion is then transferred from the merely affective-based realm of emotions (the affective mode) to the more ontic mode of habitus (being mode): clementia, misericordia, humanitas and sometimes pietas; from the Greek eleos and oiktos, the English 'mercy' and 'pity', and the French pitié (Davies 
2001:234) to the theological realm of divine $r h m$ and hēsēd. The latter refers to the unfailing faithfulness and benevolence of God as eventually expressed in theologia crucis [theology of the cross] (Moltmann 1972).

Compassion resides in the trustworthiness of God as expressed and demonstrated in the passio Dei. The latter should be seen as an exemplification of an ethos of sacrificial and vicarious replacement within human displacement (Luther: marvelous exhange, in McGrath 1993). It represents the notion of Deus migrator - God the migrant (Phan 2016:845-868) - God migration into the suffering of human displacement.

\section{- Spiritual directives within a theological interpretation of 'hospitable accompaniment': The migrating God}

The previous outline for a theological interpretation of compassionate and peaceful co-existence could be translated into four actions formulated as dynamic verbs: sharing, visioning, caring and solidarising. Further argument in the design of a diagnostic approach to the healing of human displacement is that the following four spiritual directives (directives for a meaningful, significant change, that is, indicators that create a hospitable space in human networking and eventual spiritual healing) should guide processes of habitual change in order to foster a social culture of compassionate co-existence (Louw 2017):

- Sharing and exchange: Co-sharing (A) - the intention is to enrich and to empower.

- Imagination and vision: Co-envisioning $(B)$ - the intention is to anticipate something new.

- Caring and charity: Compassionate being-with (C) - the intention is to display sensitivity, to affirm, to comfort and to heal. 
- Solidarity and participation: Cooperative action (D) - the intention is to do or act and to transform.

The four spiritual directives are encircled by two telic dimensions in a teleology of Christian wisdom thinking, namely, trust (the dimension of faith - stability and continuity) and hope (the dimension of future anticipation - creativity and imagination) (Figure 1.2). Trust refers to faithfulness and sustainability - the need for continuity. Hope refers to anticipation and transcending acts of expectation - the need for something new and accomplishment (life fulfilment); it also shapes the courage to be and establishes patience and perseverance.

In a practical theology of habitus, my proposition is that a diagnostic chart (Figure 1.2) (Louw 2017) can help different groups of people wrestling with the predicament of displacement and paranoiac responses of resisting xenophobia to detect different options. The chart must be assessed as a kind of experimental depiction of all the different components of coexistence. It depicts possible positions people can display that eventually could determine meaningful options or alternates. The different components create a networking framework of interactional, spiritual directives; they identify pointers for creating a sense of belongingness and wholeness (well-being). The chart therefore depicts the spiritual dynamics of networking co-existence within a practical theological structure and bipolar, spiritual (meaning giving) dynamics.

The four directives are also encircled by two theological paradigms (Figure 1.2), namely, (1) the covenantal faithfulness of God-Soul Friend and Host, and (2) the mercy and pity of God co-sufferer. The metaphors 'God as Soul Friend' and 'Compassionate Host' (hospitality as diakonia) are explaining the trustworthiness and pity of God: ta splanchna (Louw 2017:314317). Divine pity then refers to esplanchnizomai as the movement of the entrails. It describes a kind of practical theology of bowel categories and of the intestines: the migrating God (Figure 1.2) 


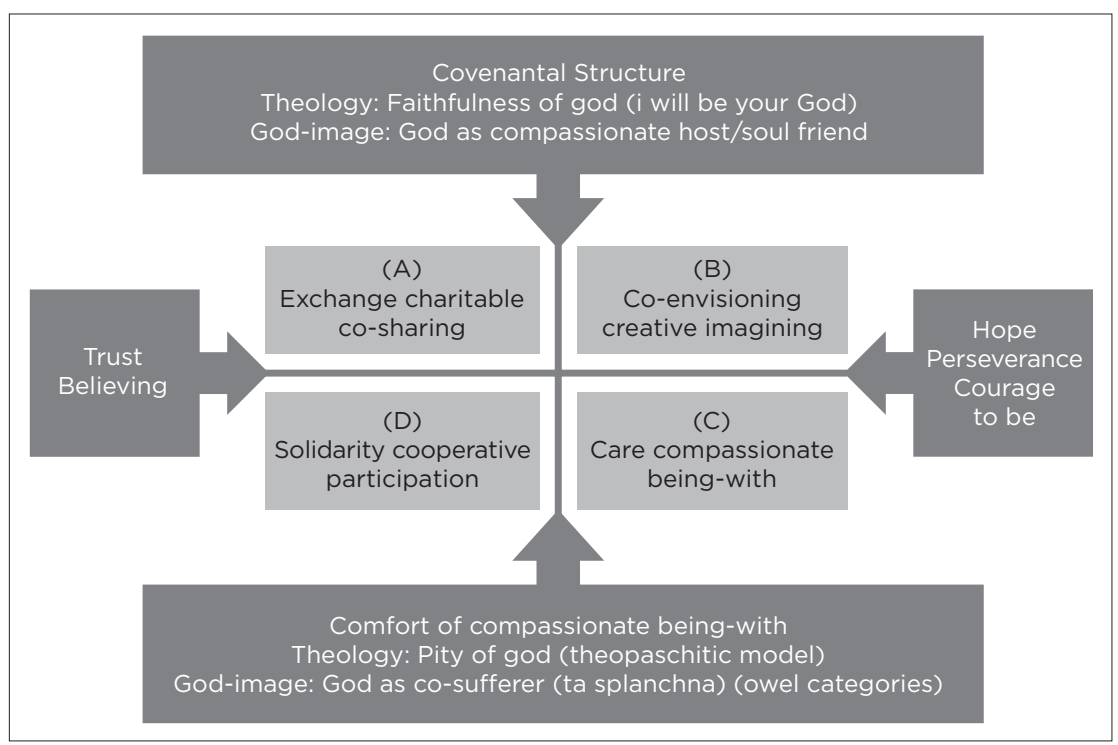

FIGURE 1.2: Dynamics of spiritual networking: Paradigmatic framework for peaceful co-existence and a 'hospitality of accompaniment'.

moves to people and meets them where they are - the co-sufferer of a theopaschitic approach.

The theological categories explain why Christian hospitality becomes a 'radical option' (Robins 2018:139-144). Holten (2016) even refers to 'postures of hospitality' as life-saving measures, and, thus, an ethical imperative. Within a more spiritual and religious context, Sweeden (2015) advocates for 'hospitality of accompaniment' amongst those who are migrating.

We now come to the burning question: what are the impacts of the previous two diagrams on existing ecclesiologies? Can we maintain an ecclesiology that keeps merely denominations and confessions going but not human beings? Can we create also a diagram for a grassroots church that operates according to the spiritual directive of compassionate co-existence? Can we design an operative ecclesiology of compassionate being-with that reforms Cathedrals into shelters for homeless people? Can we 
portray an ecclesiology of home that can give space and place to displaced human beings?

\section{On becoming a streetwise church within the complexity of social polarisation: Between xenophilia (inclusivity of hospitality) and xenophobia (exclusivity of fear or paranoia)}

Within theology, the dilemma of displacement puts a question mark behind an exclusive ecclesiology, denominational demarcations and a selective morality; thus, the focus is on an operative ecclesiology ${ }^{17}$ (Yves Congar in Berggren 2015). The ecclesial and ministerial challenge is to see the migrant crisis as a sign of our time and the place and space for contextualising our practical theological reflection (Keller 2014).

Instead of xenophobia, the practical implication of the passio Dei and the biblical metaphors of host and hospitality in pastoral caregiving, fear for the strange other should be replaced by philoxenia, the mutuality of neighbourly love as expressed by the koinonia of spiritual fellowship. The church as the body of Christ should operate in the displacement crisis as a shelter against inhumane exploitation. Ecclesial presence within experiences of displacement implies that the church should become a kind of hospice and safe haven (xenodochia) - a 'monastery of hope', a compassionate space and place of refuge where threatened people can become whole again. 'To be moral is to be hospitable

17. Operative ecclesiology is meant performative actions of being the church within concrete contexts. It reflects on ecclesial matters not merely from the viewpoint of denominational traditions and dogmatic confessions, but within communal life systems. Ecclesiology may be studied inductively and can thus draw support from various other disciplines, such as political science, history and sociology (see Berggren 2015). 
to the stranger' (Ogletree 1985:1). Hospitality is in fact about a public virtue: hospitium publicum. ${ }^{18}$

With reference to hospitality as an explication of the passio Dei and the salvific work of Christ, the following ecclesial pillars can be identified for the design of a grassroots ecclesiology of compassionate being-with and ministerial outreach to displaced migrants. 'Church' is not anymore defined by the dogmatic stance of orthodoxy and the practice of clerical hierarchy, but by a very profound understanding of leitourgia: operating along the public sphere of pavements and streets. 'Street' and 'pavement' become metaphors for a kind of streetwise witness (marturia) - being there where they are - thus, the option of a 'streetwise ecclesiology' of being the church on grassroots level.

A streetwise ecclesiology of home represents the following ecclesial parameters. They are:

- Diakonia: Reaching out. Be there where they are (the displaced other).

- Eucharistia: Sharing, partaking corporately in Christ's vicarious suffering; to remember through the co-suffering of God and not through the lens of resistance and revenge. In sharing, mutual enrichment is materialised.

- Xenodochia: Creating a sense of belongingness despite loneliness and social discriminatory rejection.

- Leitourgia: Celebrating in mutual fellowship - learning from the other cultures and religious perspectives.

- Paraklesis: Comforting the displaced other - fostering meaning within the helplessness of being dislocated.

- Oikodomein: The upbuilding of the church; the edification of members towards spiritual maturity and cooperative sharing. 'Believers are rooted and grounded in Christ (Col 2:7). The 
Christian community is built up together in the co-operation of all participants (1 Cor 3:10-4), and in unity with apostles and prophets (Eph 2:20), to become the one holy community of the Lord' (Goetzmann 1976:253). Oikodomein fosters an inclusive approach where people are excluded.

- Hamartia: On becoming realistic regarding the limitations of hospitable co-existence because of the reality of human failure and sinfulness. The body of Christ deals with human weakness (astheneia), even with the astheneia of God (weakness of God as expressed in the cross of Christ). Hamartia makes us aware of the fact that an ecclesiology of home is not perfect and a recipe for instant success in the crisis. One ministers within the realm of human weakness on both the side of displaced human beings and caregivers or church representatives. ${ }^{19}$

In the middle of this ecclesial model are the concepts of koinonia and marturia. The fellowship of believers is constituted by a sense of belongingness as established by the cross of Christ. Through his vicarious suffering, Christians become blood-brothers and blood-sisters for one another. However, the coherence factor of koinonia is not focused on an inward and exclusive maintenance of fellowship but on discipleship and missional witnessing [marturia]. Fellowship is focused on the needs of all people irrespective of gender, culture or social status. Therefore, the profound statement of Paul in Galatians 3:28 that in Christ Jesus we are not anymore accessed by the cultural criteria of being Roman, Jew or Greek; nor by social discriminatory categories of boss and slave; nor by discriminatory gender categories of man or woman. We are classified by the unconditional sacrificial love of Christ's co-suffering pity (passio Dei).

The argument and presupposition are that the theological and ecclesial principles - eucharistia, xenodochia, leitourgia,

19. The construct xenodochia [on the horizontal axis] is never the ideal of a utopia. It is always accompanied by its shadow, bipolar dimension of human weakness (astheneia), failure and sinfulness. Therefore, the bipolarity: hamartia - xenodochia. 
paraklesis, hamartia, koinonia and marturia - establish ecclesial sustainability and create a hospitable sense of being at home, ${ }^{20}$ despite the painful experience of displacement and xenophobia. Together they can establish an ecclesial framework for transforming the church into an operative, streetwise ecclesiology of home, operating alongside the street pavements of civil societal life. They foster the ecclesial awareness of a 'church without borders' (Myers \& Colwell 2012) (see Figure 1.3).

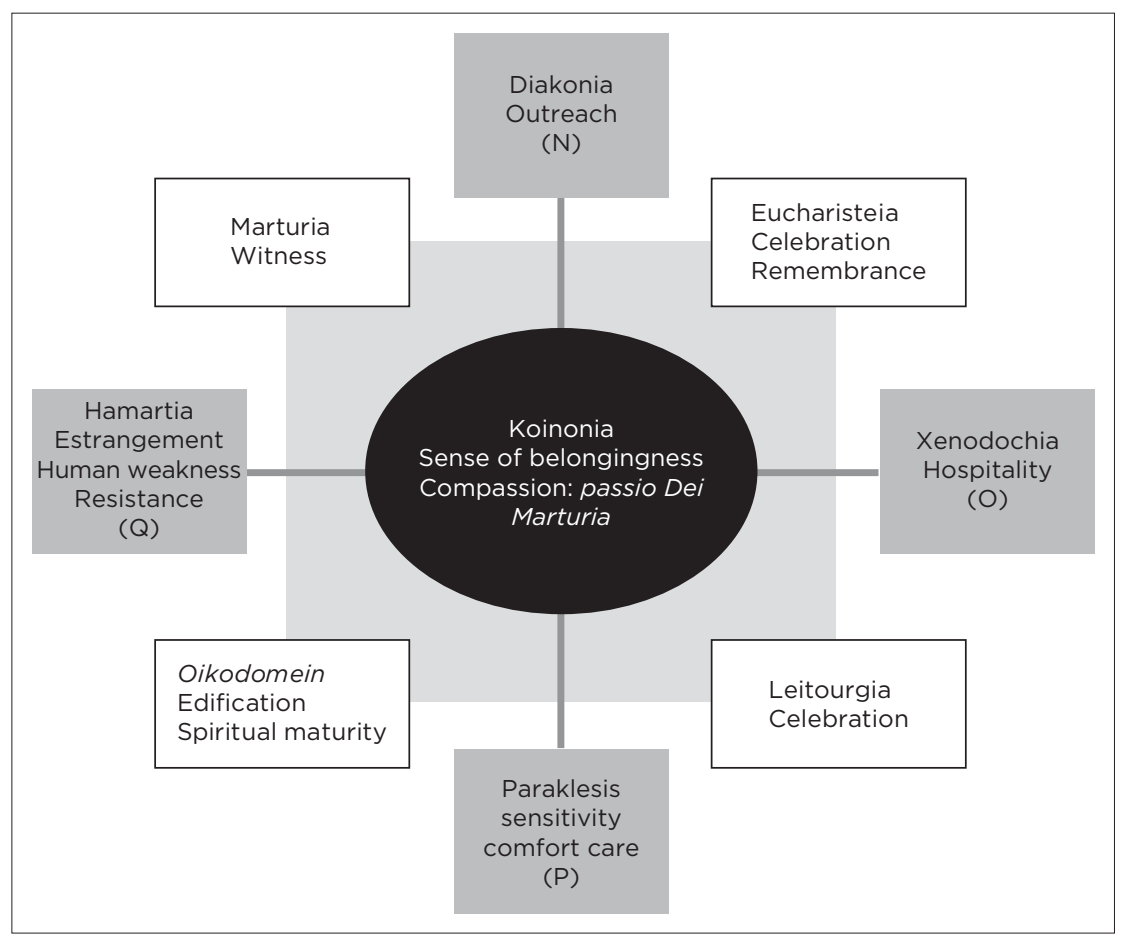

FIGURE 1.3: Theological components in an operative, streetwise ecclesiology of home.

20. Yaghmaian, a Muslim refugee, remarked as follows: '[h]ome is valuable. Home is precious. The smell of home matters a lot'. Leaving it is hard, even for those who know where their journey will end (Vick 2015:34). 


\section{Conclusion}

I concur with Bauman's (2016) proposal that the only way out (dealing with the displacement crisis in a constructive way) is the application of the spiritual principle of solidarity, compassionate being-with. Instead of the polarised dilemma, separation or integration, peaceful co-existence should be explored as a theoretical point of departure in the difficult attempt to overcome the paranoia of xenophobia. To provide a solid paradigmatic basis for sustainable compassionate being-with, the passio Dei should function as a theological directive in a ministerial outreach to the crisis of displacement. In this sense, the display of compassion becomes a kind of habitual common ground within the diversity of co-existing networking. Therefore, the argument: the hermeneutics of pastoral caregiving can be viewed as a unifying factor in the crisis of displacement. Care displays meaning and foster displays a sense of dignity. Thus, the very bold statement of Sathler-Rosa (2018:94) that within the massive flow of migrants, care should be viewed as 'unifying ontological category'.

The hermeneutical approach provides a diagnostic tool for significant pastoral engagement. The further advantage of such a spiritual and pastoral approach is that a graphic design and visual depiction describes a spiritual dynamic for a comprehensive understanding of displacement as an existential predicament. The description of basic bipolarities and the four basic dispositions indicate different shifting of positions. Healing within the dynamics of co-existence implies choices that can help people to shift to opposite quadrants (Figure 1.1): from apathy to compassionate sensitivity and from resistance (paranoia of xenophobia) to accommodative solidarity. Both the dispositions of compassionate sensitivity and accommodative solidarity operate simultaneously in a supplementary way - that is, they complete each other. Within a ministerial approach, the dynamics of habitus should be framed by the dynamics of Christian spiritual networking (Figure 1.2) and 
structured by an operative ecclesiology of home (Figure 1.3) that displays the local church as a bridge between the public and private spheres of society (Keifert 1992) - a kind of intercultural church functioning as a bridge of solidarity in the migrant crisis (Brazal \& De Guzman 2015). 


\section{Chapter 2}

\section{Negotiating nostalgia: A pastoral reflection on the notion of 'home' within the context of displacement on the African continent}

Alfred R. Brunsdon

Department of Practical Theology, Faculty of Theology, North-West University, Mahikeng, South Africa

\section{Abstract}

This chapter presents a pastoral view on the phenomenon of displacement on the African continent through the lens of nostalgia. Also resonating on the African continent, the current displacement crisis is challenging pastoral caregivers to figuratively and literally provide a home for those who become washed up on foreign shores. Presenting an overwhelming array of possible challenges, 
it is argued that the notion of nostalgia provides a fitting frame of reference that can provide valuable clues for pastoral care to the displaced. Relating the notion of nostalgia to the notion of home, this chapter attempts to understand how the idea of 'home' can both 'cause' and 'cure' nostalgia as one of the main challenges of displacement. These notions are reflected upon within a pastoral framework and aim to provide suggestions that will be of value for pastoral care in the context of displacement on the African continent.

Keywords: Human displacement; Migration; African continent; Pastoral care; Nostalgia; Home.

\section{Introduction}

The German documentary film, Human Flow, which was released during November 2017, has brought the issue of human displacement to the attention of the general public in graphic manner. Chinese producer Ai Weiwei documented the flow of refugees over a 1-year period, across 23 countries. On 07 December 2017, Guardian film critic, Peter Bradshaw, highly acclaimed Weiwei's film, describing its impact as making 'a leap of empathy, to understand what being a migrant is like in human terms' (Bradshaw 2017 n.p.). Weiwei's cine-essay on the global refugee crisis is however not the first such attempt; Bradshaw also reminds of Gianfranco Rosi's Fire at Sea and Daniel Mulloy's short film entitled Home - testifying to the urgency of making known to the world the tragedy of what has become known as human displacement.

This chapter deals with this unsettling reality with the greatest empathy towards the millions of its victims. It reflects on the matter from a practical theological paradigm, thus critically reflecting on the communicative actions of the faith community through its pastoral involvement with the victims of displacement. This reflection is done with a specific context in mind, namely, the African continent. 


\section{- Placing displacement}

It is difficult to engage the phenomenon of displacement without providing a basic explanation of the concept within the framework of this chapter. The challenge with a short explanation of the concept lies in resisting the temptation to delve deep into the finer detail of this overwhelming phenomenon - as human displacement seems to be just this: an overwhelming phenomenon that changes the lives of a growing number of people annually on a global scale. To what then does displacement refer to in this chapter?

\section{Displacement and human displacement}

In the general sense of the word, 'displacement' appears as no more than a descriptive term to indicate that something has been moved from its original or usual position. Qualifying displacement as human changes its meaning radically. Human displacement immediately evokes sorrowful imagery. Through the millennia this phenomenon has endured in many guises, although retaining the same meaning, namely, that humans had to leave, voluntarily or involuntarily, what they have known as home. Hence, human displacement will function here as an umbrella term for different ways of humans having to leave 'home'.

\section{Expressions of human displacement: From (in-)voluntary migration to fleeing in order to survive}

At the one end of the displacement scale lies migration. Sometimes thought of as a 'softer' kind of human displacement, migration is often indirectly driven by choice, ambition and yearning for a better life elsewhere. Mostly, it takes place as a sort of avoidance strategy: avoiding imminent consequences of political and economic instability or natural disasters like famine, resulting from climatic change (Burns 2017:1). It is therefore 
suggested that migration is only indirectly driven by choice - as migrants more often than not do not have much choice about their own dislocation. Because of economic and political manipulation, people have been forced for centuries into the 'migrant stream' where they are exploited and manipulated in various ways, reminiscent of the slave era (cf. Bacon 2008:51). Migration is therefore common in poor African countries, such as Senegal, Malawi and Nigeria, and elsewhere in the world. According to Loprete (2017:1), migration has become such a part of the mindset of the poor that it is seen as a normal part of life - even replacing traditional rites of passage into adulthood. Migration, driven by the longing for a better future, can even be said to have become a form of being - Migro ergo sum - I migrate, therefore I am (Loprete 2017:1). It is thus not uncommon to find youths as young as 16 years willing to leave home on behalf of their families in the hope of creating a better life for themselves and their families by sending some form of remittance to the ones who remained behind.

Migration is a legal human right as long as migrants migrate within the regulatory framework of receiving countries. It becomes illegal when migrants enter countries without the necessary legal documentation - mostly ending up in reserves, before being deported to their country of origin. Irrespective of the legal status of migrants, they remain a highly vulnerable segment of the globally displaced as they are prone to be exploited by industry and politics, often having no better future than their challenging past (cf. Bacon 2008:51-81).

At the other end of the displacement scale lies fleeing, which adds people to the ranks of refugees. Fleeing in order to survive denotes the 'worst' kind of human displacement. Driven by persecution and fear of death, fleeing offers the only chance for survival. Accentuating this type of human displacement in recent history is the ongoing Syrian crisis, which started with violent political clashes between the government of Bashar al-Assad and other forces (Ostrand 2015:255). Sadly, refugeeism is not an isolated phenomenon but has in recent years become a global 
trend, which has seen one out of every 122 people across the globe to be displaced (Vick 2015:40).

Fleeing one's country as a result of life-threatening circumstances usually grants victims refugee status, which precedes the tedious process of asylum-seeking. Asylum seekers are referred to as refugees who formally apply for protection in another country and who have rights under certain immigration laws. Hence, European countries are obliged to accommodate refugees by providing food and shelter, whilst their application for refugee status is being considered. If applications succeed, refugees receive the right to work and live in the host country. If applications are unsuccessful, they may appeal the decision once, and if that fails, they may be deported to their country of origin (Vick 2015:44).

With reference to the United States, Malwitz (2018) points out that vague definitions pertaining to refugees and the grounds on which they may apply for asylum often render refugees vulnerable. In some African countries, governments have become notorious for 'discounting the legitimacy of their (migrants) humanitarian claims in order to deny them the rights afforded to refugees and avoid the concomitant obligations placed upon the state' (Amit 2017:1), hence extraditing them yet again into further danger and uncertainty.

Between the extremities of migration and refugeeism, there are other categories that also fall under the broad umbrella term of 'human displacement'. These include the internally displaced persons (IDPs) and stateless people. According to the Emergency Handbook of the UN Refugee Agency (2018c n.p.) of the United Nations High Commissioner for Refugees (UNHCR), the former refers to people who are displaced within the borders of their own country because of life-threatening violence and the latter to 'a person who is not considered as a national by any State under the operation of its law'.

At the time this research was conducted, IDPs accounted for the majority of the total number of displaced people (40 million), whilst the stateless accounted for 10 million people (UNHCR 2018b). 
As it is suggested that the category of IDP represents by far the majority of the total number of displaced people, it is important to come to a better understanding of the dynamics behind internal displacement. Internal displacement takes place where circumstances force people to leave their primary dwellings and surroundings not only because of violent or life-threatening circumstances but also because of personal and/or spatial challenges; in this case, they cannot leave the country. Some of these challenges include natural and geographical issues like rivers and mountains that are difficult to cross, strict laws restricting entry into a neighbouring state or simply that victims are too old, young or weak to flee over long distances. Therefore, not all displaced people necessarily flee their country's borders (Onaedo, Samuel \& John 2017:10), although they are forced to flee their homes and attempt to resettle elsewhere.

A further distinction within the IDP category is thus possible in the sense that internal displacement can be intra-regional (displacement within the borders of one's own country) or inter-regional (displacement on the same continent, but fleeing the borders and hence earning refugee status). Some researchers, like Ruyssen and Rayp (2014) and Amit (2017), seem to denote migration on the same continent between countries as intraregional, but somehow it challenges clear distinctions between internal displacement within one's own country and displacement to another country on the same continent. Hence, inter-regional displacement will serve to denote displacement to another country on the same continent, and intra-regional displacement will denote displacement within the borders of one's own country.

\section{Q Quantifying displacement}

To develop some insights into the magnitude of the phenomenon of displacement, it is helpful to consider some of the available statistics. According to the UN Refugee Agency of the UNHCR (2018b), 68.5 million people are currently forcibly displaced around the world. Of this number, 25.4 million people account for 
refugees of whom $57 \%$ originate from only three countries, namely Syria (6.3 million), Afghanistan (2.6 million) and South Sudan (2.4 million). Of the total number of displaced people, more than half is under the age of 18 years. It is further estimated that 44400 people are forced to flee their homes daily as a result of conflict or persecution (UNHCR 2018b).

In terms of destinations of these refugees, the UN Refugee Agency's 'Global Trends' report (2018a) noted Turkey, Pakistan, Uganda, Lebanon, the Islamic Republic of Iran, Germany, Bangladesh, Sudan, Ethiopia and Jordan as the major host countries of refugees.

In 2017, there were about 2.7 million newly registered refugees, which is double the number of the previous year's figure (UNHCR 2017). The sharp rise in numbers is mainly attributed to new outbreaks of violence in South Sudan and Myanmar, whilst the ongoing conflict in Syria still remains the second biggest cause for the continuing rise in the numbers of refugees (UNHCR 2018a).

\section{Displacement on the African continent}

According to Amit (2017):

The world's attention has long focused disproportionately on migration to Europe. Recent images of migrants arriving on Europe's shores have only reinforced this tendency. But the reality is that the majority of migration is intra-regional. (p. 3)

The above remark is of importance for this chapter as it reminds us of the fact that the African continent is one of the largest contributors to human displacement. Both in terms of inter- and intra-regional displacement, Africa is a region where displacement, in many forms, is rife.

Studying displacement in the African context is not a novel enterprise as migration is considered to be part of Africa's essence. Africa is associated with ancient tribes that were prone to mass migrations for a number of reasons. Earlier studies, such as 
Newman (1995) and Kalipeni and Oppong (1998), have pointed out that these migrations were initially driven by the depletion of natural resources, later by foreign invaders who showed political and economic interest in Africa - and still later, driven from within as Africans often caused each other to be dislocated as a result of ethnic, religious or political conflict. In this regard, Onaedo et al. (2017:21) suggest that there are currently more Africans displaced as a result of intra-state wars than inter-state conflict. Historically speaking, and cognisant of the current African situation, it seems that a long-term secure home in Africa is a rare commodity as both natural and human-caused disasters drive millions of Africans into the human flow of migration on a growing basis.

Currently, the UNHCRs 2018 regional summary on Africa indicates Burundi, the Central African Republic, Democratic Republic of the Congo, Nigeria, Somalia and South Sudan as the areas from where most migration originates. As suggested, intra-regional migration also flows over to inter-regional displacement, as neighbouring countries are seen as better options to escape harm. One startling example in this regard is Uganda that received 1800 South Sudanese refugees per day during 2017 alone (UNHCR 2018a).

Irrespective of the specific reasons for chronic migration on and across the African continent, the phenomenon has shown a progressive upward tendency. Statistics provided by the UNHCR (cf. Kalipeni \& Oppong 1998:1641) during the early 1980s showed less than 4 million displaced people, but towards the end of 2016 , an estimated 20 million people were being displaced in sub-Saharan Africa (UNHCR 2018b), making displacement one of the greatest challenges of millennial Africa.

\section{Challenges resulting from displacement}

Whilst some of the challenges relating to displacement can probably be imagined by most humans, the harsh realities that actually come with it are much harder to express in words, 
especially if you have never experienced this tragedy yourself. This must however not deter academic reflection on the challenges relating to displacement, as clear articulation precedes the actions needed to help alleviate the consequences of this human dilemma.

Based on empirical research conducted in Northern Nigeria, Onaedo et al. (2017) attempted to describe the challenges resulting from displacement under the collective denomination of a loss of human security. Human security is then described as the 'value of life of the people of a particular society' (Onaedo et al. 2017:20). This 'value of life' (Onaedo et al. 2017:20) is further explicated in a rich description indicating that human security seats in freedom from life-threatening phenomena, such as violence and war, as well as access to the basic means that all people need in order to have a secure existence. These include things such as a stable home, access to healthcare, economic opportunities and education. When conditions change to the degree that people are forcefully displaced, compounded loss ensues, as all these sources of human security are lost at once.

In a research conducted by Alobo and Obaji (2016), which also focused on Nigeria, an elaborate attempt is made to describe the consequences of internal displacement in specific terms. This includes the following (Alobo \& Obaji 2016):

- vulnerability as a result of being in transition

- exposure to unhealthy or uncongenial environments

- the destruction of social networks, like families, as a result of members being separated

- profound psychological distress, especially of vulnerable groups like the elderly, pregnant women and children

- isolation from basic necessities, such as education or incomegenerating work

- alienation because of lack of appropriate documentation, such as identity documents. (p. 28) 
Abbot (2016:159), who focuses on the psychological impact of displacement in Europe, suggests that the majority of migrants and refugees suffer from mental disorders like post-traumatic stress disorder, anxiety and depression. This is mainly ascribed to the experience of traumatic incidents which accompany displacement. These include the witnessing of violence and exposure to dead bodies. It also relates to personal experience of violence, torture, sexual abuse and rape, natural disasters and imprisonment. According to Abbot (2016:159), the psychological consequences of displacement alone represent a 'public-health tragedy' which calls for a concerted effort in terms of intervention.

Apart from the physical and psychological challenges mentioned here, there are also challenges that are somehow underplayed, possibly because the management of the aforementioned consequences already absorbs all the energy and resources of the international community. One of these is the so-called 'displacement economies' that emanate from all forms of migration. In this regard, Hammar (ed. 2014:4) alludes to the possibility that during times of severe displacement, the values of 'things, bodies, spaces, natural resources and even money change'. Whilst the human flow of migrants may benefit the local communities of host nations, it unfortunately also creates opportunities for a darker form of economy related to such atrocities as human trafficking, sex trade and economic exploitation of the vulnerable.

Another dark consequence and challenge is often found at the end of the migrant journey. Migrants, lucky enough to reach safer places in another country, are increasingly greeted with hostility and even xenophobia that are often expressed through antagonism and physical violence, forcing them to flee once again. According to Amit (2017), antagonism especially greets migrants and refugees at the borders of African countries where local economies are already under pressure to provide for their 
own populace. In this atmosphere, reasons are often sought to deny asylum seekers the rights they have under current laws. Even if they are allowed to enter the host country, hostility awaits them that often results in xenophobic attitudes and attacks (cf. Banda 2014; Louw 2016).

\section{Displacement in a pastoral and ecclesial framework}

In the light of the aforementioned discussion, the focus now shifts to relating human displacement to a pastoral and ecclesial framework, probing the challenges created by this phenomenon for the faith community in the African context. Whilst it is true that some faith communities are still untouched by and oblivious to the reality and challenges of displacement, there are those who are actively involved with or confronted by this phenomenon.

A well-known narrative in this regard is that of the Central Methodist Church in Johannesburg, South Africa, which has opened its doors to mainly African refugees since 2000 under the custodianship of Bishop Paul Verryn (News 24 2014). There are also documented narratives of refugees themselves, which contain rich descriptions of how the church supported them in their quest to find a home (cf. Bloch \& Heese 2017:11).

Although these narratives are complicated and pay testimony to an array of challenges, they are mindful of the calling of the faith community to respond to the plight of the displaced. This is a phenomenon which seems to be growing and that will remain part of the African landscape for many years to come. There is a calling to remain faithful to the biblical imperative to have compassion for the stranger (cf. Ex 23:9; Dt 10:19; Lv 19:34; Ps 146:9; Mt 25:43), thereby calling for ongoing development of theories that support a faithful praxis of caring for the desolate. 


\section{ainding a suitable paradigm for pastoral care within the context of displacement in the African context: The loss of home}

In the pastoral expression of the faith community's compassion towards the displaced, a suitable frame of reference is needed. Any such paradigm should stand firmly on the imperative to have compassion for the stranger as well as the most prominent existential crises of the displaced. As indicated, the challenges that accompany displacement are many and highly complex as they exist on all levels of the human experience. Therefore, it cannot be argued that only one challenge or paradigm for pastoral care to the displaced exists. However, it can be argued that the loss of 'home' will be one of the main challenges for pastoral work with the displaced. This choice is motivated by the notion that was conveyed at the beginning of this chapter, namely, that displacement through the ages carried the same meaning, namely that humans had to leave what they have known as home, subsequently, having to come to terms with the 'loss of home'.

\section{Seeking the meaning of home}

Home can be understood in many ways and will probably be understood differently by different cultures. It can also be understood in a literal and figurative way. From a pastoral perspective, a holistic view is needed in order to cultivate an understanding for the depth of loss when one loses one's home. According to Taylor (2015):

$[H]$ ome is not just a singular physical building, but is the network of streets, buildings and communal spaces that make up a neighbourhood. It is the complex web of social relations which include family, friends, acquaintances, business associates and enemies. It is the water from the spring, the blossoms on the trees, the crops on the field and the food on the table. It is the conjunction of all these things at a particular moment in time. (p. 155) 
It is only by understanding the notion of home in all its diversity that we can begin to appreciate what losing and remaking home entails. For the sake of a pastoral response to the displaced within the African context, the notion of home also needs to be considered within the contexts of the Christian and African tradition.

\section{口'Home' (oikos) within the Christian tradition}

In the Christian tradition, oikos is the best-known equivalent of what resembles home. At least two basic (literal) meanings are distinguished, namely, 'a house', which may also mean 'an inhabited house', or 'dwelling place', which refers to the 'the inmates of a house, all the persons forming one family, a household' (cf. Fowlkes \& Verster 2006:327). In Paul's first letter to Timothy, the literal meaning of home is transcended to denote the faith community (ekklesia), as the faith community is now equated to the 'house of God' (1 Tm 1:15).

Conradie (2007:1) places oikos within an ecclesiastical framework and describes it as a 'theological root metaphor', which has the potential to integrate several of the church's functions within the world. This includes the church's calling in terms of 'hospitality' and 'nourishment' (Conradie 2007:2-3).

Zamfir (2014:514) hence points out that the notion of the church as the 'house of God' should not merely be understood as a metaphor for how members of the congregation should treat one another, but that it should also orientate members towards their public function, as both ekklesia and oikos refer to the public space. 'Consequently oîkoc $\theta \varepsilon o u ̂$ paradigm has broader implications than generally acknowledged' (Zamfir 2014:514). Louw (2017:5) also supports a broader understanding of oikos [thinking] that calls for an 'ecclesiology of oikodomein', which heeds the faith community to create spaces where others can live, dwell and inhabit. 
Home in the Christian tradition thus carries both a descriptive and an imperative character: home is the place where family belongs together and it also points to the calling of the faith community to create an oikos where the desolate can dwell.

\section{'Home' (ekhaya) within the African tradition}

Several researchers such as Lambo (2012), Holton (2016) and Marschall (2017) have approached the role and value of home amongst African people with sedentary or attachment theory in mind. Sedentary theory argues that a 'profound and natural bond between people and place exists' (Lambo 2012:9). Although there are some theorists who suggest that globalisation has altered the bond of people with their home or land (cf. Connolly 1991), research amongst the displaced seems to contradict this and maintains the value of home for a person (Holton 2016).

For many Africans, this is especially true as their very Zitz im Leben nurtures a strong bond between themselves, the land on which they live, the home they have erected and the networks of people that share those spaces with them (Ubuntu). Often known as pastoralists, living off the land with small herds of animals like goats, camels or cattle, home is of great significance within the African context. This close relationship is expressed in the Zulu name for home, namely khaya. Whilst khaya denotes the physical structure of a house, ekhaya refers to what a home means - or rather what is experienced at home. Louw (2017:4) thus relates ekhaya to empathy, sharing, belonging and a familial homecoming.

In a study conducted amongst Somali refugees in Kenya, Lambo (2012) has shown that displaced Somalis figuratively 'remained' in Somali because of this very strong bond with 'home'. Through media and regular fadikudire [group gatherings with the homeland as topic], 'home' is kept alive (Lambo 2012:14). This maintaining of home, even for those who have been raised in a refugee camp, relates to identity and the sense of belonging that are associated with the home of origin (Lambo 2012:7, 9, 14). 
Because of this deep meaning of home for Africans, a new form of tourism has emerged amongst inter-state African migrants to periodically return to their homes of origin in a controlled and safe environment. Also known as 'diasporic tourism', 'roots tourism', 'ethnic tourism', 'legacy tourism', 'personal heritage tourism', 'emigrant homecoming' and 'homesick tourism' (Marschall 2017:214), these are all expressions of the value home retains for African migrants.

\section{- Seeking an outcome for pastoral care within the context of displacement (loss of home) in the African context: Negotiating nostalgia}

On a spiritual and emotional level, the loss of home (ekhaya) that results from human displacement ultimately leads to nostalgia. Nostalgia is the collective name for the existential longing for home. Apart from all the physical challenges, migrants and refugees will in all probability be challenged to overcome a strong presence of this spiritual and emotional state.

According to Sekides et al. (2008:304), nostalgia finds its roots in Greek mythology describing Odysseus' longing for home whilst away during the Trojan War. A combination of the Greek nostos [return home] and algos [longing, pain, ache], it denotes the acute emotional pain of someone longing for one's home or past. In Western history, the term 'nostalgia' was first used by Johannes Hofer in 1688 to describe the symptoms displayed by displaced Swiss soldiers who had to work or fight abroad (Boym 2007:8). Seen as a medical problem, it was believed that nostalgia could be cured by medicine and rest such as during a vacation in the mountains. Currently, the condition is used to describe the painful longing amongst migrants when coming to terms with the loss of their homes of origin (cf. Lambo 2012; Taylor 2015).

It is argued here that the condition of nostalgia creates ample opportunity for pastoral work with the displaced and that negotiating nostalgia is the goal (outcome) of the 
pastoral endeavour. In this regard, the work of Svetlana Boym (2007) deserves the attention of pastoral caregivers. In her essay on nostalgia, Boym widened the notion of nostalgia to include the longing of people not only for the home of the past but also the times gone by, and hence the experiences that constituted a better and preferred time. Boym also makes an important distinction between two different expressions of nostalgia, namely, restorative and reflective nostalgia. Restorative nostalgia denotes a focus on the lost home and past itself, indulging in the yearning to restore the preferred past. Reflective nostalgia denotes a focus on the past home against the background of current realities. The first expression of nostalgia concerns the nostos [return home], whilst the latter expression concerns algia [longing, pain, ache]. In this sense, nostalgia is not only retrospective but also prospective, '[t]he fantasies of the past, determined by the needs of the present, have a direct impact on the realities of the future' (Boym 2007:8).

In pastoral work with the displaced, the notions of home and nostalgia converge in a dynamic intersection where the pastoral caregiver can negotiate nostalgia from the perspective of the Christian oikos. The strong and enduring longing for home found amongst African migrants (Holton 2016; Lambo 2012; Marschall 2017 ) is rooted in the warmth and security of the familial homecoming, as expressed in the notion of ekhaya. Presenting as a form of restorative nostalgia, it initially places the African migrant in the painful process of longing for (the) ekhaya, which was most probably lost through a distressing and forced dislocation. Intervening during the process of restorative nostalgia, the pastoral caregiver is driven by the notion of the Christian oikos that resembles the calling to make room for the 'other'. In a pastoral sense, this will refer to accommodating with much empathy the narrative of the migrant's nostalgia, even to celebrate with them the memory of the lost ekhaya which was once home.

The work of the pastoral caregiver however also extends to the facilitation of reflective nostalgia. This is done in the 
knowledge that a physical return 'home' will most probably not be possible. Facilitating reflective nostalgia is focused on a critical reflection of the future in the light of current realities regarding the home and country of origin. Its main tenets concern the recognition and acceptance of those current realities and a revisioning of the future in the light of the possibilities that reside in the Christian oikos. As such, reflective nostalgia resonates well with what Marschall (2017:214) denotes as the 'shifting sense of the self'. The notion of the 'shifting sense of the self' Marschall (2017:214) closely relates to the changes that occur within migrants who cannot return to their original home, thus cultivating a new identity in the foreign home (land). Shifting of the sense of oneself is preceded by 'slippage' Marschall (2017:214), which refers to the gradual realisation and acceptance of the fact that to return home is not possible. Often found in the inability to feel at home at the home of origin or to connect with old acquaintances or even to eat local food, all of these inabilities refer to 'slippage' Marschall (2017:214), which indicates that a shifting of the old sense of the self is taking place, leading to the formation of a new identity (Marschall 2017:220) in which the new home is accepted and embraced, hence curing nostalgia.

During the pastoral facilitation of reflective nostalgia, one of the main aims is thus to encourage realistic cognitive reflection about the feasibility of a sustainable return home. Whilst migrants still find themselves in inhospitable surroundings or are confronted by challenges such as xenophobic attitudes, the home of the past will remain a favourable object of restorative nostalgic mind journeys. It is true, as Marschall (2017:220) indicates, that new identity formation is more likely to take place once the new home has proven conducive to a better life. It is however here that an embodiment of the Christian oikos can play a pivotal role in offering the migrant, longing for ekhaya, a new alternative. Although the Christian oikos will never be able to replace the home of restorative nostalgia, it may 'make sense' within the framework of reflective nostalgia, creating hope for the future. 
Returning to Conradie's (2007) use of oikos as a theological root metaphor within an ecclesiastical framework, pastoral work with migrants requires a wider approach than the specialist paradigm usually found in western notions of pastoral caregiving. It calls for an African or Ubuntu approach where the faith community, through local congregations, takes 'nourishment' and 'hospitality' (cf. Conradie 2007:2-3) to migrants, hence embodying the Christian oikos. Through the involvement of local congregations to support and extend the work of pastoral caregivers amongst the displaced, the faith community will be able to remain faithful to the biblical imperative to have compassion for the stranger (cf. Ex 23:9; Dt 10:19; Lv 19:34; Ps 146:9; Mt 25:43), hence giving expression to the Christian oikos.

\section{Conclusion}

This chapter presented a pastoral view on the phenomenon of displacement on the African continent through the lens of nostalgia. From the descriptive overview of the phenomenon of human displacement, distinctions between different expressions of the phenomenon were drawn, whilst also making quantitative reference to the extent of the problem. Human displacement was shown to find expression in both voluntary and forced migration. In its wake, it leaves a growing number of desolate people in different categories: migrants, refugees, IDPs and even stateless people. They all, however, share one common loss: the loss of home.

Having indicated the alarming international growth in all forms of human displacement, the focus shifted to the African continent where inter- and intra-regional migration was denoted as rife. Often being underplayed in the media, inter- and intra-regional migration accounts for the largest contributor to global migration, putting Africa high on the human displacement agenda.

Building the bridge for the pastoral challenges that are presented by human displacement, some of the foremost challenges resulting from migration were articulated. These ranged 
from the loss of human security to some of the consequences of displacement in specific terms, like transitional vulnerability, profound psychological distress and isolation from basic necessities such as education or income-generating work. Attention was also paid to the psychological impact of displacement, which represents no less than a public health tragedy. Some of the lesser known challenges like 'displacement economies' were also discussed, which included atrocities such as human trafficking, sex trade and economic exploitation of the vulnerable. Challenges awaiting asylum seekers in host countries such as antagonism, hostility and xenophobia were also highlighted.

Seeking a paradigm for pastoral work with the displaced, it was suggested that the common denominator, 'loss of home', could serve as an umbrella term for pastoral engagement with the displaced. At the heart of the collective displacement dilemma lies the fact that people have lost what they experienced as home. As the notion of home transcends the mere structure where an individual or family resides, the 'loss of home' represents the convergence point of the loss of the familial homecoming.

Examining the notion of home within the Christian tradition, it transpired that the notion of home (oikos) indeed extends further than the physical familial residence, but functions as a theological root metaphor for the church (ekklesia). As such, it provides clues for the church's function in the world, namely, to become a household which exudes hospitality and provides nourishment. It is this public function of the church as hospitable and nourishing oikos that needs to be explored in the light of the crisis of human displacement and which calls for an 'ecclesiology of oikodomein' that heeds the faith community to create spaces where the stranger can live, dwell and inhabit.

In the African tradition, the notion of home stands central to the understanding of being human. Expressed through the Zulu notion of ekhaya, it also refers to more than the structure that resembles a home, but rather relates to what is experienced at home: empathy, sharing, belonging and a familial homecoming. 
Therefore, African migrants remain longing for home irrespective of where they found refuge.

This longing for home culminates in nostalgia, which denotes the existential longing for home found amongst the displaced. Hence, the notions of home and nostalgia converge in a dynamic intersection where the pastoral caregiver can negotiate nostalgia from the perspective of the Christian oikos. Drawing on the distinction between restorative and reflective nostalgia, the pastoral negotiation of nostalgia resembles at least two challenges: firstly, to make room for the 'other', accommodating with much empathy the narrative of the migrant's nostalgia, and secondly, to facilitate reflective nostalgia. Facilitating reflective nostalgia is focused on a critical reflection of the future in the light of current realities. Foremost of the current situation is that a sustainable return home is out of question for most migrants. Negotiating nostalgia in pastoral work with the displaced thus concerns recognition and acceptance of current realities and a re-visioning of the future in the light of the possibilities that reside in the Christian oikos. It is to help the displaced to develop a shifting sense of the self which ultimately leads to a new identity in a new environment.

Cognisant of the church's calling to become an oikos for the stranger, pastoral work with migrants calls for an approach which transcends the individualistic and specialist paradigms characteristic of western approaches to pastoral caregiving. Instead, it calls for an African or Ubuntu approach where the faith community takes 'nourishment' and 'hospitality' to migrants, hence embodying the Christian oikos. In this way, the faith community is able to remain faithful to the biblical imperative to have compassion for the stranger and, at the same time, embodying the Christian oikos, thereby negotiating nostalgia and making the stranger feel at home. 


\section{Chapter 3}

\section{Complexities of migration challenges in South Africa and a theological perspective: The Good Samaritan framework}

Christopher Magezi

Department of Practical Theology, Faculty of Theology, North-West University, Vaal Triangle, South Africa

\section{Abstract}

This chapter attempts to develop a theological theory on complex migrant challenges that foster constructive theological thinking that results in the embracing of migrants and appropriate responses to their existential needs. The need for the church to develop such a theory arises from the perception that migrants encounter multiple complex challenges. To accomplish its 
objective, this chapter begins by giving a detailed description of some of the complex challenges that are faced by migrants. Then it proceeds to identify and explore the narrative of the Good Samaritan in Luke 10:25-37 as a critical text that fosters constructive thinking that culminates in practical action in caring for migrants. In doing this, the chapter identifies the concept of neighbourliness in Luke 10:25-37 as a constructive theological thinking that results in one considering a foreigner, who is the other, as someone whom he or she can identify with as his or her neighbour. This reasoning is premised on the notion that people are intricately linked together by their common humanity as the bearers of the image of God.

Keywords: Migrants; Complex challenges; Neighbourliness; Ubuntu; Good Samaritan; Luke 10:25-37; Jesus; Theological theory; Foreigner.

\section{Introduction}

A considerable number of scholars (cf. Fauvelle-Aymar 2015; Gopal 2013; Kalitanyi \& Visser 2010; Manik 2013; Manik \& Singh 2013; Muthuki 2013; Rukema \& Khan 2013; Tevera 2013) agree that migrants experience various complex social, emotional, physical and spiritual existential challenges wherever they are. Accordingly, interventions to address migrants' needs are provided from multi-sectoral approaches, where different players such as govern ments, non-governmental organisations (NGOs), businesses and churches play a role (Jackson \& Passarelli 2016:5; Magezi 2018:278-304; World Economic Forum 2017:145). Effort from various stakeholders is necessary because the World Economic Forum (2017:145) notes that 'there is no single entity, organization or government [that] can deal with the complex issue of migration'.

This chapter focuses on the church's theological thinking that should contribute towards meaningful responses to migrant challenges. The task of theological thinking is to develop a theological theory within complex migrant challenges. The term 
'complexity' implies nonlinear thinking whereby one explores some frameworks that could be applied to contribute towards a constructive perspective (Magezi 2016:70-71, 76). Exploring frameworks in our context of theological discussion entails efforts to identify and interpret scriptures in a manner that could foster constructive thinking and result in practical action. This entails, amongst other things, avoiding what Reader (2008:1) calls zombie theological categories that are not useful in current contextual challenges and realities, despite being useful at some point in church history. In view of the context of complexity of migrant challenges that shall be discussed in detail in later sections, the question that could be posed is as follows: what biblical perspective could be developed to ensure that one has an appropriate understanding that results in embracing migrants. At stake is the issue of how one could consider a foreigner, who is the other, as someone who can be identified as a neighbour. This question underscores the need to develop a constructive understanding of the other as someone who is different and yet should be viewed as a neighbour.

To address the above questions, the narrative of the Good Samaritan in Luke 10:25-37 provides a biblical perspective that could shed light as well as challenge individuals to be practically involved in catering for migrants' needs. Thus, the story of the Good Samaritan serves as a locus and hermeneutical prism that can be employed to inculcate constructive socio-theological and communal responses that result in the embracing of migrants. This chapter argues that an individual is intricately linked to his or her neighbour through neighbourliness, whereupon the complex challenges of a migrant are viewed empathetically from the perspective of someone who was created in the image of God, which is also the basis of common humanity.

In order to achieve the objective of this chapter, the section 'The complexity of the challenges of migrants in South Africa' will consider the complex challenges of migrants in South Africa. Then we will link the notion of neighbourliness as an important concept that ensures that people share a common framework, 
whereupon a problem that affects one affects the other. In justifying the notion of neighbourliness as a theological theory that affects how one thinks and acts positively in response to migrant challenges, the chapter will comparatively discuss the notions of neighbourliness and Ubuntu in the African context, where human beings are intercommoned and bound together. After that, the chapter will delve into a discussion of Luke 10:25-37, where the notion of neighbourliness is clearly identified as a critical central hinge of the parable of the Good Samaritan. Finally, the chapter will conclude by giving two implications (at theory formation and practical levels) that could be drawn from the proposed text.

\section{The complexity of the challenges of migrants in South Africa ${ }^{1}$}

\section{Foreign nationals face discrimination in the labour market and accusations of stealing jobs from the native people}

It is important to acknowledge that many foreign nationals in South Africa face discrimination in the labour market (FauvelleAymar 2015). The South African labour market recognises the qualifications of foreign nationals; nevertheless, the challenge arises from the country's labour laws that favour native people and discriminate against foreign nationals (Fauvelle-Aymar 2015). Fauvelle-Aymar (2015) and De Jager and Musuva (2016:24) revealed that many international migrants who look for job

1. The challenges that are expressed in this section are also expressed in Magezi's (2018) $\mathrm{PhD}$ thesis entitled 'Theological understandings of migration and church ministry model: A quest for holistic ministry to migrants in South Africa', which was conducted at North-West University (Vaal Triangle Campus) under the supervision of Prof. Christopher Rabali. In this current work, these challenges have been rewritten to speak directly about the complexities experienced by migrants in South Africa so as to align with the argument being advanced in this research. 
opportunities in South Africa are usually more educated than the native people, yet many foreign nationals work in the South African informal sectors (Fauvelle-Aymar 2015:27). In his own words, Fauvelle-Aymar (2015) states that:

$[A]$ higher share of immigrants with a given skill level is associated with a lower level of employment for nationals with the same skill level. A higher share of immigrants is also associated with higher levels of nationals in informal activities. (p. 27)

Fauvelle-Aymar's (2015) argument is that the majority of skilled and professional foreign nationals find it difficult to get an employment in the formal sectors of South Africa, which results in many of them partaking jobs in the informal sectors so that they can meet their basic needs such as food, clothing and accommodation. This poses a challenge to the narrative that many foreign nationals find it difficult to join the formal sectors in South Africa because of lack of proper documentation (cf. Ngomane 2010:ii). That is to say, there are many reasons that make it difficult for migrants to partake in the South African formal sectors, which include lack of proper legal documentation and the preference of South African natives in the South African labour market at the expense of foreign nationals (Ngomane 2010).

Notwithstanding, some of the international migrants who get opportunities to be employed in the formal sectors still face discrimination because they are not accorded the respect that is commensurate with their occupations. Manik (2013:67-87) investigated the plight of Zimbabwean professionals such as teachers and lecturers employed in KwaZulu-Natal province and discovered that these professionals encountered discrimination in many and different ways. That is, even though the South African government needs professionals to teach critical subjects in secondary and tertiary schools, it is also true that immigrant educators are often subjected to unfair treatment. In addition, some non-native educators experience mental trauma because they are excluded from the social and professional platforms that their local counterparts are being part of (Manik 2013). 
Also, although foreign nationals partake in the informal sectors because of different reasons, Manik and Singh (2013:1) stated that they still face discrimination by the native people. The reason behind such acts of discrimination is that the natives think that migrants are competing with them for the few jobs that are on offer. This accusation is evidently encapsulated by Manik and Singh (2013):

There are some constructions of xenophobia as an attitude which has culminated in foreigners being associated with undesirable behaviour such as stealing the jobs of locals and criminal activities such as drug dealing and hijacking. (p. 1)

In expanding the aforementioned point, Magezi (2017:231), Nie (2015) and Garson and Loizillon (2003) add that native South Africans perceive foreign nationals as competing with them for scarce jobs although the majority of immigrants take up unskilled jobs that many native people are not willing to do. This is worrisome, especially when one considers that foreigners are accused of taking jobs from South African citizens, even in cases when immigrants start their own small business, which, in turn, create jobs (Kalitanyi \& Visser 2010). Kalitanyi and Visser (2010) affirm that many South Africa-based immigrants demonstrate business skills by setting up successful small enterprises that end up creating employment for both South African and foreign nationals. Kalitanyi and Visser's (2010) study further reveals that the employees benefit immensely from tacit entrepreneurial skills transfer as a result of working for immigrant entrepreneurs. Given this, it can be stated that the aforementioned discrimination in the formal labour market, ostensibly because of the foreigners' lack of legal documentation, compels the international migrants to establish their own small businesses, which, in turn, contribute to the advancement of the economy of South Africa through the creation of jobs and sharing of entrepreneurial skills with the local people. On the basis of the foregoing argument, Kalitanyi and Visser (2010:376) disagree with the conception that international migrants steal the jobs meant for South Africans; instead, the former generates employment for fellow immigrants and locals. 
However, despite the foregoing submissions, it is apparent that foreign nationals continue to be accused of stealing jobs from native people (Kalitanyi \& Visser 2010:376). This suggests that the native people continuously accuse foreign nationals of taking their jobs, despite the fact that some foreigners also create jobs through entrepreneurship by opening either small or big enterprises. R.J. Singh (2013:91) and the International Organisation for Migration (IOM) (2009:21-22) noted that even when foreigners start their own businesses, they still encounter accusations of stealing business opportunities for the native people. Gopal (2013:125) conducted a study to examine the legitimacy of the preceding accusation and found that some locals attribute their unfavourable predicaments to the influx of foreign nationals, instead of taking responsibility for their own actions, thus stimulating xenophobia. Irrespective of many clarifications that can be offered to buttress the accusation that foreigners steal jobs from locals, this chapter affirms the IOM (2009) pronouncement that one of the most dangerous opinions propagated by disgruntled South Africans is that the presence of immigrants deprives native citizens of job opportunities. Indeed, such views cause the foreigners living in South Africa to experience constant psychological trauma, as they would be uncertain of the consequences of such accusations.

\section{Foreign nationals suffer exploitation in the labour market}

Abel (2017:1-42) affirms that in South Africa, many immigrants from African countries are scorned by the native people, as some companies commonly prefer hiring foreign nationals to the natives. Crush and Williams (2001:8) state that some South African employers prefer hiring non-citizens to citizens because the former are generally regarded as 'hard-working and more diligent', 'excellent', 'more disciplined', 'less devious', 'more-skilled and well-behaved' and 'don't have a chip on their shoulder'. Furthermore, employers prefer foreign nationals to South Africans because of 
the former's perceived good work ethics, higher basic skill levels and absence of 'workplace militancy' (Crush \& Williams 2001). This means that there is an overriding notion that foreign nationals in South Africa have a more advantageous position in terms of getting jobs in both informal and formal sectors than the local people. When it comes to employment in the formal and informal sectors of South Africa, the above-stated notion presents possibilities of serious tensions between local people and foreigners.

In Crush and Williams' (2001:8) view, the presupposed tensions or discriminations that people of foreign origin encounter in South Africa because of the perception that they have an edge over native people in the employment sectors are deepened by the idea that foreign nationals usually sell their labour in both informal and formal sectors for low wages, which the native people generally reject. At this juncture, it is important to note that the employers can exploit foreigners, owing to the fact that the latter are typically not keen to seek recourse through labour laws (Crush \& Williams 2001:8; Magezi 2018:222). This is attributed to the understanding that many foreigners are not acquainted with the operations of the labour laws in South Africa (Crush \& Williams 2001; Magezi 2018). Furthermore, some of the immigrants are undocumented; therefore, they are willing to take up any kind of jobs for low wages simply to make their ends meet (Crush \& Williams 2001; Magezi 2018). This often causes South Africans to contemptuously regard foreigners because, owing to their susceptible conditions, the latter accept very low wages, which riles the native people.

As alleged by some locals, there is a possibility that some South Africa-based immigrants toil for long hours for wages that are way below statutory stipulations (Magezi 2018:222-223). In order to survive in their new homeland, migrants supplement their low wages by working for long hours in multiple jobs (Magezi 2018). Consequently, their social lives are adversely affected, as they can hardly spare time for family and friends (Magezi 2018). Migrant workers in both the formal and informal sectors are also disposed to burnouts caused by long working 
hours (Magezi 2018). Fauvelle-Aymar (2015) notes the reality that many educated foreign nationals take low paying jobs as a way of coping in their new environment that does not provide them with job opportunities that are commensurate with their educational and professional qualifications.

This chapter takes cognisance of the IOM (2009:20) conception that although foreign nationals find deskilling a fitting survival strategy in a new homeland (that does not give them job opportunities according to their profession and education), it follows that their coping mechanisms feed the hatred of foreigners by native people on the basis that foreigners take jobs meant for locals by accepting 'sub-minimum wages' that are way below South African standards. In its qualitative study that examines the reasons of South African locals for resorting to violence against foreigners, the IOM (2009) reveals that the South African employers give jobs to desperate foreign nationals who are often incapacitated to negotiate for reasonable wages and, in most instances, can settle for as little as R30 per day, thus allowing them to 'steal' jobs from South Africans. An innate South African, whose opinion on the proposed subject is representative of the wideranging sentiments amongst the locals, is quoted here (IOM 2009):

When a white man takes five people for employment, about three are foreigners and two South Africans. On arrival at the firm, a white man asks 'how much do you want?' Foreigners always quote a small amount. ... When South Africans state their money, which is normal, employers say 'no', they will employ foreigners because they accept small money. The result is high unemployment of South Africans because whites have resolved that the best is to hire foreigners. (p. 20)

Thus, although South Africa-based foreigners attempt to cope by accepting jobs not commensurate with their professional and educational qualifications and, consequently, settle for subminimum wages, one can argue that resorting to such coping mechanisms engenders the hatred of foreigners by the natives and gives credence to the mantra that foreigners accept wages that are below the statutory minimum. Indeed, such allegations subject foreign nationals to a perilous position, as their survival 
mechanisms are bound to provoke the anger of the locals. The underlying question, which has no easy solutions, is as follows: what should foreigners in the South African context do under such complex circumstances?

\section{Foreign nationals working in the formal sectors and foreign students at tertiary institutions suffer discrimination from work colleagues and fellow students}

Manik and Singh (2013:3) assert that African immigrants residing in South Africa are derisively branded 'Makwerekwere'. According to Azindow (2007:175), the label has pejorative undertones as it is used to mock immigrants from other African countries on the basis of their inability to speak South African native languages fluently. The term has also become associated with the assumption that black African immigrants come from countries that are economically and culturally inferior to South Africa (Azindow 2007). For example, S.K. Singh (2013:51-66) states that Zimbabwean educators working in primary, secondary and tertiary institutions in Limpopo province are discriminated by their counterparts in various ways, including linguistic exclusion. For example, native teachers, lecturers, community members and students defer to their native languages as a way of excluding Zimbabwean educators who do not understand the language (S.K. Singh 2013).

The hostility against foreigners in institutions of learning is not only faced by teachers and lecturers. R.J. Singh (2013:88-118) studied this phenomenon in the University of Limpopo, which has a huge enrolment of foreign nationals and found various instances of discrimination faced by foreign students studying at the institution. Instances of such discrimination include being labelled in vernacular and exclusion from academic and social discussions, as locals deliberately switch to vernacular and form cliques (R.J. Singh 2013). Furthermore, R.J. Singh (2013b) posits that foreign students are more likely to face exclusion from halls 
of residence and risk of being accused of instigating campus violence than South African students. Given this, Singh (2013) urges university authorities to look for means to safeguard the rights of international students. For instance, institutions can initiate diversity awareness programmes to help students to be tolerant and respectful of people from social and racial backgrounds that are different from theirs.

Likewise, Muthuki (2013:109-124), who assays the subject of xenophobia in tertiary institutions in urban centres, concurs with R.J. Singh's (2013) assertion that foreign students in South African universities are being discriminated by local students. This means that nationality continues to be an ongoing indicator of students' identities and group associations in the spheres of higher institutions. These acts of alienation and discrimination result in anxiety and depression, thus adversely affecting the concerned students' academic performance (Gopal 2013:129). In other words, some international students studying in South African higher education institutions leave academic environments in which they experience psychological, emotional and physical challenges (Gopal 2013:129), as they are always scared of acts of discrimination by local students. Such acts manifest in different forms, notably attitudes and physical action (Gopal 2013:129). Ongoing exposure to fear, more so in a foreign nation, naturally hampers the affected students' academic performance (Gopal 2013:129).

Remarkably, the discrimination of foreign students by their local counterparts is also pervasive in the pre-tertiary education context. Bruce (2017) highlights that the authorities of Eastleigh Primary School in Edenvale, Gauteng province, wrote to all immigrant learners' parents threatening to exclude those children whose immigration statuses were not in order. Bruce (2017) correctly observes that the school gravely erred in arrogating itself performing an immigration enforcement role, as this action would have unjustly deprived the immigrants' children of their rights to education, which they are entitled to, regardless of their 
lack of proper legal documentation. The South African Schools Act prohibits all forms of discrimination with regard to the enrolment of children in school (Bruce 2017). With this in mind, it can be assumed that some foreign students in South African universities, primary and secondary schools usually, suffer forms of discrimination that are similar to the ones established in this discussion.

\section{Migrants are accused of illegally owning properties}

Most immigrants who have some form of real estate in South Africa are accused of illegal ownership of such property. The IOM (2009) notes that the general sentiment amongst South Africans is that foreigners utilise unjustified means to own Reconstruction and Development Programme (RDP) houses at the expense of deserving natives. The RDP housing scheme is a South African government initiative that is meant to alleviate housing shortages by providing free houses to poor citizens (IOM 2009). Accusations of illegal property ownership are serious, yet are usually uttered without the benefit of any investigation to ascertain whether the concerned foreign nationals indeed own the said properties legally or illegally (IOM 2009). Irrespective of the normally spurious nature of such accusations, some native South Africans have developed serious dislike for aliens on the assumption that the latter obtain RDP houses that are meant for homeless South Africans (IOM 2009).

In 2017, the Deputy Minister of Police, Bongani Mkongi, echoed the assumption that some foreign nationals illegally own buildings, whilst many South African nationals do not have places to stay (Lindeque 2017). The Deputy Minister of Police also went on to blame the international migrants in Hillbrow for sabotaging the economy of South Africa (Lindeque 2017). He stated that Hillbrow was inhabited by $80 \%$ of migrants and this has resulted in high criminal rate in the area (Lindeque 2017). Moreover, he 
affirmed that the majority of old buildings in the Central Business Centre of Johannesburg were inhabited by foreigners, yet native people did not have anywhere to stay. Mkongi concluded by urging South Africans to arise and reclaim their land that had been taken by the foreigners.

The foregoing discussion unequivocally illustrates how some high-profile South Africans purvey unfounded accusations and stereotypes about foreign nationals. Because of such perceptions, some foreigners have been denied the right to settle in the informal settlements where many vulnerable South Africans stay (IOM 2009:19). As a result, there is an ongoing dread amongst many foreigners living in South Africa that they are unwelcome in various places, where they had been living side by side with the local people. The fear that foreign nationals are experiencing as they co-exist with the native people is worsened by high-ranking people who publicly share their xenophobic and discriminatory opinions with ordinary South Africans (IOM 2009). This point is further substantiated in the section 'Foreign nationals are targeted by high-profile people's reckless utterances on social media' (IOM 2009:n.p.).

\section{Foreign nationals are targeted by high-profile people's reckless utterances on social media}

Wose (2016:X, 11-49; cf. Manik \& Singh 2013:2; Taylor 2012; Vahed \& Desai 2013) notes that foreign nationals have also been prejudiced by xenophobic and discriminatory sentiments expressed by South African government officials and traditional leaders in public spaces or on social media. Jacob Zuma, the former president of South Africa, and Goodwill Zwelithini, the King of the Zulu Nation, are some of the officials who are on record for uttering statements that are charged with xenophobic overtones. Zuma's discriminatory and xenophobic sentiments came out in a speech he delivered on the official launch of toll 
highways in Gauteng on 23 October 2013 (Manik \& Singh 2013:2). In that keynote address, Zuma advised South African natives not to think like people from other African countries, possibly because they have better developed infrastructure and economy in comparison to other African countries (Manik \& Singh 2013:2). In putting Zuma's entire address into perspective, Manik and Singh (2013:2) understand Zuma's address to have given the South African native people a negative view of people from other nations, as it portrayed South African nationals as better than foreigners.

Likewise, King Goodwill Zwelithini uttered some discriminatory and xenophobic words that had potential to instigate violence against foreign nationals living in South Africa (South African History Online 2015). On 21 March 2015, the king demanded that foreigners should return to their countries of origin as they were destroying the culture of native South Africans and enjoying the luxuries that were because of the local people (South African History Online 2015). The king's statement was not received well by foreigners because it was made at a time when the immigrant community was mourning the deaths of beloved ones and the loss of material possessions following violent attacks by native South Africans (South African History Online 2015). Also, after the king's statement, the rate of violence against foreigners in South Africa increased. For example, on 10 April 2015, many foreign nationals, including two Ethiopian brothers, were physically attacked and severely wounded by groups of native South Africans. In the case of the two Ethiopian brothers, their shop was set on fire whilst they were inside (South African History Online 2015). As a result, one can argue that King Zwelithini's reckless statements resulted in acts of violence against foreigners.

It is apparent, therefore, that the xenophobic and discriminatory sentiments harboured by ordinary South Africans are easily ignited when shared by government officials and traditional leaders, thereby subjecting many foreign nationals to a constant state of terror. In concurrence with Vahed and Desai (2013), it can be argued that the several violent attacks on foreigners by native people in 2008 and 2013 are linked to xenophobia. As a result, 
foreigners tend to see xenophobic violence as part of their unpleasant and terrifying experiences of living in South Africa (Vahed \& Desai 2013). In view of the above discussion, it can be maintained that the reckless statements that are usually made by South African government officials and traditional leaders have the potential to instigate violence against immigrants. In some instances, foreigners lose their lives and properties (Vahed \& Desai 2013:151; cf. Amnesty International 2015; Bruce 2017; IOM 2009:7; South African History Online 2015; SAHRC 2017; Rukema \& Khan 2013; Vahed 2013). Manik and Singh (2013) also contend that the discrimination of people from other nations can be noticed in the South African social media that generally depicts non-nationals as perpetrators, as explained in the following:

Media coverage, also, has frequently been blamed for portraying foreigners as the perpetrators of unsavoury incidents, although recently the media spot highlighted the physical abuse by SA police of a Mozambican taxi driver in SA (in 2012) which led to a public outcry. After his subsequent arrest, he died in police custody fuelling speculation about police brutality towards foreigners. (p. 2)

\section{Identifying the concepts of neighbourliness and Ubuntu in the African context}

In view of the complexity of these challenges considered in the section 'The complexity of the challenges of migrants in South Africa', a biblical perspective of neighbourliness that is relevant and, at the same time, challenges people to engage in care for one another within the context of migration should be developed from the parable of the Good Samaritan in Luke 10:25-37. Before developing a biblical perspective of neighbourliness in Luke $10: 25-37$, it is imperative to initially justify the concept of neighbourliness by identifying it with the concept of Ubuntu in the African context. That is, the concept of neighbourliness that emerges in the story of Good Samaritan in Luke 10:25-37 could be arguably identified with the notion of Ubuntu in the African 
context, whereby human beings are bound together, connected, united, caring and hospitable to one another (Jolley 2011:6-7). To accomplish this task, the origin and meaning of the concept of Ubuntu in African context, as discussed in the literature, will be briefly defined. At this juncture, the meaning of Ubuntu will be delineated in light of the qualities, values and principles it is associated with. Once this is done, the concept of neighbourliness as a critical hinge of the parable of the Good Samaritan (as related by Lk 10:25-37), which challenges people to care for one another within the context of migration, is discussed.

\section{The origin and meaning of the concept of Ubuntu in the African context}

In an attempt to identify the foundation of the concept of Ubuntu in the African context, Eklund (2008:14) and Ramose (1999:49ff.) argue that Ubuntu is the root of African moral philosophy that emerges from the thoughts of Bantu-speaking people. Ubuntu has been in Africa for as long as human existence in Africa (Eklund 2008:14). Within the African continent, the concept of Ubuntu has been conveyed and preserved in diverse forms and thoughts, from one generation to another, through oral genres in African traditions and cultures such as fables, myths, proverbs, riddles, stories, songs, customs and institutions (Eklund 2008:14). This clearly indicates that there is an existing linkage between the concept of Ubuntu and African traditions and cultures. Notably, a considerable number of scholars (Bhengu 1996:50; Eklund 2008:14; Mnyaka \& Mothabi 2005:215-237) understand Ubuntu as a concept that expresses a way of living amongst African people, that is, it describes the notion of African humanness. Cilliers (2008) agrees with the aforementioned scholars when he underscores that Ubuntu is described:

As a way of life, a universal truth, an expression of human dignity, an underpinning of the concept of an open society, African humanism, trust, helpfulness, respect, sharing, caring, community, unselfishness, etc. In short it means: humanity, or humanness. (p. 1) 
It is important to note that all African languages of Bantu origin have local variants of the same saying that expresses the concept of Ubuntu (Broodryk 2006:3). For example, Ramose (1999:49) and Shutte (2001:23) note that in the Zulu aphorisms, in South Africa, the concept of Ubuntu is expressed as umuntu ngumuntu ngabantu, which is translated in English to mean that 'a person is a person through other persons' or 'I am because we are' (Bhengu 1996:5). Tutu (1999:34-35; cf. Mugumbate \& Nyaguru 2013:8284) expands the aforesaid meaning when he argues that the concept of Ubuntu means that 'a person is a person through other people'. In Tutu's (1999:34-35) view, it is not 'I think therefore I am' as some Western philosophers ascribe to. Instead, it says 'I am human because I belong. I participate, I share' (Tutu 1999:n.p.). The word umuntu in Bantu-speaking languages is translated to 'person' or 'human being', whilst Ubuntu is translated to 'humanness' (Tutu 1999). Notably, Bhengu (1996:5) indicates that the translation of Ubuntu to mean humanness in English is not an adequate expression of the meaning of the proposed concept. However, regardless of Bhengu's (1996) above observation, Cilliers (2008:1) observes that the above-mentioned Zulu aphorism, umuntu ngumuntu ngabantu, portrays the concept of Ubuntu as referring to the notion of 'a basic respect and compassion for others'. In Cilliers' (2008) view, this aphorism is both:

[A] factual description and a rule of conduct or social ethic, both descriptive and prescriptive. It does not only describe humanity as 'being-with-others', but also prescribes what the relational ethics of this 'being-with-others' entail. It takes as point of departure the systemic inter-connectedness of a society, and often is defined in terms of its moral structure, ritual embodiment and ideological usage. (p. 2)

However, because the translation of Ubuntu to mean humanness in English is not an adequate expression of the meaning of the concept, as it lacks a comprehensive notion of the proposed concept (Bhengu 1996:5), one is persuaded to concur with Eklund (2008:14), who argues that in order to understand the meaning of Ubuntu, one should explain it in relation to the salient qualities it is 
associated with. Broodryk (2006:26) and Eklund (2008:15) concur that the following qualities - caring, respect, affection, dearness, sharing, sympathy, humanity and humanness - are crucial to understand the concept of Ubuntu as they are intricately associated with it. Mkhize (2008:43) agrees with Eklund (2008) and Broodryk (2006:26) in advancing that the concept of Ubuntu 'incorporates ideas of social justice, righteousness, care, empathy for others and respect'. Likewise, Mnyaka and Motlhabi (2009:74) agree with the aforesaid scholars in avowing that Ubuntu 'is inclusive ... it is best realised in deeds of kindness, compassion, caring, sharing, solidarity and sacrifice'. In the same vein, Lefa (2015:4) endorses the qualities of Ubuntu that are listed by the aforementioned scholars as the salient characteristics of the concept of Ubuntu. Lefa (2015) further views the concept of Ubuntu in the African context as a foundational springboard to the African ways of living.

From the above discussion, one can possibly argue that, in the African context, Ubuntu is perceived as the act of 'being human, caring, sympathy, empathy, forgiveness or any values of humanness towards others' (Lefa 2015:4). In amplifying this understanding of the concept of Ubuntu, both Eklund (2008:15) and Shutte (2001:25) view it as speaking to the oneness, togetherness and unity of people within communities and societies. The Ubuntu notion of oneness or togetherness is embedded in the understanding that all human beings have something common, namely, that we are all human beings (Eklund 2008:15). The understanding that we are all human beings that are interrelated to one another results in people having empathy and sharing what they have with those who are needy or deprived so that the goal of Ubuntu in society - namely, 'to find the greatest true form of happiness' - is fulfilled (Eklund 2008:15). This is why Nussbaum (2003) states that:

Ubuntu is the capacity in African culture to express compassion, reciprocity, dignity, harmony, and humanity in the interests of building and maintaining community. Ubuntu calls on us to believe and feel that: Your pain is My pain, My wealth is Your wealth, Your salvation is My salvation. (p. 21) 
The happiness or fullness of life for individuals in a community, owing to their interaction, co-existence, sharing and participating with others, is critical because it encourages people to see themselves as intricately linked with others, rather than isolated (Nussbaum 2003:21-26). Definitely, this promotes the spirit of togetherness that results in one seeing the problems of others as one's problems, and the success of others as one's success (Nussbaum 2003:21). Indeed, in time of sufferings and challenges, the value of togetherness embedded in the concept of Ubuntu inculcates the spirit of compassion that results in one caring for the others as they strive to realise the goal of collective good life in the community (Nussbaum 2003). Given this, one would be correct to contend that the concept of Ubuntu excludes selfishness. Shutte (2001) observes the aforementioned in the following affirmation:

Our deepest moral obligation is to become more fully human and this means entering more and more deeply into community with others. So although the goal is personal fulfilment, selfishness is excluded. (p. 30)

\section{Challenges associated with the concept of Ubuntu}

Having established the concept of Ubuntu as referring to the value of oneness, togetherness and unity of people within communities and societies, it is needed to be conscious that this concept has been challenged by a considerable number of scholars (Eklund 2008:16; Eliastam 2015:1; Metz 2011:532-535; Shutte 2001:23). That is, although observation of the concept of Ubuntu yields some positive contributions in creating responsible societies or communities that care for one another, Eklund (2008:16) and Shutte (2001:23) state that the definition of the concept, as rendered above, tends to imply that a person is defined by the community, that is, a person is a person because of his or her relationship with others. This means that personhood is not something that one is born with; instead, it is a gift that one 
earns or is awarded by sharing and participating in the community with others (Eklund 2008:16; Shutte 2001:23). Here, the writer agrees with Eklund (2008:16) and Shutte (2001:23) that the aforementioned understanding is problematic because, if personhood can be awarded to someone by virtue of participating and sharing in the community with others, it follows that personhood can also be taken away if Ubuntu is treated with obliviousness and contempt (Eklund 2008:16; Shutte 2001). In saying this, the writer is aware that scientists, doctors, theologians and legal scholars, to mention but a few, differ with regard to when personhood begins, that is, some doctors and legal or human rights scholars argue that personhood begins at conception, whilst others do not define a foetus as a person (Donovan 1983:40; Henriques 2015:1). Notwithstanding, from a biblical perspective, Ling (2017:1-45) argues that although new biologists refute the Christian perspective regarding the onset of personhood, he maintains that it begins at conception, as stated in Jeremiah 1:5. Although the aforementioned issues are recognised as of interest and worth discussing, they are beyond the scope of this chapter. Instead, the above discussion simply underscores the disagreements within different fields of research regarding the commencement of personhood.

Secondly, Metz (2011:532-535) states that by emphasising the community or togetherness at the expense of individuality, the concept of Ubuntu fails to recognise the worth of the freedom of individuals. Recently, in his article entitled 'Ubuntu in flames Injustice and disillusionment in post-colonial Africa: A practical theology for new liminal Ubuntu and personhood', Magezi (2017:111) alludes to a similar point as Metz (2011) when he notes that the concept of Ubuntu emphasises togetherness and oneness. Surprisingly, Magezi (2017) further notes that the Ubuntu concept of togetherness is being ignored in Africa because of the rampant oppression and corruption that have hit the whole continent. In speaking about corruption that violates 
the concept of Ubuntu, Magezi (2017:116) and Turaki (Lecture at North-West University n.d. 2015) note that in many African societies, when someone works in government or public office, he or she is considered as a hunter. When he or she loots money, he or she goes back to his or her village to share it with family members and the community in his or her geographical proximity. The beneficiaries do not accuse their benefactor of corruption; instead, he or she is credited as having performed authentic Ubuntu as he or she would have shared with his or her people back home. In this scenario, Ubuntu is considered as a concept that is confined to someone's friends, relatives and close geographical communities, as Magezi (2017:117-118) and Turaki (Lecture at North-West University n.d. 2015) indicate. Magezi (2017:117) further argues that, in the African context, the notion that the practice of Ubuntu is generally confined to relatives, friends and people from the same communities is intensified by pervasive nepotism in Africa, especially with regard to the employment sector. Magezi (2017) explains that:

In the traditional Ubuntu framework an individual feels bound and obligated to respond to the needs of people related to them. They are also inclined to assist people who come from the same geographical area. This is evident in political and employment circles. When a new president is elected there is generally a tendency to appoint someone from the same geographical area. (p. 117)

Also, the propagation of tribal tensions in Africa violates the unity and peace amongst people that is enshrined in the concept of Ubuntu (Baloyi 2018:1). In speaking about Africa, particularly South Africa, Baloyi (2018:1) states that the tribalism that violates the concept of Ubuntu is usually precipitated by some leaders. Here, Baloyi (2018:1) mentions an aphorism attributed to the former president of South Africa, Jacob Zuma, that portrays the Zulus as superior to other tribes in South Africa, as having potential to cause tribal tensions instead of unity and peace, as accorded in the concept of Ubuntu. In discussing Jacob Zuma's aphorism, Baloyi (2018) affirms that: 
A newspaper article entitled 'I am not an African, no, I am 100\% Zulu' did not only help to sell the paper but also sketched a picture of tribalism in South Africa (Khumalo 2016). The slogan of '100\% Zulu' was made famous by President Jacob Zuma when he had to face various rape charges. (p. 1)

Perhaps, this is why Moloi (2016) notes that tribalism is not history in the South African context. Moloi (2016) states that:

The danger of tribalism is at our doorstep. It is so scary that in the current situation it is associated with our previous kings. (n.p.)

In this way, one can rightly argue that the concept of Ubuntu should be informed by Christian thinking and values (Magezi 2017:111-112) because, as discussed above, if people narrowly apply the concept of Ubuntu to families, friends and close communities, who applaud them for practising the concept of Ubuntu because they care for their people, it means that the proposed concept tends to lack universal or global relevance, as some people manipulate and abuse it in the above-mentioned way. This is the case regardless of the important values that are inherent in the concept of Ubuntu such as love, care and compassion for others. In this way, people who confine the practice of Ubuntu to relatives, friends and neighbouring communities violate the core values of Ubuntu, as this practice prejudices people who are not close to them. This narrow application of the concept of Ubuntu in the African context can also be said to emanate from some South African leaders' aphorisms that have the potential to create tribal tensions, which are antithetical to the values of unity and togetherness enshrined in the concept of Ubuntu.

If the above-mentioned challenges associated with the concept of Ubuntu in the African context are granted, the underlying issue is how the concept itself can be reformed by Christian theology and values so that one can be empathetic and compassionate to foreigners, despite ethnic, religious, linguistic, cultural and national backgrounds. That is to say, whilst Ubuntu is recognised as a useful concept that identifies 
with the envisioned concept of neighbourliness that emerges from the story of the Good Samaritan in Luke 10:25-37, which will be discussed below, it should also be acknowledged that the concept of Ubuntu has failed to transform Africans towards demonstrating care and love for all people, regardless of ethnicity, nationality, language, religion, culture, etc. This clearly indicates a need for theology to develop a constructive understanding of the other as someone who is different (ethnically, religiously, linguistically, culturally and nationally) and yet should be viewed as a neighbour.

In this way, the concept of neighbourliness that emerges from the narrative of the Good Samaritan in Luke 10:25-37 shall be identified and explored as a theological theory that affects how one thinks and acts positively in response to the complex challenges of migrants, irrespective of their nationality, ethnicity, etc. With this in mind, the discussion turns to Luke 10:25-37, where the concept of neighbourliness emerges as a theological theory that results in the embracing of migrants as a response to their complex challenges.

\section{Luke 10:25-37: Towards Jesus' extension of the definition of a neighbour as every fellow human being in need}

\section{The purpose of Luke and the immediate context of Luke 10:25-37}

It is important to note that the genealogy of Jesus Christ in Luke 3:23-38, which designates Christ as 'the son of Adam, the son of God', is meant to make both Jews and Gentiles embrace Jesus Christ as their own true saviour (Marshall 1978), that is:

The carrying back of the genealogy to Adam is meant to stress the universal significance of Jesus for the whole of the human race and not merely for the seed of Abraham. (p. 161) 
This means that Stein's (1973:26-27) argument that even though Luke might have had some Jews in mind, his primary audience were the gentiles does not matter much because Luke 3:23-28 indicates that Jesus' mission was for both Jews and Gentiles. However, for the purpose of this chapter, it does not matter whether Luke's Gospel was written to assure those who had heard and believed the Gospel of Jesus Christ or to evangelise those who had never heard the gospel. Instead, the chapter focuses on the notion of neighbourliness in Luke 10:25-37 as a theological theory that affects how one thinks and acts in response to migrant challenges. With this in mind, the discussion turns to the parable of the Good Samaritan in Luke 10:25-37, which spells out the concept of neighbourliness and challenges people to care for one another within the context of migration, in spite of disparate religious, ethic, linguistic and national backgrounds.

It is imperative to note from the onset that the parable of the Good Samaritan in Luke 10:25-37 is located within the context in which Jesus taught his disciples about profound discipleship (Lk 9:51-11:13). Luke 9:51 states that when his time to die approached, Jesus commenced a long journey that he completed in Luke 19 with the triumphant entry in Jerusalem. This journey is characterised with rejection in a Samaritan village (Lk 9:52) and Bethsaida (Lk 10:13); however, it has a glorious end, as in the last chapter of Luke's gospel, Jesus accomplished his redemptive mission for humankind by dying at the cross for their sins (Lk 23:44-49) and subsequently resurrected from the dead after 3 days to claim victory over death, as related in Luke 24, therefore accomplishing salvation for both Jews and Gentiles.

However, it is important to note that along the way to Jerusalem, Jesus taught about the cost of discipleship to a man who chose to follow him (Lk 57:57-72). Soon after teaching the man, Jesus appointed the 72 disciples and sent them in pairs to evangelise the whole non-Jewish world that has never heard of the gospel nor of the imminence of the kingdom of God (Lk 10:1-24). Luke 10:9 attests to this point when Jesus entrusted 
the 72 disciples to "heal the sick who are there and tell them, "the kingdom of God is near you"'. The section 'Discussion of Luke 10:25-37 in view of Jesus' extension of the definition of a neighbour as every fellow human being in need' ventures into an in-depth discussion of Luke 10:25-27 that narrates the parable of the Good Samaritan. This scripture brings forth the concept of neighbourliness as a theological theory that affects how one ought to positively think and act in response to migrant challenges.

\section{Discussion of Luke 10:25-37 in view of Jesus' extension of the definition of a neighbour as every fellow human being in need}

The author is aware that Luke 10:25-37 is quite related to the incident in Matthew 22:34-40 as the lawyer in this context asks a question that is also aimed at tricking Jesus (Lk 10:25a). The question that the law expert asks to Jesus relates to what one ought to do to inherit eternal life (Lk 10:25b; Ryken 2009:537). Here, Jesus answers the lawyer with another question so that the latter can respond to his own question as an expert of the law of Israel. Jesus asks the lawyer to stipulate what is exactly written in the law with regard to that matter (Lk 10:26). One can argue that Jesus' response to the lawyer's question is appropriate as the lawyer is an expert in God's law, namely, he is a Bible scholar and a theologian of the Old Testament Scripture, which he is expected to rightfully apply in his daily living (Hughes 1998:388; Ryken 2009:537).

The fact that the lawyer is an expert in the law is brought to the fore when he aptly identifies that people have to love God with all their being and to love their neighbours as they love themselves as the prerequisites to inherit eternal life (Lk 10:27; Barca 2011:7). The correctness of the lawyer's response is affirmed in Luke 10:28 when Jesus says that the lawyer had answered his own question correctly. It is also important to note that the lawyer's response 
draws from the Torah. The first part, '[l]ove the Lord your God with all your heart, with all your soul, with all your strength and with all your mind', is a literal quotation from Deuteronomy 6:4 (Zimmermann 2008:277). The second portion 'and your neighbour as yourself' is a shortened version emerging from Leviticus 19:18 (Zimmermann 2008). In other words, just like in Matthew 24:34-40, the former command in Luke 10:25-37 comes from Deuteronomy 6:4, whilst the latter comes from Leviticus 19:18 (Ryken 2009:538).

Commenting on Luke 10:25-37, Zimmermann (2008:277) notes that the injunction to love God and neighbours sums up the whole Torah, which God's people should live by in order to attain eternal life. Likewise, many of the scholars that discuss Matthew 22:35-40, which also sums God's law or command in the same manner as the lawyer states it in Luke 10:25-37, concur with Zimmermann (2008). These scholars reveal that man was created to love and serve God, as well as to love fellow humankind (cf. Mitch \& Sri 2010:289). For instance, Morris (1992:563) observes that by summarising all the precepts and instructions of the Old Testament in these proposed two commandments in Matthew 22:37-39, Jesus configures the linkage that exists between the vertical (people's love for God) and horizontal (humankind's love for one another) facets of love.

However, it is interesting to note that by inference the lawyer assumes that he has been keeping the second commandment that demands him to love his neighbour as he could have been possibly compassionate and loving to his fellow Israelites. This arises from Luke 20:29 that states, '[b]ut he wanted to justify himself, so he asked Jesus, "and who is my neighbour?"' At this juncture, Blajer (2012:20), who revisits the time of Jesus' earthly ministry to understand what the concept of neighbour meant for some groups of people, also understands that the lawyer is trying to justify himself as someone who has been loving his neighbour as he loves himself. In his research, Bajer (2012:20) discovered that during the material time, various groups of people such as 
the Pharisees, Sadducees and Essenes viewed the term 'neighbour' as referring to all their Jewish compatriots and proselytes, whilst excluding 'non-Pharisees, the sons of darkness, heretics, or even personal enemies'.

However, in answering the lawyer's question about what constitutes a true neighbour, Jesus tells the parable of the Good Samaritan. Jesus' response expands one's understanding of the definition of a neighbour as everyone who is in need, regardless of his or her ethnic, linguistic, religious, national and cultural background (Lk 10:30-37). Although the writer agrees with Manson's (2012:161) claim that the primary message of Luke $10: 25-37$ is to show people the impossibility of attaining salvation by works because people cannot keep the law, one can also underscore that in this Lukan passage, Jesus is possibly expanding the Israelites' limited definition of neighbour from their fellow Israelites to all humankind who are in need. At the end of the parable of the Good Samaritan, the lawyer perceives that to 'obey God's command of neighbourly love meant caring for anyone he came across who was in need' (Manson 2012:161).

In responding to the lawyer's question about who his neighbour is, Jesus is very innovative ${ }^{2}$ as he does not offer the lawyer a hypothetical definition of the term; instead, in Luke 10:30-37, Jesus answers indirectly by telling the story of the Good Samaritan (Ryken 2009:541). The writer agrees with Ryken (2009:541-542) that, by placing the Samaritan at the centre of this parable ( $\mathrm{v} .33$ ), Jesus makes the lawyer think beyond his usual categories of a neighbour. Now, the question is who were the Samaritans? According to Brindle (1984:47-75), the Samaritan people were considered as half Jewish and half Gentile because they 'claim[ed] to be the remnant of the kingdom of Israel, specifically of the tribes of Ephraim and Manasseh, with priests of the line of Aaron/ Levi'; however, they were anti-Jewish and did not fear God

2. Here, the writer is aware that, in the wider context of the passage, Jesus is actually saying that God's grace is not confined to Jews as he also saves and gifts Gentiles in order to use them to accomplish good purposes and plans for the world. 
(Brindle 1984:47). They adhered to the Samaritan Pentateuch, a religion that was closely related to Judaism. The Samaritans believed that their worship that was centralised in Samaritan Pentateuch was the true religion of the ancient Israelites (Brindle 1984:47-75). Because of the aforementioned claims and many more different beliefs, it is apparent that the Jews and the Samaritans had a very strained relationship to the extent that, as related in John 8:48, when the Jews wanted to curse Jesus, they called him a demon-possessed Samaritan (Brindle 1984). ${ }^{3}$

Having briefly described the background of Samaritans, it is now proper to indicate that the parable of the Good Samaritan confronts the lawyer with a dying man who had fallen amongst robbers as he was going from Jerusalem to Jericho (Lk 10:30). It is important to note that Jesus does not disclose the identity of this dying man; instead, he simply reveals that he was robbed whilst he was on his way from Jerusalem to Jericho (Blajer 2012:161). Given this, one would concur with Blajer (2012), who argues that:

Since there is no direct identification, the anonymity of the man is crucial for the rest of the narrative, and this anonymity should be preserved. Any attempt to identify the wounded man as a Jew is tendentious. (p. 161)

However, commenting on Luke 10:30, Ryken (2009:542), Nolland (1993:593) and Jeffrey (2012:149) view the perilous events in Jesus' story as common occurrences during that material time. As Ryken (2009:542) notes, the road from Jerusalem to Jericho was narrow and it passes 'through treacherous countries'. Thus, with the 'narrow passages and dangerous precipices' of the road from Jerusalem to Jericho, 'it was an ideal place for thieves and bandits to ambush lonely travelers' (Blajer 2012:162; Ryken 2009:542; cf. Jeffrey 2012:149; Nolland 1993:593).

As Jesus related in Luke 10:31-32, many people use the Jerusalem to Jericho road and saw the dying man in desperate

3. For more information about who the Samaritans were, see Brindle (1984). 
need, but refrained from offering him any help. The first two people who passed by and noticed the dying man were religious leaders, namely, the priest and the Levite (Lk 10:31-32). The writer agrees with Ryken (2009:542) and Nolland (1993:593) that what the priest and the Levite did in this case is unexpected because, as religious figures, they are supposed to stop and save the man's life. Instead of stopping and saving the dying man, the priest and the Levite pretended not to have noticed him (Lk 10:31b, 32b). The sin of the priest and the Levite, in this case, is intensified by the presumption that they could have been coming from Jerusalem to worship God or to perform their religious duties in the temple, such as offering sacrifices and reciting the law (Ryken 2009:542). However, after leaving the temple in Jerusalem, these religious leaders are confronted by a man in a desperate situation but they failed to 'keep the law of God's love or to offer themselves as living sacrifices for a neighbor in need' (Ryken 2009:542; cf. Nolland 1993:593).

Nevertheless, Luke 10:33 contrasts the Samaritan with the religious figures of Israel (i.e. priest and the Levite) and presents him as a different person, because he acts with compassion in four ways:

1. the Samaritan sees the victim, goes to him and binds up his wounds

2. he provides shelter for the dying man by taking him on his own animal to an inn, wherein he continues to take care of him

3. the Samaritan gives two denarii to the innkeeper so that he could continue to take care of the victim

4. finally, the Samaritan advises the innkeeper to address all the needs that may arise in the process of looking after the victim and he would reimburse the money when he comes back.

The juxtaposition of these three categories of people becomes sharply vivid when, in Luke 10:36, Jesus asks the lawyer to name who amongst the priest, the Levite and the Samaritan is the neighbour of the victim. The lawyer correctly responds to Jesus' question by asserting that the neighbour of the victim is the 
Samaritan who shows him mercy (Lk 10:37a). As the lawyer's response is correct, Jesus concludes the parable by asking the lawyer to go and act as the Samaritan had done to the robbery victim (Lk 10:37b).

Nolland (1993:597) submits that now the 'Samaritan has become a neighbour through his compassionate action, but integral to this concrete action has been his own seeing of the situation from the victim's point of view'. Unlike the priest and the Levite who looked at the victim from afar and pretended as if they have not seen him, the Samaritan sympathised and identified himself with the situation of the dying man and consequently took action to save his life (Nolland 1993:597). The only thing that qualifies the Samaritan as a neighbour is the mercy that he shows the victim. That is, the lawyer's response in Luke 10:37 to Jesus' question in Luke 10:36 indicates that (Nolland 1993):

[/]n showing mercy to the needy man, the Samaritan has become a neighbor to the injured man. Despite the huge distance that separated the Samaritan from the covenant community of God's people, from a desperate victim's perspective he could be neighbor. The lawyer is challenged to take up precisely this victim perspective as he is called to love his neighbor as himself. (p. 508)

\section{The concept of neighbourliness in Luke 10:25-37 as a theological theory that affects how one may think and act positively in response to migrant challenges}

In the narrative of the Good Samaritan discussed above, the lawyer's limited definition of neighbour is both challenged and corrected. The lawyer's initial assumption is that his neighbours are his Jewish compatriots, but the parable of the Good Samaritan challenges him to think otherwise (Barca 2011:100; Blajer 2012:8). Instead of acting like the religious leaders, namely, the priest and the Levite, the Samaritan demonstrates mercy towards the 
unknown victim of robbery (Barca 2011; Blajer 2012). The Samaritan's (Lk 10:25-37) clearly indicates the imperative to practise love and compassion without limits towards fellow humankind (Baca 2011:101). Here, the Samaritan's love results in him seeing the desperate situation of the robbery victim, whose identity is unknown, and treating him as a neighbour who deserves compassion and care. That is, unlike the priest and the Levite, Christians should emulate the love of the Samaritan that goes beyond ethnicity as he sees, empathises and assists the unknown victim (Barca 2011:100).

In expanding the aforementioned conception, Ryken (2009:541) and Gooding (1987:203) contend that this Lukan passage challenges the ethnocentric attitude that existed during the time of Luke when the Israelites could only speak of their neighbours as their fellow covenant community members, namely, fellow Israelites, as opposed to people from neighbouring nations (Gooding 1987; Ryken 2009). This denotes that, in the lawyer's view, specific groups of people were supposed to be included in, or excluded from, his circle of love. Although the aforementioned understanding (Gooding 1987; Ryken 2009) is reasonable, it is apparent that the authors do not discuss Jesus' rationale for not providing the ethnic or national identity of the victim in this story (Gooding 1987; Ryken 2009). In other words, although one can try to speculate about the national or ethnic identity of the victim in this Lukan passage, it would be a fruitless endeavour because Jesus does not disclose it in the text (Lk 10:25-37) for a reason (Blajer 2012:161). By excluding the identity of the victim, Jesus is moving towards the establishment of the point that a neighbour is not defined by the ethnic, religious, linguistic and national boundaries. Instead, one's neighbour is anyone who is in need, thus buttressing the notion of shared common humanity. Therefore, people should be compassionate and loving towards anyone who is in a desperate situation, as the Samaritan in Jesus' story exemplifies. At this juncture, Jesus dismisses the common misconception that a neighbour is a person from next door, a family member or someone from the 
same ethnic, national and language categories (Gooding 1987:203; Ryken 2009:440-441).

Given the above-mentioned understanding of the narrative of the Good Samaritan, one can possibly argue that as Jesus gives this parable, he has in mind the doctrine of the imago Dei [image of God] as derived from Genesis 1:27, which calls on one to view all human beings as the bearers of the image of $\mathrm{God}^{4}$ who should be treated equally (Barca 2011:18-63). That is, in this context Jesus Christ is God, the creator in the action of redefining the true meaning of neighbour to sinful mankind who are most likely to assist only those with whom they share the same ethnic and national identities (Barca 2011). In Jesus' view, one is obligated to care for every human being who is in need because everyone is a neighbour. Commenting on Luke 10:25-37, Barca (2011) understands that this passage confronts the reader with relational anthropology that:

$[D]$ emands not only recognition of the Other as neighbour, but as image of God. The double commandment of love demands an 'I-Thou' relationship with God and the Other who may be poor or non-poor, believer or not believer, but s/he is a person, child and image of God. (p. 62)

Given this, it does not matter whether the Levite and the priest in this story were in a hurry or busy; what is important is that when people come across the needy, Jesus challenges them to look beyond their national, ethnic, tribal and language boundaries and address the desperate situation, as the Good Samaritan did when he came to the aid of the dying man.

It can be argued that the above-mentioned misconception of the notion of a neighbour is evident in many and different aspects of contemporary societies and communities (Gooding 1987:203; Ryken 2009:541). For example, citizens and governments of

4. For an understanding of the meaning of human beings as the bearers of the image of God, see Simango (2016) and Magezi and Magezi (2018). In different ways, these scholars advocate for a combined understanding of the image of God in man, that is, the functional, relational and substantive perspectives. 
migrant hosting nations sometimes exclude foreign nationals on the basis of ethnicity, nationality and language differences (Gooding 1987; Ryken 2009). Given this, the writer concurs with Ryken's (2009) application of this Lukan passage to contemporary contexts in the following way:

The attitude is equally common today. Sometimes we draw the boundary along ethnic lines, excluding people from a different background. Sometimes we draw it along religious lines. We do a decent job of caring for other Christians, but we much less concern for people outside the church. Sometimes we draw the boundary along social lines, making a distinction between the deserving and the undeserving poor. Sometimes we simply exclude people whose problem seems too large for us to handle. But wherever we draw the line, we find the lawyer's logic compelling. We have to make choices in life. Our love has to have no limits. (p. 541)

Magezi (2019:11) agrees with Ryken's (2009) observation that Luke 10:25-37 qualifies that, with regard to caring for the needy, shared national, ethnic, cultural, linguistic and religious backgrounds should not be considered as prerequisite conditions. This is because the good news of the gospel that emanates from the proposed Lukan passage implies that being a neighbour is an act, not a status. It can, thus, be contended that the discussion considered so far with regard to the story of the Good Samaritan in Luke 10:25-37 provides a biblical perspective that sheds light as well as challenges individuals to cater for the needs of migrants without considering their national, cultural, ethnic and linguistic backgrounds.

Arguing from a theory formation level, the concept of neighbourliness that emerges from Luke 10:25-37 views all human beings as intricately linked on the basis of shared common humanity, which holds that all people are bearers of the image of God. This theory should thus operate as the locus and hermeneutical prism that shapes Christian thinking and provides the theological basis for Christian ethics in the complex situation of migrants. At a practical level, the aforementioned theory formation of the concept of neighbourliness should inculcate a constructive socio-theological and community response that 
results in host citizens and nations embracing migrants and responding to their needs. In bringing together the theory formation level and practical dimensions of the concept of neighbourliness, it can be concluded that the proposed concept of neighbourliness challenges one to have the following worldview in the context of complex migrant challenges: my neighbour and / are intricately linked together through neighbourliness whereupon the complex challenges of a migrant are viewed empathetically from the perspective of someone based on common humanity as created in the image of God.

\section{- Conclusion}

This chapter has provided a considerable number of complex challenges of migrants that demand the church to develop a theological theory of these challenges. Complexity implies nonlinear thinking, whereby one has to explore frameworks that could be applied to contribute towards a constructive perspective. The chapter also identified and explored the narrative of the Good Samaritan, in Luke 10:25-37, as a critical text that fosters constructive thinking, which results in practical action in caring for migrants. The concept of neighbourliness was identified with the African concept of Ubuntu, which seems to have failed to be of much significance in fostering care and compassion for one another in the African context. After that the concept of neighbourliness, which emerges from Luke 10:25-31, was advanced as the basis for developing a certain theological thinking that results in one considering a foreigner, who is the other, as someone whom he or she can identify as his or her neighbour. In other words, the chapter contended that the concept of neighbourliness in the narrative of the Good Samaritan, in Luke 10:25-37, offers a biblical perspective that could shed light, as well as challenge individuals to be involved with migrants' needs, despite the differences in national, cultural, ethnic and linguistic backgrounds. 
Towards understanding migrants' coping mechanisms and development of an operative ecclesiology as church care response: Home away from home migrants' church care

Vhumani Magezi

Department of Practical Theology, Faculty of Theology, North-West University, Vaal Triangle, South Africa

How to cite: Magezi, V., 2020, 'Towards understanding migrants' coping mechanisms and development of an operative ecclesiology as church care response: Home away from home migrants' church care', in A.R. Brunsdon (ed.), The human dilemma of displacement: Towards a practical theology and ecclesiology of home, pp. 85-101, AOSIS, Cape Town. https://doi.org/10.4102/aosis.2020.BK198.04 


\section{Abstract}

Displaced people termed migrants experience various challenges. The countries receiving migrants either accept, welcome and accommodate them or reject them overtly or covertly. To cope with their situation, amongst other things, the migrants have established their own separate churches in host countries. The members of these churches tend to be migrants from the same countries or regions of origin. These migrant practices seek to provide a sense of home and belonging as well as ensure survival. Within this context, theological reflection and ministry on migration have largely focused on one side, namely, churches in migrant receiving nations (host). The discussion has tended to focus on exclusion as well as inhospitable aspects of host nation churches but overlooking the contribution of migrants themselves to exclusion through formation of exclusive migrant ethnic and racial churches. This chapter develops a church responsive ministry to migrants that employs the notion of eschatological home. At a theoretical level, the chapter employs a kingdom reversal principle and eschatological perspective, which guides the development of three operative ecclesiological principles: congregational conscious raising and empowerment, congregational seeing and congregational practical interventions.

Keywords: Migrants ministry; Kingdom reversal and eschatology; Eschatological home; Home away from home; Migrants' coping mechanisms; Operative ecclesiology; Inclusive churches; Migrant contextual ministry.

\section{Introduction}

Migration, which, according to Skeldon (2013:2), refers to moving from a place of 'origin to a destination, or from a place of birth to another destination across international borders', has risen in recent years. Migration and refugees are mutually and intricately connected concepts. Gilmore (2016), the Deputy High Commissioner for Human Rights, in her keynote address on 
'Migrants in transit' rightly used the term migration to include refugees. She (Gilmore 2016:n.p.) maintained that the word migrant does not 'exclude refugees or other more precisely defined legal categories of persons such as victims of trafficking'. On the contrary, the term migration is a 'neutral umbrella term for a group of people who have in common a lack of citizenship attachment to their host country' (Gilmore 2016:n.p.). Refugees refer to people who move across the borders because of life-threatening crisis. Hence, refugees refer to a kind of forced migration, whilst other migrants can migrate voluntarily to their countries of interest. However, whether the moving is voluntary or forced, in essence, both categories of people are migrants. Migration can be both local and international (IOM 2015:35; Skeldon 2013:2). Notably, migrants and refugees are displaced people. In this chapter, the term migrant will be used as an inclusive term to refer to displaced people (i.e. migrants and refugees). The displacement causes destabilisation of people's whole being at different levels, namely, physical, social, emotional and spiritual. To cope with the destabilisation, support for migrants by host communities is imperative, whilst attitudes of migrants are equally critical for coping as well as effective migrant and host integration.

Coping entails an individual's effort to survive, solve problems and reduce stress. Coping is controlled by habitual traits as well as one's social environment. With migrant people's environment disrupted, their home and support structures have vanished. Hence, the notion of home needs to be rethought amongst migrants. At the same time, host communities need to consider how to make the environment homely for migrants. However, within the dynamic relationship of migrant and host, a new sense of what 'home' means needs to be considered. At a theological level, the notion of home needs to be rethought by both migrants and host communities to foster a new understanding and perspective of home. A new perspective of home should foster practical care and concern for migrants as well as unreserved embrace by hosts. The question that emerges is: how should home be understood to foster a perspective that challenges 
churches to care for migrants? How should this understanding of home shift from only placing a burden on host communities to also challenge migrants to rethink their notion of home to stimulate them to actively explore integration with host communities? At stake is the question: within a theological understanding of home, what practical ministerial structures can possibly be developed within churches to assist migrants to cope? What church community structures can be erected to aid the coping of migrants? How can the challenge of embracing migrants be a catalyst for transformative ecclesiological and ministerial approaches where both migrant and host interact in manner that brings about reciprocal humaneness and mutual compassion? This chapter argues that the church as a subsystem of society can adopt an operative ecclesiological approach to encourage church care response that is driven by a notion of home. Such an understanding is informed by an eschatological perspective of home. To employ the notion of home meaningfully, the 'kingdom reversals and eschatological recognition' (Broughton \& Prentis 2019:8) approach will be employed within a context of public theology.

\section{Towards a kingdom reversal and eschatological recognition framework}

Theology done at the public square where there are pluralistic voices is complex. The public space, which in our context refers to migrants, requires public theology's interruptive and imaginative task (Fretheim 2016). Pearson (2019) clarified the task of public theology as being able to be:

$[B]$ ilingual and evoke much needed passion for truthfulness, integrity and civil discourse, especially in a time when fake news is too easily and too often trumped up. The purpose of public theology is also to express its concern for the public good in a way to be acted upon. (p. xvi)

Enacting public good in situations such as migration is stressful. The migrants' demand for care amongst host communities is 
causing burn out and compassion fatigue across the globe (Louw 2015; Schjonberg 2017). In this situation, one theological approach that could give public theology 'arms and feet' beyond just reflection in our context is the theology of great reversals in the gospel of Luke. Broughton and Prentis (2019:8) explained that in the gospels, sin is often portrayed as blindness, which reminds us that we do not recognise God or each other because we are finite, fallen and foolish. The gift of sight to the blind (seeing again), which entails seeing God, ourselves and others regarding our shared history, is one key dimension of the reversals. Thus, the promise of full recognition as indicated in 1 Corinthians 13:1 is eschatological in nature because we currently see dimly and partly, but we shall see fully later as we have been fully known by Christ. Full seeing and full recognition are a promise in Christ. The gift of seeing has ethical responsibilities for people in the kingdom of God. Therefore, Broughton and Prentis (2019) concluded that:

The gift of seeing each other afresh animates reversals where guests become hosts, and hosts become guests. The mutual giving and receiving required by such reversals mean that both parties must recognise something about themselves in order to recognise the other. The discussion of guests and host in the kingdom begins, naturally, with God as host surrounded by a large and diverse gathering of hosts. (p. 8)

To illustrate the reversal, in Luke 13, God welcomes many guests at his table in an eschatological banquet where guests are fully known (Lk 13:29). However, there is a reversal as the people will come from east, west, south and north, whilst those who thought deserved to be there are thrown out. There are many such teachings, but in Luke 19 where Jesus encounters Zacchaeus provides another clearer reversal picture. Zacchaeus is a sinful individual who amassed wealth through tax collection. Despite his wealth, Zacchaeus was not satisfied and longed to see Jesus. Reversals happen to Zacchaeus. Jesus invites himself to Zacchaeus's house. This rich host Zacchaeus should open his home and heart. In this encounter with Zacchaeus, Jesus is the true generous host who discovers Zacchaeus's emptiness and need for forgiveness resulting in him (Jesus) inviting himself to 
Zacchaeus's house. Zacchaeus, the host, receives Jesus as the guest. However, Jesus is the true generous host who recognises the need in Zacchaeus's life. In this story, instead of being a guest, Jesus becomes the host who receives Zacchaeus into the kingdom and embraces him generously. The host (Zacchaeus) got reversed to guest, whilst Jesus, the guest, becomes the host.

In our context of migrant responses, the kingdom reversal framework presents a challenge and reality that host communities in control should be freed from their privileged position of being in their comfortable homes to be transformed to care for migrants. And yet, the migrants also should realise their weaknesses and emptiness as well. Importantly, the great reversal occurs through pneumatological transformation where kingdom people perform evident public good deeds.

\section{- Conception of home amongst migrants and some coping strategies}

To gain clarity on the situation of migrants, the notion of home and what it entails should be employed to understand their (migrants) losses and challenges. Home to many people, particularly to migrants of African descent, means a lot of things (Magezi 2019a:4-6). At a surface level, it means a dwelling place. However, at a deeper level, it means the essence of being a human being (Magezi 2019a:4-6). Home is associated with many things that make an individual whole and to be truly human. Amongst African people, home is closely linked to physical, social, religious, spiritual, culture, emotions and psychological well-being. Home cannot be conceived outside these integrated dimensions.

Home is conceived as a physical and geographical place. For instance, people travel from cities where they work to rural homes during holidays such as Easter and Christmas. People work hard to build good houses and make investments like buying cattle in their rural homes despite having a dwelling place in the city. The rural home is considered the real home where one retires and 
gets buried when they die. Home is a place where one has familiar people whom they share a history, culture and tradition with. Home is where one's family, particularly extended family, is located. A geographical place where relatives and family members are not located is considered a temporary shelter, and not a real home. Wealth that is accumulated in cities or any other place of work and not brought back to one's geographical home where relatives live is considered lost and wasted. Any place away from your geographical location is a temporary place for sourcing goods, a kind of a hunting place where one should collect goods to bring home (Magezi 2017a:111-114).

One's social networks are found at home, a place of your birth, which is also a place of your ancestors. Your religion and tradition is preserved and nurtured at home. At home, your community shares a common religion as you. Despite adopting other religions such as Christianity or Islam, one's home and family religion hold great sway on an individual. Your home defines your identity, life and 'compass' in life. Your ancestors are found in the land of your fathers, which is your home. For this reason, Bhugra (2004) observed that:

When individuals migrate, they do not leave their beliefs or idioms of distress behind, no matter what the circumstances of their migration. Their beliefs influence their idioms of distress, which influence how they express symptoms and their help-seeking behaviour. (p. 134)

Home brings peace and stability in one's life and psyche. Success and progress are shared with one's family and home. Ekhaya [home] is a place of emotional gratification, fulfilment and affirmation by the whole community. Thus, ekhaya [home] brings belonging, appreciation, purpose and a sense of being fully human (Louw 2017:1).

Therefore, when one's home is disrupted through migration, a huge gap exists. A void that needs to be filled will be felt and experienced in all dimensions of one's life. It is understandable why migrants from similar geographical backgrounds tend to look out for each other. A community of people who share a 
similar background are considered empathetic and sympathetic to one's experiences and struggles. For instance, Kenyans, Congolese, Somalians and so on would look out for each other in a foreign land (Adogame 2013:494). In cases of 'in country' migration, people from the same geographic areas look out for each other also. Thus, Datta et al. (2006:17) observed that at community level, migrants use community-based coping strategies that entail the use of networks to share information about accessing work and many other needs. Information-sharing amongst ethnic networks is especially important amongst migrant communities. Amongst other things, these social networks assist to find cheap accommodation and employment. Sometimes migrants share accommodation with others to reduce costs. Migrants also direct each other to where employment opportunities exist.

Adogame (2013:494) observed that religion, particularly churches or mosques are also a critical coping resource for migrants. Adogame (2013:494) explained that ethnic groupings are part of the main reason for the existence of ethnic churches in the diaspora. He (Adogame) stated that Christianity as a religion and religious belonging provides a central motive for mutual migrants support for each other. Thus, religious identity can be a crucial resource for decision-making processes in the host countries, for vitalising culture of origin and for action within the integration processes in a host context. Also, religious institutions provide migrants with opportunities of vital import for mixing with people from different cultural backgrounds under the umbrella of a common religion. Consequently, the search for physical access to resources, emotional support and nurturing of the feeling of ethnic home, and the search for survival of social networks interplay to sustain diaspora ethnic religious communities such as churches.

These diaspora efforts aim to provide a kind of a buffer to the lost home whilst at the same time create a sense of a new home. The physical, social, emotional and spiritual void created by the 'lost' home finds some form of replacement in ethnic churches. 
Within this situation, the question that arises is: what meaningful roles can churches play to address the needs of migrants? How could the void of a 'lost home' be somehow replaced through an operative ecclesiology and practical migrant ministry? Magezi (2017b) explained that:

An operative ecclesiology refers to performative actions of being the church within concrete contexts. It reflects on ecclesial matters not merely from the viewpoint of denominational traditions and dogmatic confessions, but within communal life systems. At the heart of an operative ecclesiology is the question: what does it mean to be church in my context? And within the context of migrants and host nation churches in our global world, where people are in a constant move, it poses the question: how should church be done and practiced in order to reflect the multi-coloured face that it is portrayed - every people, language, and tongue (Rv 7:9)? (pp. 238-239)

An operative ecclesiology could be aided by the eschatological perspective within the situation of migration.

\section{Eschatological perspective within the notion of home amongst migrants}

Eschatology is a doctrine that focuses on the final or last things, which derived from the Greek word eschaton, meaning 'last'. However, eschatology does not only refer to the end of time but also to 'the now'. The now dimension of eschatology is called realised eschatology, a term that was coined and popularised by C.H. Dodd (Sanders 2009:2). Sanders (2009:2) explained that Dodd argued that realised eschatology replaces 'the end is near' with 'the end is here'. Dodd maintained that we should understand Jesus' message that 'the kingdom of God is at hand' (Sanders 2009:2) with an emphasis on the kingdom of God's presence as right here. Further to the realised eschatology by Dodd, Ladd coined the phrase 'already/not yet' referring to the notion that Christ brought the final things in his own person and work and yet there are still unredeemed things awaiting his return (Sanders 2009:3). Thus, the kingdom now and not yet signifies a tension within a Christian's life. Accordingly, the church is sandwiched in 
the realised eschatology (kingdom now) and kingdom not yet (unrealised eschatology). Louw (1998) in Pastoral Hermeneutics of Care and Encounter explained that this tension is resolved through adopting a pneumatological perspective. A pneumatological perspective entails that an individual becomes part of the kingdom now through spiritual transformation and exists in this ontic being and continues right through to end (i.e. realisation of the kingdom not yet) through the pneumatological enablement. Locating the discussion within a context of pastoral care, Louw (2014) clarified that eschatology provides a constructive perspective by the fact that:

Due to the not-yet factor, life is never complete and our being human always incomplete and unfinished, thus the notion of homo absconditus [the essence of being is a mystery, hidden in the not-yet of human existence]. (p. 2)

Within the context of migration where people have been displaced from their homes, Magezi (2017b:239-240) linked the notion of a physical home to an eschatological home. Magezi (2017b) explained that an individual's eschatological position, particularly in the situation of displacement:

$[R]$ epresents a progressive and constructive mind-set that emerges from a pneumatological state of being, a state of spirituality where home is both a state of being (realised eschatology) and an anticipated 'still to come' home/place (unrealised eschatology). The actual home and citizenship (Philippians 3:20) are a place of dwelling with Christ (John 14:1-4) in heaven (Revelation 21:3). However, home is here now by virtue of union with Christ (realised eschatology) and not necessarily geographical and also futuristic only. In this sense, both host country people and migrants are strangers on a migrating journey to a real home (unrealised eschatology). They are homo viator, pilgims, and people on their way towards a final home. This mind-set challenges individuals to be in a continuous state of transformation and re-imagination of what it means to live in a global village where migrants are a key part of that life. It helps people to redefine and explore new approaches to being human in a global village. It makes one contend with complexity and options, which Korsch (2011) calls exploring new categories ('Spuren des Selbstausdrucks und Wetaneignung'). (pp. 239-240) 
In the context of our discussion, an eschatological perspective challenges churches to cultivate Christian public ethics. Public ethics refers to Christian duty because of one's pneumatological ontic being (realised eschatology). Christian public ethics is about doing ethics in the public space, that is, a non-church environment where church and non-church migrants exist. Christians exist in this public space as an institution (church) and as private human beings (individuals in the community and in their homes). It is in this space, Müller (2004) argues:

$[W]$ here specific contexts and experiences are interpreted; incontext experiences are listened to and described; interpretations of experiences are made, described and developed; a description of experiences as it is continually informed by traditions of interpretation; a reflection on God's presence, as it is understood and experienced in a specific situation; a description of experience, understood through interdisciplinary investigation and the development of alternative interpretations that point beyond the local community. (p. 300)

Müller's argument is that our human actions as Christians should have an intentional goal of co-existence with other human beings such as migrants. We are bound in contextual realities with other people. Thus, Christian public ethics represent the health of the church, an apt metaphor for the church as an 'organism' - the 'sent' church - that has a public role to play. This suggests that public ethics should be a thermometer to measure what church and Christianity should look like under the Lordship of Christ. The purpose of the church is to serve the Lord in serving the world filled with people who are struggling such as migrants. Noting this challenge, the task of public practical theology, public pastoral care and Christian public ethics is to guide church reflection actions in the frontline of people's lives. According to Osmer's (2008:4) practical theology framework, which is a useful underpinning framework for practical Christian ministry, practical theology assists one to interpret situations or contexts presented from a hermeneutical perspective relying on biblical concepts to construct ethical norms to guide and provide responses to the existential questions, which should lead to devising strategies for action that will influence situations and practically impact people. 
Thus, from the above discussion, physical home should be transformed to an eschatological home. An eschatological home indicates a new state of 'thinking about home' and 'living at home'. Both a migrant and a host country person view their current existential situations they call home redefined and transformed to a state of temporariness (realised eschatology) but with a long-term view of permanent home (unrealised eschatology). Home becomes a place for service where people display public ethics of mutual care and embracing communities.

In view of the previous discussions, how then do we proceed from the understanding of eschatological home and the notion of kingdom reversals to develop congregational ministries that effectively provide care for migrants as well as cultivate a health perspective to both host people and migrants?

\section{Reversals and eschatological home as operative ecclesiological framework}

The demands and expectation to care for migrants are increasingly putting immense pressure on host people. Care for migrants is indeed causing compassion fatigue. Louw (2015) commented that:

Researchers are of the opinion that compassion fatigue is related to compassion stress, burnout, secondary victimisation, co-victimisation, contact victimisation, vicarious victimisation, secondary survivor and emotional contagion. The fact is that the experience of trauma affects all of the people involved, including the support systems. (p. 1)

Good intentions by hosts to care for migrants can sometimes be construed as pushing migrants as one makes effort to lead them in certain directions to ensure integration. Integration and inclusion efforts may also cause tensions and discomfort on both hosts and migrants. In this complex situation, migrants may develop a victim mentality, whilst host people may be complacent to offer any help to migrants. In this situation, a kingdom reversal perspective is a critical mental shifting approach that should be encouraged. 
The host people who are in comfortable situations should embrace kingdom of God ethics. This entails using other people as a mirror, a solidarity and identification of host and migrant. Solidarity is having a relationship with every other human being and an obligation to pursue their well-being, especially in situations where they are not able to take actions on their own. This pertains to the fact that an individual is morally required to be concerned for the good of others. Therefore, solidarity is the recognition of interdependence and the duty to act for the common good, that common good ultimately stretching to all who inhabit this planet. Identity relates to a sense of shared belonging that is founded on a common vision of the nature of human life and relations in co-ordinating their behaviour to realise shared ends based on norms governing these. Christian ethics are guided by the principle 'Do to others whatever you would like them do to you. This is the law and the prophets' (Mt 7:12). This is encouraged by the words of Jesus, 'the kingdom of God is among you' (Lk 17:21). Therefore, authentic Christian spirituality is undoubtedly concerned with the shaping of and practice of human life, but embodies everyday practicalities and serves as a framework of ethics (Sheldrake 2019:xi).

Kingdom reversal and eschatological thinking places responsibility to both host and migrants. It avoids a one-sided focus where hosts are blamed for lack of hospitality. Magezi (2017b:241) explained that an eschatological perspective 'represents a constructive position, a mind-set and responsive action to be possessed by both migrants and host nation individuals (and communities)'. Furthermore, an eschatological perspective is a (Magezi 2017b):

$[P]$ rogressive and constructive mind-set that emerges from a pneumatological state of being, a state of spirituality where home is both a state of being (realised eschatology) and an anticipated 'still to come' home/place (unrealised eschatology). The realisation that humans are homo viator evokes gratitude in a person. To the migrant, gratitude arises among other things, from appreciating provisions in a foreign country, while to the host, the peace enjoyed in the host country should also arouse gratitude. (p. 241) 
Thus, an eschatological thinking makes both host and migrant people who have been welcomed by the host Jesus Christ in his kingdom where equality exists. In this situation, host people's seeming situation of peace and comfort is reversed to a situation of need. Both host and migrant are in a dim situation where they strive to be welcomed by God who is the real host in future eschatological home. However, in the interim, there should be a mutual and gracious embrace of the other.

How then do we proceed to develop a congregational ministry that effectively provides care for migrants as well as cultivate a health perspective to both host people and migrants? In response, an operational ecclesiology that is driven by three mutually interactive responses, namely (1) congregational conscious raising and empowerment, (2) congregational seeing and (3) congregational practical interventions, is proposed (see Figure 4.1).

Within the proposed operational ecclesiological approach, congregational conscious raising and empowerment dimension

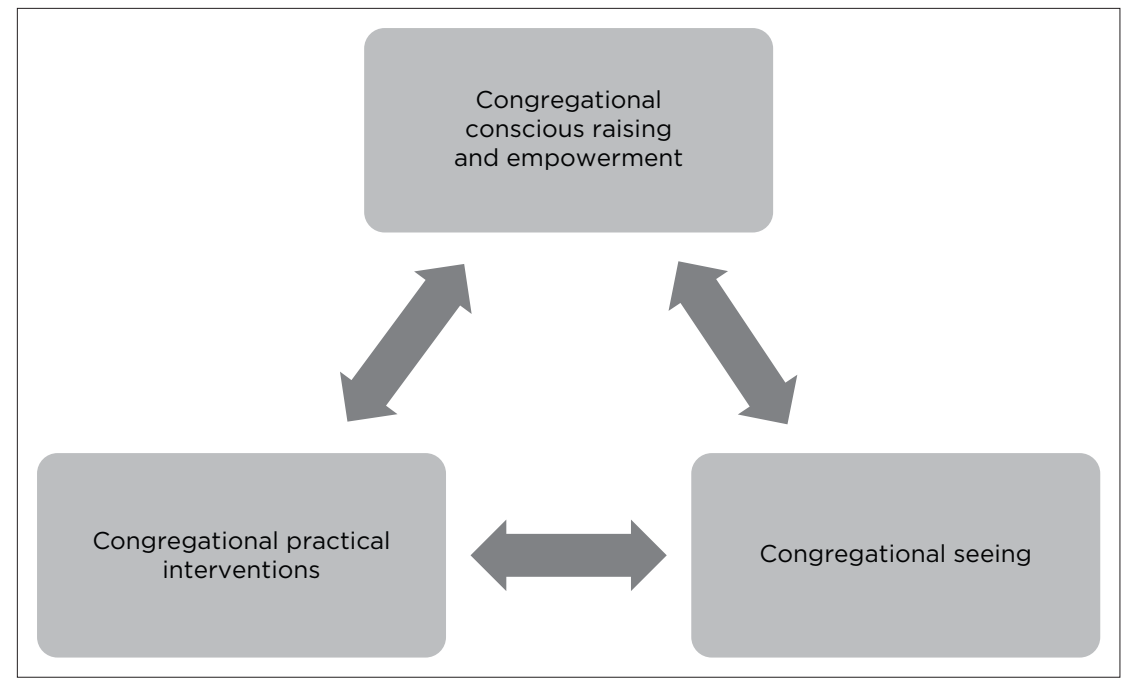

FIGURE 4.1: Interactive migrant responses within an operational ecclesiology. 
entails preparing the congregation for a practical ministerial response through information-sharing to build awareness and consciousness on migrant issues. This is a systematic sociotheological engagement and discussion to unfreeze possible negative attitudes towards migrants. Information-sharing raises consciousness on how to practically live out the life of faith. This process also entails guiding congregation members on responding to the diverse challenges posed by migration to avoid a numbness and overwhelming experience because of migrants' many needs. To ensure church members as individuals and corporately critically reflect on their positioning in migration situation, reflection and reflexion should be done. Reflection within the situation of migrants entails critical thinking about the congregation's practices towards migrants. Reflexivity refers to reflecting back on oneself. It is a critical approach where the congregation questions its position and involvement in the situation of migrants. The congregation might be apathetic and contributing to the pain and ostracisation of migrants. At the same time, migrants themselves might be acting in a manner that causes ostracisation such as forming migrant enclaves and resisting integration.

Thus, conscious raising and empowerment is providing information and cultivating a culture of critical reflection. In this process, theological thinking and resources that could be used for migrant care are explored and discussed. The use of theological resources and church activities such as Bible studies is focused on relevant themes such as counselling, identity in Christ, humanity and human dignity, mutual support, supportive counselling and so on. During this process, most appropriate and relevant approaches are identified and prioritised for practical implementation.

Congregational seeing is a metaphor that implies developing systematic approaches of observing community people's needs such as migrants and developing clear ways to intervene. The Systematic Theologian Smit (2003:476) in his essay 'On learning to see?' guided that Christian ethics start with an act of seeing. 
This entails perceiving the problem, accepting the challenge and interpreting ways of responding. Seeing entails proper analysis of the situation, finding possible actions available, testing options and making decisions. Hendriks (2004) described the process of seeing as contextual analysis whereby the data are drawn through contextual analysis methodologies. In our context of migration, seeing entails efforts to overcome possible congregational apathy through clear identification of migrants' needs. This entails observing changes in the context of the congregation, inflow of new people, noticing needs of new people coming into the area, identifying and profiling where they are coming from, understanding their background, identifying their needs and so on. Seeing is an approach of cultivating and challenging the congregation to be immersed in the contextual realities of the people around it as well as national and global challenges. Therefore, from seeing, practical interventions are sought to address the identified (seen) needs. Practical seeing overcomes apathy by challenging congregations to practically act. Migrants' needs are not theoretical. Their needs range from spiritual to physical.

Congregational practical interventions entail developing relevant practical interventions to address the diverse needs of migrants. Migrants have physical, economic, spiritual, social, emotional, legal and security needs. The church needs to develop a systematic approach of addressing systemic needs of migrants. Some may require proper documents, whilst others may require a spiritual home. The congregation there should be alert and be responsive. However, the challenge is that the congregation will be pulled in many directions and has limited resources. Magezi (2019b) noted that:

As the church engages in various church ministries, the pastor gets pulled in different directions. As a result, the pastor relies on teams of volunteers who have their own family and home priorities as well. Straddling between spiritual and development work stretches the pastor beyond his or her limits. This poses a risk of leaving other things undone. Therefore, making strategic choices on the issues to engage is critical, which Greider (2008:54) referred to as choice on what to triage. (p. 11) 
To overcome the risk of the pastor doing everything, there is a need to develop an ecosystem of support for referral of cases to other urgencies. This challenges the pastor to develop a systematic way of managing migrant challenges to avoid being overwhelmed.

\section{Conclusion}

The chapter considered the need to develop a church responsive ministry within a context of displaced people who are migrants. The chapter also argued that the displacement of results on loss of homes is the central aspect of their being. To cope with the displacement, migrants should accept a redefinition of home by embracing an eschatological home. To proceed from a theoretical understanding of home to challenge congregations to practically support migrants, the notion of eschatological home should be translated to practical action by employing a public Christian ethical position informed by the kingdom reversal principle. The kingdom reversal principle and eschatological perspective guided the development of three important operative ecclesiological principles: congregational conscious raising and empowerment, congregational seeing and congregational practical interventions. These principles are practical approaches that churches could adopt in efforts to develop migrant ministries. 



\section{Chapter 5}

\section{Evaluating 'prophecy' as a South African Neo-Pentecostal pastoral response to the challenges of xenophobia}

Marius $\mathrm{Nel}^{1}$

Unit for Reformational Theology and the Development of the South African Society, Faculty of Theology, North-West University,

Potchefstroom, South Africa

1. Marius $\mathrm{Nel}$ is a research professor at the Unit for Reformed Theology of the Faculty of Theology, North-West University, South Africa; marius.nel@nwu.ac.za. He wrote the concept of the chapter. Amos Yong, Professor of Theology and Mission and Director of the Centre for Missiological Research (CMR) at the Fuller Theological Seminary, USA; amosyong@fuller.edu, advised on several issues in the chapter.

How to cite: Nel, M., 2020, 'Evaluating "prophecy" as a South African Neo-Pentecostal pastoral response to the challenges of xenophobia', in A.R. Brunsdon (ed.), The human dilemma of displacement: Towards a practical theology and ecclesiology of home, pp. 103-128, AOSIS, Cape Town. https://doi.org/10.4102/aosis.2020.BK198.05 


\section{Abstract}

Displacement is a challenge that many countries in Africa face and in times of crisis citizens of these countries tend to cool their anger and frustration inter alia through violent acts of xenophobia. Another feature of the African scene (as a part of the Global South) is the growth of the Pentecostal movement in its diverse forms, with classical pentecostals, charismatic pentecostals in mainline churches and Neo-Pentecostal groups outnumbering members of the Roman Catholic Church in Africa. It is argued that prophecy forms an integral element in the contribution of the Neo-Pentecostal movement to the solution of displacement and the resultant xenophobia as a problem in Africa. Prophecy stands in the service of Neo-Pentecostals' emphasis on salvation and healing, within the wider context of African cosmology's view of a spirit world populated by good and evil spirits and animating the seen world. Evil spirits are causative for the occurrence of some cases of death, barrenness, illnesses and other misfortunes; the prophet can decipher and uncover the human and spiritual causes of events and prescribe a possible way to overcome it. Neo-prophecy provides guidance for the displaced as well as for those who are challenged to accept and welcome the displaced strangers in their world. The chapter describes the phenomenon of neo-prophecy and evaluates its benefits and shortcomings as a pastoral response to xenophobia.

Keywords: Xenophobia; Neo-prophetism; Prophecy; NeoPentecostal churches; Prophets.

\section{Methodology}

In this study, a phenomenological approach is utilised by way of qualitative content analysis of the phenomena of prophecy and xenophobia, to understand meanings associated with messages involving the analysis of the contents on newspaper reports, blogs and editorials, and academic articles containing 
such research. The purpose is to view xenophobia and a NeoPentecostal response to it in the available material. The use of language, symbols and visual images is investigated to understand the particular discourse.

\section{Xenophobia in South Africa}

Africa has been experiencing the challenges of displacement and migration for many centuries. Legal entries of foreigners into South Africa increased dramatically after 1994 and most of the foreigners who entered the country came from Africa, mainly from countries in the Southern African Development Community region (Crush 2008:1; Dodson \& Crush 2016:279). In 2013, the number of international immigrants in South Africa was already more than 2.3 million and it increased between 2000 and 2013 at a rate of $6.7 \%$ per annum, according to figures released by the United Nations (Gordon 2016:4, 2017:19-20). ${ }^{2}$

Estimates of the total number of irregular (or undocumented) migrants present in South Africa range from 1 million to an implausible 10 million; it is impossible to quantify it because of the clandestine nature of irregular cross-border entries or overstaying (Dodson \& Crush 2016:279).

In 2010, out of 180000 asylum seekers, close to 150000 were Zimbabweans. ${ }^{3}$ By 2015, this had changed so that citizens from the Democratic Republic of the Congo and Somalia were the main sources of asylum seekers (Dodson \& Crush 2016:280), whilst unofficial numbers representing illegal refugees are likely in the millions. Most of them self-settle in urban areas amongst

2. By comparison, in the 2011 census, the official number was 2199 871, or approximately $4 \%$ of the population. Because census enumeration is unlikely to have captured all undocumented immigrants, the real figure is higher (Dodson \& Crush 2016:278).

3. In 2009, the Department of Home Affairs announced a special dispensation for Zimbabweans where 4-year residence and work permits were issued to 245000 Zimbabweans who were already in South Africa without visas or other permits; these were reissued for a further 4 years in 2014 (Dodson \& Crush 2016:280). 
other poor people for lack of governmental support (Labys, Dreyer \& Burns 2017:697).

In the words of Ideheu and Osaghae (2015:79), xenophobia is a dislike or hatred towards foreigners. Its social stereotypes and prejudices are often disguised with the phenomenon of nationalism. A word in local vocabulary, Makwerekwere, is used for someone who is not proficient in a local South African language and who comes from a country that is seen in local prejudice as economically and culturally backward, betraying a deep resentment against foreigners (Ideheu \& Osaghae 2015:80).

Xenophobia is the result of economic and material factors such as poor black people vying for jobs with immigrants who are sometimes better qualified or more willing to work hard for less remuneration, social factors where the 'other' in postapartheid South Africa is redefined as 'foreign Africans' and political factors such as a lack of political leadership and elite discourses on immigration (Dodson \& Crush 2016:286-288). ${ }^{4}$ Gordon (2016:12-14) argues that anti-immigrant sentiment is the result of a lack of intergroup contact, stereotypes about

4. The Institute for Security Studies (ISS) in their research finds two myths about foreigners fuel xenophobic attacks. In the first place, it is perceived that foreign nationals take jobs that should be reserved for South Africans, leading to an escalation of unemployment figures. In the second place, the idea persists that foreign nationals are involved in much of the crime in the country (Kangwa 2016:539). According to Harris (2002), even the conciliatory former President Nelson Mandela hinted that undocumented foreigners are responsible for crime in South Africa. Mangosuthu Buthelezi as leader of the Inkatha Freedom Party (IFP) stated as Home Affairs Minister that 'all Nigerian immigrants are criminals and drug traffickers' (Tella \& Ogunnubi 2014:154). A survey in 2006 showed that $47 \%$ of South Africans supported the deportation of foreign nationals, and $74 \%$ supported a policy of deportation for any immigrant not contributing economically to the country (Dodson \& Crush 2016:285; Ideheu \& Osaghae 2015:80). Crush (2008) finds that 48\% of South Africans saw migrants from neighbouring nations as a criminal threat, $29 \%$ believe these migrants are carriers of diseases and 15\% reported losing jobs to foreigners. The Afrobarometer survey of 2011 states that as many as $45 \%$ of South Africans strongly do not want foreigners to live in the country because their jobs are threatened by foreigners, while $36 \%$ admitted that they would prevent foreigners to establish businesses in their neighbourhoods and $33 \%$ would actively attempt to stop foreigners even from settling in their neighbourhoods (Ejoke \& Ani 2017:171). 
immigration and immigrants and a general weakening of race relations in the country. The effect is that immigrants and refugees experience everyday forms of discrimination from fellow-citizens and officials in accessing those state services and rights to which they are legally entitled.

Anti-immigrant hostility and violence also drives frustrations with horrid social and economic conditions (Gordon 2016:5). Although the African Nationalist Congress government expanded the social welfare net in the 2000s to provide welfare grants to 17 million people and the number of people living below the food poverty line decreased by 4.9 million (Gordon 2016:4), poverty still remained widespread. In 2014, 12.2 million South Africans were living below the food poverty line, resulting in the South African Gini Coefficient measuring inequality at 0.64 in 2014. This makes South Africa one of the most unequal countries in the world.

The South African government policy can be regarded as resistant if not directly hostile to immigration, contributing to a pervasive climate of xenophobia (Ideheu \& Osaghae 2015:83), targeting primarily immigrants of African origin. The state represents a 'protectionist' position for the benefit of its own citizens when they introduced restrictive immigration policies, sharpened border control (Gordon 2016:2) and promoted nativism (Gordon 2017:31), which underscores the implementation of various regulatory and policing responses that undermine and negatively affect migrant entrepreneurship. It is based on high levels of negative perceptions about migrants with politicians and officials who blame the lack of sufficient state resources and criminal activities on illegal immigrants (Dodson \& Crush 2016:285). ${ }^{5}$ In this way, xenophobic sentiments are incubated

5. The International Organization for Migration (IOM) finds that these perceptions and prejudices are not based on good evidence. To the contrary, they found that foreign nationals are not responsible for the rise in crime and unemployment; in fact, migrants are twice as likely to be entrepreneurs than South African nationals, actively contributing to generate employment. They employ on average five to six people (https://southafrica.iom.int/). 
that threaten black brotherhood sentiments amongst all Africans (Ideheu \& Osaghae 2015:87).

Post-apartheid South Africa experiences many service delivery protests that are at times accompanied by violent attacks on municipal property (Saloojee 2016:263) and immigrants, including looting their businesses (Saloojee 2016:273). ${ }^{6}$ The tragic fact is that xenophobic attacks were mainly perpetrated by poor South Africans of African heritage on poor African migrants (Chiweshe 2016:133; Gordon 2016:2). Jean Pierre Misago (in Baker 2015), a researcher at the African Centre for Migration and Society, estimates that about 350 African migrants were killed from 2008 to 2015 in xenophobic attacks.

Another fact is that some of the perpetrators of xenophobia are dedicated members of churches and many victims of xenophobia look to the local church for safety and practical assistance in the aftermath of attacks (Phakathi 2010).

6. In 2004-2005 (from April to April), there were 7382 peaceful protests and 662 protests with unrest; in 2010-2011, there were 11681 peaceful and 973 violent protests; in 2012-2013, there were 10517 peaceful and 1882 violent protests; and in 2013-2014, there were 11688 peaceful and 1907 violent protests. The acceleration in violent protests is significant (Saloojee 2016:269). Between 2009 and 2012, there were 2.95 unrest incidents a day, an increase of $40 \%$ more than the average of 2.1 unrest incidents a day recorded for the period from 2004 to 2009 . The top grievances by protestors were about housing, water and sanitation, political representation and electricity and it centres on unaccountable and corrupt local government and issues of community safety (Saloojee 2016:271). In 2008, in xenophobic attacks that started in Johannesburg and spread to Pretoria and Cape Town, South African citizens and migrants lost their lives and property. In 2015, the Zulu King Goodwill Zwelithini allegedly asked foreigners to pack their bags and go back to their countries because they were enjoying South African resources at the expense of locals (Tella 2016:142-143), stating, 'I would like to ask the South African government to help us. We must deal with our own lice in our heads. Let's take out the ants and leave them in the sun. We ask that immigrants must take their bags and go where they come from' (https://www.herald.co.zw/zwelithini-likens-immigrantsto-lice-ants/; The Herald, 17 April 2015). This led to several attacks of homophobic nature. 


\title{
'Prophecy' in the Neo-Pentecostal churches in South Africa?
}

\begin{abstract}
As in African Christianity in general, pentecostalism in its diverse forms ${ }^{8}$ is fast becoming the representative face of South African black Christianity. With the advent of Neo-Pentecostal groups (also called New Prophetic Churches [Quayesi-Amakye 2014:256] or churches of the Spirit [Anderson 2016:304]) since the 1990s and the ongoing pentecostalisation of mainline churches along with the link of pentecostalism with African Indigenous/Initiated/ Independent Churches (AIC), pentecostals form the fastest growing Christian movement within our times in South Africa (Anderson 2007:117). ${ }^{9}$ And through the millions of members,
\end{abstract}

7. The author's presupposition is that contemporary prophecy in the pentecostal movement in its reception and contents stands in a way in continuity with the phenomenon of prophecy as found in the Bible (cf. Nel 2017) and that may represent a form of extra-biblical revelation. This is contra the widespread Reformed and Roman Catholic cessationist perspective that the prophet is rather an engaged observer who criticises actions and policies that differ from God's intentions. It serves as an authentically Christian mode of moral discourse (De Villiers 2016:154).

8. Barrett (1970:50) perceived half a century ago that African Christianity is transforming 'Christianity permanently into a primarily non-Western religion'. Although a classification of pentecostalism is risky because of its diverse branches, it is customary to speak of three waves of classical pentecostalism that looks back for its origin to the beginning of the 20th century with Charles Parham's Bible Schools and William Seymour's Azusa Street Revival in Los Angeles and similar incidents (not all agree that pentecostal origins in other countries go back to Los Angeles; sometimes it might have been the result of indigenous revivals; cf. Anderson 2007), of the charismatic renewal of the mainline churches since the 1950s and of an independent movement since the 1970s with its synthesis between pentecostal theology and practice and several other theological traditions. This last wave is sometimes denoted as Neo-Pentecostalism. The discussion is limited to these churches of which many have become macro churches centred around apostles or prophets (cf. Anderson 2001; Gifford 2011; Kalu 2008; Quayesi-Amakye 2013 for further discussion).

9. Pentecostalism is defined in terms of groups that stress the baptism with the Holy Spirit, leading to direct divine inspiration and guidance which is presented in a celebration of the charismata, with emphasis on glossolalia, divine healing and parallel phenomena (cf. Soko 2016:92-93). 
these churches attract; they are influencing and impacting the social, economic and political fabric of post-apartheid SouthAfrica (Frahm-Arp 2016:283; Keener 2016:89).

A feature of Neo-Pentecostal African churches is the category of prophets (along with apostles) serving as leading religious functionaries. Prophets and prophecy historically and traditionally played a significant role within pentecostalism with its emphasis on the experience of Spirit baptism and the resultant expectation of the revelation of God's power and guidance to the contemporary believer. ${ }^{10}$ Within the classical Pentecostal movement, the charisma of prophecy is valued highly, and room exists in any worship service that believers may participate spontaneously by bringing a prophetic word or revelation." The believer who prophesies is not called a prophet except in exceptional cases where the person is used regularly to such an extent that the (local or regional) church regards them as faithful 'prophets'. However, in the Neo-Pentecostal tradition, the phenomenon of prophets shows an emerging dominance with specific individuals regarded and honoured as prophets. In the classical Pentecostal tradition, prophecy is concerned with a word for the assembly (mostly) or an individual, in the form of an encouragement or

10. See the definition of Kroesbergen-Kamps (2016:29) of prophecy that she compiled from interviews with Zambian pastors from various denominations, that prophecy is 'speaking the word of God to give direction in order to bring change'. The debate about the definition of 'prophecy' is still continuing; for purposes of this article, her definition is being used.

11. It seems as if 1 Corinthians 14 stresses that while prophecy is a manifestation of the Spirit it also involves speaking intelligibly with the mind so that the gathered are able to follow the message. Although prophecy is a form of instruction, it also reveals things that pierce the human heart so that the secrets of listeners' hearts become manifest (1 Cor 14:25). The term 'revealing' ('анок< $\# 125>\lambda \cup \varphi \theta \hat{\text { ) }}$ in 1 Corinthians 14:30 suggests that prophetic insight might contain content which could not have been gained through rational thought and study alone, as Ellington (2016:177) acknowledges. At the same time, because prophecy occurs through the agency of humans, all inspired prophecies are, in part, subject to human limitations such as subjectivity, requiring the injunction in 1 Corinthians 14:29 that after two or three

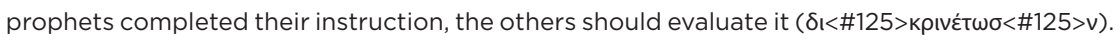
The purpose of discerning is according to Fee (1994:252) not to evaluate whether a person is speaking by a foreign spirit but whether the prophecy itself truly conforms to the Spirit of God. 
warning, often in biblical terms and seldom related to prediction of the future. In the Neo-Pentecostal tradition, prophecy is mainly concerned with a word aimed at an individual as part of a pastoral discourse, although prophets' preaching often also contains prophetic announcements.

The Neo-Pentecostal prophet operates in the same context as the diviner in African Traditional Religion (ATR), focusing on diagnosing individual ailments and finding spiritual cures to all manner of challenges (Ngong 2010:143). ${ }^{12}$ Neo-prophets are perceived as having a unique relationship with God, allowing them continuing access to supernatural knowledge of the seekers' problems as well as the power to bring about solutions to those problems. ${ }^{13}$ The solution in many cases consists of something that the believer must do or stop doing. In this sense, it also differs from the Pentecostal definition of a prophet. In their manner of operating, neo-prophets link rather with the phenomenon of prophecy within the AICs (as portrayed, e.g., in the excellent article of Wepener \& Barnard 2016) than with classical pentecostalism so that Neo-Pentecostalism may be viewed as the 'AIC'ination' of African pentecostalism (cf. Cox 1995:250). ${ }^{14}$ Because of these differences, it seems sensible to

12. The similarity between the diviner and neo-prophet is that both have the task of uncovering the cause or root of a problem or felt need (Omenyo 2011:34); however, the similarity ends when the neo-prophet interprets the problem in terms of a revelation of the Spirit.

13. Research found that the most common problems to which people seek the help of prophets include incurable diseases, marital issues and unemployment, according to Sakupapa's (2016:123) research.

14. Similarities between the prophetic ministry in AICs and neo-prophetism include that individual worshipers are called to another room to be prophesied to, with a third person who interprets; prophecies are sometimes written down; some prophecies may contain injunctions to drink holy water or another liquid, blessing of possessions, predictions that an illness will disappear when the believer follows certain injunctions, injunctions to the assembled people to help poor people and instructions what to do to ensure that businesses are blessed (Wepener \& Barnard 2016:77-84). 
call this phenomenon 'neo-prophetism', to distinguish it from the Pentecostal custom. ${ }^{15}$

The history of prophetism within the Neo-Pentecostal tradition (and to a certain extent in African pentecostalism as well) can be traced to the role played by prophets in AICs (Omenyo 2011). ${ }^{16}$ Within these churches, the prophets are defined by Baeta (1962:6-7) as individuals characterised by a striking personality and the ability to impose to convince others that they are special agents of God. Specific powers are credited to them, such as healing, deliverance, revealing of hidden things, predicting of the future, and cursing and blessing. In its initial period (1860-1960), the AICs emerged in Southern Africa for political and religious reasons, as a successful vernacularisation of the gospel for Africans (Quayesi-Amakye 2016:288) and peaceful and silent protest against colonisation and mission Christianity representing churches established by missionary agencies from Europe and America that were intolerable of traditional African worship and practices (Kalu 2008:23). There are direct links with primal religion in the phenomenon amongst the AICs.

Neo-prophetism provides in what Sakupapa (2016:118) calls 'the prophetic craze amongst many Christians' irrespective of church tradition or doctrine. Again, it seems that NeoPentecostalism succeeds in what Cox (1995:247) describes as an important ingredient of its recipe for success, to assimilate a wide variety of African indigenous religious practices whilst it links with the direct needs of ordinary people in the idiom that they

15. Prophetism has always formed an integral part of African Christianity contra Western mission-churches as a perennial phenomenon (as described by Baeta 1962:6; Omenyo 2011:31; cf. also Oosthuizen 1992; Sundkler 1961).

16. The phenomenon of AICs is notoriously complex; various attempts have been made to classify the phenomenon along diverse lines. Anderson's (2001:15-18) and Oosthuizen's (1992:1-2) classification makes the most sense, with AICs classified as Ethiopian, Zionist, Prophet/healing and charismatic/pentecostal or Spirit-churches. Anderson (2016:306) mentions that in some parts of Africa, Spirit-churches constitute up to $40 \%$ of the total population. 
understand and by emphasising the power of the Holy Spirit to provide in any need of contemporary believers, including childlessness and infertility, bodily and mental illness, drought and natural catastrophes, accidents and bad luck, poverty, racism, sexism, classism, colonialism, neo-colonialism, imperialism, injustice, political dictatorship and repression, imprisonment without trial and all that dehumanises the African personality (Quayesi-Amakye 2016:293). ${ }^{17}$ Some of these prophets enjoy wide media coverage through online social media and digital television. That these prophets attract many South African black people is not only related to Neo-Pentecostals' this-worldly perspective on salvation ${ }^{18}$ but also to the affinity of their practices to certain ATR beliefs that underlie the African worldview. Muindi (2012:211) argues that the Neo-Pentecostal charism of prophecy has a particular appeal because it echoes the traditional African prophetic spirituality which accentuates inter alia aspects such as 'spirit possession', 'divine seizure' and 'supernatural revelations' concerning the spiritual causes of actual events amongst people (Nel 2019:2). ${ }^{19}$ Kalu (2008:186) agrees and states that it has produced a culture of continuity with primal worldviews, in the process regaining a pneumatic and charismatic religiosity that

17. The quest for divine immediacy is vital to pentecostal spirituality, in opposition to many Protestant theologians' cessationism that limits supernatural intervention and the (so-called supernatural) charismata to the apostolic era.

18. Pentecostals traditionally emphasised divine healing, connecting salvation, wholeness and holiness (in Afrikaans: 'heil, heelheid en heiligheid', demonstrating its common root). In demonstrating this connection, Maddocks (1990:7) defines health as a foretaste of the wholeness to come, when the kingdom is established and creation healed. A Christian can never talk about healing without having Jesus in mind. The meaning of his name reflects the terms 'save/heal' and speaks of the unleashing of power that brings human beings and society to a new spaciousness that releases its members to perform their function (Maddocks 1990:9). The kingdom's shalom consists of salvation, good health, contentedness and peace between nations (Duncan 1988:37). Holiness is viewed as the equipment necessary to become whole (Maddocks 1990:12-14).

19. Cox (1995:219) suggests religions in Africa that grow will necessarily include and transform elements of pre-existing religions because these elements retain a strong grip on the cultural subconscious. In this sense, pentecostal churches help Africans to recover some of the vital elements in their culture threatened by modernisation (Cox 1995:222). 
characterised traditional society and which contemporary Africans can identify with. ${ }^{20}$ In African traditional life, birth, illness, death, drought and material challenges were explained as acts perpetuated by good or evil spirits. Human beings are vulnerable and open to both evil and benevolent forces and the forefathers should be appeased because of their influence on the world of spiritual forces. The power of evil is perpetuated by bad witchcraft, ancestral spirits and bad muti or herbal medicines and potions made by sangomas, which are believed to cause misfortune in the lives of people. The powers of evil cause illness, poverty and broken relationships (Frahm-Arp 2016:271; Quayesi-Amakye 2013:51-85). Because people are curious about their existential concerns, they explore sources of vital forces to change their destinies for the better, hence the popularity and constancy of prophetism in Africa's religious climate (Quayesi-Amakye 2016:302). Salvation consists of freedom from evil powers that hinder human beings from achieving well-being (Ndiokwere 1981:239-243). Neo-prophetism appropriates the holistic African worldview when it perceives the spirit world as impinging on the visible world that determines the welfare or woe of human beings. Existential challenges are decided in the spirit world and secular analysis as viewed by Western society cannot contribute to understand it (Ngong 2006:524). ${ }^{21}$ At the same time, ancestor veneration is not accepted as a way to appease spiritual forces and Christians are encouraged to break with their extended families who practise ancestor veneration. Christians' fight is

20. Traditionally mission churches with their cerebral-analytical 'class-room religion' (Taylor 1963:21-22) rejected the African worldview and primal vision and taught new believers that they need to formulate a new worldview in accordance with the Bible without acknowledging any connection between a biblical and African worldview. Kangwa (2016:544) argues that only when African Christianity retrieves and applies vital African values will they serve Africans. For that to happen, they need a spirituality of holism and a sacramental worldview. By accepting the African worldview, it also changes in important respects in correlation with biblical perspectives.

21. Western misunderstanding of African neo-prophetism may be linked to its neglect of the primal African vision that believes that fundamentally all things share the same nature in their interaction upon each another in cosmic oneness (Taylor 1963:72). 
against evil forces such as the ancestors, evil spirits, hobgoblins and Satan (Frahm-Arp 2016:271-272).

Their soteriology consists of two elements: the need to minister to the needs of believers and the expectation of the second coming of Christ, with the accompanying final reward for believers, of eternal life. Prophecy is concerned with physical, spiritual, emotional, social, legal and psychological challenges as well as spiritual and bodily well-being and material prosperity. ${ }^{22}$ Clients visit prophets to seek spiritual direction (isiqondiso esingokomoya in Sesotho or isiqondiso esingokomoya in Zulu). They elicit information or acquire knowledge about their lives when the prophets 'read' and 'speak' into their lives (QuayesiAmakye 2013:246), getting psychological support that helps to calm confused minds so they can embrace the future with confidence. These blessings are accessed by living a good Christian life, giving generously to the church in terms of money and time, and faithfully attending church services and group Bible studies (Frahm-Arp 2016:269).

The result is that Neo-Pentecostalism has grown because of its cultural fit into indigenous worldviews (Kalu 2008:170). African indigenous worldviews still dominate contemporary African experience, including the new middle class. In the words of Asamoah-Gyadu (2013:18), Neo-Pentecostals succeed in

22. While it is not denied that some versions of prosperity theology are theologically suspicious, many evaluations of the prosperity gospel of Neo-Pentecostal churches are made from a Western theological perspective. For instance, Grady (2013) criticises neo-prophets for their emphasis on prosperity and argues that it fuels greed, feeds pride, works against formation of Christian character, keeps people in poverty as it gets the little they have in the name of getting rich and abuses the Bible. What is needed is that the phenomenon of the health and wealth gospel in African churches should be analysed and evaluated from the perspective of African people and the values deduced from their worldview. The impact of a prosperity message on the emerging youthful population of Africa with a taste for exotic lifestyles is enormous (Quayesi-Amakye 2016:301). Wepener's (2013:91) remark is important that healing is most probably the main motivation why people go to worship in Africa. Healing is interpreted in Africa in the holistic sense that it includes the total well-being of the individual, including financial success. Anderson's (1996) observations of Neo-Pentecostals led to his remark that the neo-prophets' primary function is to be healers. 
innovatively appropriating its very experiential and versatile spirituality to serve the contextual needs of Africans in post-colonial times in an idiom that accommodates the indigenous worldview.

\section{['Prophecy' as a pastoral response to xenophobia}

It is argued that one of the most distinguishing characteristics of Neo-Pentecostal churches is its prophetism that serves as its primary pastoral response to social challenges such as xenophobia. Anderson (1996) writes:

Prophecy in Africa also often becomes an extremely effective form of pastoral therapy and counsel, mostly practised in private, a moral corrective and an indispensable facet of Christian ministry. It can become an expression of care and concern for the needy; and in countless cases, it actually brings relief. (p. 180)

The beneficial effects of prophecy in terms of xenophobia can be seen in at least four aspects. ${ }^{23}$

In the first place, prophecy serves as social critique of society's norms and values and the government's policies. Kangwa (2016:543) argues that as the church took a leading role in dismantling apartheid in South Africa, it should now help shape democracy and dismantle the uglier aspects of liberal democracy in post-apartheid South Africa. Kangwa (2016) concludes:

African Christianity must add its voice to the call for a continent in which there is less pain and suffering. The church can help to transform Africa into a fountain of life. (p. 543)

Prophecy challenges ruling governments, in some instances characterised by corruption and state plundering, pressing them to deliver meaningful development that is of benefit to citizens. During the years that Zuma was president of South Africa (2009-

23. Some arguments and conclusions of this article were used in a keynote address at a webinar of the South African Theological Seminary on 13 and 14 June 2018 that was eventually published in their journal, Conspectus ( $\mathrm{Nel} 2018$ ). 
2018), various prophets and other leaders of Neo-Pentecostal churches criticised aspects of government policy and ethical governance and nurtured civic responsibility, working for the alleviation of poverty, promoting education and advocating for peace and justice (Kgatle 2017:2).

Ejoke and Ani (2017:180) are of the opinion that the South African government needs strong support from outside authorities like the church, to assist in curbing the menace of xenophobia by staging powerful anti-xenophobic campaigns that accentuate important African values such as Ubuntu. The social norm of Ubuntu entrenched in the Xhosa saying, 'Umntu ngumntu ngabantu' [every individual becomes because of others], denotes peace and co-existence and needs to be reinforced and mainstreamed. Prophecy can and does contribute to the national discourse about xenophobia by engaging with the government and NGOs about their policies concerning migrants.

Neo-prophetism is not only word-based, but it includes acts of healing, exorcism and deliverance based on the belief in God as the great power that can overcome any power of destruction, with a pneumatological soteriology expressed in interventionist terms (Sakupapa 2016:120). ${ }^{24}$ A second beneficial effect of prophecy is that it serves the needs of migrants by accepting them in the faith community and counselling them about the future in a new country ( $\mathrm{Nel}$ 2018:27). On the one hand, it formulates a dream of the coming kingdom of heaven with healing, wholeness and holiness in its wake. On the other hand, it shows a prerogative for displaced and disenfranchised people

24. Cf. Anderson's (2016:305) remark that an African religion that does not promise deliverance from evil or promote health and prosperity is a dysfunctional religion without any future; hence, that prosperity gospel has flooded the economically poorest continent. It is directly related to the religious world of Africa that is holistic. Everything is invested with religious meaning and there is no clear-cut division between spiritual and secular. Its spirituality is pragmatic, practical and this-worldly (Anderson 2016:315). The African holistic worldview does not allow for separation between secular and religious, requiring of $\mathrm{Neo}-$ Pentecostalism to include also the political on its agenda. 
when the local church provides a place of spiritual security and personal community for migrants (Anderson 2016:312) because Christians define themselves as strangers in an alien land like Israel in Egypt and they seek the prosperity of a strange country like Israel in the Babylonian exile (Yong 2010:254).

African prophets assumed a new role in terms of challenges such as HIV and AIDS, and xenophobia. These challenges become a hermeneutical key with which Neo-Pentecostals interpret the Bible (Anderson 2001:223), operating on the assumption that God wants to meet his people's needs in a direct manner. In this sense, Neo-Pentecostal prophets have become an innovative alternative to traditional healers (Anderson 2001:224). They support migrants who consult them by providing hope and practical help by their involvement in schools, clinics and hospitals, labour unions, self-help groups and development and relief organisations (Yong 2010:248).

Thirdly, prophets care for the psychological well-being of migrants. Labys et al. (2017:698) state that refugees who are threatened by xenophobia are at risk of mental illness. It is supported by studies that explored migrants' psychological wellbeing; for example, in Johannesburg, 77 refugees were surveyed and research reported that $66 \%$ of them were in need of mental healthcare; high rates of post-traumatic stress disorder (PTSD) (69\%), anxiety (91\%) and depression (74\%) were found in clients of a centre for torture survivors; and in Durban, a high prevalence of depression (54\%), anxiety (49\%) and PTSD (25\%) symptoms were found in 335 refugees. Forced migration, low social support and socio-economic hardships (including food insecurity) were the main risk factors for poor mental health outcomes in this population group. In their own research, Labys et al. (2017:701) find that migrants have difficulties with xenophobia/racism, work, physical safety, housing exploitation and healthcare. The impact of these difficulties was seen in psychological effects such as feelings of worry, stress, fear, emotional pain, anger and an inability to cope (Labys et al. 2017:703-707). Most of their interviewees (78\%) reported that religion formed an essential 
part of migrants' lives. The church meeting was key for meeting friends, praying, feeling blessed, feeling happy and regaining hope. One participant who attended church every evening and Sunday mornings stated, 'They [Pentecostal church] give you lots of hope'. Praying (39\%) and faith were further sources of strength, joy and hope, providing reassurance that was crucial for survival. Prophets' involvement with migrants allows them to minister healing and hope in a situation that might at times be desperate ( $\mathrm{Nel}$ 2018:28).

Lastly, prophets influence personal morality of believers. They encourage believers to resist participation in populist action when large crowds are driven to irresponsible and irrational action by the madness created by mass hysteria characterising some of the township protests. According to Yong (2010:239-242), prophetic politics recognises and announces that allegiances to the state are secondary to allegiances to God and encourages Spirit-filled believers to explicitly witness in the public square, even and specifically in the South African secularist 'naked public square', characterised by the absence of religion from both the political and civic arena (Yong 2010:239-242).

\section{An evaluation of the Neo-Pentecostal pastoral response to xenophobia}

One of the primary ways Neo-Pentecostals reacts to xenophobia is through its practice of prophetism, as stated above. In this section, the phenomenon's ability to address the challenges of xenophobia is evaluated.

In analysing Neo-Pentecostal prophetism, Ngong (2010:147) argues that it promotes an African spiritualistic worldview that does not pay sufficient attention to the scientific imagination. With its emphasis on physical healing, it does not allow for the successes of medical science whilst at the same time its ascription in a wholesale manner of socio-economic and political challenges to the demonic as Neo-Pentecostal 
prophets customarily do cannot be upheld (Mana 2004:96). ${ }^{25}$ However, the remark generalises and does not take into account that many Neo-Pentecostal prophets do allow room for the contribution of medical science and the reality of sociopolitical and economic woes because of hard-core capitalism and greedy politicians. And when they are faced with the challenges of xenophobia in their communities, they address the problems forcibly.

Still there is some truth in the remark. Whilst providing in thisworldly needs of individuals, the causes of their challenges can be spiritualised to such an extent that blame is shifted onto evil spirits and contemporary human beings need not accept responsibility for their own lives, as taught, for instance, by Derek Prince and the Nigerian Emeka Nwakpa (Quayesi-Amakye 2016:301). ${ }^{26}$ It is not enough to cast out the demon of xenophobia; believers need to hear the important gospel message again and again that all people are to be treated with dignity because they have been created in the image of God. Mana (2004:97) proposes that a bridge should be erected by Neo-Pentecostals between popular expectations of deliverance and theoretical analyses of liberation and reconstruction by the church to transform hearts and minds in the building of peaceful and flourishing societies that accommodate migrants as well. What is needed is prophetic politics informed by Pentecostal spirituality and piety that

25. African Traditional Religion pacifies evil deities and ghosts with animal sacrifices, necromancy, spiritism and ritualism and some have asserted that the AICs inappropriately mix the Christian faith with ATR by serving the same agenda. The African worldview explains misfortune in terms of the influence of evil spirits, necessitating their pacification. If Neo-Pentecostalism indiscriminately intends to pacify evil spirits without an unapologetic commitment to biblical finality of authority, it would degenerate into a syncretisation with questionable beliefs and practices (Quayesi-Amakye 2016:294).

26. Frahm-Arp (2016:274) describes the emphasis Bishop Moso Sono of Grace Bible Church places on hard work, moral living, personal discipline and prayer to combat poverty and difficulties, rather than blaming evil forces. The unemployed may never give up their dreams and deflect responsibility by blaming their misfortunes on the power of Satan or witchcraft. 
engages the public sphere boldly ${ }^{27}$ and provides all kinds of counter-cultural and counter-conventional communities where the displaced experience companionship and solidarity in the form of 'family' and as a counter-history, counter-ethics and counter-ontology to that of the myth of secularism (Yong 2010:228). The result will be that Pentecostal communities function as alternative 'cities' that intentionally ignore the broader political realities and provide solidarity for those on the margins of the polis (Yong 2010:13).

Another argument is that neo-prophetism's emphasis on prosperity may disqualify it from reaching the disenfranchised and marginalised, such as most immigrants are, because of its appearance as a rich church and a rich man's church. 'Unfortunately, Christians, especially those from Pentecostal-Charismatic circles, are not very keen to confront social and political causes of poverty on the continent', writes Kangwa (2016:544). ${ }^{28}$ As Quayesi-Amakye (2013:247) explains, what should be kept in mind is that when Neo-Pentecostals concentrate on this-worldly needs of believers their prophecies most of the time provide guidance derived from the Bible, although it must be admitted that scripture might be misappropriated. As explained, thisworldly challenges then become the hermeneutical key to the interpretation of the Bible, in a historicist way where the socialhistorical background and horizon of the text are ignored and it

27. According to Yong (2010:248), a prophetic politics challenges that state to do what it is supposed to do, to uphold the law.

28. However, such a stereotyping is not true because of the diverse and changing participation of Neo-Pentecostal groups in politics. Cf. Frahm-Arp's (2016:279-280) discussion of South African megachurches that initially did not participate in politics but in the end became involved. For instance, Jacob Zuma as president of the ANC invited Ray McCauley of Rhema Bible Church to head the National Interfaith Leadership Council (NILC), and before the 2009 elections McCauley invited Zuma to Rhema to 'preach' to his congregation (Frahm-Arp 2016:267). Grace Bible Church invited political officials from different affiliations to address their congregations in the build-up to the 2014 elections. They motivated it by stating that the congregation should be informed about political choices to elect Christians into key political positions (Frahm-Arp 2016:271). 
is interpreted as though it was written exclusively for contemporary believers. It also characterises a large part of the sermons in $\mathrm{Neo}$ Pentecostal churches. The manner to address this issue is by bringing the importance of a sound theological training for all Neo-Pentecostal pastors, prophets and apostles to the attention of the movement's leaders, a difficult task because it is not organised into alliances or denominations, as is the case with classical pentecostalism.

In most cases, neo-prophets do not have any or only loose connections with church mother bodies, implying that they are not answerable to anyone and they use market techniques to ply their ministries (Zulu 2016:103). The lack of accountability and transparency is harming the Neo-Pentecostal movement and the behaviour of a few prophets is discrediting the movement as a whole. For instance, a few cases have been reported about prophets who exploited the trust of their clients by abusing and assaulting them sexually or emotionally, or requiring exorbitant payment for their healing prayers (Mwale \& Chita 2016:52-53). ${ }^{29}$ That there are excesses and abuses within the Neo-Pentecostal movement that are perpetuated by some prophets cannot be denied (cf. Kgatle 2017:3-5 for some examples). Presumably turning water into wine, ordering believers to drink petrol and paraffin to prove their faith according to Mark 16:17-18, turning water into petrol, turning a snake into chocolate, walking on thin air, 'healing' cancer, HIV and AIDS, 'raising' the dead and predicting soccer and election results are some of the excesses

29. An example can be found in the Universal Church of the Kingdom of God (UCKG). In 2000, the South African Human Rights Commission found that the church exploited the poor financially and performed rituals that amount to forms of psychological conditioning. After a legal battle, the Commission had to retract its findings (cf. Van Wyk 2014 for full details). Prophetic practices should be normalised and regulated; some of the implications discussed by Yong (2010:250-251) are that the church provides a site where Spirit-filled believers are emboldened to bear prophetic witness and learn how to live prophetically in the Spirit but also to engage the world external to the church, providing a prophetic alternative to the world's conventions of corruption, patronage and oligarchy and empowered by charitable works sensitive to larger socio-structural projects and tasks, even when it implies confrontation with the principalities and powers when necessary. 
that received wide and negative coverage in the daily Southern African press (Mwale \& Chita 2016:51; Zulu 2016:104), doing damage to the Pentecostal movement as a whole. Its most prominent leaders should be encouraged to organise the movement to such an extent that it can protect itself from swindlers and charlatans that damage its reputation with the public and governments. ${ }^{30}$

Another negative feature of Neo-Pentecostal prophetism is the emphasis on the charisma and person of the individual prophet, also in advertisements of the ministry, and the accompanying adoration and veneration of the prophet. ${ }^{31}$ The prophets' status might also lead to their enrichment and personal gain through gifts presented to them to secure their services or as gratuity for supposed services (Banda 2016:221). QuayesiAmakye (2016:303) refers to it as 'prophetic monetization' (cf. the critical work of Chitando, Gunda \& Kügler 2013).

30. A tragic example is the Ngcobo Killings of 21 February 2018 where five policemen and an off-duty soldier were shot during an attack on a police station in Ngcobo, between Mthatha and Komani (previously Queenstown) in the Eastern Cape. During the attack, 10 firearms and a police van were stolen from the police station before an ATM, a short distance from the police station, was robbed (https://www.enca.com/south-africa/five-police-dead-in-attackon-station). Their motive was presumably to access funds because of the dire financial straits of the church. The South African Council of Churches says it lodged a complaint with government over the Seven Angels Church but was ignored. The Commission for the Promotion and Protection of the Rights of Cultural, Religious, and Linguistic Communities (CRL) chairwoman Thoko Mkhwanazi-Xaluva reacted to the events at eNgcobo and said the church was probed already in 2016 and authorities were alerted to children living at the church and not attending school. The committee suggested that the government should regulate church leadership by way of registration. The co-operative governance and traditional affairs portfolio committee of Parliament responded to the committee's report by stating that the state could not prescribe when it came to beliefs and religious convictions because of the value of religious liberty ensconched in the Constitution of the Republic, but it unanimously condemned the abuse of vulnerability by religious leaders (http://www.enca. com/south-africa/parliament-slams-crl-chairs-comment-on-engcobo).

31. One of the important distinctions between the phenomenon of prophecy in the classical and Neo-Pentecostal movements is the former's emphasis on prophecy as a gift to the church by way of the participation of all believers and the latter's emphasis on the permanent office of the prophet. 
Some of the positive benefits of neo-prophetism should also be described. Neo-Pentecostal churches purposefully do not take denominational issues seriously in consideration for the post-modern sentiment of respect for people with different opinions. Doctrinal differences play only a peripheral role because as part of the Pentecostal movement the emphasis is on people meeting the truth in the person of Christ rather than in the Bible. Perhaps the Neo-Pentecostal movement may serve as a catalyst for ecumenical engagement between Christians. ${ }^{32}$

Whilst it is true that African pentecostals in the past were mostly apathetic to social concerns, they have awakened to their civic obligations (Quayesi-Amakye 2016:296). Examples of the neoprophets' concern for the underprivileged and disenfranchised are evident. Several neo-prophets' involvement in issues of social justice, their financial contribution to projects for the benefit of migrants and their relationship with African political leaders have received much publicity. ${ }^{33}$ It can be accepted that these leaders were influenced in a positive way by emphasising issues related to social justice. ${ }^{34}$ However, in general, it is true that neo-prophets

32. Also, in the wider pentecostal movement one's unique experience in encountering God is given more value than one's doctrine, allowing for a difference in opinion within the movement. Orthodoxy in the Protestant sense of the word is exchanged for meeting with the Truth, and the resultant transformation of believers' lives.

33. The most publicised case is the donation of Prophet T.B. Joshua's ministry of $\$ 20$ million to causes of education, healthcare and rehabilitation programmes for the vulnerable, including legal and illegal migrants. On 13 May 2017, the church also provided food and money for over 250 Nigerian deportees who arrived from Libya. The refugees who were deported from Libya found refuge at The Synagogue, Church of All Nations (SCOAN) (http:// dailypost.ng/2017/05/13/tb-joshua-donates-food-n7m-cash-150-nigerian-deportees-stormchurch-photos). And on 07 June 2017, the church donated money to the less privileged in the north of the country, most of which were Muslims (https://bulawayo24.com/index-idnews-sc-local-byo-111753.html). Banda (2016:221) accuses the church that its ulterior motive is self-prestige and winning the heart of the populace for personal interest, a remark that is not substantiated in any way.

34. For instance, Cyril Ramaphosa visited the Shembe Church on 02 May 2017 where he met with the leadership. In his speech before the congregation he said, 'This church has always led the way in teaching the youth the value of hard work, the importance of education and the significance of ethical conduct ...' He called the church a 'nation-building institution', 
should address more publicly structural political, economic and social issues that cause poverty, ethnic violence, xenophobia and other forms of violence that characterise Africa. ${ }^{35}$ It can be accepted that their prophetic task includes guidance in terms of xenophobia as it relates to individuals rather than interpreting their prophetic task to include consideration of social ethics and structural challenges that should also enjoy their consideration.

It cannot be denied that neo-prophetism also contributes to transformation effects on the lives of its members including migrants, as demonstrated by sociological research (cf. Massey \& Higgins 2011; Portes 2008). Social and cultural capital generated in Neo-Pentecostal churches leads to upward social mobility of individuals, families and eventually whole communities, especially by way of entrepreneurship (Portes 2008:15). ${ }^{36}$ In many cases, the beneficiaries of neo-prophetism were the disadvantaged and marginalised who were offered hope. However, there should also be a concerted effort by neo-prophets to address factors that rob from people the fullness of life, such as poor governance, poverty, unemployment, corruption, crime, HIV and AIDS and the erosion of African value systems (Kangwa 2016:545), factors that contribute to the maintenance of deep inequalities that fuel xenophobia.

and an 'African asset and national treasure' that provides practical solutions to our complex socio-economic challenges, and that is averse to wickedness, malicious gossip, public spats by leaders and disrespect of one by another (https://www.enca.com/south-africa/catch-itlive-ramaphosa-joins-congregants-in-celebrating-the-life-of-prophet-isaiah).

35. Cf. Yong's (2010:7) warning not to generalise the statement that pentecostals, including neo-prophets, hardly address political issues; he refers to several examples in diverse contexts of pentecostal engagement with the political with impacting influence on societies.

36. See, for example, His People Christian Ministries' vision to transform the world by having committed Christians in positions of leadership. To realise their goal, they present workshops, seminars, conferences and courses aimed at helping young people develop so they would have the skills needed to become leaders in their chosen careers. They teach them how to budget their money so that they would be able to tithe and meet their financial commitments, negotiation skills, time management skills, how to develop a personal brand and how to begin and manage a small business. Research in 2003-2004 showed that most members of the church described these social-skills-development courses as the most valuable part of their church life (Frahm-Arp 2016:272-273). 


\section{Conclusion}

\section{Synthesis}

Increasing numbers of legal and illegal immigrants live in South Africa, facing the possibility of xenophobic acts which portray the open hatred of African people not of South African heritage by mostly poor South Africans. At times, the South African government's discourse reveals animosity towards the displaced, strengthening homophobic sentiments amongst the public. As victims of xenophobia and violent crime, refugees in South Africa are at risk of mental illnesses such as anxiety, depression, PTSD, negative feelings and an inability to cope. In many instances, religion forms an essential part of migrants' lives.

One of the primary pastoral responses amongst NeoPentecostals to social challenges such as xenophobia is prophecy, as an effective form of pastoral therapy and counsel, mostly practised in private. It is proposed that Neo-Pentecostal prophetism should be distinguished from the phenomenon amongst pentecostals because the category of 'prophets' (along with apostles) serves amongst Neo-Pentecostals as leading religious functionaries whilst pentecostals emphasise prophecy as a temporary gift to individual believers. In the Neo-Pentecostal tradition, prophecy is also mainly concerned with a word aimed at an individual as part of a pastoral discourse whilst amongst pentecostals it functions mostly within the context of the worship service. The Neo-Pentecostal prophet operates rather in the context of the diviner in ATR, focusing on diagnosing and proposing solutions to individual existential ailments and challenges. In their manner of operating, neo-prophets link with the phenomenon of prophecy within the AICs, implying that Neo-Pentecostalism may be viewed as the 'AIC'ination' of African pentecostalism.

In evaluating prophecy as a pastoral response to xenophobia, it was noted that whilst neo-prophetism provides in this-worldly needs of individuals, the causes of their challenges are at times spiritualised to such an extent that their clients are absolved from 
accepting responsibility for their own lives. It was argued that the demon of xenophobia should not only be cast out, but believers need to learn that the gospel demands that all people, including immigrants, should be treated with dignity because they have been created in the image of God. The needs of people also serve as the hermeneutical key in a historicist way to interpret the Bible, a feature that emphasises the necessity of a sound theological training for all Neo-Pentecostal leaders.

The lack of accountability and transparency in terms of excesses and abuses of neo-prophets that is harming the NeoPentecostal movement was noted and it was proposed that prominent leaders should be encouraged to organise the movement into alliances to protect it from charlatans. The emphasis on the charisma and person of the individual prophet might lead to personal enrichment, necessitating supervision by church mother bodies that should be established.

On the positive side, for Neo-Pentecostals, doctrinal differences play only a peripheral role because of their emphasis on the experiential as a precondition for doing theology, making ecumenical engagements with other Christians possible. They are also concerned about the underprivileged and disenfranchised, in many instances funding projects that serve the needs of migrants. However, neo-prophets hardly address structural political, economic and social issues because their ministry is aimed at individuals. Neo-prophetism also contributes to transformation in the lives of its members and the beneficiaries are the disadvantaged and marginalised.

\section{Acknowledgements}

This chapter represents substantial reworking (more than 50\%) and amalgamation of two published articles:

Nel, M., 2019, 'The African background of Pentecostal theology: A critical perspective', In die Skriflig 53(4), a2418. https://doi. org/10.4102/ids.v53i4.2418 
Nel, M., 2019, 'Prophetic witness in weakness: A response to Prof Robert Vosloo from a Pentecostal perspective', In die Skriflig 53(4), a2419. https://doi.org/10.4102/ids.v53i4.2419

These two articles were published under the Creative Commons Attribution 4.0 International (CC BY 4.0) licence, according to which permission is granted for reworking. 


\section{Chapter 6}

\section{The plight of unaccompanied migrant children in South Africa: Challenges en route to a practical theology and ecclesiology of home}

Hannelie Yates

Department of Practical Theology, Faculty of Theology, North-West University, Potchefstroom, South Africa

Sinenhlanhla S. Chisale ${ }^{a, b}$

aDepartment of Practical Theology, Faculty of Theology and Religion, University of Pretoria, Pretoria, South Africa

${ }^{b}$ Department of Religious Studies, Faculty of Arts, Midlands State University, Zvishavane, Zimbabwe

How to cite: Yates, H. \& Chisale, S.S., 2020, 'The plight of unaccompanied migrant children in South Africa: Challenges en route to a practical theology and ecclesiology of home', in A.R. Brunsdon (ed.), The human dilemma of displacement: Towards a practical theology and ecclesiology of home, pp. 129-149, AOSIS, Cape Town. https://doi.org/10.4102/aosis.2020. BK198.06 


\section{Abstract}

Displacement is a living reality for many people in all stages of life. Children in critical phases of development probably wonder about where and what home is when confronted with the realities of migration. The aim of this chapter is to problematise the human crisis of displacement from the perspective of the plight of migrant children and to contribute towards the construction of a practical theology of home. The focus of this chapter is primarily on the category of unaccompanied migrant children in the context of South Africa. A brief overview of unaccompanied migrant children in South Africa in relation to legal and policy frameworks is provided as a contextual orientation. Empirical data are utilised to present the meanings a group of unaccompanied migrant children assigned to the human dilemma of displacement and to the concept of 'home'. We applied the hermeneutics of listening to identify challenges in the construction of a practical theology of home based on the lived experiences of unaccompanied migrant children.

Keywords: Displacement; Unaccompanied migrant children; South Africa; Hermeneutics of listening; Practical theology of home.

\section{Introduction}

This chapter aims to problematise the human crisis of displacement from the perspective of the plight of unaccompanied migrant children' in South Africa and to explore the challenges that the living realities of migrant children present to a practical theology of home. By practical theology, we mean a certain mode of doing theology, a kind of theology that is not restricted to only the context of academia, nor to the exclusive focus on clerical or

1. We use the term of 'unaccompanied migrant children' as defined in legal and policy frameworks and 'unaccompanied refugee minors' interchangeably. The empirical data gathered refer to children mainly as unaccompanied refugee minors because the majority of the children who participated in the study were from Zimbabwe. 
congregational tasks without taking the wider contemporary culture into account. We choose deliberately for the inclusion of the religious and spiritual practices and theological reflection processes of ordinary people within faith communities and civil societal spaces in our understanding of the study field and methodology of practical theology. With this understanding of practical theology, we place ourselves within the paradigm of public practical theology, ${ }^{2}$ which seeks to respond theologically to issues of public concern. Migration is a living reality for many people globally and locally, both for the people on the move and for citizens who find it hard to survive on the limited resources and services available. It is an issue of public concern that requires a theological response.

In the spirit of public practical theology, this chapter views the context of unaccompanied migrant children in South Africa as central to the discussion. There is great value in a proper understanding of the complexity of the migration reality as experienced by children themselves. We attempt to imagine a transformed society where all people, also unaccompanied migrant children, can experience a sense of belonging and a feeling of being at home by theologising from the bottom up, in other words by facilitating a dialogue between the lived experiences of unaccompanied migrant children and the resources of the Christian faith.

The chapter proceeds, firstly, to provide a contextual and methodological orientation. Secondly, we present the lived experiences of unaccompanied migrant minors in South Africa. On the basis of the lived experiences of migrant children, challenges related to finding home and being at home are highlighted, all the whilst considering the implications for the

2. Dreyer (2004:919) emphasised the importance of public theology - 14 years ago - when she defined public theology as the practice of reflecting critically on both the Christian tradition and social and political issues. She argued that practical theology no longer singularly focuses on church praxis and the clergy because the field has expanded to include local, national and global everyday life (Dreyer 2004:919-920). 
construction of a practical theology of home. Finally, we present our concluding remarks.

\section{- Unaccompanied migrant children in South Africa}

Unaccompanied migrant children ${ }^{3}$ refer to displaced ${ }^{4}$ children (United Nations 2005):

[U]nder the age of 18 who have been separated from both parents or legal caregivers and are not being cared for by an adult who, by law or custom, is responsible for him or her. (n.p.)

Since democracy, South Africa has a constitutional obligation to adhere to international, regional and national legislative and policy frameworks in governing the provision of human rights for all people in South Africa. There are a number of international and regional instruments that South Africa has signed and ratified and these instruments provide guidance with regard to South Africa's response to unaccompanied migrant children. The international legal framework is primarily based on two international treaties - the United Nations Convention on the Rights of the Child (1989) (UNCRC) and the African Charter on the Rights and Welfare of the Child (Organization of African Unity 1990) (ACRWC), whereas the domestic legal framework is guided by the Refugees Act 130 of 1998 and the Children's Act 38 of 2005 (Sloth-Nielsen \& Ackerman 2016:7-12).

Different terms are used to identify unaccompanied children in migration, and these include but are not limited to the following: unaccompanied migrant children and unaccompanied refugee children or minors. This depends largely on the immigration policy of the country. The South African immigration policy does

3. The term 'unaccompanied child' or 'illegal foreign child' is to be found in different policies, for example, the Immigration Act 13 of 2002; the Refugee Act 130 of 1998 and the Prevention and Combating of Trafficking in Persons Act 7 of 2013.

4. 'A displaced person is someone who has been forcibly uprooted and displaced within their own country' (UNHCR 2015 n.p.). 
not refer to unaccompanied children from other countries as 'unaccompanied refugee minors', but rather 'unaccompanied child migrants' or 'unaccompanied foreign migrant children' (The Immigration Act 13 of 2002; The Refugee Act 130 of 1998; The Prevention and Combating of Trafficking in Persons Act 7 of 2013) so that the state is able to send them back to their countries without the country being bound to legal implications. The Department of Home Affairs' Passport Control Instruction No. 1 of 2004 refers to unaccompanied children from other countries as 'unaccompanied minor illegal foreigners'; the Department of Social Development refers to them as 'unaccompanied foreign migrant children' or 'unaccompanied children on the move in South Africa'; the South African Schools Act 84 of 1996 refers to 'unaccompanied foreign children' and the South African Children's Act 38 of 2005 to 'unaccompanied foreign migrant children'. All the legal entities have carefully selected the term used to refer to minors or children who migrate to South Africa from other countries. 'Refugee' is avoided at all costs. In this chapter, we use unaccompanied refugee minors (URMs) to emphasise the urgency of treating their cases.

Whilst South Africa is a destination of choice for migrants from across the globe, particularly from Africa, this chapter focuses on URMs from Zimbabwe because they are the most visible amongst URMs from other countries. The majority of unaccompanied migrant children are pushed into South Africa by desperate poverty (Skelton 2010:5). They are in South Africa to 'earn a living'. Several scholars confirm that migrant children from countries without war migrate to neighbouring African countries to 'earn a living' and to support siblings (Bourdillon 2009:295; Mahati 2011:76). Unaccompanied refugee minors from Zimbabwe became more frequent in South Africa between 2007 and 2009 when Zimbabwe's economy collapsed completely. Citizens of Zimbabwe struggled to earn enough money to feed and educate their children, and this became the dominant push factor for URMs to migrate into South Africa (Chisale 2014:168). Research on migration indicates that URMs from Zimbabwe in South Africa are 
economic migrants in search of a living (Mahati 2011) rather than political refugees. Although URMs from Zimbabwe are economic migrants, their vulnerability as children makes them refugees.

South Africa is also home to migrant children who are seeking asylum from political persecution. Such children are pushed into South Africa by political instability in their home countries (Mbabaali 2012). It seems as if such migrant children are few in South Africa because they stay in refugee camps, mostly in the countries neighbouring their country of origin. They cross the Southern African borders to seek refuge in South Africa mostly when they are over the age of a minor. Research confirms this reality by highlighting that most refugee children from war zones migrate to European countries or America through humanitarian agents, and some illegally cross the sea (Save the Children 2007). However, in all these cases, displacement causes a crisis for children as they face daily survival challenges and an uncertain future. Limited by a lack of protection, care, discrimination by the social welfare system of the country and repeated struggles to find access to basic necessities like food, shelter, education, healthcare and employment, are some of the numerous challenges children encounter (Staunton, Mclvor \& Bjornestad 2008:xi).

Furthermore, in South Africa, some children become unaccompanied and stateless because they are born from parents who are illegal in the country. Sections 34(1) and 41 of the Immigration Act, 13 of 2002, give an immigration officer the power to take a person into custody if the officer is not reasonably convinced that the person has the legal right to be in the Republic. Detention is meant to give immigration officials the opportunity to verify the person's identity and immigration status. It may not exceed 48 h. However, in terms of Section 34(1), an illegal foreigner can be arrested and detained for as long as 30 days without a warrant if the goal is to deport the person. This period can be extended for up to another 90 days (Republic of South African Immigration Act 13 of 2002, Government Gazette). Some 
unaccompanied migrant children have lost parents because of the deportations and detentions that separate parents and children.

\section{Methodology}

This chapter draws from empirical data that one of the authors collected from 2011 to 2014 for the purposes of her doctoral studies. Twenty URMs between the ages 14-18 years under the guardianship of the then Bishop Paul Verryn participated in the study. Participants in the broader study included URMs, Paul Verryn, caregivers and the clergy around Johannesburg metropolitan. ${ }^{5}$ This chapter uses data from the URMs that were not used in the doctoral study. The URMs were from different religious affiliations: the majority belonged to different Christian denominations, some were Islam and some did not adhere to any religion (Chisale 2014:167). Data from URMs were captured using semi-structured in-depth interviews, narrative (story telling) essays, participant observations, and art or drawings. Interviews were conducted in the mother tongues of the participants (both Zimbabwean Ndebele and Shona) and translated into English by one of the authors who is fluent in both languages. Pseudonyms are used for all URM participants to protect their anonymity.

The theological focus of this chapter is the construction of a practical theology of home. The question that guided our engagement with the human crisis of displacement from a theological perspective was: What constitutes home for unaccompanied children in search of a home away from their physical home? A further question that arose was: What challenges

5. We appreciate the role the then bishop Paul Verryn played during the research period and also in the year 2010. He provided shelter to a group of more or less 56 unaccompanied refugee boys and girls, the majority of whom were Zimbabwean, at a building owned by the Methodist Church. However, we acknowledge that although much can be learned from the example of Paul Verryn, the system created under his leadership was not without problems and challenges. 
do their conceptualisation of their living reality and their idea of what home is posed to the construction of a practical theology of home? How can the good news of the gospel give meaning to the daily lives of unaccompanied migrant children? Put differently, what kind of Christian spirituality is needed to respond to unaccompanied migrant children and their crisis of displacement?

The 'hermeneutics of listening to children', as conceptualised by Swart and Yates (2012), is critical in our public practical theological approach to the existential reality of unaccompanied migrant children:

$[L]$ istening to children in the process of practical theological interpretation offers newly found opportunities for Christian theology and the church to contribute to the well-being of children as a local, national, continental and global public concern. Listening to children's voices does not only address questions about social justice, the participation rights of children and children's position as active agents in society; the act of listening to children is also about the survival and development of children, caring for them and protecting them from living conditions that dehumanise them - a way of promoting the human dignity of children as the image of God in each human being ... it is also about communicating and being in relationships with children in order to realise supportive and companionable interactions in adult-child spaces. (p. 1)

The hermeneutics of listening, we argue, may be a first step a practical theologian could use to avoid the dangers of theorising about and colonising unaccompanied migrant children or refugees who are deemed not able to speak for themselves. In this case, we attempt to see and understand the process of constructing a practical theology of home through migrant children's eyes and voices. However, we are aware of the ethical considerations and power dynamics between adult researchers and children as co-researchers. One of the co-authors neutralised the power dynamics as she shared the social and immigration status with the migrant children, and they related to her as one of them. Furthermore, we consider our different ethnic backgrounds and our diverse subjective identification with migration as valuable in responding to the question of displacement from an insider-outsider perspective. 


\section{- Lived experiences of unaccompanied migrant children ${ }^{6}$}

The majority of migrant children in South Africa, both unaccompanied and accompanied, live in shelters. However, research indicates that they run away from shelters for different reasons and sometimes opt for the streets of big economic hubs such as Johannesburg, Pretoria and Cape Town (Chisale 2014). They are also visible in the border towns and have limited to no access to proper accommodation and nutrition (Skelton 2010). Migrant and refugee children who stayed in the Central Methodist Church in Johannesburg and the Soweto Methodist Community Centre under the guidance of the then Bishop Paul Verryn were asked the reasons for coming to the Methodist Church. Based on the narratives of URMs, we could deduce the daily life challenges, felt needs and expectations of children in relation to the concept of home.

\section{Home as a safe place and a space of care, love and respect}

Kinky, a 16-year-old girl, explained her reasons for coming to the Methodist Church:

'When I arrived in Johannesburg, I was sent to a children's shelter to stay there with other children, but when I went there I met other unaccompanied refugee minors (URMs) like myself and South African children. Us URMs were discriminated against by social workers and other workers, cleaners and kitchen staff in children's homes who never stopped reminding us that we do not have rights equal to South African children, so we must stop complaining. South African children were always given first preference in food, bedding and everything. We were treated like orphans. So most of us when we heard about the Bishop that he is taking care of migrant children in his church we ran away and came to the church, because we wanted a home where there is peace, security and respect'. (In-depth interview, 17 June 2014)

6. Some of the verbatim presented in this chapter was presented in a doctoral thesis, by one of the authors (Chisale 2012). 
Flower, a 17-year-old girl, confirms Kinky's narrative on the struggles and basic longings of URMs when she shared (Chisale 2014):

'With all the pains I went through when I stayed with a stranger in a Johannesburg flat, I just needed a better home where I will experience peace, love and someone to care for me, and I found that in the church with the Bishop. In the church there were evil people who had their hidden agendas, but we were protected when the Bishop moved us to Soweto where there are caregivers. In this community we are at home, we experience the love of God as children, our caregivers treat us like their own children they love and respect our needs, there is no police or home affairs to arrest us'. (In-depth interview, 24 June 2012; pp. 177-178)

Many male migrant children started their life in Johannesburg in the dangerous streets of the city and experienced violence and pain, motivating them to move into the church building. This emerges from Rambo, a 17-year-old boy, who said:

'Life in the streets of South Africa is not nice, you face violence from all angles. One is forced to always dodge the police and home affairs personnel, who harass people in the streets of Johannesburg by asking for IDs or passports. So, I came to church to seek for protection, care, respect and counselling. Otherwise in the streets I would have become a criminal trying to defend myself from the evils of street life. The Bishop saved us by welcoming us to live in his church, we are no longer harassed by police because the Bishop protects us'. (In-depth interview, 14 July 2012)

Stix, a 16-year-old boy, explained how he suffered in Johannesburg's streets because he did not have shelter (Chisale 2014):

'When I heard the name church, I knew that it is where I will find the love and mercy of God. I had experienced suffering at home in Zimbabwe and on the way and in the streets of Johannesburg. I just needed someone who will look at me with sympathy and provide shelter for me until I can stand up for myself and have my own accommodation. One day I was chatting with a security guard discussing the evil life of living on the streets, he then told me that church is offering security and shelter to migrants and refugees, in my mind I saw God's grace there protecting me. The first day I went 
to church I saw some refugees going to the alter to pray I did the same, the church is not a building but it is God's presence in what we do. Now the church was going to be my shelter...because of God's grace I survived and found a reason to live...now I go to school, I have a home and I expect to have a degree in Engineering'. (In-depth interview, 14 July 2012; p. 177)

Valentine, Sporton and Nielsen's (2009) research findings on displaced children's subjective understanding of space and place present themes such as fear, risk, trust and belonging. These findings resonate with URMs who narrated experiences of xenophobia and crime that caused them fear. These experiences cause a lack of trust and uncertainty in URMs. This then seems to have invoked the spiritual dimension of space. Practical theologians like Louw (2017) have addressed the spiritual dimension of space by referring to space and place in connection to a philosophy of belonging and a spirituality of habitus.

\section{Home as relational and communal}

Some of URMs highlighted that their reason for going to the church were to reunite with their families who they thought could be staying at the church. They also wanted to be at a place where there are people who share their experiences. Themes such as family, friends, brothers and sisters emerged.

According to Dombo, a 17-year-old boy, a home is a familial space:

'As for now I feel like I am at home in this church with brothers and sisters who have become my friends and family, we do have problems here and there but I feel like I am at home in this church and the Bishop is a true father different from my mean father back at home, I am at home away from home and this is a better home than my home in Zimbabwe. We share common experiences and understand each other's pains'. (In-depth interview, 07 July 2012)

Musoja's, a 15-year-old boy, said his reason for coming to church was to be with other Zimbabweans. For him this was an antidote to xenophobia: 
'I cannot speak any South African language, so it was difficult for me to hide from the police that I am from Zimbabwe. In the streets; vendors, police and other children always tormented us foreigners, they kept on saying we must go back home. So I came to church to be in a Zimbabwean community. It made me feel safe and at home. The bishop made sure that all children felt at home in this community, because he treated us like his family. Since I came here I no longer have a headache of hiding from police'. (In-depth interview, 07 July 2012)

Shasha, a 17-year-old boy, said for him there is no place to call home in Zimbabwe because of his struggles and abuses:

'When I left Zimbabwe, I wanted to find a place I can call home, I did not have a home in Zimbabwe, although it is where my umbilical code is buried. The people who were supposed to care for me threw me away. I don't have a home, I have a home here with the bishop. He and the other children living here are my family. His love and care is warm and enough for me, he took the responsibility of our parents'. (In-depth interview, 17 June 2012)

Girls' reasons for coming to church were mainly for shelter and security. Unlike boys, they thought of this shelter as temporary in hopes that they will one day go back to their home in Zimbabwe where there is the biological and extended family. Missy, a 16-yearold girl, shared:

'I came to Johannesburg to work for my family, but I did not have papers, finding work or shelter is difficult without papers. So, I heard that the church; provides shelter to refugees. I then came to get security and shelter. I have made a family in this church. When I go back home, I will miss this family, the Bishop is very kind to all of us, he has made a warm home for us in this place where we experience love and security'. (In-depth interview, 24 June 2012)

In the response of Gloss, a 16-year-old girl, the yearning to visit home or to go back permanently one day, is evident:

'I have suffered along the way and in Johannesburg, I found security when I came to the church. I miss home, but this is my home for now. I'm getting education, love and respect here. The day I will find a job I will visit home in Zimbabwe and provide for my siblings. We are protected and taught good Christian values in this community by the bishop and caregivers. When I go back home, I will be a responsible person and will be able to teach my siblings the good Christian 
values, so that our home will be full of love, peace and security'. (In-depth interview, 07 July 2012)

Dimples, a 15-year-old girl, also confirmed her desire to go back home:

'A security guard brought me to the church and said I will be safe here and church is better shelter than the streets. I made friends and family, everyone was concerned about my security. The bishop loves us like his own biological children, he wants the best for us. When I grow up and get a degree I will go back home in Zimbabwe and I will tell them about the love of the Bishop ...'. (In-depth interview, 14 July 2012)

A clear theme that emerges from the responses of the URMs is that of relationships, family and community. It seems that URMs were drawn to the church in search of a place to call home - a home that is relational and communal. They go back and forth in their understanding of home by comparing this home that they found in South Africa with their home in their countries of origin (Zimbabwe). Louw (2017) argues that home is a familial space of togetherness:

Ekhaya as familial homecoming is embedded in cultural structures that communicate a safe space and friendly environment. It has to do with values, education and language because it touches the very fibre of our being human. (p. 4)

Cultural understandings of home are also evident in the responses of URMs. Home is where one's umbilical cord (Inkaba in Ndebele and other Nguni languages) is buried, according to Shasha. However, if he finds a better home than his family home where his umbilical cord is buried, he will prefer that better home and abandon his familial home where Inkaba is buried. Africans regard the Inkaba as spiritually important.

The burial of the Inkaba in some African families takes place a few weeks after the birth of a child, once the Inkaba has dried and fallen off the newly born baby. During the ritual of burying the Inkaba, the placenta and some of the hair that the child was born with are buried in order to introduce the newborn baby to its ancestral home. The Inkaba symbolises a person's ancestral 
home and also the connection between the individual and his or her clan, the land and the spiritual world. It is believed that the burial place of the Inkaba is where the home of that person is. It is the place where all the rituals of the person should be performed including death rituals. Against this background, home is both spiritual and spatial.

\section{Challenges of finding home and 'being at home'}

This part of the chapter discusses challenges to the construction of a practical theology of home based on the lived experiences of URMs. In South Africa, one of the challenges migrant children face is the xenophobia incited by security agents such as police and home affairs officials. South African citizens blame foreigners for the problems the country face, such as unemployment, crime and limited resources and services for basic survival. Another challenge migrant children face is the absence of the nuclear and extended family to protect, nurture and guide them in finding a home and being at home in South Africa. The absence of the extended family causes cultural and spiritual dilemmas for children who have to face confusion about which cultural and spiritual dynamics to embrace and where to compromise without facing severe consequences or dilemmas.

\section{Xenophobia}

The children revealed that differences in language exposed them as foreigners and often triggered xenophobic behaviour towards them. Unaccompanied refugee minors expressed that it was hard to find a home outside the protection they found in the church with Bishop Verryn. Unaccompanied refugee minors lamented that they often played hide and seek with state security agents because they were afraid that they will be harassed, arrested and deported back to Zimbabwe. Even in the state-regulated child and youth care centres, children felt unwelcome. They 
experienced discrimination by social workers and other workers, for example, cleaners and kitchen staff. They would constantly be reminded that they are not South African, and do not have the rights of the local children and therefore have no basis on which to complain about anything. Xenophobia is triggered by their homelessness and in turn creates in them feelings of homelessness. Wherever an unaccompanied migrant child does not feel welcome, that child experiences xenophobia and rejection.

\section{$\square$ From a culture of xenophobia to a culture of welcoming}

Xenophobia is perpetuated by the divide that exists between foreign and native. It is based on exclusion and inclusion, outsider and insider, discrimination and appreciation. A public practical theology embraces a culture of welcoming, motivated by an image of God that can identify with the human crisis of displacement. The child Jesus was forced to be a migrant. Jesus and his family experienced challenges with finding a home because of the persecutions Herod started in pursuit of the child Jesus (Mt 2:3-18). As such, Jesus became a refugee child when he was a minor. Migration was the only way to protect Jesus from the wrath of Herod, who wanted to kill him because he was perceived to be a threat to Herod's throne. This highlights the abuse of power and authority within a particular space. The ownership of spatiality (space and things) and spatial contestations raise ownership challenges such as 'my space, my country, my land'. A new person in a space is considered a threat and the occupants then make it hard for him or her to find a home. This is mirrored in the actions of those URMs who ran away from children's homes and shelters because they were told that services rendered there were not for them, but for South African children. They were treated as second-class citizens.

Working towards a culture of welcoming and belonging in the midst of experiences of xenophobia means that churches that are focused inwardly - exclusively on its existing membership - 
should be transformed into welcoming churches. An embodied spirituality of hospitality is needed for a culture of welcoming in emulation of Jesus.

\section{Absence of the extended family}

Unaccompanied migrant children face the challenge of an absent nuclear and extended family. In Africa, the extended family is significant in children's care and development. It is essential in guiding and providing children with a solid grounding within the web of life. The extended family provides children with a sense of belonging, security and identity. In the absence of this structure, there is lack of guidance that causes the 'spiritual reality triangle' (balance of relationships between God, ancestors, self and the rest of creation) to be fragmented. It causes a human crisis of relational disengagement and confusion.

In Africa, guiding a child is central to that child's well-being in the present and future. It entails taking a parental role in directing him or her on the journey of life in accordance with the accepted values and norms. Guiding liberates a child because it does not impose but rather facilitate finding purpose and meaning in life. Lartey (2003:65) explains the principle of guiding as '[e]nabling people through faith and love, to draw out that which lies within them. This is not to deny the sharing of information and offering of ideas and views .... A lack of guidance exposes a child to various risks and crises. It forces them to continuously search for home. There are times where they fall into the wrong hands, as one of the male URMs, explained when he said that he went to the church building to seek protection, care, respect and counselling because he was afraid that on the streets, alone and without adult guidance, he would have fallen into criminal activities in an attempt to defend himself from the evils of street life.

Chisale (2014:141) argues that the guidance parents, the extended family and the community provide is significant for children's well-being. She argues that for a child to be liberated 
from neglect, cruelty and exploitation, there should be guidance from a caring family with the child's best interest at heart. Where there is a concerned and caring family, children experience purpose and meaning as they have a home and are at home. In the crisis of displacement, unaccompanied migrant children are isolated from a concerned and caring extended family. This situation may lead to tension and conflict between continuity and discontinuity in finding home and feeling at home. This is because there is a future to look forward to and a history that remains part of them in their journey as African children.

\section{$\square$ From living in isolation to a community of love and companionship}

The challenge of living as unaccompanied migrant children in the absence of the biological extended family means that a practical theology and ecclesiology of home should advocate for the recovery of a supporting and caring community. It should offer a caring community that takes on the communal role and responsibility in a child's growth and development. The focus on a community of love, care and companionship resonates with the theological anthropological understanding of being created in the image of God. Our relational God created human beings not only to be in relationship with God but also in relationship with others. When children live in isolation, they cannot enjoy true humanity and in its fullness. This also resonates with the sacrament of child baptism where the emphasis is on the covenant God who takes the initiative to relate to his children and to bring them into a relationship with a family of believers. The parents and godparents, including the church as the body of Christ, are assigned to be responsible for the child's spiritual, social and physical well-being. The sacrament of baptism can serve as a meaningful ritual for unaccompanied migrant children, affirming their position and status as a beloved child of a loving God. They not only belong to God, as loving Parent, but also to the family of believers. They become part of a family who has the God-given 
task to guide and nurture a hopeful living in the search of finding home and being at home in the midst of displacement.

A practical theology and ecclesiology of home thus value communality and relationality because God is a covenant God who takes the initiative of being in a relationship with his children. Our view and understanding of God thus determine our view on the status and place of unaccompanied migrant children. All human beings are created in the image of a covenant God and are designed to live in relation with others. According to the Christian life and world view, people who do not live in connection with God and other people cannot experience a life of abundance where there is purpose and meaning in life.

This implies that individual members of faith communities should express and embody Christian values like honesty, integrity, recognition, love, respect, appreciation and friendship. When children are on the receiving end of these values in a community where they can experience a sense of belonging, it is easier for them to internalise these values. In this way, children are enabled to take up their roles and responsibilities to ensure reciprocity - a mutual give and take in their relationships with others.

\section{Cultural-spiritual dynamics}

Cultural-spiritual dynamics are significant in finding a home. The dual homes that are common amongst Africans, with a traditional, cultural or spiritual home and an urban western home, seem to be present in URMs' narratives too. They highlighted the significance of a native home with spiritual connections to which they will one day return (homecoming). The urban home with its individualist western connotations is a home that they found in the urban space of the receiving country (South Africa) before they went to the church building to find shelter. It seems from the narratives of URM that migration did not completely separate them from their rural traditional world views. Magezi (2018:2) confirms this, as he argues that the movement from the rural to the urban space does not disconnect people from their 
traditional beliefs. However, migration may cause inner conflict about what to preserve from the country of origin and what to embrace in the new destination, particularly for children without adult guidance.

The urban space in Zimbabwe is not as complex as the receiving urban space in South Africa (Johannesburg) where there are different cultures as migrants who come from different religious spaces mingle. The diversity of cultures and religion in the receiving destination may confuse an unaccompanied child with regard to cultural and spiritual security and stability. This resonates with Magezi's (2018:7) argument that people are in between rural and urban lifestyles as they 'desire to embrace urban life fully but at the same time wanting to retain something of their traditional values, norms and practices'. Unaccompanied refugee minors raised the issue of the Inkaba buried at their original homes as something that caused tension for them in their efforts to find a home and be at home in a foreign country. The idea of having multiple homes leaves them conflicted because that would mean that a person is spiritually disconnected from ancestral land or home. This is worse for children, particularly in the absence of extended family who can guide and connect them to ancestral roots. This is a crisis for children who does not have a good understanding of their own cultural and spiritual world views yet.

\section{$\square$ From a fragmented cultural-spiritual life to a contextualised holistic cultural-spiritual life}

The challenge of unaccompanied children who may experience a disconnection from their cultural and spiritual worldviews has the implication that a practical theology and ecclesiology of home should embrace the cultural-spiritual realities of people to facilitate holistic cultural and spiritual well-being.

A contextualised holistic life acknowledges that all people are embodied cultural beings. Jesus himself entered human life as a cultural being. He lived his life as a Jew and respected the spiritual 
significance of being a child born amongst the Jews. Thus, the Inkaba, as highlighted by URMs, is a strong symbol of their culture and spiritual identity. It links closely with their understanding of their permanent ancestral home. McCarthy and Marks (2010:592) offer a framework for improving URMs' well-being in their destination country. One of the aspects included in this framework is to reconnect URMs with their home and their families. This plays an important role in their happiness and well-being. The idea of the framework was to create a space where URMs will feel closer to home, in the midst of absent parents and guardians. In designing a practical theology and ecclesiology of home, attention should be given to how children can own the Christian message in their own language and with their own cultural symbols and expressions, enabling them to respond to the Christian message by becoming the good news themselves in the midst of the human crisis of displacement.

\section{Conclusion}

It seems from the voices of unaccompanied migrant children that for displaced children home and security intersect. In the vernacular languages of participants, home is Ekhaya in Ndebele and Kumusha in Shona. The majority of the migrant children referred to the Central Methodist Church in Johannesburg and Methodist Community Centre in Soweto as a shelter and home. This indicates that for children, home is where there is security, love, peace and comfort. Two boys even referred to the church as a better home than their homes in Zimbabwe and the then Bishop Verryn as a true father compared to their biological fathers at home.

A public practical theology has at its core the social transformation of civil society so that all people may experience a humane life. We attempted to contribute to the construction of a contextual practical theology by highlighting the challenges that unaccompanied migrant children's voices revealed to us. As a response to the challenges, we suggested shifts that should occur in civil society through the faithful witness of Christians. 
These are shifts in culture that is needed in civil society to work actively towards a home - a humane society for all.

Christians, when driven by the humanity and deep love of Jesus Christ for all people, can embody a spirituality that can transform dehumanising spaces in society into homes where all are welcomed in love and friendship as whole and integrated human beings. Listening to the voices of unaccompanied migrant children whilst keeping our mutual status as pilgrims in mind, can help us understand how to journey with all displaced people towards finding home and be at home in the midst of migration. 



\section{Chapter 7}

\section{A life beyond iron bars: Creating a space of dignity and hope for the displaced father in prison}

Fazel E. Freeks

Department of Practical Theology, Faculty of Theology, North-West University, Potchefstroom, South Africa

\section{Abstract}

Migration trends and the global increase in the number of displaced refugee fathers have raised urgent and serious concerns, such as the air of hopelessness amongst foreigners, the disruption of family lives because of the absence of fathers and problematic fatherhood. Migration trends are foregrounding issues such as national identity and civil connectivity, and the

How to cite: Freeks, F.E., 2020, 'A life beyond iron bars: Creating a space of dignity and hope for the displaced father in prison', in A.R. Brunsdon (ed.), The human dilemma of displacement: Towards a practical theology and ecclesiology of home, pp. 151-170, AOSIS, Cape Town. https://doi.org/10.4102/aosis.2020.BK198.07 
refugee crisis has given rise to xenophobia. This chapter examines resilience in the face of problems such as displacement, refugee status, the absence of fathers, and the effects and after-effects of prison life, as many displaced fathers unfortunately walk down this path. Displaced fathers who have served prison terms have been traumatised by prison life, and this remained even after they had obtained parole or are released to go back to their homes and communities. The prison bars are not easy to forget and the adaptation to freedom and the idea of a new life are not always easy. Inmates often echo very similar cries: '/ am longing for my wife and children'; 'Guilt feelings over the things I did are tearing me up here in prison'; 'I am heartbroken and lost because I miss my family'; 'I am neglecting my role as a father and God is punishing me'. Such are the desperate cries of fathers who have been displaced and who have lost their opportunity to be fathers. This study includes the use of the fatherhood training and equipping programme to guide, train and equip displaced fathers with skills and knowledge about their role. They receive help to process the pain and suffering brought about by separation and to become responsible fathers. When an effort is made to restore dignity and build resilience, displaced fathers could be reunited with their homes and the society.

Keywords: Prison; Space; Dignity; Resilience; Displaced; Refugee; Father absence; Fatherhood.

\section{Rationale}

The website of Correctional Services reported in 2011 that South Africa has 159265 prison inmates, of whom 110905 are sentenced offenders and 48360 are awaiting trial. These numbers include a large proportion of illegal immigrants (Anon 2011). In 2013, the World Prison Brief reported that South Africa has the largest correctional population in Africa, and the 9th largest in the world (Anon 2013). Further, Makou, Skosana and Hopkins (2017) noted 
in a yearly report that South Africa had 236 operational prisons that had catered for both South African citizens and foreigners at the end of March 2016. However, these estimates and statistics do not differ much from those for the rest of the world. Darrah (2017), for example, indicates in a report released in 2017 that in the United States of America (USA), 92\% of the foreigners in federal correctional facilities are illegal immigrants. A very recent report has confirmed this by indicating that approximately 12.1 million immigrants have been living illegally in the USA since January 2014 (cf. Robertson 2018:1). The crisis of illegal immigration is a great concern worldwide, not to mention those in correctional facilities. It is therefore crucial to look at the situation found in South African prisons in respect of illegal immigrants. A 2011 report states that most foreign prisoners hailed from Zimbabwe and Mozambique, with 3931 foreigners in prison awaiting trial (Anon 2011). Of this total, 1887 were Zimbabweans and 916 from Mozambique. Further, 605 sentenced offenders originated from Lesotho, 100 came from Swaziland, 11 from Namibia and 10 from Botswana (Anon 2011). The report also mentioned that 426 Nigerians were behind bars: 184 were sentenced offenders and 242 offenders were in the awaiting-trial category (Anon 2011). In 2013, Minister Sibusiso Ndebele from correctional services mentioned that $30 \%$ of prisoners are awaiting trial, and most of them are young black men (Anon 2013). Furthermore, 53000 inmates were youths as young as 17 years old and guilty of shocking crimes because they dropped out of school, leaving them homeless and illiterate. Sibusiso also indicated that although 23000 prisoners are released each year, 25000 other inmates are signed into the correctional services system, a serious financial burden on the Department of Correctional Services. It costs them approximately $\mathrm{R} 8000$ per month to keep an inmate in prison (Anon 2013). The report also indicated that 64959 offenders were at that time not incarcerated. Of these, 48323 were released or were on parole, 14917 had been on interim acquittal and another 1719 were on a waiting trial (Anon 2013). 


\section{Introduction}

This chapter deals with fathers who are in prison and as a result experience great trauma. Most of the fathers in prison are South African citizens, with a small number of illegal immigrants who have been displaced and now find themselves in South African prisons for various crimes. The chapter is not restricted to only one group in prison, because immigrants and South African citizens co-serve punishment for their crimes. Although the fatherhood training and equipping programme provides and caters for all groups of men (South African citizens and immigrants), the focus of this chapter is on the displaced father in prison. Furthermore, the chapter investigates and reports on migrant crisis and its challenges, because illegal immigration remains a troubling issue in the world. Fathers who are in prison have very little contact with their family, especially their children. Therefore, imprisonment exacerbates the dilemma of father's absence in any community and society.

Absent fathers is not a dilemma unique to South Africa, but it is one of the major challenges faced by South Africa. Lack of a father's love, protection and provision leads to father hunger (cf. McGee 1993:19). A current major issue is dysfunctional family life, and fatherlessness and absence of father contribute greatly towards this issue (Freeks 2018a:168). Although research confirms that fatherhood is fundamental, families worldwide still suffer immensely because of father absence and fatherlessness. Today, fatherlessness, father absence and the fatherhood disease have become worldwide tendencies and phenomena (Carstens 2014:129; Freeks 2013:3-9, 2016a:3-9, 2017c:90, 2018:129; Stringer 2009:16-17). It is evident that many people around the world recognise the current crisis in manhood and are trying desperately to correct this basic societal flaw (cf. Cole 1992:1). Yet fathers are becoming ever more absent from the lives of their children, and this tendency has created a father hunger in most of our children today (cf. Richter et al. 2012; Freeks 2011b:1-4; McGee 1993:15-19; Perrin et al. 2009). 
According to Carstens (2014:9), fatherlessness is one of the biggest problems in the world (cf. also Richter et al. 2012; Freeks \& Lotter 2009:520-524). Statistically, families and society at large cannot escape the insufferable truth that there is a fatherhood disease in the world. This epidemic of fatherlessness is defining a lost generation of children (The Herald 2002:18). As the situation on fatherhood seems to be acute globally, it is crucial to examine the current fatherhood problem in South Africa.

The society in South Africa has drifted away from recognising the essence of fatherhood (Freeks 2017c:90; Ratele, Shefer \& Clowes 2012). As a result, communities in South Africa are experiencing severe challenges of father absenteeism (Bartlett 2013:1-3; Del Russo 2009; Dobbs 2013:2; Freeks 2017c:90, 2018:170-171). It is proven that South Africa is swiftly moving towards a fatherless society, which has led to a drastic decline in fatherhood because men behave like monsters towards children and women (cf. Feni 2016:2). Further, it is evident that father absenteeism in the South African context is accumulating. This tendency has created issues such as aggressive behaviour amongst children, broken families as well as poverty, financial and social ills (cf. Freeks 2016a:2). Father absenteeism in South Africa has increased since 2011 from 42\% to 48\% (cf. Bartlett 2013:1). The influence of fathers in families has also declined significantly since democracy in South Africa. South African society has long neglected the importance of fatherhood (Ratele et al. 2012). In 2012, South Africa was ranked as one of the countries in the world with the top percentage of father absenteeism (Freeks 2016a:6; Richter et al. 2012:2).

The fact that South Africa has the second highest rate of father absenteeism in Africa after Namibia is shocking (Richter, Chikovore \& Makusha 2010:360). One should keep in mind that South African fathers do not differ that much from fathers elsewhere, but South Africa has unique circumstances that impact and affect families immensely. For example, during the era of migrant labour system, families were disrupted because fathers had to abandon their 
immediate family to do labour in faraway cities and mines. Fathers used to return home only over the Christmas period (Frazier 2015). Another factor is that absent and abusive fathers are usually no role models of paternity. They set no examples of how to raise their children, and therefore it is not surprising that this dilemma is identified as one of the major reasons putting family life in endangerment (cf. Bertelsmann 2016). A further example is that in several cases the family is reformulated, but significantly the father does not count in this reformulation (cf. Ford et al. 2008).

The dilemma of absent fathers has led to a debate in South Africa. In 2010, the statistics of the Institute of Race Relations in South Africa indicated that $56 \%$ of parents are divorced, and $48 \%$ of these children have no fathers. Nine million children grow up without fathers (Frazier 2015). The unfortunate reality for most of the children is that $50 \%$ of the fathers in South Africa do not communicate and do not have contact with their children on a daily basis (Richter et al. 2010:361). A further negative aspect is that $63 \%$ of reported youth suicides in South Africa occur in fatherless homes (Frazier 2015). Another disturbing factor is that one-third of the country's prisoners are in the age group of 18 to 25 years, and they have children outside prison walls. Research shows that if children grow up without fathers, anti-social behaviour and poor educational outcomes are common aspects resulting in disarrayed avocation (Frazier 2015). Other factors that are directly or indirectly influenced by the presence of father include health, well-being, academic performance, self-confidence and behaviour control in boys and girls (Frazier 2015).

Another disturbing factor is the xenophobic attacks that indicate acute lack of father figures in the fragmented society (Anon 2008b:15). During the xenophobic attacks of 2008, the perpetrators were described as the 'fatherless sons of violence' (Anon 2008b:15). During these attacks, numerous people, especially men, were brutally murdered, beaten up, stabbed 
and raped, and more children were left fatherless (Hans 2008:5). The negative impact of these attacks was that millions of children and adolescents were left without parents, and South Africa during that time was described as a fatherless society (Anon 2004, 2008a:15). An urgent request was made 12 years prior to the xenophobic attacks to lessen the impact of fatherlessness, considering that millions of South African children have very less or none physical acquaintance with their fathers. The Human Sciences Research Council Fatherhood Project (2002) was an initiative to lessen the impact of fatherlessness and to encourage the development of social fathers (The Herald 2002:16).

It is important to take cognisance that fatherless households are a serious problem in the South African society and this problem cannot be ignored any longer. The problem is also complex because there are no clear paths or solutions to take on this detrimental societal problem. From a biblical point of view, this problem originated with the fall of humans into sin and it has resulted in a cycle of problems caused by fathers who are not fulfilling their roles (Freeks 2017d:181-184; Munroe 2008:9-13; also cf. Gn 3:1-24). The fall of man brought humanity out of God's purpose (Munroe 2001:66). As a result, men and women are facing identity crises pertaining to their gender, sexual orientation and even their roles in life, and men do not have any comprehension or understanding of how to be fathers (Freeks 2016c:236-237; cf. Stringer 2009:108).

Whatever questions are addressed in the political sphere, fatherless children are a greater risk as it brings with it destructive consequences such as substance abuse, mental illness, suicide, poor education and criminality (cf. Feni 2016:2). Children who grow up fatherless or have no father figure at all have an emotional challenge. Therefore, it is crucial that men should develop relationships with their children as father's bond with them emotionally, even if they are in prison (cf. Botha 2013:34). 


\section{The Potchefstroom remand detention facility (previously known as Potchefstroom correctional services)}

The establishment of prison for inmates (fathers) in Potchefstroom was not an easy task and function. The first building was built in 1847, a one-room building with walls of hay and a roof of reeds to serve as a prison. The second prison was built in 1864, but it was a half-finished rotten affair. The third prison was built between 1874 and 1876 but was damaged during the 1880-1881 battle between the English and the Afrikaners or Boers. The fourth prison was constructed in 1967, accommodating approximately 390 prisoners. These prisoners were to help build a larger prison to meet the needs of growing prison population. In 1977, the fifth prison was set up and today it serves as command offices. Later, all the prisoners were transferred to a new prison, which is also referred to as the sixth prison. The Potchefstroom correctional services, better known as Potchefstroom remand detention facility accommodate approximately 2050 prisoners, including both men and women (cf. Veltman 2018).

\section{The fatherhood training and equipping programme}

\section{An ideal and unique programme for convicted inmates (fathers)}

The fatherhood training and equipping programme (Freeks 2011a) was started in 2015 at the Potchefstroom remand detention facility, previously known as Potchefstroom correctional services. The programme is in collaboration with Families South Africa (FAMSA) and the Faculty of Theology, North-West University (NWU) as part of the faculty's community engagement programme and project. The fatherhood training and equipping programme is an ideal and unique programme. It carries the sub-title: Daddy should be present! From the fatherhood training and equipping programme flows the project: $A$ life beyond iron bars, which focuses on and 
supports inmates (fathers) who are on parole or are released from prison. The trainer and presenter of the programme monitors inmates on parole and acts as a mentor to them. The fatherhood training and equipping programme was first drafted in 2011 (cf. Freeks 2011a) and structured and compiled from own research (cf. Freeks 2004, 2011b). It was later extended, amended and adapted from other studies on fatherhood, father absenteeism, uninvolved fathers and the fundamental task of a father in a family context (cf. Freeks 2013, 2016a, 2016b, 2017a, 2017b, 2017c, 2018a, 2018b; Freeks, Greeff \& Lotter 2015; Freeks \& Lotter 2009, 2014; Freeks, Strydom \& Bartlett 2015). The fatherhood training and equipping programme has the potential to be expanded and make a positive impact on fathers to positively influence them against negative and destructive behaviour.

\section{Layout of the fatherhood training and equipping programme}

The layout of fatherhood training and equipping programme comprises a manual, a workbook and practical activities (cf. Freeks 2011a). The themes of the stated programme are as follows (Freeks 2011a):

- The concept of fathering

- Self-mage

- Character versus career

- How to overcome labelling?

- How to handle disappointments?

- The father as a developer

- Becoming fully you.

\section{Purpose of the fatherhood training and equipping programme}

The fatherhood training and equipping programme is currently offered to fathers (inmates) at the Potchefstroom remand detention facility. The purpose of the programme is to make 
fathers more involved in the lives of their families, especially their children (FAMSA 2014). Further, the programme aims to enable men to connect with each other, to feel empowered, to help identify common purposes amongst themselves and with regard to their families, and to create a space within which new possibilities could emerge for fathers. The impact fathers could have especially on the development of children is profound and could last for a lifetime. Fathers guide, guard and govern their homes (Stringer 2009:49). A father's emotional engagement with his children could lead to multiple positive outcomes. Building upon the foundation of trust, mutual respect, connection and engagement, families could once again flourish within a society.

\section{The role of Families South Africa Who and what is Families South Africa?}

The acronym FAMSA stands for Families South Africa. It is a nongovernmental or not-for-profit organisation and focuses mainly on families, children and youth of different communities. Families South Africa is better known for its specialised services with various counselling sessions; therapeutic services; prevention programmes such as relationship counselling, marriage counselling, divorce counselling, marriage preparation and marriage enrichment; therapy; and prevention programmes such as families against violence, parenting, and fatherhood. Families South Africa programmes are mainly for prevention, training and rendering purposes and families are assisted with conflict management and parenting skills (FAMSA 2014:14-18, 2015:14-24).

Families are trained with parenting and life skills so to raise emotional and physical health, balanced families and children. Examples of such programmes are parenting, families against violence, school holiday programmes for learners', that is bullying, teasing, and other programmes and projects with destructive behaviours. Families South Africa delivers constant levels of 
excellent services to their clients, implying that people continue to improve themselves (cf. FAMSA 2014, 2015).

\section{The aim of Families South Africa}

Families South Africa aims to empower parents, including fathers in prison, in their valuable parenting skills and fatherhood to ensure that families, and especially the children, should receive the love, care and structure they needed within a household context. The traditional image of a family structure of mother, father and children has changed significantly in recent years. In South Africa, single-parent households are almost considered a norm in communities. Most children do not even know their fathers. Children very seldom receive love, attention and care from both parents, and this leaves them with a hollow space in their hearts (cf. FAMSA 2014, 2015).

\section{The dilemma of refugees, foreigners and displaced people}

\section{Background}

Displacement has been a reality since the beginning of universe, so the refugee crises and displacement facing the world right now are not a new phenomenon. Throughout history, people have remained on move (Polak 2014:1). Adam and eve, for example, were removed from their place made by God because of their sin and disobedience. Another example was Cain; he was judged and chased away from the place he had made his home because of murder and jealousy. God, however, extends ample mercy, favour and grace to displaced people (cf. Das 2016:34).

The Gospel of John (19:9-10) asks us a prominent question to be considered within a practical theological approach: Where are you from? (cf. Namli 2011:815). Jesus was a refugee according to the Gospel of Matthew (2:13-23), and he is today joined by tens 
of millions of brothers and sisters (cf. Shore 2016:1). One should take cognisance that human beings are constantly on the move and looking for a better place to live and stay. People have been always on the move to other countries in search of religious freedom, food, shelter and safety for their children or to escape wars, political persecution or torture (Warr 2010:269).

Migration, asylum-seeking and refuge have been a worldwide dilemma of vulnerable people being persecuted, displaced or fled because of war and conflict (Langmead 2014:30). Migration is a part of human history ever since its existence, and nearly 200 million people, one person out of 35 people globally today is staying at faraway places away from their home country (Groody 2009:638). Migration evoked a foreign turmoil where it launched a new idea of domestic relatedness and national identity (Polak 2014:1). In fact, migration is an approach of explaining identity, which is a social dilemma and a major attachment of human existence (cf. Castles \& Miller 2009:299). Economic migrants choose to move to other lands to better their lives and refugees move to other places to protect their lives (Warr 2010:270). However, these moves cause interruption to cultural, socio-economic, political and personal influences as well as family life in all spheres of life (Warr 2010:270). The world, for the past decades, has experienced the largest migrations ever written in history (cf. Falicov 2002).

\section{The refugee and the displacement crisis in the world}

Displacement has increased over the last 50 years and has become a major humanitarian challenge. It is difficult to work with numbers and statistics in this chapter because they are always changing but revealing (Langmead 2014:30-31). According to the global statistics released by the office of the UNHCR in 2011, there were estimated 11 million refugees, 1 million asylum seekers, 15 million displaced persons and 3 million stateless 
people (cf. Langmead 2014:30-31). According to estimates, around 600000 people or more had moved to Europe in 2015 (Vick 2015:26-34). Displacement and refugee problem have raised urgent concerns, such as disruption of human lives in certain lands and putting heavy burdens on receiving countries, which, in fact, causes internal conflicts between receiving communities (cf. Soares, Lotter \& Van der Merwe 2017:1). This refugee dilemma opens not only the dangerous plight of millions of people but also the problem of moral predicament for many countries (Galli 2015:33-34).

Countries such as Germany welcome 800000 refugees, and Illinois, one of the US states, serves 5500 immigrants and refugees a year (Galli 2015:33-34). In the last three decades, the USA has become a shelter for refugees and radar of trust and hope for ample African refugees displaced by man-made or natural disasters and the majority of those who are displaced after noticing severe traumatic incidents such as rape, violence, murder and domestic war battles (Adedoyin et al. 2016:95). Reports from Australia, Turkey and the USA recount the plight of refugees and migrants who were victimised or killed after having arrived in countries they thought would be safe for them (Shore 2016:4). China, for example, is one of the countries where people fled for their lives (cf. Koop 2005:355). In 2010, South Africa received about 180600 applications for asylum, which were the largest number globally for the fourth successive year, and these applications were from Zimbabwe and the Horn of Africa (cf. Holscher \& Bozalek 2012:1097). However, 'South Africa on the other hand remains one of the most unequal societies in the world with poverty increasing by the day' (Hoogeveen \& Ozler 2005:1).

According to Crush et al. (2008):

South Africa has traditionally high levels of xenophobia, race-based discourses and practices. The Zimbabwean migration to South Africa increased in the early 2000 s, contributing to a series of xenophobic attacks in 2008. (pp. 1-2) 
The 11 May 2008 attacks were shocking in South Africa, where the anti-migrant violence in Alexandria Township of Johannesburg disseminated to other townships and informal settlements across the city and the country (Bompani 2015:199). Ensuing a series of xenophobic violence and attacks in May 2008, over 100000 foreigners were displaced and most of these displaced refugees found shelter in churches (cf. Holscher \& Bozalek 2012:1093). Approximately 62 migrants and 21 South Africans died, 670 persons were wounded, 100000 were displaced and innumerable women were raped during these attacks (Bompani 2015:199). Most of these migrants and refugees were assisted by churches (Bompani 2015:197), and many NGOs and governmental agencies were asked to offer help to these displaced people by providing shelter, food, water, education and skill programmes (cf. Bompani 2015:199). Churches, for example, were opened and accommodated these refugees, and most of them found sanctuary, communion, shelter and a place to unfold a new life (Neumark 2004:9). Most churches hosted these refugees temporarily in church rooms (Koop 2005:355). It is further indicated that some churches began as refugee gatherings (Cohn 2011:46). Studies had afterwards indicated that African refugees have suffered more traumatic experiences compared to any other refugees from other parts of the world' (cf. Adedoyin et al. 2016:96).

In the case of Libya, 'hundreds of thousands of Liberians remain displaced within the country's borders in West Africa and more than 300000 refugees are in the capital Monrovia' (Nyberg s.a.:39-41). In 2011, the sub-Saharan migrants flee by ship to Libya because of its violence but unfortunately were drowned because many of these migrants were unable to swim (Groody 2015:314). Also in 2011, the World Council of Churches (WCC) addressed the refugee crisis and expressed concern over the humanitarian situation in Libya (Dilonno 2011:20-21). Further, an example of desperation, 250 migrants fled the chaos and were missing after their boat sank off the Italian coast and the ecumenical groups, 
by requests from government and aid agencies to give assistance, provide aid and protection to refugees and migrant workers in the Libya crisis (Dilonno 2011:20-21).

Canada has the most vulnerable refugees in the world, and this migration of people is mostly influenced by religion (cf. Bramadat 2014:909). It was estimated at the end of 2015 that there were 65.3 million forcibly displaced people worldwide, and 21.3 million of these people were refugees (Shore 2016:1). Every day, nearly 34000 people leave and flee their home countries because of conflict and persecution, and over half of the world's forcibly displaced people are children (cf. Shore 2016:1-2). More than 40000 migrants' deaths globally are documented today, since the year 2000 (Groody 2015:315).

\section{Who is a refugee: A displaced person and a stranger?}

The refugee convention defines a refugee as (Naja et al. 2016):

$[S]$ omeone who, owing to a well-founded fear of being persecuted for reasons of race, religion, nationality, membership of a particular social group or political opinion, is outside the country of his nationality and is unable or unwilling to avail himself of the protection of that specific country. (p. 78)

The UN uses the same definition (cf. Adedoyin et al. 2016:96).

Refugees are displaced people who have been forced to flee their own countries (Shore 2016:1). Displacement could be an outcome of natural disasters or war and has a long history through ages (Das 2016:33). Refugees are furthermore poor, live in poverty and have lost their homes and identity (Das 2016:33).

Pertaining identity, it is crucial to keep in mind that identification is one of the most obvious markers of safety and reliability, especially when you are displaced (cf. Namli 2011:813). Displacement is one element that desolates identity and the sensibility of self and dehumanising, and belonging to a land 
gives a person identity. For example, Paul of Tarsus and Joseph of Arimathea indicated not only their hometown but also identified who they were in terms of their families (Das 2016:36). Even Jesus the Son of God was referred to as Jesus of Nazareth (cf. Das 2016:36; Mt 4:13; Mk 1:9; Lk 1:26; 4:16, 29; Jn 1:45, 46). Furthermore, asylum seekers and refugees are amongst the most marginalised, powerless and dislocated or displaced human beings in the world, and hospitality should be the most appropriate approach towards these people (Langmead 2014:29-30). Dimensions of hospitality should include protection of human rights, acceptance, justice-seeking, hospitable church life, etc. (cf. Langmead 2014:29-30).

\section{God's view and his care for refugees and the displaced persons}

The phenomena of refugees and displacement of people are not only analysed through political, economic and social lenses but also through spiritual lens. The gospels do not speak much about displacement or refugees. The gospel occasionally refers to strangers and briefly mentions that Jesus, as a child, was a refugee. However, Jesus follows the tradition of Old Testament by showing compassion for vulnerable in the society. Approximately $75 \%-85 \%$ of Jesus' audiences were poor, which included foreigners residing in the land (Das 2016:36).

God is concerned about refugees, displaced persons, strangers and the vulnerable. It is evident that Jesus has shown much compassion for the vulnerable in society. He cares and has compassion for the displaced and people who live on the edge of society; he is also concerned about the people who even spiritually are not part of his kingdom (Das 2016:36). The notion of God's view and care pertaining to refugees and the displaced is that he takes care of the poor, weak, vulnerable, refugee, broken, discarded and rejected because he created them and for him such people are of equal value, irrespective of their ethnicity, 
nationality, and social or economic status (cf. Das 2016:34-36). God wants to pour out his heart to this fatherless generation, including refugees and the displaced. In fact, God wants to be the father to this generation that has been misguided and misdirected by a sense of hopelessness (cf. Stringer 2009:131). God adopts each and every person who comes to him through Christ, and wants to nurture them with love, affirmation, acceptance and self-worth (cf. McGee 1993:219-220).

The Samaritan woman, for example, belonged to a community that was despised and marginalised by the Jews. However, Jesus shows her respect, compassion and understanding (Jn 4:5-15). Another example is that of the centurion, who approached Jesus for healing his servant. Jesus honours the centurion in front of crowd for his authority and faith by healing his servant (Lk 17:1-10). A further example is where Jesus delivers the daughter of a SiroPhoenician woman from demonic spirits (Mk 7:24-30; Mt 15:21-28). The Lord does not ignore her and heals her daughter. The woman did not even belong to the Jewish community.

If Jesus could show respect and compassion to all at every instance and even met their needs (cf. Das 2016:39), then how would we as Christians respond and understand the displaced, and what would be our religion towards refugees and the displaced? According to Porobic (2012:317-330), religion could be a positive factor in dealing with refugee experiences. A question is regularly asked when dealing with refugees and displaced people: Is religion different? (cf. Churgin 2016:20132015). How bad the refugee and displacement crises might be, it still gives an opportunity for Christians to shine brightly in the light of Christ's love than ever before (cf. Galli 2015:33-34). Robert Guppah, a pastor in Monrovia's Sinkor district, says that 'we must be a people of hope and Jesus Christ is the basis of our hope' (cf. Nyberg s.a:39-41). It is therefore important to preach and teach the refugee stories because how would it be possible for us as Christians to live faithfully at a time of such mass displacements (cf. Shore 2016:2). 


\section{Displaced fathers could be reintegrated in society if we restore their dignity and build spiritual resilience}

Building spiritual resilience and restoring dignity amongst displaced fathers at the Potchefstroom remand detention facility is fundamental because it reduces destructive behaviour amongst such persons. Building resilience is necessary because it brings hope to displaced fathers, especially against the spiritual challenges that many of the fathers are facing in their daily lives.

In 2017, research was conducted amongst displaced fathers at the Potchefstroom remand detention facility. A total of 38 fathers participated in this research. Findings in terms of the fatherhood training and equipping programme were based on resilience building in four specific areas, namely emotions of fathers before the programme, emotions of fathers after the programme, areas of growth after the programme and fathers' spiritual life after the fatherhood programme.

Before the presentation of fatherhood programme, fathers indicated that they felt very depressed. This problem was further explored in group discussions, and reasons included that the fathers had no hope, no support, and lacked skills development and poor training. They also felt inferior because of family rejection, degrading life in prison and poor living conditions. After the fatherhood programme, it was significant to see that fathers felt more positive and were more hopeful compared to before. Furthermore, fathers indicated that they felt happier than before because of follow-up, emotional support, and building positive values and relationships between the presenter, fathers, facilitators and the staff of the correctional services.

Because of the positive relationship that fathers had built amongst themselves, it was remarkable to notice the positivity of fathers towards the programme, facilitators and correctional staff. Furthermore, growth was evident in terms of own identity, and that most of them took responsibility of their life, actions and 
choices. Furthermore, it was noteworthy to observe as to how fathers indicated their positive growth in terms of their spiritual life. The fatherhood programme indicated that it was important for fathers to do self-introspection, and many of them were motivated and willing to do so. This behaviour is, however, evident and could be seen from their participation in spiritual activities such as the Bible study, prayer groups and spiritual services on specific Sundays. Fathers also indicated that they felt part of a spiritual family, and that they had a deep desire to be transformed. Unfortunately, a smaller group of fathers indicated a sense of responsibility, which was, in fact, a great inadequacy in terms of responsible fatherhood.

\section{Christian's responsibility for the displaced fathers}

Refugees and displaced people often need help in bereavement, grief and loss (cf. McLellan 2015:131-138), and this is what the fatherhood training and equipping programme does in its project: A life beyond iron bars. It offers hope, builds resilience, offers relief and strength, gives encouragement, provides solutions and inspires inmates (fathers) to make progress in life (cf. Freeks 2011a).

The fatherhood programme implies that Christians should have and practice a compassionate ministry towards displaced people. Christians should act as families to those displaced people who have lost their families. They should minister impoverished and previously disadvantaged and less-developed communities, and reach out to orphans and vulnerable children. Christians must ensure that different ministries are in place to build sound marriages, complying with generation and steadfast families (cf. Freeks 2018a:200).

Furthermore, Christians must build faith through worship because worship songs enhance trust in God as a father to the fatherless and mother to the motherless and provide comfort. Worship songs strengthen the faith that God is present with 
powerless and in abandonment of their life situations. In an article examining the Afro-American understanding of Psalm 68, Gilkes (1989:134-152) explains how the words of Psalm 68:5 provided hope in the worst of circumstances imaginable in their communities, along with the assurance of Psalm 27 that if their mothers or fathers had forsook them, God would surely 'take them up', they found the image of God that transformed their lives (Gilkes 1989:134-152).

Pertaining development amongst displaced persons, it is necessary to train and equip displaced fathers. This should take place through various strategies such as workshops, road shows, conferences, seminars and camps on marriage and family enrichment, premarital counselling programmes, equipping events as well as programmes and activities for community training. All these strategies should focus on building strong and steadfast families and providing training for effective parenting. Christian fellowship for the displaced is fundamental and should be encouraged in the society because of the mutual aspect of care. Fellowship with the displaced means worshipping God together and knowing him in all circumstances. This fellowship is further significant because it also includes taking care of their needs, for example sharing meals and praying together to deal with challenges.

One of the core aspects of the fatherhood programme is that it teaches inmates (fathers) to become teachers in their families, especially teaching them the Word of God and about God as their Father (Freeks 2019:12). This is a major challenge for men because many men are intimidated by their wives (cf. Munroe 2008:31).

Fatherhood has to be taken seriously and with cognisance because it gives an anticipation of what and who is our Father (cf. Freeks \& Genade 2017), and if human fatherhood does not exist then all truth and knowledge about God, the Father, is void and insignificant. Today, fatherhood has become an element, and perhaps the most threatening element in the world. That's why, Christian responsibility has become all the more crucial and relevant pertaining to displaced father. 


\section{Chapter 8}

\section{Migrants, missio Dei and the church in South Africa}

Johannes J. Knoetze

Department of Missiology, Faculty of Theology, North-West University,

Mahikeng, South Africa

Paul Verryn

Methodist Church,

Soweto, South Africa

\section{Abstract}

The chapter is written from a missional perspective and attends to the possible responses of local churches in South Africa towards migrants. The parable of the sower, as found in Matthew 13, is used as an analogy to discuss these responses. Some practical examples of the responses of the churches are cited. The last part of the chapter discusses different aspects of the ministry of local churches that could contribute to a missional response.

How to cite: Knoetze, J.J. \& Verryn, P., 2020, 'Migrants, missio Dei and the church in South Africa', in A.R. Brunsdon (ed.), The human dilemma of displacement: Towards a practical theology and ecclesiology of home, pp. 171-187, AOSIS, Cape Town. https://doi.org/10.4102/ aosis.2020.BK198.08 
Keywords: Migrants; Matthew 13; Missional church; Globalisation; South Africa.

\section{Introduction}

The chapter is written from a missional perspective and attends to the possible responses of local churches in South Africa towards migrants. The parable of the sower, as found in Matthew 13, is used as an analogy to discuss these responses of churches. Together with a critical literature and exegetical study, the method used in the analogy could be viewed as an ethnographic study. This implies that the authors are personally involved in, and in many instances 'responsible' for a ministry with migrants, and write from their own experiences, perspectives and contexts. One of the authors is working with migrants nationally; the other author is working with a group of migrants in one of the most rural areas of the North West Province near the border of Botswana. However, it seems as if the responses from different denominations and local churches do not differ much when it comes to ministering together with strangers. After looking at the reactions of local churches, the chapter attends to some principles to help local churches act in a more missional manner in welcoming migrants as participants in the ministry.

\section{Background}

We live in a pluralistic society where millions of people travel everyday across borders from one country to another. Many of these people cross the borders of their country of origin permanently as they are looking and hoping for a better future. Migration and mission - to make God known in the world - have remained inseparable throughout the Bible (Knoetze 2012:40-44). When God created his covenant with Abraham as the father of all believers ( $\mathrm{Rm} 4$ ), God called 
Abraham, from his country, from his land, from his father's house, to an unknown land (Gn 12:1). In the Old Testament, God uses the migration of people such as Abraham and Israel to make himself known to the world (Wright 2006:75-104). Even the church could then be nothing less than a migrating movement; we live in a kingdom which is not from this earth (Jn 18:36), we live with hope of a new life and a new earth, an eschatological hope that characterises our current reality. The first letter of Peter reads: 'To God's chosen people who live as refugees scattered throughout the provinces of ...' (1 Pt 1:1). It is along these lines of movement, or migration, that Myers (2017) argues about globalisation and the influence on and of the poor in relation to Christian mission in the current hyperconnected, post-modern world. The present authors agree with Myers (2017) statement:

$[T$ ] hat God is the God of history, all of history, and that God's story has an end and purpose. I take it on faith that God is working on a project of redemption and restoration and thus that nothing in history or in the lives of human beings is outside the scope of God's project. (p. 16)

Myers (2017) makes a very important remark when he says:

I believe that proclamation by word must always be part of the church mission, but I wonder if the part about the Kingdom, about loving our neighbours and even our enemies, needs some serious renovation. (p. 16)

The focus of this chapter is to understand something of how God's redemption plan plays out from the perspective of kingdom through migration and migrants, who are viewed and treated as people from the margins.

In spite of wonderful definitions of mission, the general understanding of mission is '(a) propagation of faith; (b) expansion of the reign of God; (c) conversion of the heathen and (d) the founding of new churches' (Bosch 1991:1). It is from this general understanding that Myers' remarks about the 
kingdom and loving our neighbours and even our enemies become relevant when focusing on migrants. This chapter seeks to focus on the reaction of local churches in urban and rural South Africa, as faith communities, towards immigrants from outside South Africa as well as migrants from rural to urban South Africa. As such, the mission of the church is understood in the context of immigrants as centripetal, moving to the centre and moving to the church as part of God's mission project of redemption and restoration. Ott and Straus (2010:23) write about the centripetal understanding of mission: 'Yet at the consummation of the Old Testament eschatological vision, the direction will reverse again, and the nations will be drawn centripetally to Zion, the New Jerusalem'. This chapter indicates that faith communities as part of missio Dei are to communicate with immigrants as marginalised people and welcome them into the kingdom of God. There are clearly some contact points with the parable of the Great Feast (Lk 14:15-24) and the command to 'Go out to the country roads and lanes and make people come in, so that my house will be full' (Lk 14:23). Focusing on the kingdom of God and centripetal mission, this chapter seeks to use the parable of the sower (Mt 13:1-23) as an analogy of church's different responses to immigrants in South Africa.

It would be true to say of any country that migrants are regarded as superfluous to the essential fabric of society. A visit to the department of home affairs would quickly expose an intricate maze of regulations that govern the legitimacy process. At the heart of being a migrant in South Africa from another country is the unspoken message of restriction and unwantedness. The journey to essential belonging is truncated and awkward and certainly does not convey to the migrant concerned a welcome and an affirmation of their personhood or giftedness. We must understand that this is in direct contradiction to the gospel which seeks to emphasise a welcome to any outsider and worse still a welcome to a sinner in the presence of sanctified. This unspoken paradigm is also applicable to migrants within the country, 
although far less regulated by our bureaucracy. The unspoken prejudices of tribe and clan make the free movement of people in South Africa very uneasy. One has to listen to officials from large metropoles or Gauteng province to discern anger at their obligations to provide services to people who come from 'other provinces', let alone other countries. To return to the discussion around foreign nationals and their experience of South African attitude, the scourge of xenophobia has shamed the Christian community of this country and has left images reminiscent of institutionalised apartheid in our memories. Considering the vulnerability of many migrants to South Africa and the considerable trauma that many of them have faced at the hands of alienating governments, the picture of a migrant being necklaced in Alexandra during the height of xenophobic attacks is undoubtedly an unmitigated crime against humanity, and that also in a country that considers itself Christian.

\section{Application to Matthew 13:1-23}

Although Matthew is the focus of interpretation, it is important to note that there are synoptic similarities that are relevant (cf. Mk 4:1-20; Lk 8:1-15).

\section{Context of the parable in the text}

In Matthew 12:46-50, Jesus explains that his call surpasses loyalty to family. Similarly, the calling of Abraham out of family and land emphasises the priority that obedience to God has over personal commitments (Gn 12:1ff.). This certainly breaks the norms surrounding Middle Eastern family ties and the socio-historical context of the New Testament where family ties are a priority. We must therefore recognise that our engagement with migrants confronts our comfort zones and priorities. Therefore, expectation is to expand the biological definitions of family to include the 'other', the marginalised. The principle of taking care of the vulnerable and the marginalised is recognised throughout 
the Old and New Testaments. Matthew 13 therefore re-emphasises the gospel prerogative for all of life and shifts focus from our traditional or cultural interpretation of life to a new focus of the kingdom of God. The implication of the church universal is to shift focus from the institutionalised church or faith community to God and the coming of his kingdom in the world.

Although Matthew 12 expounds Jesus' confrontation of the Pharisees with the nature of the kingdom, we must understand that Matthew is probably referring to the church of his day, struggling with the signs of the kingdom. His reference to Isaiah 6:9f. emphasises that blindness and deafness would be the ongoing struggle of the church community.

With this short background, it is clear why the focus of this parable is on the soil receiving the seed. The analogy would be that the believing community here is equivalent to the soil. At first Jesus speaks to the multitude (Mt 13:2) when he tells this parable, but when he interprets the parable, he speaks to the disciples (Mt 13:10) and to the church. Stiller (2005:36) remarks when a storyteller ends his story with an interpretation of its meaning: 'It is a signal to take it seriously'. This could be seen clearly in Matthew 13:9, where Jesus calls for discernment in the understanding of this parable.

Having a clear understanding of the relationship between the missio Dei and the kingdom of God, the church needs to decide how it is going to react to the opportunities and threats or challenges that immigrants contribute to living the kingdom of God and to being in church. These decisions become clear in the manner the church treats immigrants, that is to say either as 'seed' from God, or 'beggars' from elsewhere. An important principle is that both mission and church belong to God. Within the context of the parable, both the 'seed' and the 'soil' belong to God in his kingdom and he is busy fulfilling his redemptive plan through them. We, both immigrants (seed) and the church (soil), have the privilege to participate and be included in this plan (cf. Mogensen 2016:56). 
When Jesus talked about the soil in Matthew 13, he identified four different types of soils and how the seed reacted in each soil. The seed that fell along pathways was consumed by birds, that which fell on rocky soil was scorched, the seed that fell amongst thorn bushes was choked and the seed which fell on good soil produced a large harvest.

Some tangential thoughts to consider relating to migrants would be to try and understand the correlation between the seed having to die first to bear fruit, and what dying or transformation for the migrant would be in a new context. According to John $12: 24-26$, if a grain of wheat does not die, 'it remains just a grain of wheat' (Newman \& Nida 1980:405). For the migrant (or the church) to die means to become and live as part of the body of Christ and not just to remain a migrant or a church. Attending to John 12:26, it literally reads 'and where I am, there my servant will be', meaning a 'died grain' would serve God (Newman \& Nida 1980:407). Furthermore, it might be worth imagining the correlation between the smallness of migrant seed as compared to a large mustard tree that might result from a migrant exposed to good soil in the church (Mt 13:31-35).

\section{Application of the parable to migration}

\section{Seed along the pathways}

The church that does not recognise that migrants in their context are part of God's mission is avoiding its responsibility to the kingdom of God. For instance, in many of our inner cities, we find mainline churches' service communities that travel far distances to the church to be entertained by the Sunday service but have no connection with the migrants that are crammed into hijacked buildings at their doorstep. In fact, many of these churches are oblivious to the exponential need for the hope of the gospel in these contexts. Much money is spent on ensuring security systems that would keep the unwanted and marginalised at bay. Probably, most profoundly expressed is the story of a policeman 
finding the dead body of a baby - unidentified and of no importance - in the rubbish dumpster outside a church. Death along the pathway gains new dimensions of insensitivity in this narrative. Luke 10:31f. describes a similar indifference towards the vulnerable. Of course, this assumes recognition that the migrant is vulnerable until exposed to the good soil. The deeper issue which is raised confronts the church with its fundamental understanding of mission. The decision of a church community to engage in God's mission implies a dramatic shift from maintenance to radical engagement with the context and therefore the world. It implies a decision to take seriously the fact that God loves the world, possibly even more than he loves the church ( $\mathrm{Jn} 3: 16$ ). This paradigm shift is as immense as the shift from death to life for church community. It implies a change in priorities and obviously the way in which the finances of church govern themselves. The pathway would always be relatively clean, unobstructed, accessible, predictable and seemingly leading to a goal, because a lot of sown seeds were snatched away (Mt 13:19).

\section{Seed on rocky places}

This would be symbolic of the church which at first was enthusiastic but as the troubles started creeping in and the realisation of the commitment dawned, enthusiasm withered. The experience at Central Methodist Mission, when first the doors to migrants were opened, quite conservatively, was applauded, especially by the governing bodies of the church. However, as soon as the implications on budgets, infrastructure, loss of space for church meetings, cleanliness, organised predictability, and relationships with municipality and government departments became problematic, the narrative was literally suffocated. Of course, the demands made in this context covered each and every detail of human existence, from proper cleaning facilities to intimate relationships, power struggle, crime and drugs, struggle to resolve political difficulties that had caused migration in the first place, to grief, psychological dysfunction and brokenness. 
The mountain was too steep to climb, often for people from the church community. Many people of this community came to the church really to connect with a place of sanity but were confronted with the inhumanity of scarcity and desperation. The rocks depleted the potential for the expansion of kingdom.

\section{Seed amongst the thorn bushes}

It is not, that the church is not willing to commit to immigrants and their needs, it is just that the church is preoccupied with many other issues such as worries of survival, or the deceitfulness of wealth. Therefore, the migrants have to compete with these other issues, which are described as thorn bushes in the parable. One of the ongoing mantras of xenophobia is, 'they are stealing our resources, our jobs, our women, our social services'.

In the context of South Africa, the absurdity of these complaints is unspeakable. If one considers that many of those who were involved in the so-called liberation of this country were hosted, educated and employed by the very countries from which we are now receiving migrants, these complaints are simply absurd. When South Africa projects to the world an image of economic stability and lucrative success in business, we must not be surprised that for economically downtrodden people, this nation seems to be a destination of hope, and indeed we are a destination of hope. The wealth of this nation really does imply that there should be no poor in our midst and that this is a political destiny which has resolved its conflicts. There is something crude in trying to balance in our minds the bizarre levels of corruption and basically the theft in the light of the struggle to survive.

An interesting conundrum emerged during discussions with a migrant community in the deep rural areas of the North West province, particularly regarding their relocation to Mahikeng. Some relocations have taken place, but there was an outcry that previously earmarked government subsidy houses (RDP) have been reassigned at this relocation and thus these new migrants 
should not be given priority in the context of such a dire need. The public protector would need Solomon's wisdom to balance priorities. Some of these real struggles don't even seem to fall within the ambit of church's imagination, let alone providing a space to people seeking a new beginning. In many respects, the church has been smothered by the lure of wealth and comfort. To some, it offers a place of relief from the struggle of survival, but in many instances, our church buildings represent middle to upper class in both appearance and accumulated wealth. These things, it is thought, cannot be sacrificed for anything, let alone the kingdom.

\section{Good soil}

Within the context of Matthew, the disciples were disturbed that Jesus was not taking over leadership by initiating an armed struggle and evicting Romans (intruders). Instead of taking up the sword and fighting people, Jesus insisted on spreading his kingdom vision. Within the current migration context of South Africa, the church should not be disturbed by migrants but receive them as part of God's kingdom. The 'good soil' church is the church that understands God's vision. Unfortunately, for some, this reality demands a decisive engagement and not a somewhat ambivalent rejection. The latter has been the prevailing position of the church.

It is true to say that the South African community has been benefited hugely from the injection of migrations that have happened in this country since the beginning of the 21st century, in particular. For instance, our academic institutions are controlled by international scholars, many of whom are essentially migrants from other African countries. The intellectual capital introduced in this country has saved lives, transformed a fiscus and opened up spaces of hope right down to the streets of local townships. On a far more practical level, the investment shown by migrants to the cleanliness and maintenance of the infrastructure of our 
cities through participation in the recycling industry has been exemplary.

Furthermore, for the first time, literally in centuries, this southern tip of Africa has been exposed to the culture and spirituality of a continent that is profoundly nuanced and wise. When the church risks allowing the seed to fall within its walls, the richness of interaction and human development could not be measured.

We cannot be unaware of the fact that amongst some of the migrants there could well be and are opportunists and thieves and robbers who carry with them the infection of corruption. It is naïve to imagine that every migrant by implication of being a migrant is good and clean and fresh. However, the parable that follows our study speaks of weeds that ultimately need to be exposed and punished (Mt 13:24-30). As an aside, we must also note that South Africa could be considered as a university for criminals and corruption. It has been alleged that foreign nationals sow the seeds of criminality in our society. However, to imagine that all foreign nationals are criminals and need to be treated with appropriate suspicion is not unlike the prejudice which had bedevilled South Africa for so many centuries, where black people were assumed to be wrong in every dimension of life. They stole, smelt and were untrustworthy and stupid.

A further example could be taken from the establishment of Albert Street School in downtown Johannesburg. On 05 July 2008, three teachers requested to open a school in a church in Albert Street because ' 40 children, mostly unaccompanied minors, had arrived in the Central Methodist building, subsequent to the closing of the xenophobic violence camps, and if we did not take the initiative, they would learn from the streets' (unspecified speaker, teacher, 05 July 2008).

The school started operating on 08 July 2008 and has consistently produced outstanding $O$ level results in the Cambridge examinations. Despite several attempts, the 
secondary school is still not recognised by the Department of Basic Education. The primary school is registered but has not received a cent in subsidy for the hundreds of learners that they have kept off the streets and for whom a bright future is being crafted. Those three school teachers understood profoundly the good soil, and now witness to many professionals serving this country and adding value to the truth that the seeds bear fruit in good soil.

Sitler (2005:44) clearly indicates the tension between the idea of the disciples sowing seeds and launching a new order. The fact that something as harmless as seeds would upset the world is ridiculous. Within the context of welcoming migrants as possible 'seed' of God and the apathy of local and national church bodies towards migrants and the marginalised, we are challenged to engage with the ideal of the kingdom in a new way. Whether we engage this challenge or not, it must be understood that a new mission movement from the margins, Together Towards Life (Keum 2013), is initiating a new order of church on the soil of Africa. Predictably, this disturbs the institutionalised church in South Africa, especially when it has to consider that this new movement would emerge, as it has always happened, from the most marginalised in the world and the church.

The dictum of Marx that the religion is the opiate of masses must always remain a challenge to the institutionalised, settled, comfortable and efficient church. Just as migration disrupted Abraham and began a completely new way of understanding a relationship with God, so migration in this context opens a new window to our understanding of mission and our relationship with God. Indeed, it cannot be seen as anything less than a redefinition of our humanity. Just as the mission of Paul to the gentiles disrupted the comfortable traditions and predictable safe spaces for the early church, so our determination to redefine community must disrupt the neat tick-a-box bureaucracies of departments of home affairs and international relations. Once again, the powerless in every respect are about to disrupt 
the neatly organised desks of who-belongs-where. At the heart of this entire discussion lies the more profound challenge of belonging. In essence, Christ's incarnation implies the intrusion of a foreigner into our mind space and our spiritual order. The irony is that our prejudices have always presented themselves as reasonable, understandable and imminently decent. They are in fact the quintessence and creation of chaos. And here lies the irony that the removal of these barriers, although initially disrupting our comfort zones, is actually the opening to a wider grasp of what it means to be human in God's world. It is still difficult for us to imagine that God confronts us as an equal in Christ, but this in essence is what the gospel expects of those who call themselves by his name in this journey comparing with those who do not belong.

\section{Implications of migration for the church as kingdom community The pathways exposing the need to create community}

One of the needs of migrants is to be found in their search for belonging, and one of the characteristics of the church community is that it should provide migrants a place of community and therefore belonging. According to Matthew 13, the pathway depicts a place of movement where there is no time for the creation of community. When we deal with migration, we can either choose to deal with it as an intrusive chaos or as an extension of community. Dealing with migration as part of our community gives impetus to two powerful forces that have influenced the future of church in South Africa. The first force towards the church is centrifugal, 'It dislodges people, their beliefs, values and relationships, from traditional foundations, and thrusts them outwards into the bewildering "cosmopolitan", (Clark 2015:5). In this regard, it links closely to the missional church movement where the church and congregational life is 
focused on service to life outside the church (Burger 2017:25). The other force as a reaction to centrifugal is centripetal, 'Here people are impelled inwards in an attempt to retain or reclaim their physical and human roots, their common heritage and a distinctive identity' (Clark 2015:5). In this regard, it links closely to Christendom's institutionalised church. Although both these forces carry with them certain threats to community, 'the quest for community is as much about depth as about breath' (Clark 2015:9), and a fine balance has to be struck between these two.

Some of the threats, for example centrifugal threats such as anonymity and amorality, and centripetal threats such as xenophobia, directly or indirectly, could be related to migration as discussed above. However, it is the image of the kingdom community that offers us the most reflective and convincing vision of what community is all about. God's kingdom is not only about the sovereignty of God but also about all those living in accordance with his purposes. As such, the kingdom includes the following gifts to humankind - life, liberation, love and learning. According to Clark (2015), the church as a servant of the kingdom community:

[/]s called by God, to witness to the epitome of all learning communities, the kingdom community, and to build communities that manifest the kingdom community's gifts of life, liberation, love and learning. (p. 57)

To address the seed falling on the pathways, the church has to create kingdom communities. If the soil of a church can be compared with the soil of the pathways, then the church needs to address the two-fold issues raised by Clark, that is the centrifugal and centripetal forces.

\section{The rocky places exposing the need to act and serve as church}

In our analogy, rocky places could be symbolic of the church community that offers people a strong sense of security, based 
on collective territory and common heritage, as well as significance and solidarity embedded in family and parish life (Clark 2015:58). The described church communities are also closely linked to secular power and, as such, soul saving. At first, these communities are enthusiastic about the challenges and opportunities offered by migrants, but as troubles start coming and the full implications of commitment are realised, enthusiasm wanes. Niyonsaba (2018:459) describes church's mission as not only saving souls but also as having a diaconal dimension, 'The practical implications of diakonia is a call to action as a response to challenges of human suffering, injustice and care for creation'. One of the benefits of a diaconal church is an effort to bridge old and unhealthy divides between spiritual and social gospels. Bevans and Schroeder (2004) describe this as Type A theology 'mission as saving souls and extending the church'. This theological view follows the exclusive redemption model of institutional church and has a negative view of humans. According to this understanding of theology, the original creation of human beings in the image of God no longer exists after the fall, and the life is seen in dualistic terms as body and soul (Rooms 2017:307-308). In this theology, power is important and there is a clear hierarchy and separation between the clergy and the laity. When the church decides to address the rocky soil, it must imagine the implications of holistic diaconal ministry. This ministry is of word and deed, and body and soul. It implies the determination to overcome race, class, power and gender divides prevailing in society.

\section{The thorn bushes expose the need to respect the ministry of clergy and laity}

The church, as made up of laity and clergy, is preoccupied with the concerns of survival and lure of wealth. Although the church, as a servant of the kingdom community, has always retained a mystical and sacramental character, to embrace the implications of a pluralistic society involving migrants, we need a radically 
different form of ministry than has been experienced for centuries (Clark 2015:102).

The missional movement in South Africa helped us to rediscover 'the truth that the saving gospel is not primarily about the church but about God and Jesus' (Burger 2017:27). We need leaders who are able to discern God's redemptive and restorative work within different contexts. Our task is to empower and coordinate different gifts of different people within the church for 'their work of Christian service' (Ep 4:12). Church leaders who empower and coordinate have at least two major responsibilities: The first is to empower the church to be a community that obviously makes the gifts of life, liberation, love and learning. The second is to be a catalyst for the church to become a learning community and expose interdependence of the clergy and laity, enabling 'the laity to interpret the Christian faith not as a closed book, but as an ongoing journey of spiritual discovery in search of the meaning of the kingdom community' (Clark 2015:107).

\section{The good soil exposes the full potential of the church as a vibrant community}

Within the current pluralistic context of South Africa, the church is not embattled by migrants but receives them as part of missio Dei. The good soil church recognises the visitation of migrants as an opportunity to expand its participation with God in a new creation. Its key responsibilities are to enable the healing and wholeness of damaged people, to open spaces for the gifts of a new humanity and to sacrifice the self-satisfied inflexibility of exclusion. The good soil church knows that the opening of its doors ultimately means its reason for being.

\section{口 Conclusion}

Migration obviously implies a journey. The journey presents the challenges of discovery, rejection, learning and giving. At the 
heart of the gospel is the action of love, the action of journey (Cape Town Commitment 2010):

Such love is the gift of God poured out in our hearts, but it is also the command of God requiring the obedience of our wills. Such love means to be like Christ himself: robust in endurance, yet gentle in humility; tough in resisting evil, yet tender in compassion for the suffering; courageous in suffering and faithful even unto death. Such love was modelled by Christ on earth and is measured by the risen Christ in glory. (para. 5) 



\section{Chapter 9}

\section{A pastoral encounter with the stranger: The basic ambivalence of hostility to hospitality inherent to the human response}

Amanda L. du Plessis

Department of Practical Theology, Faculty of Theology, North-West University,

Potchefstroom, South Africa

\section{Abstract}

This chapter examines what a pastoral encounter with a stranger should entail, with a special focus on the basic ambivalence inherent to the human response that makes us waver between hostility and hospitality. In this context, 'strangers' refers to displaced human beings, whether immigrants or refugees. 
Statistics show that more than 50 million people have been displaced. This results in a human dilemma, which gives rise to new challenges for society. Many countries close their borders to refugees because they see these groups as a threat to the stability and resources of their country. The question investigated here is based on the role of the church and especially that of the pastoral caregiving ministry in helping displaced persons find the resilience to not only cope with their hardships, but to find a sense of meaning in life and in helping others in the same circumstances. The research is presented in four parts. An exegetical study is first conducted on Acts 10 to establish the scriptural foundation of the calling of believers to witness and care for strangers from different ethnic and cultural backgrounds. The focus then shifts to what a pastoral encounter with a stranger entails. This is followed by a discussion of the rapidly changing world of today. The chapter concludes with a view on how to help without hurting, an explanation of the paradigm shift from divine definition to divine infinition and three guidelines or principles for a pastoral encounter with a stranger.

Keywords: Pastoral encounter; Stranger; Church ministry; Resilience; Divine infinition.

\section{Introduction}

Nobody can doubt that the world is changing. The recent research in the field of practical theology provides evidence for the changing discourse. Scholars may never stop asking: what is changing? What is new? What is coming tomorrow? What does it mean for us? The church must be aware of the rapidly increasing changes across the globe. A responsiveness will help the church to resist the threats, and also be prepared to employ every beneficial innovation for the advancement of God's kingdom and the glory of Christ. Sills (2015:211) states that the only way in which the church could be ready to meet the 
challenges of the changing world, is to approach their ministry with an open Bible, an open newspaper and an open mind. He (Sills 2015:211) also warns that there is a more crucial task before the church, even more crucial than our attempt to ensure the contextualisation of theology, 'The most vital and challenging aspect is to make the essential changes whilst safeguarding what must never change: the Gospel'. This is also a challenge for the pastoral ministry of the church as believers work in cultures that are different from their own, come into contact with different rituals, symbols and metaphors and try to find the way to inner peace and inner healing. The biggest challenge to the pastoral ministry is to stay true to the Word of God. Whilst this challenge is always present for the church, it is even greater when dealing with strangers. Jean (1997:42) writes that the world is in crisis and the growing number of refugees is a tragic illustration of the convulsions that plague the planet. For the purpose of this chapter, strangers refer to displaced people immigrants, refugees, foreigners and those from a different culture. They are the evidence of war, famine, corruption and oppression that force millions of people into exodus. During a pastoral encounter between a believer and a stranger on this road, the basic ambivalent human response that wavers between hostility and hospitality is always present. The pastoral caregiver is confronted with the choice to respond with fear or with trust; to act as a master or a servant or to bring death or life to the circumstances. This research departs from a practical theological point of view as its epistemology, with a special focus on pastoral ministry. In an effort to understand this ambivalent reaction, the chapter unfolds through the following sections:

- Do not call anything that God has made clean as impure.

- An encounter with a stranger.

- The changing world.

- Helping without hurting - divine definition to divine infinition. 


\section{Do not call anything that God has made clean as impure}

The encounter between Peter and Cornelius in Acts 10:1-11:18 shows that believers have the calling to minister cross-culturally, and in a certain sense Acts 1:8 offer the geographical outline for the growth of the church. When considering Luke's narration of this particular encounter, it is evident that the leading theme is for believers to move beyond known customary borders. According to Wilson (2018:83), the characters in the narrative take 'steps of faith' to move beyond not only geographical borders but also borders created by purity codes, dietary restrictions and identity markers. Wilson (2018:96) shows that the geographical borders are especially important in relation to the historical context of this narrative. Caesarea - a bastion of Roman authority - was the setting of the constant tension and frequent conflicts that marked Jew-Gentile relationships. Joppa, on the other hand, was characterised by its legacy of Jewish nationalism. Because Peter was aware of the political tension in Caesarea, one doubts whether the visit of the messengers from Cornelius would have proceeded so peacefully if it was not for the spirit guiding Peter to go with the men, 'doubting nothing' (Ac 10:20). It is in this atmosphere of racial tension that Cornelius extends hospitality towards Peter. Luke shows something of Peter's hostility in verse 28-29 when Peter explains that it is unlawful for a Jew to visit a foreigner (stranger). Cornelius's hospitality in verse 33 communicates a lesson of divine neutrality ('do not call anything impure that God has made clean', Ac 10:15). Peter's response shows a willingness to change from hostility to hospitality as he learns the lesson of the rooftop vision. He answers: 'truly I understand that God shows no partiality, but in every nation the one who fears him and works righteousness is acceptable to him' (Ac 10:34-35) - a statement that shows that Cornelius's household, though foreign to Peter, is prepared to share in the gospel. The general features of the early kerygma are all present, although adapted to a company of gentiles 
(Bruce 2008:1264). The integration of geography and ethnicity in this narrative and the intervention of God are significant for the trajectory of the early church. The importance of this narrative lies in the universality of God's presence and the universal lordship of Jesus Christ over all nations alike.

The challenge posed to Peter in this narrative is still relevant to the church today, despite an ever-changing world. As a volunteer working with Doctors Without Borders, Shawgrass (1997:2) refers to a publication by Eric Morris, head of the office of the UNHCR from 2002 to 2005 where he argues that 'the world is in the throes of the creation of new states emerging from the collapse of an old world order'. The old world order refers to the Cold War. He (Morris 1997) further states:

$[W]$ ith this process of creation the demands of and for ethnicity have become ever more virulent. No one quite knows what it means - ancient hatred ... has become the catchall cliché to describe and explain it - but the effects have been powerfully destructive. Ethnic demands have played an important part in creating something approaching chaos in international relations at the least disorder. (p. 2)

With the call for decolonisation of the African continent around 1960, some of the ethnic dignity and respect of Africans were restored. In 1963, the Organization of African Unity was formed, but sadly what started with hopeful enthusiasm soon withered as more and more revolutions occurred and military dictatorships arose (Paas 2016:413). The decolonisation discourse is currently strongly evident in South Africa. Shawgrass (1997:1) describes decolonisation as a possible reason for the instability of the continent because governments 'fought guerrilla liberation movements, which were often based on a desire for independence and on some form of political morality'. He (Shawgrass 1997:2) describes decolonisation as a period of non-structured or destructive conflict. It is sometimes called 'identity-based', and in this regard, Shawgrass quotes a senior officer of the International Committee of the Red Cross, who said that almost every individual in Africa was looking for his or her own identity and that this was 
the main reason for the conflict. The 20th century is known as the period in history where a shift took place from ad hoc responses and selective cohesion to a universalisation and institutionalisation of the refugee problem because of the continuing conflict (Jean 1997:42). For this reason, the church must be prepared for an encounter with the stranger.

\section{An encounter with a stranger}

Deuteronomy is the richest book in the Bible with respect to the stranger and lessons for believer on behaviour towards the stranger. A few examples include Deuteronomy 10:18; 16:11; 24:17 and 27:19. The Hebrew word ger is translated as xenos in Greek and peregrinus or advena in Latin. This word is particularly suggestive in that it connotes (1) one who comes from outside, from afar, from the future (advena), and (2) one who migrates across borders of nation, tribe or home (peregrinus). The meaning includes a sense of surprised exclamation about the coming of this estranged and estranging outsider, almost like a sense of unknowability calling for risk and adventure. Hospitality to the stranger does not come naturally, and whilst the Bible acknowledges the predictable impulse to persecute seeming intruders, it exhorts the believer to hospitality (Kearney 2010:22).

Kearney (2010:17-39) conducted a study involving encounters with strangers as found in the Abrahamic religions. He starts with Judaism and uses the history of the Hebrew Bible to show how such encounters come down to the choice between hostility or hospitality. He highlights that it is a choice that has to be made repeatedly with every encounter. He (Kearney 2010:n.p.) explains that biblical religion, like most other religions, 'is capable of the best and the worst' depending on a hermeneutical reading of the Word of God. When believers choose hospitality over hostility, they open themselves to a new life. His description of the encounters with a stranger or the other in Christianity also involves Jesus himself. His disciples have portrayed him as a 
terrifying alien apparition on several occasions. Consider, for example, the events that took place on Mount Tabor when he is transfigured or when he appears to his disciples after his resurrection. Each time, Jesus responds to them with 'do not be afraid' and he turns their terror into communion: preparing fish on the lakeshore, breaking bread for the Emmaus disciples and other such events. Jesus is portrayed as both the one who believes in providing hospitality to the thirsting stranger, and the one who calls on believers to host him as their guest (Kearney 2010:27). In this way, Jesus announces his role as the uninvited guest. When he describes the believer's behaviour towards 'the least of these' in Matthew 25:31-46, xenophilia, love for the stranger, becomes love for God.

The manner in which believers treat strangers reflects their love for God. At the Sermon on the Mount, Jesus preaches that it is easy to love those who love you (Mt 5:43-48), but it is difficult to love a stranger, especially an adversary. It is the most difficult and the most divine - thing of all. Calvin (transl. by Pringle 1845) comments as follows on this pericope in Matthew:

It is astonishing, that the Scribes fell into so great an absurdity, as to limit the word neighbour to benevolent persons: for nothing is more obvious or certain than that God, in speaking of our neighbours, includes the whole human race. Every man is devoted to himself; and whenever a regard to personal convenience occasions an interruption of acts of kindness, there is a departure from that mutual intercourse, which nature itself dictates. To keep up the exercise of brotherly love, God assures us, that all men are our brethren because they are related to us by a common nature. Whenever I see a man, I must, of necessity, behold myself as in a mirror: for he is my bone and my flesh (Genesis 29:14). Now, though the greater part of men break off, in most instances, from this holy society, yet their depravity does not violate the order of nature; for we ought to regard God as the author of the union. Love your enemies. This single point includes the whole of the former doctrine: for he who shall bring his mind to love those who hate him, will naturally refrain from all revenge, will patiently endure evils, will be much more prone to assist the wretched. Christ presents to us, in a summary view, the way and manner of fulfilling this precept, Thou shalt love thy neighbour as thyself (Matthew 22:39). For no man will ever come to obey this 
precept, till he shall have given up self-love, or rather denied himself, and till men, all of whom God has declared to be connected with him, shall be held by him in such estimation, that he shall even proceed to love those by whom he is regarded with hatred. (p. 157)

What Calvin describes here is that the commitment to radical hospitality is central to the Christian mission of service. On the one hand, hospitality cultivates a community that offers a home to someone who has lost his or her own home. It is based on xenophilia (love for the stranger), and creates a space where the believer and the stranger can meet to enter into a (pastoral) encounter. Hostility, on the other hand, causes further damage to the stranger's sense of home and is based on xenophobia (fear of the stranger), thus alienating the stranger even more. The main aim of hospitality is to create a home for those who are far from their own homes. In the pastoral encounter with the stranger (working cross-culturally), an attitude of presence is especially important. Du Plessis (2018:7) describes it as 'being with, feeling with, thinking with and acting with' the stranger. This presence is rooted in the context of the believer's faith. In the 16th century, hospitality was also a core principle of St. Benedict's Rule. The following passage of the rule is characteristic and pioneering (Kearney 2010; Rule of St. Benedict, ch. 53):

Let all guests who arrive be received like Christ, for He is going to say: 'I came as a guest, and you received Me.' And to all let due honor be shown, especially to the domestics of the faith and to pilgrims ... In the salutation of all guests, whether arriving or departing, let all humanity be shown. Let the head be bound or the whole body prostrated on the ground in adoration of Christ, who indeed is received in their persons. (p. 29)

When this is taken into consideration, how is it then that the church today has become so distanced and estranged from the world? What is the church doing to support the more than 50 million immigrants or refugees who are victims of a changing world? 


\section{Changing world}

In Genesis 4:7, we read that Cain built a city and named it after his son, Enoch. Since then, human beings have lived in cities. The dynamics of globalisation started evolving when the first nations started living near, trading with and battling one another (Sills 2015:23). Urbanisation and globalisation are not new to the modern or post-modern world, but the exponential growth and the challenges they present to the pastoral ministry of the church are certainly new. According to a United Nations survey in 2011, the world has become more urban than rural for the first time in human history. More than half of the world's population lives in urban cities and the globe is becoming increasingly urbanised and globalised. Inherent to this change is the phenomenon of human displacement. According to Louw (2017a:2), the refugee dilemma and migrant crisis have become a global, civil and political nightmare. Human displacement challenges what we know of our culture. Worldviews influence and are influenced by interaction. Sills (2015:25) describes this phenomenon as 'cultural mosaics' and Van der Walt (2003:98) describes the strangers who come into contact with different cultures as 'divided souls' or people with an 'identification conflict'.

Apart from the phenomenon of human displacement, Christianity has also experienced a profound shift to the south in its geographical centre of gravity (Johnson 2005). In the 1900s, more than $80 \%$ of all Christians lived in Europe and North America, but by 2005 this percentage had dropped below $40 \%$. The centre of gravity for Christianity is moving south and east ${ }^{1}$ and this has resulted in three key challenges. Because Christianity is moving south and east, what was once considered a Western religion no

1. The term 'Global South' refers to the countries that lie south of the equator, previously referred to as developing nations, the Third World, the Two-Thirds World or the Majority World (Sills 2015:189). 
longer remains so. The first challenge is the influence of the southern and the eastern cultures on the gospel and their understanding of what it means to be a believer. The second challenge is the change in the dominant language(s), and the third challenge is the influence of the near-neighbour religions such as Islam, Hinduism and Buddhism. The Global South plays an increasingly significant role on the world stage, even though many areas are still unstable because of corruption (Sills 2015:190). The crippling burden of poverty and oppression has influenced many communities to grab hold of extreme forms of the prosperity gospel and liberation theology. Thus, not only is the world changing, but the changes have the potential to change the unchanging message of the Bible, especially if believers are not attentive to the process and respond to it with an attitude of presence.

Kearney (2010:49) refers to Ricoeur who called for an 'interconfessional hospitality', meaning a linguistic hospitality that takes the form of an exchange between host and guest languages, and 'Eucharistic hospitality' as an exchange between selves and strangers. Starting with the basic hermeneutics paradigm of translation, Ricoeur writes (Kearney 2010):

Bringing the reader to the author, bringing the author to the reader, at the risk of serving and of betraying two masters: this is to practice what I like to call linguistic hospitality. It is this which serves as a model for other forms of hospitality that I think resembles it: confessions, religions, are they not like languages that are foreign to one another, with their lexicon, their grammar, their rhetoric, their stylistics which we must learn in order to make our way into them. And is Eucharistic hospitality not to be taken up with the same risks of translation-betrayal, but also with the same renunciation of the perfect translation? (p. 49)

According to Kearney (2010:50), cross-reading (or listening) lies at the core of interreligious hermeneutics and it involves an endless and reversible process of translation between one religion and the next: a process whose aim is not some unitary fusion but 
mutual disclosure and enhancement'. Interconfessional dialogue does not aim to eliminate differences, but to welcome them. It is important to notice that the phrase 'to welcome them' does not mean adopt and conform to them. When reflecting on the meaning of the words hospitality and hostility, the following conclusions are marked. Whilst hospitality does not necessary include approval, hostility conveys overt disapproval and rejection. Hospitality allows an openness and a willingness to listen to another, whilst hostility is compelling and prescriptive. Hospitality makes communication possible, whilst hostility results in further estrangement. A pastoral encounter that seeks to understand the stranger implies hospitality with an openness of mind in the process of conversation, whilst an open Bible is 'settled' in the heart of the pastoral caregiver. In 1990, when South Africa's first democratic president, Nelson Mandela, was released from prison, he began his speech with the words 'I stand here before you not as a prophet but as a humble servant of you, the people' (Anon 1990:n.p.). It was an attitude of hospitality that Mandela portrayed, although it can be assumed that he had reason to be hostile.

Another matter of concern is that animism is a religious worldview that permeates the Global South (Sills 2015:197). Animism is based on the belief that everything that exists has a spirit or the life force. The traditional belief system is that benevolent, malevolent and ambivalent spirits, as well as ancestral spirits, must be considered and often appeased. What is considered by the Western world as a primitive worldview of tribal nations who embrace an 'unevolved' superstitious belief system based on witchcraft and folk stories, is finding its way into presidential offices and the boardrooms of powerful policy shapers (Sills 2015:198). The sad consequence is that most religious expressions are blended with animism, and the citizenry embraces the resulting syncretism. 
To be relevant in today's changing world, pastoral caregivers must be aware of the cultural preferences of the Global South and consider how the gospel may be contextualised (not decolonised). The church must be cautious of the deceptive slide towards an expression of Christianity that is more cultural than Christian. Van der Walt (2003) indicates very strongly that the biblical message is clear: 'the Gospel associated itself with different cultures - never to be domesticated, nor to be the captive of these cultures, but to liberate and transform them' (p. 102). In the year 1952, Niebuhr wrote his classical work on the Christian faith and culture, and formulated various models in an attempt to understand the relation between these two themes:

- The rejection and anti-model: in this approach, Christ is portrayed as against culture.

- The accommodation model: in this approach, Christ is portrayed as the Christ of culture.

- The synthesis model: Christ is portrayed above culture, that is, to maintain the distinction between Christ and culture.

- The dualistic model: Christ and culture are portrayed in a paradoxical relationship.

- The operational model: Christ is seen as the transformer of culture. Niebuhr believes that this last model is the best working model for the context in which the church finds herself and states that although Christ is above culture, he operates through it to transform (convert) it.

The church is facing numerous and complex issues in the cosmopolitan pluralistic world, and therefore it is necessary to have a new look at what the scriptures teach regarding an encounter with the stranger so that pastoral caregivers can help without hurting. Pastoral caregivers must find the resilience to change from hostility to hospitality in their encounters with strangers. 


\section{Uelping without hurting: From divine definition to divine infinition}

We find ourselves in an era where knowledge is freely available and where there is more knowledge than ever before, but we still do not have solutions to many of the direst problems. Even pastoral caregiving is confronted with the burning issue of its role in the (rapidly) changing world. Louw (2016:13) states that the church should admit that an immediate solution to the human displacement dilemma is not possible because of several contradictions and opposing issues. There should be a universal network of interculturality that indicates our common humanity. Hospitality is a core value in a Christian understanding of pastoral caregiving. Xenophilia allows an inclusive approach that agrees to an encounter with the stranger despite the differences because the believer understands that love, care and compassion are unpretentious Christian values.

In the light of these values and attitudes, the so-called 'atheist' Ludwig Feuerbach warned the church in the early 20th century against 'an idol of God with "brains," but without any passion and "heart"' (Louw 2016:15). How is it that a stranger to the Christian faith could identify the heartlessness of the church and the church failed to see this herself? Believers should then not be surprised by a statement such as (Kearney 2010):

My wager ... is that it is only if one concedes that one knows virtually nothing about God that one can begin to recover the presence of holiness in the flesh of ordinary existence. Such holiness ... was always already there - only we didn't see, touch or hear it. This is what Jacob discovered after he wrestled with the stranger through the night, realizing at dawn that he had seen the face of God. It is what the disciples of Jesus discovered after they walked with the stranger down the road of Emmaus before recognizing, retrospectively, after the breaking of bread, that this wanderer was their risen rabbouni. (p. 5) 
Kearney (2010:5) describes this wager as anatheism - a return to God after God. Ana means repetition and return, a turning back to the (true) gospel. Louw (2017b) describes this paradigm shift as a:

[M]ove from a fixed dogmatic approach to a more flexible dynamics of hermeneutics within different cultural contexts; i.e. the dynamics of 'presenting' - a position of 'not knowing' and being open for the mystery and surprise of God's intervention from the 'eschaton' into the vulnerability of the existential here and now of daily events. (p. 11)

If the pastoral caregiver wants to help without hurting, there must be a shift from divine definition to divine infinition - the active expression of the love commandment as a servant and not a master. Furthermore, there must be a clear understanding that the concept of God in the Old Testament (Ex 3:14) is an infinitive verb, which indicates that God will always be where human beings are. Louw (2017b:11) describes God as an exodus-God and not a cathedral-God. The presence of God is an infinitive mode a continuously ongoing ever-present divine encounter through and by the indwelling Holy Spirit. El Shaddai refers to the allempowering presence of the Lord that is displayed as a cosuffering source of encouragement, resilience and hospitality. Within this uneasiness with and awareness of the contradictions and opposing issues that the church is facing today, the focus must not be on divine definition of omniscience and omnipotence, but on divine infiniscience - 'the on-going intervention of God and the faithful presence of a covenant God in all spheres of life' (Louw 2017b:11), through believers (Praxis pietatis).

Vorster (2018:6) describes four themes found in reformed social thought that might be helpful for peaceful co-existence, namely 'the recognition of universal dignity, respect for the symbiotic and associational nature of human existence, the commitment to truth-seeking, and the understanding that continuous social reform is important'. Unity in co-existence is the theme of many papers today. Paas (2016:431) writes that according to scripture, unity is characterised by diversity and truth. Diversity and truth apply to God and his creation. 
In scriptures such as Deuteronomy 6:4, Mark 12:29-32; Romans 3:30 and James 2:19, the oneness of God is emphasised, but in other parts (e.g. $1 \mathrm{Jn}$ 5:7) the diversity (or Trinity) of God is evident. God's diversity is an essential aspect of his character. Diversity in unity is also a main characteristic of the created things, for example, the body of human beings (1 Cor 12:12ff.). Paas (2016:431) says that according to scripture, there is truth also in unity (e.g. Jn 14:6; Dt 32:4). True unity, however diverse, is strong, healthy and trustworthy. The whole world is a 'composition of endless variety that is composed to a faithfully working oneness of beauty and strength' (Paas 2016:431).

The concept of 'working with oneness of beauty and strength' links with the continuous act of forming (divine infinition). The Latin word formosus means to bring out the beauty. The same meaning is conveyed in Paul's words in Galatians 4:19 when he writes that Christ must be formed in believers (Du Plessis 2018:3). Pastoral caregiving to a stranger therefore also implies the continuous formation to bring out the beauty in diversity and truth. Whilst hostility results in stagnation, hospitality opens the door for continuous formation - therefore, the need for resilience to change from hostility to hospitality in human response.

In the last part of the 20th century, practical theology (with pastoral caregiving as a subdivision) has developed into an authoritative science and is defined as the religious actions of believers, with special attention to the encounter between God and human beings in sacred life and in ordinary life events (Heyns \& Pieterse 1990:6). The emphasis is again on actions - a verb, an activity. Canda and Furman (1999:1) define spirituality powerfully as religious actions: '(spirituality) is the heart of helping - the heart of empathy and care, the pulse of compassion, the vital flow of wisdom and the driving force of action to service'. In today's world, where the value of human beings more often rests on what they produce rather than on their humanity, religion and spirituality can provide a sense of meaning. This is especially true in the case of the stranger (the homeless, the displaced person) who is at the mercy of others. Pastoral caregiving thus involves 
taking care of life - irrespective of whether the person is a stranger or not, it is a life - with the goal to help others to know God in such a way that God is glorified. In the ambivalence between hostility and hospitality in human response, helping others to become whole and to find dignity again, is at the core of resilience. Resilience refers to a process where human beings manage not only to endure hardships, but also to create and sustain meaningful lives in the hardship and contribute to those around them (Van Hook 2013:1). Pastoral caregiving with an attitude of presence (there where the stranger is) can strengthen resilience by providing support in the form of a sense of unity, hope, care and compassion - the praxis pietatis and divine infinition.

But what does a praxis pietatis entail? First of all, in a servant attitude of presence the pastoral caregiver must know that he or she is only an instrument in the hands of God - they are totally dependent on the work of the Holy Spirit flowing through them to care for the other. It is therefore not an attitude of 'I have all the answers', but let me care for you. Caring means supporting and making space for the other to find their dignity. It is said that the biggest need of a human being is to know 'who am I?' and 'to whom do I belong?' For the more than 50 million displaced people all over the world, these two questions are not easy to answer. They are uprooted from where they belong and therefore confused about who they are. Hospitality creates a space to find answers to this basic question of identity and value. Because of the complexity of the phenomenon, believers do not have all the answers, but they do have a calling to be channels or representatives of God's infiniscience.

Secondly, we must know that - just like other religions Christianity (therefore, pastoral caregiving also) has the potential to heal or to hurt. Religion can decrease resilience when it is practised with an attitude of demoralisation. Hospitality implies being sensitive to the commonality between 
us and the stranger (humanity) and to react with respect in adoration for the immanent Christ in the stranger. Help without hurting is based on the recognition of commonality - 'do not call anything impure that God has made clean'.

Thirdly, a pastoral encounter with the stranger is based on the hermeneutics of inclusiveness to create a safe space for communication. Note that inclusiveness does not necessarily mean agreement, and communication also does not mean persuasion. Although pastoral caregiving also includes evangelism, the other's beliefs and rituals have to be respected. In pastoral caregiving, actions speak louder than words. Actions of care can result in an opportunity to share the gospel, but even the sharing of the gospel is the continuous formosus of God.

\section{Conclusion}

The world is changing and the rapid changes result in many social problems. One such a problem is the dilemma of human displacement. This chapter views important aspects of what a pastoral encounter with a stranger should entail, with special focus on the basic ambivalence about hostility or hospitality in the human response. The word 'stranger' is used to refer to the more than 50 million displaced human beings, whether immigrants or refugees. Many countries close their borders to refugees because they are seen as a threat to the stability and resources of the country to which they turn. The article examined the role of the church and especially of the pastoral caregiving ministry of the church in helping displaced human beings find the resilience to not only cope with their hardship but also find a sense of meaning in life and helping others in the same circumstances. The research was presented in four parts. Firstly, an exegetical study of Acts 10 was conducted to formulate a scriptural foundation for the calling of believers to witness and care for strangers from other ethnic and cultural backgrounds. Secondly, the focus shifted to looking at what a pastoral encounter with the 
stranger entails. Thirdly, the rapidly changing world we currently live in was discussed. Finally, the article concluded by describing how believers can help without hurting by making the paradigm shift from divine definition to divine infinition. The article provided three guidelines or principles for a pastoral encounter with a stranger based on this principle. 


\section{Chapter 10}

\section{Embracing compassion, hospitality, forgiveness and reconciliation: The quest for peaceful living in the human displacement crisis}

Rudy A. Denton

Department of Practical Theology, Faculty of Theology, North-West University, Potchefstroom, South Africa

\section{Abstract}

Increase in the migration of asylum seekers and refugees has turned out to be a major global challenge. Addressing relationships

How to cite: Denton, R.A., 2020, 'Embracing compassion, hospitality, forgiveness and reconciliation: The quest for peaceful living in the human displacement crisis', in A.R. Brunsdon (ed.), The human dilemma of displacement: Towards a practical theology and ecclesiology of home, pp. 207-229, AOSIS, Cape Town. https://doi.org/10.4102/aosis.2020. BK198.10 
between the people of host countries and displaced foreigners (refugees) is essential to create peaceful co-existence within the parameters of 'welcoming the stranger' and 'defending one's own territory'. What we should deal with is not the dread and division of right-wing and jihadi extremism but the challenges faced by both people of host countries and displaced foreigners who are struggling to live in a peaceful co-existence as significant 'others', to show hospitality and compassion and find a safe place to live and being at home in this world. This chapter unfolds challenges for societies to face the impact of globalisation on social changes and individuals' or groups' understanding and conceptualisation of a safe haven and country for peaceful living, wherein people could move away from prejudice and discriminatory discourses. The multidimensional concepts of compassion, hospitality, forgiveness and reconciliation position xenophilia as a replacement of xenophobia, and appeal to people in host countries and displaced foreigners to abolish the feelings of resentment, panic, fear, suspicion and insecurity towards one another.

Keywords: Refugees; Peaceful co-existence; Compassion; Forgiveness; Reconciliation.

\section{Introduction}

Increase in the migration of asylum seekers and refugees has turned out to be a major challenge in the shrinking planet framework of globalisation. Globalisation could be described 'as the intensification of worldwide social relations which link distant localities in such a way that local happenings are shaped by events occurring many miles away and vice versa' (Giddens 1990:64). In their article 'Globalization and conflict resolution', Tidwell and Lerche (2004) have described the complicated and interrelated relationship of globalisation and conflict:

Globalization, understood broadly, is an accelerator of social change, and as such, may act as a catalyst for conflict, aggravating the tensions in any given society and even creating new ones. At the same 
time, it may also catalyze and accelerate conflict resolution. Thus, the intensifying interconnectedness which characterizes globalization has unintended consequences for both conflict and peace processes ... (pp. 47-48)

Globalisation, conflict and conflict resolution may emerge in various actions that affect the expression of conflict, which Tidwell and Lerche (2004:50) claim, 'including disturbing local events, providing new resources over which to compete, and threatening deeply held values or symbols'. Tidwell and Lerche (2004:57) also indicate that 'conflict resolution processes such as negotiation, mediation, or other third party processes may also be impacted by globalisation' and concluded that 'one cannot simply state that globalization will either escalate or de-escalate conflict'. However, Vorster (2017:203) has stated that because of the 'reaction against the new value systems and culture posed by globalisation, people become possessed with an over-estimation of the own national, religious and cultural identity'.

According to Lerche (1998:n.p.), the paradoxical effect of globalisation on re-shaping societies, 'is that while it seeks to homogenise, it also increases awareness of social heterogeneity'. With the loss of control over societies, as an effect of globalisation and the dynamics of cultural conflict, Fuller (1995:152) has indicated that 'cultural anxieties are welcome fuel to more radical political groups that call for cultural authenticity, preservation of traditional and religious values, and rejection of the alien cultural antigens'.

Within this shrinking planet framework of globalisation, 'culture conflict' tends to intensify fundamentalist religious and ethnic ideologies in international community. Louw (2016:5) emphasises that 'religious radicalism has become the spiritual pathology in the global village and is intoxicating the belief systems of communities of faith'. One troublesome living proof of the ripple effects of globalisation and conflict could be found in the international context of increasing right-wing and jihadi extremism. According to Louw (2016):

Instead of spreading peace in the global village, the radicalisation of abstract belief systems is contributing to the phenomenon of 
xenophobia and is increasingly becoming a schismatic factor rather than a reconciling factor, dividing civil societies along religious prejudices. (p. 5)

The following events are an example of recent extremism within the framework of globalisation and conflict.

On the one hand, the Christchurch shootings of 15 March 2019 at the Al Noor Mosque and the Linwood Islamic Centre injured numerous people and killed 51 whilst the gunman live-streamed the Al Noor Mosque shooting on Facebook. The shootings have been linked to right-wing extremists and white supremacism driven by Islamophobic hatred (cf. Barton 2019). In his 17 000word, 87-page manifesto of white supremacist militant ideology, the gunman defined his heritage as follows: 'The origins of my language is European, my culture is European, my political beliefs are European, my philosophical beliefs are European, my identity is European and, most importantly, my blood is European' (Ward 2019:1). According to Coalson (2019:n.p.), the gunman characterises the shootings as 'anti-immigration, anti-ethnic replacement and anti-cultural replacement'.

On the other hand, next to the threat posed by right-wing extremism, in what looks like retaliation and revenge to the jihadi Islamist extremism and jihadi terror attacks in parts of the world, jihadi extremism is a comparable threat to the well-being and security of the world. The Tony Blair Institute for Global Change (2018:n.p.) has pointed out that violent extremism, 'both the violence and the underlying ideology that drives it, is an urgent and pressing challenge that holds back development, stability and opportunity for many around the world'. A selection from the Global Extremism Monitor (GEM) report of 2017 reveals the following on jihadi Islamist extremism:

- Extremistic groups orchestrated deadly campaigns against civilians to infuse fear and erode public morale.

- Violent extremist groups that targeted civilians deemed to be heretics for failing to respond to jihad call, which in turn triggered intensifying community tensions around the world. 
- Executions of individuals and minority groups accused of spying and disobedience, and suicide attacks (istishhad martyrdom) are used to execute violent terror attacks.

- More than 95\% of sectarian attacks targeted Muslim Shiaminority groups, and a substantial amount of attacks had focused on the religious persecution of Christians, symbols of the Christian faith and Christian denominations.

- The GEM also captured data of violent groups that apply punishments to force discipline and spread fear amongst their ranks and civilians under their rule to enforce their ideological extremism.

- Following violent attacks around the world, violent extremist groups have a colonising goal to pursuit by carrying out local insurgencies and expanding their terrorist missions across borders into new territories.

In spite of the ideology and rhetoric of right-wing and jihadi groups, their extremism and attacks, whether offensive, defensive or ritualistic, have, instead of uniting and protecting the global community, divided it. Because of escalating conflict, persecution, war and human rights violations, the global migration crisis, caused by violent extremist attacks, has brought about a global emerging security crisis on countries to safeguard their territories (space and place). In order to outline the international context of increasing right-wing and jihadi extremism and the scenario of attempts to generate 'a kind of globalised paranoia and international and intercultural systemic network of panic and fear' (Louw 2016:2), it is important to focus on the challenges of migration of displaced and homeless people (refugees) all over the globe.

Against this background, the world faces the challenges of migration of displaced and homeless people, and host countries are 'forced to adjust to a sudden arrival of hundreds or thousands of people from different cultures, languages and religions' (Rebelo, Fernández \& Achotegui 2018:239). Within the parameters of global turmoil of violence and revenge, the question of 'welcoming the stranger' or 'defending one's own territory' rises 
to the centre stage (cf. Louw 2016:1). It emphasises the challenging issues of human displacement, migration and the 'refugee crisis' that incite prejudice, xenophobia and terror attacks from right-wing and jihadi extremism.

This chapter examines multidimensional concepts that focus on the issues of human displacement crisis and migration developments of strangers, outcasts and marginalised homeless immigrants (refugees) who are increasingly being discussed in the practical theological concepts of faith-seeking compassion, space and place (cf. Louw 2017:2). It reveals a challenge to societies to face social changes and individuals' or groups' understanding of multidimensional concepts of compassion, hospitality, forgiveness and reconciliation.

\section{The complexity of human displacement}

The word 'stranger' or 'alien' (xénos) refers to the variety of what a person could be, specifically guest, host, friend or foreigner (cf. Derrida 2005:19). On 10 December 1948, the General Assembly of the United Nations approved the Universal Declaration of Human Rights (UDHR), which describes the fundamental rights of all human beings, including foreigners and refugees (ed. Brown 2016). Langmead (2014) briefly summarises the rights and freedoms of all people in the UDHR as follows:

$[T]$ hat all humans have dignity, are treated fairly and without discrimination, can move freely, know security and freedom from violence, have rights before the law, are not imprisoned for political reasons, may speak freely, may hold religious beliefs freely, may assemble peacefully, can vote freely, are able to work, receive medical care, have a roof over their heads, and have access to education. (p. 39)

Unfortunately, regardless of the UDHR, people displaced as a result of conflict, persecution, war and human rights violations have become a major humanitarian challenge. Increase in involuntary migration by refugees and asylum seekers has 
increased excessively, and the UNHCR's (2019a) statistics database is an alarming indication of this global trend. At the end of 2017, there were 71.44 million forcibly displaced people globally, the count that is anticipated to increase rapidly. The UNHCRs (2019b) global appeal update has also indicated South Africa as one of the three main migration routes and destinations of refugees and asylum seekers:

The north-west route converging on the central Mediterranean Sea and crossing into Europe mainly through Libya, the north-east route transiting Somalia or Djibouti across the Red Sea and converging in war-torn Yemen into the Gulf States, and the southern route into South Africa. (p. 67)

The involuntary migration of refugees and asylum seekers to relocate to new countries is a global social concern that forces hosting countries into persistent and complex humanitarian challenges. The growing number of populations and individuals migrating to new countries because of social threats has posed challenges, such as protection and developing of strategies to aid newcomers with basic needs and finding a safe place to live, for host countries around the world.

\section{Challenges of human displacement}

The homogeneous human community of the 21st century is globally confronted with national and transnational migrations. Louw (2016:3) describes migrants and refugees as people 'without home in search of a secure space and place'. Homelessness implies, according to Louw (2016:3), dislocation and displacement: 'It is about the quest for a safe haven and country wherein one can regain dignity, stabilise family life and start a new life'. Within the context of South Africa, Klaasen (2016:1) describes the motive for immigration as 'the result of scientific innovation, expansion of territory, conflict, poverty and globalisation', and emphasises the complex threat within a homogeneous identity and migration:

Homogeneity is now threatened by the redefining of once clear and definite borders and frameworks of being. The biggest threat to identity 
is migration of people across borders and the racial distinctions and consciousness that such migration accompanies. (p. 1)

Migration creates a space for tension amongst people and communities who cherish their differentness and foreignness in today's global village and reinforce their alienation to accommodate refugees. This refugee crisis could manifest into discrimination and stigmatisation that deprive them of their basic needs of living normal and productive lives in host countries. The growing number of migrants who pose a challenge to host countries obligated their population to adjust to an unexpected influx of foreigners from diverse cultures, religions and languages (Rebelo et al. 2018:239). On the other hand, migrants entering a new environment are also faced with the challenges of adapting to the host country's cultural habits and customs, languages and religions. Sonn (2010:433) refers to the challenges of immigration as 'uprooting and subsequently reconstructing lives in a new social, cultural and political context'. Adjustment to a changing unfamiliar new environment could trigger uncertainty, confusion and anxiety in both the general population of host countries and the inbound migrants (Kristjánsdóttir \& DeTurk 2013:196). The extent of social changes and cultural space between the cultures of host country and that of migrants could result in the feelings of fear and suspicion, which could generate prejudice, isolation, anger, insecurity about the future and xenophobia.

\section{Prejudice}

Within the realm of stigmatising and discriminatory prejudices towards foreigners, host countries are exposed to the challenges of their internal political strains, poverty, economic problems and unemployment. Prejudice towards refugees, dislocated strangers and outsiders could lead to communal paranoia, increased radicalisation of emotions, exclusive thinking and self-defence actions to isolate and safeguard own territory (cf. Louw 2016:2). Prejudice intensifies judgement that foreigners and outsiders are not only displaced strangers but also possible perpetrators, 
insurgents and 'suspects of terrorism, dangerous outsiders and outcasts' (Louw 2016:2).

\section{Polarisation, separation and isolation}

As the world and societies face social changes, deteriorating economic conditions and internal political tensions could be the main factors triggering polarisation and separation, where the people of host countries tend to resent and blame refugees for 'culture conflict', economic problems and unemployment (cf. Magezi 2017:232). The research conducted by Nyamnjoh (2006:45) and Soares, Lotter and Van der Merwe (2017:4) has revealed that most people in host countries feel that foreigners and outsiders should stay in their domestic countries and solve their problems themselves instead of competing for resources and opportunities in foreign countries. Consequently, people of host countries could deny foreigners the right to protection and dignity; access to services and basic needs; fulfilment of meaningful relationships to establish new social networks or to find employment by separating themselves and alienating outsiders (cf. Fozdar \& Hartley 2013:130).

\section{Xenophobia}

Refugees, dislocated strangers and outsiders fear rejection and are uncertain about their future, given the occurrences of xenophobia in host countries. The South African Human Rights Commission (SAHRC) defined xenophobia in general as 'the deep dislike of non-nationals by nationals of a recipient state' (South African History Online 2018). Xenophobia is also an expression of racism and shares prejudiced and discriminatory discourses based on evaluating foreigners and thereby generating negative assumptions. The labelling and profiling of dislocated strangers and outsiders have shown that 'profiling in the case of racism is on the basis of race, [and] in the case of xenophobia on the basis of nationality' (South African History Online 2018). 
Continuous re-emergence of xenophobic eruptions demonstrates the fragile society composition of South Africa with its complex socio-political history and various cultural contexts. Representation of refugees as 'criminals' or 'illegals' appears to be continuing historically based on fears of the 'other'. Fear of the 'other' has been a feature of colonial discourse and is a frequent theme fuelling anti-foreigner and anti-refugee sentiments. The colonial discourse on 'race' that formed philosophies of an 'anti-apartheid' mindset in multicultural South Africa continues to incorporate concepts of 'racial' ideology as a social construct in the human rights debates on refugees (cf. Klaasen 2016:2). The concept of 'race' also remains central to discussions on xenophobia and national identity issues. Vorster (2017:201) stated that "the term "racism" can also be used to describe "bias" and intolerance between groups other than racial groups, such as ethnic and religious groups'. According to Hall (1992:255), this design of national identity based on 'race or racism' amplified the 'racial' boundaries between belongingness and otherness. This highlights the challenging 'refugee crisis' that could incite reciprocal prejudice, xenophobia and terror attacks from right-wing and jihadi extremism.

\section{Tolerance and hospitality}

Extending Christian hospitality is fundamentally a call to authenticity and faithfulness to receive strangers as guests, and then 'insiders at home' (cf. Langmead 2014:39). French philosopher Derrida (2003:126) describes the problematic European view of a stranger through the epitome concept of an inbuilt ambivalence of tolerant culture within an atmosphere of suspicion and resistance (cf. Namli 2011:819). Derrida (2003:126) stated that 'the word "tolerance" is first of all marked by a religious war between Christians, or between Christians and non-Christians'. To understand tolerance as a form of charity, Derrida (2003) specified that:

Indeed, tolerance is first of all a form of charity. ... Tolerance is always on the side of the 'reason of the strongest', where 'might is right'; it is 
a supplementary mark of sovereignty, the good face of sovereignty, which says to the other from its elevated position, I am letting you be, you are not insufferable, I am leaving you a place in my home, but do not forget that this is my home. (p. 127)

According to Derrida (2003), tolerance is actually the opposite of hospitality to foreigners:

If I think I am being hospitable because I am tolerant, it is because I wish to limit my welcome, to retain power and maintain control over the limits of my 'home', my sovereignty, my 'I can' (my territory, my house, my language, my culture, my religion, and so on).... Tolerance is a conditional, circumspect, careful hospitality. (p. 126)

Social tension is, according to Louw (2016:7), 'the welcoming and the setting of limitations' and 'tolerance and resistance'. To describe the tolerant conditional or unconditional hospitality culture towards a foreigner, Derrida (2003) defines the epitome concept as follows:

Indeed, and so a limited tolerance is clearly preferable to an absolute intolerance. But tolerance remains a scrutinized hospitality, always under surveillance, parsimonious and protective of its sovereignty. ... We offer hospitality only on the condition that the other follow[s] our rules, our way of life, even our language, our culture, our political system, and so on. ... But pure or unconditional hospitality does not consist in such an invitation ('I invite you, I welcome you into my home, on the condition that you adapt to the laws and norms of my territory, according to my language, tradition, memory, and so on'). Pure and unconditional hospitality, hospitality itself, opens or is in advance open to someone who is neither expected nor invited, to whomever arrives as an absolutely foreign visitor, as a new arrival, non-identifiable and unforeseeable, in short, wholly other. I would call this a hospitality of visitation rather than invitation. (p. 128)

Derrida (2003) explains that the ambivalence of tolerance and hospitality could be eventually found in the risk-taking of the 'impossibility' of unconditional hospitality:

An unconditional hospitality is, to be sure, practically impossible to live; one cannot in any case, and by definition, organize it. ... No state can write it into its laws. But without at least the thought of this pure and unconditional hospitality, of hospitality itself, we would 
have no concept of hospitality in general and would not even be able to determine any rules for conditional hospitality (with its rituals, its legal status, its norms, its national or international conventions).

Without this thought of pure hospitality (a thought that is also, in its own way, an experience), we would not even have the idea of the other, of the alterity of the other, that is, of someone who enters into our lives without having been invited. We would not even have the idea of love or of 'living together (vivre ensemble)' with the other in a way that is not a part of some totality or 'ensemble'. (pp. 129-130)

Within the framework of Christian religious traditions (Mt 25:31-46), the risk-taking of tolerant unconditional hospitality culture is the call 'to receive the stranger with all the uncertainty that every estrangement bears within itself' (Namli 2011:820). Hospitality could turn out to be 'a divine moment' and a transformation process for the homeless foreigner who is seeking refuge and one's own identity through the risk-taking of hospitality to a stranger (cf. Langmead 2014:46).

\section{Compassion and hospitality}

Displaced persons and foreigners share a common need, that is, to have compassion from host countries; hence, a strong emphasis should be placed on compassion, concerning social justice for displaced persons and foreigners. The Christian faith proclaims that compassion is vital within the outlines of Jesus Christ's focus on the marginalised, the poor, the stranger and the outcast. Within this context, the homeless, the oppressed, the displaced and the suffering refugees and migrants all over the world could be included. According to Louw (2016):

The intention in a Christian performance of compassion is not to solve the tensions and to come up with instant solutions for the refugee and migrant dilemma. The challenge is to demonstrate xenophilia in such a way that both perpetrator and victim become objects of care. (p. 10)

It is within the quest for place and space (meaning and belonging) that compassion could play a vital role by assuming that a 
theology of home affects people in their relation to God to reveal love of God. Louw (2017:1-2) emphasises that the 'experience of displacement create[s] an awareness of not being at home in this world', which culminates in the human quest for home, the quality of daily living and a sense of meaning and belongingness in the world. According to Louw (2016):

Compassion in Christian spirituality is not a fleeting emotion of empathy; it is a new state of being and condition; it displays the mindset of Christ's vicarious suffering on behalf of the other; it exemplifies a hospital place and room for displaced human beings even for displaced perpetrators. (p. 10)

\section{Biblical references to displaced people}

Displacement, migration and refugees are not unfamiliar to the biblical narrative. When searching the Bible for clarification on displacement, the Old and New Testaments have numerous references to displaced people:

- Adam and Eve are the first case of displaced persons, driven from the Garden of Eden by God for their disobedience against God's instruction (Gn 3:22-24). In this first narrative of displacement, before God sent them out of the Garden of Eden, God revealed his compassion and provided relief to Adam and Eve and covered them in clothes of skin (Gn 3:21) as a visible sign of care and to address their lost dignity (cf. Neufeld 2005:681).

- The flight of Lot and his family, from Sodom and Gomorrah in Genesis 19, presents a situation of family displacement. Henry (2012:585-595) associated suffering with the loss of possessions, friends and everything for the meaning of home and belonging. The narrative shows God's care and mercy for a family of refugees by saving them to escape to safety before destroying Sodom and Gomorrah (Gn 19:28-29). 
- Food shortage was not an unusual phenomenon in biblical period. Jacob and his family were forced to migrate to Egypt as refugees to survive famine and to be reunited with his son Joseph (Gn 46-47). As a result of the famine in the land of Canaan, the narrative of Jacob and his family is a descriptive example of family displacement which caused dislocation and relocation of the entire nation of Israel to Egypt (Gn 42:6, 46:3-4). Jacob's dislocation to Egypt saved the nation of Israel from famine, but later had a period of slavery at the hands of Pharaoh (Ex 1:8-14).

- The Lord heard the Israelites' call to be rescued from slavery and oppression in Egypt and freed them from Egyptians and led them out of Egypt under the leadership of Moses (Ex 3:9-10). In the desert, the Israelites lived a semi-nomadic way of life and experienced challenges of displaced people (Phillips 2000:28). The exodus journey was a lesson of trust and obedience in God's wisdom and provision (Gn 15:6; Ex 14:31).

- Exile, or forced migration, is one of the main themes found in the Bible. Whilst in exile in Assyria (722 BC; cf. 2 Ki 17:4) and Babylon captivity (586 BC; cf. 2 Ki 25:1-21), the displaced people of God were oppressed and treated poorly by the host country (Scott 1995:60-61; Walvoord \& Zuck 1985:571). Living in exile outside the Promised Land in captivity and without a temple, created a challenge for the people of God. They developed new ways of establishing their community whilst confronting powerful cultural pressures of a foreign land and endured the period of exile in order to maintain their religious identity. Knowles (2004:65-67) states that after 70 years of exile, God showed mercy to his people by bringing them back to the Promised Land (2 Chr 36:22-23; Ezr 1:1-4; Jr 31).

- Jesus' earliest years were, according to Matthew 2:13-18, spent as a refugee in Egypt to escape Herod's massacre. Joseph, Mary and Jesus fled to Egypt as refugees, and Jesus lived as a displaced refugee child a long way from his family's original home in Nazareth (cf. Taylor 2017). 
Like many modern-day displaced migrants, people in biblical times were also vulnerable and delivered to the religious, political and economic changes of their homeland. In the biblical narrative, God always cared for the displaced and homeless people, showed mercy to them, set them free and brought them back to their homeland.

\section{Displacement of strangers and foreigners residing amongst God's people}

The people of Israel's living space also included the strangers and foreigners who lived amongst them and became part of God's people (Lv 19:10). Scriptures have referred to displaced people as 'the stranger', 'the foreigner' or 'the alien', and a number of biblical texts have teamed foreigners with the 'widows', 'orphans' and 'strangers' in difficult circumstances, and deserved shelter and protection (Ex 22:22; Dt 10:18; Ps 146:9; Jr 7:6, 22:3; Zch 7:10; MI 3:5).

God also taught his people to embrace strangers and provide for the needy in the Law of Moses (cf. Chester 2011:89). The same law and regulations applied to both the Israelites and the foreigners residing amongst Israelites (Ex 12:49). On the protection and well-being of displaced strangers and foreigners who live amongst Israelites, Bromiley (1995:569) and Soares et al. (2017:3) point out that the laws given to Moses revealed the following:

- $\quad$ provision for rest to foreigners on the Sabbath (Ex 20:10, 23:12; Dt 5:14)

- ensuring righteousness in court, which confirmed that foreigners received similar protection as the Israelites (Dt 1:16)

- protection of people who seek asylum and access to cities for refuge if their lives were endangered ( $\mathrm{Nm}$ 35:15; Jos 20:9)

- participation in religious festivities (Lv 16:29; Nm 9:14; Dt 16:1, 11)

- provision of food security for sustenance (Lv 23:22; Dt 24:20)

- financial aid from the three-year tithe (Dt 26:11). 
To ameliorate compassion towards foreigners who took refuge in Israel, the Israelites' social responsibility towards refugees were prescribed in Exodus 22:21 and linked with the period they were foreigners in Egypt: 'Do not ill-treat or oppress a foreigner; remember that you were foreigners in Egypt'. Bosch (1980) points out how the people of God should serve and show compassion to displaced strangers and foreigners residing amongst them:

Israel, who had been stranger in Egypt, had to have compassion on the stranger in her midst. The constitutive element here was neither the ethnic, nor the biological, nor the cultural; the stranger who lived in Israel had to be accepted completely and without reserve. (p. 52)

Refugees continuously face numerous challenges as they search for protection and hospitality in a new social environment when they have been forced to leave their native land of origin because of situations that posed threat to their lives. Langmead (2014:34) highlights that 'a strong and focused concern for the most marginalized is deeply embedded within the Christian tradition'. In his life, Jesus upholds the human dignity of people on the sidelines of society. Vorster (2007:27) indicates that 'as the perfect image of God, Christ is the model for true humanity'. By referencing Isaiah 58:6 and 61:1-2, Jesus declared in Luke 4:18-19 that the Spirit of the Lord is upon him because the Lord has anointed him to proclaim good news to the poor, freedom for the captives, healing for the sick and liberation for the oppressed. The prophetic tradition from which Jesus communicates with his listeners requests God's people for compassion and social justice (Is 58):

6The kind of fasting I want is this: Remove the chains of oppression and the yoke of injustice, and let the oppressed go free. ${ }^{7}$ Share your food with the hungry and open your homes to the homeless poor. Give clothes to those who have nothing to wear, and do not refuse to help your own relatives. ${ }^{8}$ Then my favour will shine on you like the morning sun, and your wounds will be quickly healed. I will always be with you to save you; my presence will protect you on every side. (vv. 6-8)

The imago Dei, as the key concept of theological anthropology, compels man to extend compassion and hospitality to fellow 
humans in society (cf. Oberdorfer 2010:232). Klaasen (2016:1) points out that 'faith plays a role in the formation of identity and that faith creates space for cohesive coexistence'. Of particular relevance and focus for the marginalised, the poor, the stranger and the outcast are Jesus' teaching in Matthew 25 for showing friendship and love to the most vulnerable in societies by serving the hungry, thirsty, sick, naked, imprisoned and foreigners:

${ }^{35}$ For I was hungry and you gave me something to eat, I was thirsty and you gave me something to drink, I was a stranger and you invited me in, ${ }^{36}$ I needed clothes and you clothed me, I was sick and you looked after me, I was in prison and you came to visit me. (vv. 35-36)

Jesus reached out to the poor and the marginalised, showing compassion and displaying God's inner nature. Jesus revealed the love of God in serving the hungry and thirsty, providing hospitality to the homeless and stranger, clothing the naked, healing the sick and visiting the prisoner (cf. Carter 2000:445). Through this command, Jesus emphasises the relation between the love for God and love for one's neighbour, declaring that those who extend compassion and hospitality to fellow humans actually identify with Jesus and God (cf. Viljoen 2015:7). Klaasen (2016) states:

Immigrants and minority race groups do not threaten the existence of the group in the centre but is significant others, who form an integral part of the process of becoming in the image of God. (p. 5)

\section{Embracing forgiveness and reconciliation in the human displacement crisis}

The relevance of forgiveness and reconciliation are two complex and challenging subjects when migration creates a space for tension instead of peaceful living within the human displacement crisis. On the one hand, people in host countries may tend to reinforce their alienation to accommodate refugees by stigmatisation and discriminatory prejudice towards foreigners. 
Challenges from their own social changes, internal political tension, deteriorating economic conditions, poverty and unemployment could lead to communal paranoia, increased radicalisation of emotions, exclusive thinking and self-defence actions to isolate refugees and dislocated strangers. Xenophobic eruptions in host countries could trigger polarisation and separation through extreme terror attacks from right-wing extremists, who want to safeguard own territory against the unexpected influx of foreigners from diverse economic adversity, cultures, religions and languages. On the other hand, competing for resources and opportunities, and social isolation could result in migrants' experiences of hostility and rejection, which could escalate xenophobic eruptions from people of host countries who tend to resent and blame foreigners for 'culture conflict', economic problems and unemployment. Adjustment to the changing and unfamiliar new environment, insecurity about the future and xenophobic eruptions could trigger uncertainty, confusion, fear and anxiety. Consequently, sustained negation of migrants' rights of protection and dignity, access to services and basic needs, fulfilment of meaningful relationships to establish new social networks or to find employment could incite reciprocal terror attacks from jihadi extremism.

In this discussion about forgiveness and reconciliation, it is necessary to distinguish between the two. Forgiveness is understood to be detached from condoning, excusing, pardoning, justifying, forgetting and reconciliation (Enright \& Fitzgibbons 2000; Hook et al. 2012:687). Forgiveness does not necessarily entail reconciling, but it is nearly impossible for reconciliation without some mode of forgiveness. Enright (2011:31) argues that 'one may forgive and not reconcile, but one never truly reconciles without some form of forgiving taking place'.

Forgiveness could activate reconciliation and restoration of a fragile society when social relations are emphasised (cf. Denton 2018:1; Vorster 2011:75). McCullough, Fincham and Tsang (2003:540) well defined forgiveness as a pro-social transformation in thoughts, emotions, motivations or behaviours, although 
socio-cultural worldviews connect to one's understanding of forgiveness and might affect how individuals or groups understand forgiveness based on cultural context. Hook et al. (2012) argue that individuals do tend to view forgiveness differently on intrapersonal-interpersonal dimension, and these differences may influence feelings about the relationship':

How individuals or groups conceptualize forgiveness may affect their expectations and interpretation of the events following a transgression. A person with a strong interpersonal conceptualization of forgiveness may expect there to be substantial interpersonal interactions following the transgression, whereas a person with a more intrapersonal conceptualization of forgiveness may not expect or desire these interactions. (pp. 688, 691)

Individuals or groups within one's socio-cultural worldview, situation or context could benefit from the interpersonal conceptualisations of forgiveness, whilst other individuals or groups within another socio-cultural worldview, situation or context could benefit more from intrapersonal conceptualisations of forgiveness (cf. Worthington 2001). Different conceptualisations of forgiveness have an influence on individuals' or groups' process to forgive. Derrida (2005:33) argues that 'forgiveness must announce itself as impossibility itself. It can only be possible in doing the impossible'. An interpersonal type of personality with a collectivistic worldview 'tends to view forgiveness within the context of reconciliation and relational repair' (Hook et al. 2012:691), whilst an intrapersonal type of personality defines 'forgiveness as a process that happens within the mind and heart involving emotions, cognitions, and motivations' (Hook et al. 2012:687). Forgiveness, whether interpersonal or intrapersonal, is an indispensable practice of reconciliation and restorative healing within the context of relational repair and within the mind and heart (cf. Denton 2018:3).

However, people are much more reticent when forgiving refugees, dislocated strangers and outsiders. Forgiveness can be described as 'more moral in nature and starts as a private act' and 'reconciliation is the act of two people coming together after 
separation' (Enright 2011:31). According to Enright and North (1998:78), 'it is possible to forgive without reconciling, without coming together again in love and friendship. But it is not possible to reconcile truly without forgiving'. That is why a premature reconciliation would serve no purpose, given the resentment and blame, people in host countries may feel following a sudden arrival of foreigners from different cultures, languages and religions, who are seen as the cause of 'culture conflict', economic problems and unemployment.

Reconciliation is a continuous process of renouncing violence and fear and maintaining social peace. In its progressive dimension, reconciliation means to get on with life and establishing a civilised society. Huyse (2003:19) claimed that reconciliation prevents, 'the use of the past as the seed of renewed conflict'. The process of reconciliation brings people together for the common purpose to live in peace; it halts the cycle of violence to restore democratic societies or reinforces a newly established social order. Thesnaar (2014:7) appealed that 'we need to embody reconciliation and peace by, amongst others, respecting the human dignity of all involved in the conflict, especially the "other," and emphasising justice and not revenge'.

Before reconciliation begins for a peaceful and non-violent society, trust and compassion must be embodied in people's minds and hearts, thus connecting thoughts, emotions, motivations or behaviours in the reconciliation process. According to Huyse (2003:24), different mechanisms are needed to initiate a process of reconciliation such as practices to promote healing, truth-telling, restorative justice and reparations.

Reconciliation is seen as a vital feature of conflict prevention, even though lasting reconciliation requires the reconciling of individuals, and groups and communities as a whole. In order to implement reconciliation, it has to be embedded with essential values, for example equality and respect, be attentive to specific matters of culture, identity, religion and ethnicity, and addressing disputes in a paradoxical impact of globalisation that pursues to 
homogenise whilst intensifying consciousness of social heterogeneity. Although authorities are not able to enforce reconciliation or forgive on behalf of sufferers or enforce trust and empathy by decree (cf. Huyse 2003:26), they can however make every effort to create a social environment that may precede reconciliation process.

Forgiveness and reconciliation are possible when forgiveness paves way to reconciliation. Forgiveness involves a Christian duty based on the theology of reconciliation and salvation through God's love, redemption and reconciliation (cf. Mt 6:14; Col 3:13; Eph 4:29-32). Enright, Freedman and Rique (1998) outline forgiveness as follows:

[A] willingness to abandon one's right to resentment, negative judgment, and indifferent behavior toward one who unjustly injured us, while fostering the undeserved qualities of compassion, generosity, and even love toward him or her. (pp. 46-47)

Christian forgiveness calls on Christians 'to live in their community and society as forgiven, redeemed and reconciled people', committed to compassion and justice (Denton 2018:4). For forgiveness to be viable or even constructive, people in host countries must be willing to forgive, and a process of healing proceeds that moment, where restorative justice outweighs retributive justice.

\section{The quest for peaceful living}

Addressing relationships between people of host countries and displaced foreigners (refugees) is essential to helping create peaceful co-existence within the parameters of 'welcoming the stranger' and 'defending one's own territory'. What we should deal with is not the dread and division of right-wing and jihadi extremism, but the challenges faced by host countries and displaced foreigners (refugees) struggling to live in a peaceful co-existence as significant 'others'. To reveal hospitality and compassion and find a safe place to live and being at home in this 
world are major challenges face by host population and displaced persons. According to Louw (2016:9), the complexity of human displacement and migration emphasises the paradox that the refugee crisis can bring out the ugliness in human beings, but reveal the best as well'.

Migration creates a space for tension amongst people and communities which may generate prejudice, isolation, anger, insecurity about the future as well as xenophobic eruptions, which could incite reciprocal terror attacks from right-wing and jihadi extremism. To the extreme, right-wing and jihadi extremism could bring out violent ugliness in human beings.

The imago Dei compels man to extend compassion and hospitality. Hospitality towards displaced foreigners is fundamentally a call to receive strangers to become guests and 'insiders at home'. Compassion is vital within the outlines of Jesus Christ's friendship and love towards vulnerable and marginalised. The multidimensional concepts of compassion and hospitality reveal the best in human beings and demonstrate xenophilia as a replacement of xenophobia. Forgiveness and reconciliation call on the people of host countries and displaced foreigners to abolish the mutual feelings of resentment, panic, fear, suspicion and insecurity towards one another and replace the same with xenophilia.

\section{Conclusion}

In conclusion, if we are not able to incorporate concepts of 'compassion and hospitality' and 'forgiveness and reconciliation' into our quest for peaceful co=existence between the people of host countries and displaced foreigners (refugees), we would continue to suffer with prejudice, isolation, anger, insecurity about the future and xenophobic eruptions in society. The end result is that we could possibly see ever-increasing right-wing and jihadi extremism in society. Within these parameters of global turmoil of violence and revenge, we would be less welcoming to strangers and defending our territory based on political history, social context, culture, race, ethnicity, religion and language. 
This chapter reveals a challenge for societies to face the impact of globalisation on social changes. It further calls for individuals' or groups' understanding and conceptualisation of a safe haven and country for peaceful living - a society wherein people could move away from prejudiced and discriminatory discourses based on fear of the 'other', or the assertive assumption of 'us' against 'them'. In the ethics of welcoming, to generate a space of meaning and belonging, Langmead (2014:45) describes the act of hospitality and compassion comparable to the act of embrace, and refers to Volf's (1996) four movements:

We open our arms in offer (or open the door). We wait for a free response to accept. We close our arms in embrace (or invite others into our house and make them at home). But finally and most importantly, we open our arms again (or let the guest go), symbolizing a recognition of difference, a willingness for the other to be them-selves, though perhaps now in a new space. These are the ethics and dynamics of hospitality and embrace. (pp. 140-147) 



\section{References}

\section{Chapter 1}

Amann, M., Friedmann, J., Hoffmann, C., Knaup, H., Knobbe, M., Müller, P. et al., 2015, 'Das neue Deutschland [The new Germany]', Der Spiegel 36, 18-29. https://doi.org/10.1055/s-0034-1396238

Bauman, Z., 2016, 'Nationalismus ist ein Ersatz: Spiegel-Gespräch [Nationalism is a substitute: Mirror conversation]', Der Spiegel 36, 122-125.

Berggren, E., 2015, Catholicity challenging ethnicity: An ecclesiological study of churches in post-Apartheid South Africa, Uppsala University, Uppsala.

Bollnow, O.F., 2011, Human space, Hyphen Press, London.

Brazal, A.M. \& De Guzman, E.S., 2015, Intercultural church: Bridge of solidarity in the migration context, Borderless Press, Manchester.

Brown, D., 2017, Happy: Why more or less everything is absolutely fine, Penguin Random House UK, London.

Busch, E., 2007, 'A general overview of the reception of Calvin's social and economic "Thought”, in E. Dommen \& J.D. Bratt (eds.), John Calvin rediscovered, Westminster John Knox, Louisville, KY.

Calvin, J., 1854, Commentaries on the Epistles of Paul to the Galatians and Ephesians, Printed for the Calvin Translation Society, T. Constable, Edinburgh.

Castels, S. \& Miller, M.J., 2009, The age of migration: International population movements in the modern world, Castillo Guerra, New York, NY.

Davies, O., 2001, A theology of compassion: Metaphysics of difference and the renewal of tradition, William B. Eerdmans Publishing Company, Grand Rapids, MI.

De Gruchy, J., 2009, John Calvin: Christian Humanist \& Evangelical Reformer, Lux Verbi.BM, Wellington.

De Gruchy, J., 2018, 'Christian humanism, progressive Christianity and social transformation', Journal for the Study of Religion 31(1), 2018. https://doi. org/10.17159/2413-3027/2018/v31n1a3

Drehsen, V., Gräb, W. \& Weyl, B., 2005, Kompendium Religionstheorie, Vandenhoeck \& Ruprecht, Göttingen.

Duffy, M., 2016, 'Klaus Schwab on the digital revolution', Time 187(2), 12.

Forohaar, R., 2015, 'Europe's gamble: Migrants could be a key to a stronger economy', Time. Special Report. Exodus. The Epic Migration to Europe \& What Lies Ahead, 19 October 2015, pp. 60-61.

Gibbs, N., 2015, 'The choice', Time 186(25-26), 23-24. https://doi.org/10.1515/ 9781400865567-012

Goetzmann, J., 1976, 'Oikodomeō', in C. Brown (ed.) Dictionary of New Testament Theology, vol. 2, pp. 251-253, Paternoster Press, Exeter. 
Gorney, C., 2008, Mexico's other border, viewed 16 November 2015, from http:// ngm.nationalgeographic.com/2008/02/mexicos-southern-border/cynthiagorney-text.

Gruber, J. \& Rettenbacher, S. (eds.), 2015, Migration as a sign of the times: Towards a theology of migration, Brill Academic Publishers, Leiden.

Holten, M.J., 2016, Longing for home: Forced displacement and postures of hospitality, Yale University Press, New Haven, CT.

Jackson, M., 1991, 'Heal the world', YouTube, official music video, viewed 19 October 2019, from https://www.youtube.com/watch?v=BWf-eARnf6U.

Kassam, Z., 2018, 'Muslims and migration: Global realities, local opportunities', in D. Schiapani, M. Walton \& D. Lootens (eds.), Where are we? Pastoral environments and care for migrants: Intercultural and interreligious perspectives, pp. 77-90, SIPCC Publication, Düsseldorf.

Kaunda, K., 1967, A humanist in Africa: Letters to Colin Morris, Longman, London.

Keifert, P.R., 1992, Welcoming the stranger: A public theology of worship and evangelism, Augsburg Fortress Press, Minneapolis, MN.

Kessler, T., 2014, Migration als Ort der Theologie, Verlag Friedrich Pustet, Regensburg.

Kierkegaard, S., 1962, Works of love, Harper \& Row, New York, NY.

Klinger, E., 2012, 'The search for meaning in evolutionary goal-theory perspective and its clinical implications', in P.T.P. Wong (ed.), The human quest for meaning: Theories, research, and applications, pp. 23-79, Routledge, New York, NY.

Klein, J., 2015, 'As chaos grows in Syria, Iran could be a surprising American Ally', Time. Special report. Exodus. The epic migration to Europe \& what lies ahead, pp. 24-25, October 19, 2015.

Kunzig, R., 2016, 'The New Europeans', National Geographic, 19 May, 82-115.

Lartey, E., 2018, 'Foreword', in D. Schiapani, M. Walton \& D. Lootens (eds.), Where are we? Pastoral environments and care for migrants: Intercultural and interreligious perspectives, pp. ix-xi, SIPCC Publication, Düsseldorf.

Levinas, E., 1968, Totalité et Infini: Essai sur l'extériorité, Martinus Nijhoff, La Haye. Louw, D.J., 2017, 'Black-White polarisation in \#MustFall campaigns: Towards a practical theological diagnostics of "peaceful coexistence"', In die Skriflig/In Luce Verbi 51(1), 9 pages. https://doi.org/10.4102/ids.v51i1.2220

Mandela, N., 2005, In the words of Nelson Mandela, Penguin Books, London.

Manheim, K., 1966, Ideology and utopia, Routledge \& Kegan Paul LTD, London.

McGrath, A., 1993, A life of John Calvin: A study in the shaping of western culture, Blackwell, Oxford.

Myers, C. \& Colwell, M., 2012, Our God is undocumented: Biblical faith and immigrant justice, Orbis Books Maryknoll, New York, NY.

Nilson, F., 2007, 'Towards a Dialectic complexity framework: Philosophical reflections', in K.A. Richardson \& P. Cilliers (eds.), Explorations in complexity 
thinking: Pre-proceedings of the 3rd International Workshop on complexity and philosophy, ISCE Publishing, Mansfield, pp. 236-249.

Mbaku, J.M., 1999, 'General introduction', in J.M. Mbaku (ed.), Preparing Africa for the twenty-first century: Strategies for peaceful coexistence and sustainable development, pp. 1-16, Ashgate, Aldershot.

Morin, E., 2008, On complexity, Hampton Press, Inc., Cresskill.

Padilla, E. \& P.C. Khan (eds.), 2013, Contemporary issues of migration and theology, Palgrave Macmillan, New York, NY.

Phan, P.C., 2016, 'Deus migrator - God the migrant. Migration of Theology and Theology of Migration', Theological Studies 77(4), 845-868. https://doi. otg/10.1177/0040563916666825

Polak, R., 2014, 'Migration als Ort der Theologie', in T. Kessler (ed.), Migration als Ort der Theologie, pp. 1-20, Regensburg, Verlag Friedrich Pustet.

Polak, R., 2018, 'Practical theological reflections on the refugee crisis in Europe', in D. Schiapani, M. Walton \& D. Lootens (eds.), Where are we? Pastoral environments and care for migrants: Intercultural and interreligious perspectives, pp. 19-51, SIPCC Publication, Düsseldorf.

Ramphele, M., 2012, Conversations with my sons and daughters, Penguin Books, Johannesburg.

Robins, R., 2018, 'We were once strangers: Discussions on radical hospitality during challenging times', in D. Schiapani, M. Walton \& D. Lootens (eds.), Where are we? Pastoral environments and care for migrants: Intercultural and interreligious perspectives, pp. 139-144, SIPCC Publication, Düsseldorf.

Sathler-Rosa, R., 2018, 'Care, spirituality, and social action: A pastoral theological approach', in D. Schiapani, M. Walton \& D. Lootens (eds.), Where are we? Pastoral environments and care for migrants. Intercultural and interreligious perspectives, pp. 93-101, SIPCC Publication, Düsseldorf.

Shuster, S., 2015, 'Smuggler's cove', Time. Special report. Exodus. The epic migration to Europe \& what lies ahead, October 19, 2015, pp. 38-43.

Steger, M.F., 2012, 'Experiencing meaning in life: Optimal functioning at the Nexus of well-being, psychopathology, and spirituality', in P.T.P. Wong (ed.), The human quest for meaning: Theories, research, and applications, pp. 165-184, Routledge, New York, NY.

Sweeden, N.B., 2015, Church as the way: Hospitality and migration, Pickwick Publications, Eugene, OR.

Taleb, N.N., 2010, The black swan: The impact of the highly improbable, Penguin Books, London.

Vick, K., 2015, 'The great migration', Time. Special report. Exodus. The epic migration to Europe \& what lies ahead, October 19, 2015, pp. 26-34.

Vick K. \& Shuster, S., 2015a, 'Angela Merkel - Person of the year: Chancellor of the free world', Time, viewed 14 November 2017, from http://time.com/timeperson-of-the-year-2015-angela-merkel/. 
Vick, K. \& Shuster, S., 2015b, 'Angela Merkel: Chancellor of the Free World', Time 186(25-26), 26-51.

Wong, P.T.P., 2012, 'Toward a dual-systems model of what makes life worth living', in P.T.P. Wong (ed.), The human quest for meaning: Theories, research, and applications, pp. 3-21, Routledge, New York, NY.

\section{Chapter 2}

'No home for church refugees', News24, 31 December, 2014, viewed 13 August 2018, from https://www.news24.com/SouthAfrica/News/No-home-forchurch-refugees-20141231.

Abbot, A., 2016, 'The troubled minds of migrants', Nature 538(7624), 158-160. https://doi.org/10.1038/538158a

Alobo, E. \& Obaji, S., 2016, 'Internal displacement in Nigeria and the case for human rights protection of displaced persons', Journal of Law, Policy and Globalization 51, 26-33.

Amit, R., 2017, African refugees in South Africa are often unable to access their rights, viewed 06 August 2018, from http://blogs.Ise.ac.uk/africaatlse/2016/01/29/ african-refugees-in-south-africa-are-often-unable-to-access-their-rights/.

Bacon, D., 2008, Illegal people: How globalization creates migration and criminalizes immigrants, Beacon Press, Boston, MA.

Banda, H.C.C., 2014, 'Xenophobia as a form of human insecurity: Plight of Malawian migrants in South Africa', African Renaissance 11(3-4), 97-124.

Bloch, J. \& Heese, S., 2007, I am an African: Stories of young refugees in South Africa, New Africa Books, Claremont.

Boym, S., 2007, 'Nostalgia and its discontents', The Hedgehog Review 9(2), 7-18.

Bradshaw, P., 2017, 'Human flow review - Ai Weiwei surveys shocking plight of migrants on the move', The Guardian, International edition, 07 December, viewed 27 July 2018, from https://www.theguardian.com/film/2017/dec/07/ human-flow-review-ai-weiwei-migration-documentary.

Burns, J.J., 2017, Preventing the world's next refugee crisis: Famine, conflict, and climate change in Nigeria, South Sudan, Somalia, and Yemen, American Security Project, Washington, DC.

Connolly, W., 1991, 'Democracy and territoriality', Millennium Journal of International Studies 20(3), 463-484. https://doi.org/10.1177/0305829891020 0030301

Conradie, E.M., 2007, 'The whole household of God (oikos): Some ecclesiological perspectives (part 1)', Scriptura 94, 1-9.

Fowlkes, D.W. \& Verster, P., 2006, 'Family (oikos) evangelism for reaching forward caste Hindus in India', Verbum et ecclesia 26(1), 321-338. https://doi. org/10.4102/ve.v27i1.138

Hammar, A. (ed.), 2014, Displacement economies in Africa: Paradoxes of crisis and creativity, Zed Books, London. 
Holton, M.J., 2016, Longing for home: Forced displacement and postures of hospitality, Yale University Press, New Haven, CT.

Kalipeni, E. \& Oppong, J., 1998, 'The refugee crisis in Africa and implications for health and disease: A political ecology approach', Social Science Medicine 46(12), 1637-1653. https://doi.org/10.1016/S0277-9536(97)10129-0

Lambo, I., 2012, In the shelter of each other: Notions of home and belonging amongst Somali refugees in Nairobi, New issues in refugee research, Research paper no. 233, The UN Refugee Agency, pp. 1-27.

Loprete, G., 2016, 'Migro ergo sum - I migrate, therefore I am - Social pressure as a driver of economic migration from West Africa', Africa at LSE, viewed 11 August 2018, from https://blogs.Ise.ac.uk/africaatlse/2016/01/14/migro-ergo-sum -i-migrate-therefore-i-am-social-pressure-as-a-driver-of-economic-migrationfrom-west-africa/.

Louw, D.J., 2016, 'The refugee dilemma and migrant crisis: "Charity begins at home" or "being home to the homeless"? The paradoxical stance in pastoral caregiving and the infiltration and perichoresis of compassion', HTS Teologiese Studies/ Theological Studies 72(2), a3267. https://doi.org/10.4102/hts.v72i2.3267

Louw, D.J., 2017, 'Ekhaya: Human displacement and the yearning for familial homecoming: From throne (Cathedra) to home (Oikos) in a grassroots ecclesiology of place and space: Fides Quaerens Domum et Locum [faith seeking home and space]', HTS Teologiese Studies/Theological Studies 73(4), a4484. https://doi.org/10.4102/hts.v73i4.4484

Malwitz, C.C., 2018, 'Particular social groups: Vague definitions and an indeterminate future for asylum seekers', Brooklyn Law Review 83(3), 1149-1173.

Marschall, S., 2017, 'Migrants on home visits: Memory, identity and a shifting sense of self', International Journal of Tourism Research 19(2), 214-222. https://doi. org/10.1002/jtr.2103

Newman, J.L., 1995, The peopling of Africa: A geographic interpretation, Yale University Press, New Haven, CT.

Onaedo, E., Samuel, O. \& John, S., 2017, 'An Assessment of the impact of internal displacement on human security in Northern Nigeria (2009-2016)', Acta Universitatis Danubius 10(1), 19-42.

Ostrand, N., 2015, 'The Syrian refugee crisis: A comparison of responses by Germany, Sweden, the United Kingdom, and the United States', Journal of Migration and Human Security 3(3), 255-279. https://doi.org/10.1177/233150241500300301

Ruyssen, I. \& Rayp, G., 2014, 'Determinants of intraregional migration in subSaharan Africa (1980-2000)', The Journal of Development Studies 50(3), 426443, https://doi.org/10.1080/00220388.2013.866218

Sekides, C., Wildschut, T., Arndt, J. \& Routledge, C., 2008, 'Nostalgia. Past, present and future', Current Directions in Psychological Science 17(5), 304-307. https:// doi.org/10.1111/j.1467-8721.2008.00595.x

Taylor, H., 2015, Refugees and the meaning of home: Cypriot narratives of loss, longing and daily life in London, Palgrave MacMillan, Basingstoke.

United Nations High Commissioner for Refugees (UNHCR), 2017, UNHCR Global appeal 2018-2019 Regional summaries, Africa, viewed 07 August 2018, from 
http://www.unhcr.org/en-us/publications/fundraising/5aObfe697/unhcrglobal-appeal-2018-2019-africa.html.

United Nations High Commissioner for Refugees (UNHCR), 2018a, Global trends: Forced displacement in 2017, viewed 06 August 2018, from http://www.unhcr. org/5b27be547.pdf.

United Nations High Commissioner for Refugees (UNHCR), 2018b, Figures at a glance, viewed 06 August 2018, from http://www.unhcr.org/figures-at-aglance.html.

United Nations High Commissioner for Refugees (UNHCR), 2018c, Emergency handbook, viewed 07 August 2018, from https://emergency.unhcr.org/.

Vick, K., 2015, 'The great migration', Time, Special Report. Exodus. The epic migration to Europe \& what lies ahead, 19 October, pp. 40-45.

Zamfir, K., 2014, 'Is the ekklesiia a household (of God)? Reassessing the notion of oĩkoৎ $\theta \varepsilon$ oṽ in 1 Tim 3.15', New Testament Studies 60(4), 511-528. https://doi. org/10.1017/SO028688514000174

\section{Chapter 3}

Abel, M., 2017, 'Labour market discrimination and sorting: Evidence from South Africa', Southern Africa Labour and Development Research Unit 205(1), 1-42. https://doi.org/10.1596/1813-9450-8180

Amnesty International, 2015, 8 ways to solve the world refugee crisis/Amnesty international, viewed 27 March 2020, from https://www.amnesty.org/en/ latest/campaigns/.../eight-solutions-world-refugee-crisis.

Azindow, Y.M., 2007, 'Insiders and outsiders: Citizenship and xenophobia', African Studies Review 50(1), 175-176. https://doi.org/10.1353/arw.2005.0090

Baloyi, E.M., 2018, 'Tribalism: Thorny issue towards reconciliation in South Africa A practical theological appraisal', HTS Teologiese Studies/Theological Studies 74(2), 4772. https://doi.org/10.4102/hts.v74i2.4772

Barca, M.A.C., 2011, Virtue of ethics in the parable of the Good Samaritan shaping Christian character, Boston College University Libraries, Boston, MA.

Bhengu, M.J., 1996, Ubuntu: The essence of democracy, Novalis Press, Cape Town.

Blajer, P., 2012, The parable of the Good Samaritan (Luke 10:25-37): Its function and purpose within the Lukan Journey Section, Catholic University of America, Washington, DC.

Brindle, W.A., 1984, 'The origin and history of the Samaritans', Grace Theological Seminary 5(1), 4-75.

Broodryk, J., 2006, Ubuntu: African life copying skills, Ubunto School of Philosophy, Pretoria.

Bruce, L., 2017, Recurrence of xenophobic attacks in South Africa: Centre for Applied Legal Studies, University of the Witwatersrand, Johannesburg. 
Cilliers, J., 2008, In search of meaning between Ubuntu and into: Perspectives on preaching in post-Apartheid South Africa, viewed 23 March 2020, from http:// citeseerx.ist.psu.edu/viewdoc/summary?doi=10.1.1.487.9558.

Crush, J. \& Williams, V., 2001, 'Making up the numbers: Measuring "illegal immigration" to South Africa, Migration Policy Brief No. 3. The Southern African Migration programme', viewed 12 August 2017, from https://samponline.org/ wp-content/uploads/2016/10/brief3.pdf.

De Jager, N. \& Musuva, C., 2016, 'The influx of Zimbabweans into South Africa: A crisis of governance that spills over', Journal Africa Review 8(1), 1-30. https:// doi.org/10.1080/09744053.2015.1089013

Donovan, P., 1983, 'When does personhood begin?', Family Planning Perspectives 15(1), 40-44. https://doi.org/10.2307/2134544

Eklund, H., 2008, Ubuntu: An analysis of the political rhetoric of a traditional concept in contemporary South Africa, Hogskolan, Dalarna.

Eliastam, J.L.B., 2015, 'Exploring Ubuntu discourse in South Africa: Loss, liminality and hope', Verbum et Ecclesia 36(2), Art. \#1427, 8 pages. https://doi. org/10.4102/ve.v36i2.1427

Fauvelle-Aymar, C., 2015, Immigration and the South Africa Labour market, viewed 17 October 2017, from http://data.leo-univ-orleans.fr/media/seminars/241/ fauvelle-aymar-articleseminaireleo2015.pdf.

Garson, J. P. \& Loizillon, A., 2003, The economic and social aspects of migration OECD, viewed 18 May 2017, from www.oecd.org/migration/mig/15516948.pdf.

Gooding, D., 1987, According to Luke: A new exposition of the Third Gospel, Eerdmans, Grand Rapids, MI.

Gopal, N., 2013, 'They call us Makwerekweres' - Foreign learners speak out against xenophobia', in S. Manik \& A. Singh (eds.), Love thy neighbours: Exploring and exposing xenophobia in social spaces in South Africa, pp. 125-144, Interdisciplinary Journal for the Study of the Arts and Humanities in Southern Africa, Durban.

Henriques, G., 2015, When does 'it' become a person, psychology today, viewed 27 March 2020, from https://www.psychologytoday.com/us/blog/theoryknowledge/201508/when-does-it-become-person.

Hughes, R.K., 1998, Luke Volume One: That you may know the truth, Crossway Books, Wheaton, IL.

International Organization for Migration (IOM), 2009, Towards tolerance, law, and dignity: Addressing violence against foreign nationals in South Africa, viewed 17 October 2017, from https://southafrica.iom.int/publications/towards-tolerancelaw-and-dignity-addressing-violence-against-foreign-nationals-south-africa.

Jackson, D. \& Passarelli, A., 2016, Mapping migration, mapping churches' responses in Europe: Belonging, community and integration: The witness and service of churches in Europe, World Council of Churches, viewed 26 August 2017, from https://ccme.eu/wp-content/uploads/2018/12/2008-05-28_CCME_Publ_-_ Mapping_migration_-_Mapping_Churches_responses.pdf.

Jeffrey, D.L., 2012, Luke: Brazos Theological Commentary on the Bible, Brazos Press, Grand Rapids, MI. 
Jolley, D.R., 2011, 'Ubuntu: A person is a person through other persons', Master's thesis, Southern Utah University, viewed 22 March 2020, from https://www. suu.edu/hss/comm/masters/capstone/thesis/jolley-d.pdf.

Kalitanyi, V. \& Visser, K., 2010, 'African immigrants in South Africa: Job takers or job creators', SAJEMS NS 13(4), 376-390. https://doi.org/10.4102/sajems. v13i4.91

Lefa, B.J., 2015, 'Ubuntu in South African Education', Studies in Philosophy and Education 1(1), 15.

Lindeque, M., 2017, 'Deputy police min accuses foreign nationals in Hilbrow of economic sabotage', Eyewitness News, viewed 15 September 2017, from https://ewn.co.za/2017/07/14/deputy-police-minister-accuses-hillbrowforeign-nationals-of-economic-sabotage.

Ling, J. R., 2017, 'When does human life begin? Christian thinking and contemporary opposition', The Christian Institute, viewed 27 March 2020, from https://www. christian.org.uk/wp-content/uploads/when-does-human-life-begin.pdf.

Magezi, C., 2018, 'Theological understandings of migration and church ministry model: A quest for holistic ministry to migrants in South Africa', PhD thesis, North-West University, Potchefstroom.

Magezi, C., 2019, 'Migration, instrumental to accomplishing God's redemptive purpose to humankind: Perspectives from Ruth and Joshua', In die Skriflig 53(1), a2462. https://doi.org/10.4102/ids.v53i1.2462

Magezi, V., 2017, 'Ubuntu in flames - Injustice and disillusionment in post-colonial Africa: A practical theology for new "liminal Ubuntu" and personhood', in J. Dreyer, Y. Dreyer, E. Foley \& M. Nel (eds.), Practicing Ubuntu: Practical theological perspectives on injustice, personhood and Human dignity, pp. 111122, LIT VERLAG GmbH \& Co. KG Wien, Klosbachstr.

Magezi, V. \& Magezi, C., 2018, 'Migration crisis and Christian response: From Daniel De Groody's image of God theological prism in migration theology to a migration practical theology ministerial approach and operative ecclesiology', HTS Teologiese Studies/Theological Studies 74(1), 4876. https:// doi.org/10.4102/hts.v74i1.4876

Manik, S. \& Singh, A., 2013, 'Editorial, love thy neighbours - Exploring and exposing xenophobia in social spaces in South Africa', in S. Manik \& A. Singh (eds.), Love thy neighbours: Exploring and exposing xenophobia in social spaces in South Africa, pp. 1-8, Interdisciplinary Journal for the Study of the Arts and Humanities in Southern Africa, Durban.

Manik, S., 2013, Zimbabwean Immigrant Teachers in KwaZulu-Natal Count the Cost of Going under the Hammer', in S. Manik \& A. Singh (eds.), Love thy neighbours: Exploring and exposing xenophobia in social spaces in South Africa, pp. 67-87, Interdisciplinary Journal for the Study of the Arts and Humanities in Southern Africa, Durban.

Manson, J. G., 2012, Luke: An unexpected God, Aquila Press, Sydney.

Marshall, H.I., 1978, The Gospel of Luke: A commentary on the Greek Text, William B. Eerdmans Publishing Company, Grand Rapids, MI. 
Metz, T., 2011, 'Ubuntu as a moral theory and human rights in South Africa', African Human Rights Law Journal 11(2), 532-559.

Mitch, C. \& Sri, E., 2010, The gospel of Matthew: Catholic commentary on sacred Scripture, Baker Academic, Grand Rapids, MI.

Mkhize, N., 2008, 'Ubuntu and harmony: An African approach to morality and ethics', in R. Nicolson (ed.), Persons in community: African ethics in a global culture, pp. 35-44, University of KwaZulu-Natal Press, Scottsville.

Mnyaka, M. \& Mothlabi, M., 2005, 'The African concept of Ubuntu/Botho and its socio-moral significance', An International Journal 3(2), 215-237. https://doi. org/10.1558/blth.3.2.215.65725

Mnyaka, M. \& Motlhabi, M., 2009, 'Ubuntu and its socio-moral significance', in M.F. Murove (ed.), African ethics: An anthology of comparative and applied ethics, pp. 63-84, University of KwaZulu-Natal Press, Scottsville.

Moloi, T., 2016, 'Tribalism is new apartheid', News24, 06 July, 2016, viewed 27 March 2020, from https://www.news24.com/news24/SouthAfrica/Local/ Express-News/tribalism-is-new-apartheid-20160705.

Morris, L., 1992, The gospel according to Matthew, William B. Eerdmans Publishing Company, Grand Rapids, MI.

Mugumbate, J. \& Nyanguru, A., 2013, 'Exploring African philosophy: The value of ubuntu in social work', AJSW 3(1), 82-100.

Muthuki, J., 2013, 'The complexities of being a foreign African student in a South African Tertiary Institution', in S. Manik \& A. Singh (eds.), Love thy neighbours: Exploring and exposing xenophobia in social spaces in South Africa, pp. 109-124, Interdisciplinary Journal for the Study of the Arts and Humanities in Southern Africa, Durban.

Ngomane, T.S., n.d., 'The socio-economic impact of migration in South Africa: A case study of illegal Zimbabweans in Polokwane Municipality in the Limpopo Province', Master's thesis, Limpopo University, Limpopo.

Nie, Z., 2015, 'The global edge: The effects on host countries', viewed 23 May 2017, from https://globaledge.msu.edu/blog/post/30996/the-effects-of-refugeeson-host-countries.

Nolland, J., 1993, Luke 9:21-18:34: Word Biblical Commentary, Word Books Publishing, Dallas, TX.

Nussbaum, B., 2003, 'Ubuntu: Reflections of a South African on Our Common Humanity', Reflections 4(4), 21-26.

Ramose, M.B., 1999, African philosophy through Ubuntu, Mond Books, Harare.

Reader, J., 2008, Reconstructing practical theology: The impact of globalization, Ashgate, Aldershot.

Rukema, J.R. \& Khan, S., 2013, 'Chronicling the effects of the 2008 xenophobic attacks amongst a select group of Congolese and Burundian women in the City of Durban', in S. Manik \& A. Singh (eds.), Love thy neighbours: Exploring and exposing xenophobia in social spaces in South Africa, pp. 176-196, Interdisciplinary Journal for the Study of the Arts and Humanities in Southern Africa, Durban. 
Ryken, P.G., 2009, Luke Volume I: Chapters 1-12, Reformed expository commentary, P\&R Pub, Phillipsburg, NJ.

South African Human Rights Commission (SAHRC), 2017, 'SAHRC condemns Deputy Police Minister's “xenophobic” comments', viewed 04 March 2019, from https://www.sahrc.org.za/index.php/sahrc-media/news/item/751-sahrccondemns-deputy-police-minister-s-xenophobic-comments.

Shutte, A., 2001, Ubuntu an ethic for a new South Africa, Cluster Publications, Pietermaritzburg.

Simango, D., 2016, 'The Imago Dei (Gen 1:26-27): A history of interpretation from Philo to the present', Studia Historiae Ecclesiasticae 42(1), 172-190. https://doi. org/10.25159/2412-4265/1065

Singh, S.K., 2013, 'Zimbabwean Teachers' experiences of xenophobia in Limpopo Schools', in S. Manik \& A. Singh (eds.), Love thy neighbours: Exploring and exposing xenophobia in social spaces in South Africa, pp. 51-66, Interdisciplinary Journal for the Study of the Arts and Humanities in Southern Africa, Durban.

Singh, R.J., 2013, 'Examining xenophobic practices amongst university students - A case study from Limpopo province', in S. Manik \& A. Singh (eds.), Love thy neighbours: Exploring and exposing xenophobia in social spaces in South Africa, pp. 88-108, Interdisciplinary Journal for the Study of the Arts and Humanities in Southern Africa, Durban.

South African History Online (SAHO), 2015, 'Xenophobic violence in democratic South Africa', viewed 26 September 2017, from https://www.sahistory.org.za/ article/xenophobic-violence-democratic-south-africa.

Stein, R.H., 1973, The New American commentary: An exegetical and theological exposition of Holy Scripture: Luke, Broadman Press, Nashville, TN.

Taylor, D., 2012, 'Specter of xenophobia haunts South Africa', Voice of America, 27 November 2012, viewed 22 June 2017, from https://www.voanews.com/africa/ specter-xenophobia-haunts-south-africa.

Tevera, D., 2013, 'African migrants, xenophobia and urban violence in postapartheid South Africa', Alternation 20(7), 9-24.

Tutu, D.M., 1999, No future without forgiveness, Rider, London.

Vahed, G. \& Desai, A., 2013, 'The May 2008 xenophobic violence in South Africa: Antecedents and aftermath', in S. Manik \& A. Singh (eds.), Love thy neighbours: Exploring and exposing xenophobia in social spaces in South Africa, pp. 145-175, Interdisciplinary Journal for the Study of the Arts and Humanities in Southern Africa, Durban.

Vahed, Y., 2013, 'Fear of crime, and xenophobia in Durban, South Africa', in S. Manik \& A. Singh (eds.), Love thy neighbours: Exploring and exposing xenophobia in social spaces in South Africa, pp. 197-214, Interdisciplinary Journal for the Study of the Arts and Humanities in Southern Africa, Durban.

Wose, K.G.T., 2016, 'International dimension of xenophobic attacks on foreign nationals in South Africa', Master's thesis, North-West University, Mafikeng. 
World Economic Forum (WEF), 2017, 'Migration and its impact on cities', viewed 28 March 2020, from https://www.weforum.org/reports/migration-and-itsimpact-on-cities.

Zimmermann, R., 2008, 'The etho-poietic of the parable of the Good Samaritan (Lk 10:25-37): The ethics of seeing in a culture of looking the other way', Verbum et Ecclesia 29(1), 269-292. https://doi.org/10.4102/ve.v29i1.16

\section{Chapter 4}

Adogame, A., 2013, The African Christian Diaspora: New currents and emerging trends in world Christianity, Bloomsbury, London.

Bhugra, D., 2004, 'Migration, distress and cultural identity', British Medical Bulletin 69(1), 129-141. https://doi.org/10.1093/bmb/ldh007

Broughton, G. \& Prentis, B., 2019, 'Recognition without dignity: The politics and theology of postponement of Aboriginal peoples' justice in Australia', in C. Pearson (ed.), Enacting a public theology, pp. 1-14, Sun Media, Stellenbosch University.

Fretheim, K., 2016, Interruption and imagination: Public theology in times of crisis, Pickwick Publications, Eugene, OR.

Gilmore, K., 2016, “Keynote address: Side event “Migrants in transit” by Ms. Kate Gilmore, Deputy High Commissioner for Human Rights', United Nations Human Rights Office of the High Commissioner, viewed 20 February 2020, from https://www. ohchr.org/EN/NewsEvents/Pages/DisplayNews.aspx?NewsID=18485\&LangID=E.

Greider, K.J., 2008, 'Pedagogy in practical theology: Two problems in the case of pastoral care', International Journal of Practical Theology 12(1), 52-58.

Hendriks, J., 2004, Studying congregations in Africa, Lux Verbi, Wellington.

International Organisation for Migration (IOM), 2015, World migration report 2015 - Migrants and cities: New partnerships to manage mobility, Imprimerie Courand et Associés, Geneva.

Kavita, D., Cathy, M., Yara, E., Joanna, H., Jon, M. \& Jane, W., 2006, Work and survival strategies among low-paid migrants in London, Department of Geography Queen Mary, University of London, London.

Korsch, D., 2011, 'Life science - gelebte Religion - Theologie als Lebenswissenschaft', in T. Klie, M. Kumlehn, R. Kunz \& T. Schlag (Hrsg.), Lebenswissenchaft Praktische Theologie?! Praktische Theologie im Wissenschaftsdiskurs, Band 9, pp. 341344, De Gruyter Berlin, New York, NY.

Louw, D.J., 1998, A pastoral hermeneutics of care and encounter, Lux Verbi, Cape Town.

Louw, D.J., 2014, 'Cura animarum as hope care: Towards a theology of the resurrection within the human quest for meaning and hope', HTS Teologiese Studies/Theological Studies 70(1), Art. \#2027, 10 pages. https://doi.org/ 10.4102/hts.v70i1.2027 
Louw, D.J., 2015, 'Compassion fatigue: Spiritual exhaustion and the cost of caring in the pastoral ministry. Towards a "pastoral diagnosis" in caregiving", HTS Teologiese Studies/Theological Studies 71(2), Art. \#3032, 10 pages. https:// doi.org/10.4102/hts.v71i2.3032

Louw D.L., 2017, 'Ekhaya: Human displacement and the yearning for familial homecoming. From Throne (Cathedra) to Home (Oikos) in a grassroots ecclesiology of place and space: Fides Quaerens Domum et Locum [faith seeking home and space]', HTS Teologiese Studies/Theological Studies 73(4), a4484. https://doi.org/10.4102/hts.v73i4.4484

Magezi, V., 2017a, “Glocal” and integrated churches within a practical theological imagination of "home away from home": Towards a ministry of migrants and refugees in diaspora', Stellenbosch Theological Journal 3(1), 227-250. https:// doi.org/10.17570/stj.2017.v3n1.a11

Magezi, V., 2017b, 'Ubuntu in flames-injustice and disillusionment in post-colonial Africa: A practical theology for new "liminal ubuntu" and personhood', in J. Dreyer, Y. Dreyer, E. Foley \& M. Nel (eds.), Practicing ubuntu: Practical theological perspectives on injustice, personhood and human dignity, pp. 111-122, LIT Verlag, Zurich.

Magezi, V., 2019a, 'Pastoral care to migrants as care at the "in-between" and "liminal" home away from home: Towards public pastoral care to migrants', Verbum et Ecclesia 40(1), a1805, a1990. http://dx.doi.org/10.4102/ve.v40i1.1990

Magezi, V., 2019b, 'Doing public pastoral care through church-driven development in Africa: Reflection on church and community mobilisation process approach in Lesotho', HTS Teologiese Studies/Theological Studies 75(4), a5501. https:// doi.org/10.4102/hts.v75i4.5501

Müller, J.C., 2004, 'HIV/AIDS, narrative practical theology, and postfoundationalism: The emergence of a new story', HTS Teologiese Studies/Theological Studies 60(1\&2), 293-306. https://doi.org/10.4102/hts.v60i1/2.516

Osmer, R.R., 2008, Practical theology: An introduction, William B. Eerdmans Publishing Company, Grand Rapids, MI.

Pearson, C., 2019, 'Signing the Times: An Introduction', in C. Pearson (ed.), Enacting a public theology, pp. vii-xvi, Sun Media, Stellenbosch University.

Sanders, F., 2009, C. H. Dodd and Realized Eschatology, viewed 06 April, from http://scriptoriumdaily.com/c-h-dodd-and-realized-eschatology/.

Schjonberg, M.F., 2017, 'One disaster after another: Coping with compassion fatigue can be a challenge', The Episcopal Church, viewed 07 April 2020, from https://episcopalchurch.org/library/article/one-disaster-after-anothercoping-compassion-fatigue-can-be-challenge.

Sheldrake, P., 2019, The spiritual way: Classic traditions and contemporary practice, Liturgical Press Academic, Collegeville, PA.

Skeldon, R., 2013, 'Global migration: Demographic aspects and its relevance for development', Technical paper No. 2013/6, United Nations Department of Economic and Social Affairs, New York, NY, viewed 01 March 2020, from http:// www.un.org/esa/population/migration/documents/EGM.Skeldon_17.12.2013.pdf. 
Smit, D.J., 2003, 'On learning to see? A reformed perspective on the church and the poor', in P.D. Couture \& B. Miller-McLemore (eds.), Poverty, suffering and HIV-AIDS: International practical theological perspectives, pp. 271-284, Cardiff Academic Press, Fairwater.

\section{Chapter 5}

Anderson, A., 1996, 'The hermeneutical processes of Pentecostal-type African Initiated Churches in South Africa', Missionalia 24(2), 171-185.

Anderson, A., 2001, African reformation: African initiated Christianity in the 20th century, Africa World Press, Trenton, NJ.

Anderson, A., 2007, Spreading fires: The missionary nature of early pentecostalism, Orbis, Maryknoll, New York, NY.

Anderson, A.H., 2016, 'The spirit and the African spiritual world', in V. Synan, A. Yong \& J.K. Asamoah-Gyadu (eds.), Global renewal Christianity: Spiritempowered movements past, present, and future, vol. 3: Africa, pp. 304-320, Charisma House, Lake Mary, FL.

Asamoah-Gyadu, J.K., 2013, Contemporary Pentecostal Christianity: Interpretations from an African context, Wipf and Stock, Eugene, OR.

Baeta, C.G., 1962, Prophetism in Ghana: A study of some spiritual churches, SCM, London.

Baker, A. 2015, 'Brutal murder is sparked by anti-immigrant rage in South Africa', Time, viewed 22 February 2018, from https://time.com/3828398/xenophobiasouth-africa/.

Banda, L., 2016, 'Prophets of God or neo-diviners? A theological assessment of prophecy in Zambia today', in H. Kroesbergen (ed.), Prophecy today: Reflections from a Southern African context, Special edition of Word and Context Journal, pp. 208-229, Christian Literature Fund, Wellington.

Barrett, D., 1970, 'AD 2000: 350 Million Christians in Africa?', International Review of Mission 59(233), 39-54. https://doi.org/10.1111/j.1758-6631.1970.tb00933.x

Chitando, E., Gunda, M. \& Kügler, J., 2013, Prophets, profits, and the Bible in Zimbabwe, University of Bamberg Press, Bamberg.

Chiweshe, M.K., 2016, 'Social positionality and xenophobia: The case of rugby player Tendai Mtawarira in South Africa', Africology: The Journal of Pan African Studies 9(7), 132-149.

Cox, H., 1995, Fire from heaven: The rise of Pentecostal spirituality and the reshaping of religion in the twenty-first century, Da Capo, Cambridge, MA.

Crush, J. (ed.), 2008, 'The perfect storm: The relationship of xenophobia in South Africa', Southern African Migration project, viewed 23 February 2018, from https://samponline.org/wp-content/uploads/2016/10/Acrobat50.pdf.

De Villiers, E., 2016, 'Do the prophetic and reformist approaches in Christian ethics exclude one another? A responsibility ethics attempt at reconciliation', 
in H. Kroesbergen (ed.), Prophecy today: Reflections from a Southern African context, Special edition of Word and Context Journal, pp. 148-162, Christian Literature Fund, Wellington.

Dodson, B. \& Crush, J., 2016, 'Migration to South Africa since 1994: Realities, policies and public attitudes', in T. Kepe, M. Levin \& B. Von Lieres (eds.), Domains of freedom: Justice, citizenship and social change in South Africa, pp. 277-297, University of Cape Town Press, Cape Town.

Duncan, D., 1988, Health and healing: A ministry to wholeness, Pastoral care and ethical issues, Saint Andrew, Edinburgh.

Ejoke, U.P. \& Ani, K.J., 2017, 'A historical and theoretical analysis of xenophobia in South Africa', Journal of Gender, Information and Development in Africa 6(1\&2), 163-185. https://doi.org/10.31920/2050-4284/2017/v6n1_2a8

Ellington, D.W., 2016, 'Be cautious about prophets but zealous to prophesy: 1 Corinthians 14 and today's questions about prophecy', in H. Kroesbergen (ed.), Prophecy today: Reflections from a Southern African context, Special edition of Word and Context Journal, pp. 174-190, Christian Literature Fund, Wellington.

Fee, G., 1994, God's empowering presence: The Holy Spirit in the letters of Paul, Hendrickson, Peabody, MA.

Frahm-Arp, M., 2016, 'The rise of the megachurches in South Africa', in V. Synan, A. Yong \& J.K. Asamoah-Gyadu (eds.), Global renewal Christianity: Spiritempowered movements past, present, and future, vol. 3: Africa, pp. 263-284, Charisma House, Lake Mary, FL.

Gifford, P., 2011, 'Healing in African pentecostalism: The victorious living of David Oyedepo', in C.G. Brown (ed.), Global Pentecostal and charismatic healing, pp. 251-266, Oxford University Press, Oxford.

Gordon, S., 2017, 'A desire for isolation? Mass public attitudes in South Africa toward immigration levels', Journal of Immigrant \& Refugee Studies 15(1), 1835. https://doi.org/10.1080/15562948.2016.1151096

Gordon, S.L., 2016, 'Understanding evaluations of foreigners in modern South Africa: The relationship between subjective wellbeing and xenophobia', Journal of Happiness Studies 17(6), 545-566. https://doi.org/10.1007/s10902016-9838-6

Grady, J.L., 2013, 'Five ways prosperity gospel is hurting Africa', Charisma, viewed 22 February 2018, from http://www.charismamag.com/blogs/fire-in-mybones/19113-5-ways-the-prosperity-gospel-is-hurting-africa.

Harris, B., 2002, 'Xenophobia: A new pathology for a new South Africa?', in D. Hook \& G. Eagle (eds.), Psychopathology and social prejudice, pp. 169-84, University of Cape Town Press, Cape Town.

Ideheu, R.O. \& Osaghae, F.S.O., 2015, 'Xenophobia in South Africa: Re-thinking the Nigeria foreign policy of Afrocentrism', African Research Review 9(4), 78-91.

Kalu, O., 2008, African pentecostalism: An introduction, Oxford University Press, New York, NY. 
Kangwa, J., 2016, 'African democracy and political exploitation: An appraisal of xenophobia and the removal of the Rhodes Statue in South Africa', The Expository Times 127(11), 534-545. https://doi.org/10.1177/0014524616630702

Keener, C.S., 2016, Spirit hermeneutics: Reading Scripture in light of Pentecost, Eerdmans, Grand Rapids, MI.

Kgatle, M.S., 2017, 'The unusual practices within some neo-pentecostal churches in South Africa: Reflections and recommendations', HTS Teologiese Studies/ Theological Studies 73(3), a4656. https://doi.org/10.4102/hts.v73i3.4656

Kroesbergen-Kamps, J., 2016, 'Prophetic struggles: Zambian pastors' diverse views on prophecy', in H. Kroesbergen (ed.), Prophecy today: Reflections from a Southern African context, Special edition of Word and Context Journal, pp. 28-40, Christian Literature Fund, Wellington.

Labys, C.A., Dreyer, C. \& Burns, J.K., 2017, 'At zero and turning in circles: Refugee experiences and coping in Durban, South Africa', Transcultural psychiatry 54(5-6), 696-714. https://doi.org/10.1177/1363461517705570

Maddocks, M., 1990, The Christian healing ministry, 2nd edn., SPCK, London.

Mana, K., 2004, Christians and churches of Africa: Salvation in Christ and building a new African society, Orbis, Maryknoll, New York, NY.

Massey, D.S. \& Higgins, M.E., 2011, 'The effect of immigration on religious beliefs and practice: A theologizing or alienating experience', Social Science Research 40(5), 1371-1389. https://doi.org/10.1016/j.ssresearch.2010.04.012

Muindi, S., 2012, 'The nature and significance of prophecy in pentecostal-charismatic experience: An empirical-biblical study', PhD thesis, University of Birmingham.

Mwale, N. \& Chita, J., 2016, 'Religion and the media: The portrayal of prophecy in the Zambian media', in H. Kroesbergen (ed.), Prophecy today: Reflections from a Southern African context, Special edition of Word and Context Journal, pp. 41-63, Christian Literature Fund, Wellington.

Ndiokwere, N., 1981, Prophecy and revolution: The role of prophets in the African churches and in biblical tradition, SPCK, London.

Nel, M., 2017, 'The Pentecostal movement's view of the continuity of tongues in Acts and 1 Corinthians', In die Skriflig 51(1), a2198. https://doi.org/10.4102/ids. v51i1.2198

Nel, M., 2018, 'Pentecostal prophecy: A pastoral response to the challenges of South African xenophobia', Conspectus Special Edition (December 2018), 20-39, viewed 22 February 2018, from https://www.sats.edu.za/nelpentecostal-prophecy-pastoral-xenophobia.

Nel, M., 2019, 'Prophetic witness in weakness: A response to Prof Robert Vosloo from a Pentecostal perspective', In die Skriflig 53(4), a2419. https://doi. org/10.4102/ids.v53i4.2419

Ngong, D., 2006, 'In quest of wholeness: African Christians in the new Christianity', Review \& Expositor 103(3), 519-540. https://doi.org/10.1177/ 003463730610300305 
Ngong, D., 2010, The Holy Spirit and salvation in African Christian theology: Imagining a new hopeful future for Africa, Peter Lang, Oxford.

Omenyo, C., 2011, 'Man of God, prophesy unto me: The prophetic phenomenon in African Christianity', Studies of World Christianity 17(1), 30-49. https://doi. org/10.3366/swc.2011.0004

Oosthuizen, G., 1992, The healer-prophet in Afro-Christian churches, Brill, Leiden.

Phakathi, S., 2010, 'The response of churches to the May 2008 xenophobic violence', The Atlantic Philanthropies, viewed 22 February 2018, from https:// www.atlanticphilanthropies.org/wp-content/uploads/2010/07/11_Church_c.pdf.

Portes, A., 2008, Migration and social change: Some conceptual reflections, Keynote address to the conference on 'Theorizing Key Migration Debates', Oxford University, July 1, 2008, pp. 1-47, viewed 27 February 2018, from https:// www.migrationinstitute.org/files/events/portes.pdf.

Quayesi-Amakye, J., 2013, Christology and evil in Ghana: Towards a Pentecostal public theology, Rodopi, Amsterdam.

Quayesi-Amakye, J., 2014, 'Coping with evil in Ghanaian pentecostalism', Exchange 43(3), 254-272. https://doi.org/10.1163/1572543X-12341327

Quayesi-Amakye, J., 2016, “'Nativizing” the gospel: Pentecostalism and theology in Africa', in V. Synan, A. Yong \& J.K. Asamoah-Gyadu (eds.), Global renewal Christianity: Spirit-empowered movements past, present, and future, vol. 3: Africa, pp. 287-303, Charisma House, Lake Mary, FL.

Sakupapa, T., 2016, 'Prophets in the Zambian/African context: A survey from an ecumenical perspective', in H. Kroesbergen (ed.), Prophecy today: Reflections from a Southern African context, Special edition of Word and Context Journal, pp. 113-128, Christian Literature Fund, Wellington.

Saloojee, A., 2016, 'Social protests and the exercise of citizenship in South Africa', in T. Kepe, M. Levin \& B. Von Lieres (eds.), Domains of freedom: Justice, citizenship and social change in South Africa, pp. 259-276, University of Cape Town Press, Cape Town.

Soko, L.R.K., 2016, 'Culture and the practice of prophecy today: A challenge of Christianity in Zambia', in H. Kroesbergen (ed.), Prophecy today: Reflections from a Southern African context, Special edition of Word and Context Journal, pp. 89-98, Christian Literature Fund, Wellington.

Sundkler, B., 1961, Bantu prophets in South Africa, Oxford University Press, London.

Taylor, J.V., 1963, The primal vision: Christian presence and African religion, SCM, London.

Tella, O., 2016, 'Understanding xenophobia in South Africa: The individual, the state and the international system', Insight on Africa 8(2), 142-158. https://doi. org/10.1177/0975087816655014

Tella, O. \& Ogunnubi, O., 2014, 'Hegemony or survival: South Africa's soft power and the challenge of xenophobia', Africa Insight 44(3), 145-63.

Van Wyk, I., 2014, The universal church of the kingdom of God in South Africa: A church of strangers, Cambridge University Press, Cambridge. 
Wepener, C., 2013, 'Liturgical "reform" in sub-Saharan Africa: Some observations on worship, language and culture', Studia Liturgica 44(1-2), 82-95. https://doi. org/10.1163/1572543X-12341327

Wepener, C. \& Barnard, M., 2016, 'Worship in the Zion Christian Church (ZCC): A descriptive exploration of a prophetic phenomenon', in H. Kroesbergen (ed.), Prophecy today: Reflections from a Southern African context, Special edition of Word and Context Journal, pp. 74-88, Christian Literature Fund, Wellington.

Yong, A., 2010, In the days of Caesar: Pentecostalism and political theology, William B. Eerdmans, Grand Rapids, MI.

Zulu, E., 2016, "'Sow a seed" and prosper? A critical examination of the trends, practices of "prophecy" in a Zambian context', in H. Kroesbergen (ed.), Prophecy today: Reflections from a Southern African context, Special edition of Word and Context Journal, pp. 99-112, Christian Literature Fund, Wellington.

\section{Chapter 6}

Bourdillon, M.F.C., 2009, 'Working children in Zimbabwe', in H.D. Hindman (ed.). The world of child labour: An historical and regional survey, pp. 292-296, M.E. Sharpe, London.

Chisale, S.S., 2014, 'Pastoral care with children in a context of HIV and AIDS: Towards a contextual pastoral care model with unaccompanied refugee minors (URMs) from Zimbabwe in the Methodist Church community centre in Johannesburg', DTh thesis, University of South Africa.

Dreyer, Y., 2004, 'A public practical theological theory for religious education of secularised youth', HTS Teologiese Studies/Theological Studies 60(3), 919945. https://doi.org/10.4102/hts.v60i3.615

Lartey, E.Y., 2003, In living color: An intercultural approach to pastoral care and counseling, Jessica Kingsley Publishers, London.

Louw, D.L., 2017, 'Ekhaya: Human displacement and the yearning for familial homecoming. From Throne (Cathedra) to Home (Oikos) in a grassroots ecclesiology of place and space: Fides Quaerens Domum et Locum [faith seeking home and space]', HTS Teologiese Studies/Theological Studies 73(4), a4484. https://doi.org/10.4102/hts.v73i4.4484

Magezi, V., 2018, 'Changing family patterns from rural to urban and living in the in-between: A public practical theological responsive ministerial approach in Africa', HTS Teologiese Studies/Theological Studies 74(1), 5036. https://doi. org/10.4102/hts.v74i1.5036

Mahati, T.S., 2011, 'The representations of unaccompanied working migrant male children negotiating for livelihoods in a South African border town', in M.F.C. Bourdillon \& A. Sangare (eds.), Negotiating the livelihoods of children and youth in Africa's urban spaces, pp. 67-85, Council for the Development of Social Science Research in Africa, Dakar.

Mbabaali, F., 2012, 'Exploring the sense of belonging of war affected refugee youth', MEd dissertation, University of Manitoba, Winnipeg. 
McCarthy, C. \& Marks, D.F., 2010, 'Exploring the health and well-being of refugee and asylum-seeking children', Journal of Health Psychology 15(4), 586-595. https://doi.org/10.1177/1359105309353644

Organization of African Unity, 1990, African Charter on the Rights and Welfare of the Child, viewed 20 September 2018, from https://www.un.org/en/africa/ osaa/pdf/au/afr_charter_rights_welfare_child_africa_1990.pdf.

Republic of South Africa, 1998, Refugees Act 130 of 1998, Parliament of the Republic of South Africa, Cape Town.

Republic of South Africa, 2002, Immigration Act 13 of 2002, Parliament of the Republic of South Africa, Cape Town.

Republic of South Africa, 2013, Prevention and Combating of Trafficking in Persons Act 7 of 2013, Parliament of the Republic of South Africa, Cape Town.

Save the Children, 2007, 'Children crossing borders: Report on unaccompanied minors who have travelled to South Africa', viewed 10 April 2010, form http:// www.crin.org/docs/children-crossing-borders.pdf.

Skelton, A., 2010, Curatrix AD Litem's report, viewed 14 June 2012, from http:// www.info.gov.za/speech/DynamicAction?pageid=461\&sid=22999\&tid=48244.

Sloth-Nielsen, J. \& Ackermann, M., 2016, 'Unaccompanied and separated foreign children in the care system in the Western Cape - A socio-legal study', PER / PELJ 2016(19). https://doi.org/10.17159/1727-3781/2016/v19iOa1207

Staunton, I., Mclvor, C. \& Bjornestad, C., 2008, Our broken dreams: Child migration in Southern Africa, Weaver Press, Harare.

Swart, I. \& Yates, H., 2012, 'Listening to Africa's children in the process of practical theological interpretation: A South African application', HTS Teologiese Studies/Theologica/ Studies 68(2). https://doi.org/10.4102/hts.v68i2.1310

United Nations, 1989, Convention on the Rights of the Child, viewed 10 March 2006, from http://www2.ohchr.org/english/law/pdf/crc.pdf.

United Nations, 2005, 'Committee on the Rights of the Child General Comment No 6: Treatment of unaccompanied and separated children outside their country of origin', United Nations Committee on the Rights of the Child, s.I.

United Nations High Commissioner for Refugees, 2015, 'Global facts and figures for displaced individuals', UNHCR, viewed 16 September 2018, from https:// documents-dds-ny.un.org/doc/UNDOC/LTD/G15/141/15/PDF/G1514115. pdf?OpenElement.

Valentine, G., Sporton, D. \& Nielsen, K., 2009, 'Identities and belonging: A study of Somali refugee and asylum seekers living in the UK and Denmark', Environment and Planning D: Society and Space 27(2), 234-250. https://doi.org/10.1068/d3407

\section{Chapter 7}

Adedoyin, A.C., Bobbie, C., Griffen, M., Nobles, C. \& Neeland, K., 2016, 'Social work and Christianity', Journal of the North-American Association of Christians in Social Work 43(1), 95-107. 
Anon, 2004, 'Lessening the impact of fatherlessness', Natal Witness, 16, 24 June. Anon, 2008a, 'The fatherless sons of violence', Cape Argus, 15, 23 June.

Anon, 2008b, 'The fatherless sons of violence', Star, 35, 25 Jun.

Anon, 2011, 'Most foreign prisoners from Zim, Moz', News24, viewed 13 August 2018, from https://www.news24.com/News24/Most-foreign-prisoners-fromZim-Moz-20110624.

Anon, 2013, 'SA has most inmates in Africa', News24, viewed 13 August 2018, from https://www.news24.com/SouthAfrica/News/SA-has-most-inmates-inAfrica-20130304.

Bartlett, E., 2013, 'Die impak van afwesige vaders op adolessente meisies se psigososiale welstand', BA hons dissertation, North-West University.

Bertelsmann, M., 2016, 'Where have our fathers gone?', parent24, viewed 30 June 2018, from http://www.parent24.com/Family/Parenting/where-have-our-fathersgone-20160217-2.

Bompani, B., 2015, 'Local religious organisations performing development: Refugees in the central Methodist mission in Johannesburg', Journal of International Development 27(2), 197-212. https://doi.org/10.1002/jid.2900

Botha, M., 2013, 'Fatherhood's a struggle for the fatherless', Mail and Guardian, 21 November, 2013, p. 34.

Bramadat, P., 2014, 'Don't ask, don't tell: Refugee settlement and religion in British Columbia', Journal of the American Academy of Religion 82(4), 907-937. https://doi.org/10.1093/jaarel/Ifu040

Carstens, C., 2014, The world needs a father: A trainers' guide, Paarl Media Printers, Cape Town.

Castles, S. \& Miller, M.J., 2009, The age of migration, international population movements in the modern world, Castillo Guerra, New York, NY.

Churgin, M.J., 2016, 'Is religion different? Is there a thumb on the scale in refugee convention appellate court adjudication in the United States? Some preliminary thoughts', Texas International Law Journal 51(2), 213-228.

Cohn, A., 2011, 'Migrating ministry', Christianity Today, May 2011, pp. 46-48.

Cole, E.L., 1992, Real man, Thomas Nelson publishers, Nashville, TN.

Crush, J., McDonald, D.A., Williams, V., Lefko-Everett, K., Dorey, D., Taylor, D. et al., 2008, The perfect storm: The realities of xenophobia in contemporary South Africa, SAMP migration policy series no. 50, Southern African Migration Project, Cape Town.

Darrah, N., 2017, 'Report reveals 92 percent of foreign nationals in federal prisons are illegal immigrants', Fox News, viewed 13 August 2018, from http:// www.foxnews.com/politics/2017/12/21/report-reveals-92-percent-foreignnationals-in-federal-prisons-are-illegal-immigrants.html.

Das, R., 2016, 'Refugees: Exploring theological and missiological foundations', Journal of European Baptist Studies 16(2), 33-47.

Del Russo, J.M., 2009, 'Emotionally absent fathers and their adult daughter's relationship with men', Doctoral dissertation, Chestnut Hill College. 
Dilonno, M., 2011, 'Refugees', Christian Century, 3 May 2011, pp. 20-21.

Dobbs, P., 2013, 'The impact of fatherlessness on the way one relates to God as Father', MTh dissertation, University of Otago.

Falicov, C., 2002, 'Foreword', in R.K. Papadopolous (ed.), Therapeutic care for refugees: No place like home, pp. xv-xviii, Karnac Books, London.

Families South Africa (FAMSA), 2014, Annual general meeting, pp. 1-22, FAMSA, Potchefstroom.

Families South Africa (FAMSA), 2015, Annual general meeting, pp. 1-28, FAMSA, Potchefstroom.

Feni, L., 2016, 'Forum raises concern over fatherless society', Daily Dispatch, 21 March, p. 2.

Ford, J., Nalbone, D.P., Wetcher, J.L. \& Sutton, P.M., 2008, 'Fatherhood: How differentiation and identity status affect attachment to children', American Journal of Family Therapy 36(4), 284-299. https://doi.org/10.1080/01926180701647074

Frazier, T., 2015, The result of fatherlessness in South Africa, viewed 30 June 2018, from http://www.tumifrazier.com/fatherlessness-in-south-africa/.

Freeks, F.E., 2004, 'Die rol van die ontbrekende vaderfiguur in die Suid-Afrikaanse konteks. 'n prakties-teologiese studie', MA dissertation, Noordwes-Universiteit.

Freeks, F.E., 2011a, Fatherhood training and equipping manual for fathers: Dad becoming fully you, Ivyline Technologies, Potchefstroom.

Freeks, F.E., 2011b, 'The role of the father as mentor in the transmission of values: A pastoral-theological study', PhD thesis, North-West University.

Freeks, F.E., 2013, Dad is destiny: The man God created to be, Ivyline Technologies, Potchefstroom.

Freeks, F.E., 2016a, 'Die noodsaak van Skrifgefundeerde vaderskap as antwoord op die voortslepende probleem van vaderskapafwesigheid in Suid-Afrika', Tydskrif vir Christelike Wetenskap 52(1 \& 2), 1-27.

Freeks, F.E., 2016b, 'Youth intervention through training and equipping in the midst of challenges and crisis: The LIFEPLAN" programme as a possible solution', Missionalia 44(2), 205-223. https://doi.org/10.7832/44-2-150

Freeks, F.E., 2016c, 'Old Testament figures as possible current "mentors": Exploratory pastoral-theological reflections', Scandinavian Journal of the O/d Testament 30(2), 236-248. https://doi.org/10.1080/09018328.2016.1226413

Freeks, F.E., 2017a, Dad be the father God called you to be: Values-based parenting for Christian families, Africa Scholars Press, Cape Town.

Freeks, F.E., 2017b, 'Responses of adolescents regarding the indispensable role of the Christian father as mentor within the family: A qualitative study', In die Skriflig 51(1), a2255. https://doi.org/10.4102/ids.v51i1.2255

Freeks, F.E., 2017c, 'Responding to the challenge of father absence and fatherlessness in the South African context: A case study involving concerned fathers from the North West Province', Stellenbosch Theological Journal 3(1), 89-113. https://doi.org/10.17570/stj.2017.v3n1.a05 
Freeks, F.E., 2017d, 'A pastoral-theological view on the fundamental role of the father in variance with contemporary family structures and its adverse challenges for fatherhood: A literature review', Journal for Christian Scholarship $53(3$ \& 4), 177-188.

Freeks, F.E., 2018a, 'A missional evaluation of the LIFEPLAN' training and equipping programme for youth in rural areas. A case study of its impact in the Christiana district of South Africa', PhD thesis, North-West University.

Freeks, F.E., 2018b, 'Views of mothers on the fundamental role of the Christian father as mentor in a nuclear family environment', In die Skriflig 52(1), a2365. https://doi.org/10.4102/ids.v52i1.2365

Freeks, F.E., 2019, 'The problem of father absenteeism in South Africa: A possible solution according to Biblical guidelines', Journal for Humanities 59(4), 12. https://doi.org/10.17159/2224-7912/2019/v59n4a17

Freeks, F.E. \& Genade, A.A., 2017, Dad \& God-becoming a father shaped by the Father - 31 days of change, daily devotional, Ivyline Technologies, Potchefstroom.

Freeks, F.E., Greeff, M. \& Lotter, G.A., 2015, 'Views of Christian fathers of their role as mentors in the transmission of values within the family', Journal for Christian Scholarship 51(1), 21-45.

Freeks, F.E. \& Lotter, G.A., 2009, "n Prakties-teologiese ondersoek na die uitwerking van afwesige vaders: 'n Verkennende kwalitatiewe ondersoek in die Promosa-gemeenskap', Koers 74(3), 519-534. https://doi.org/10.4102/koers. v74i3.136

Freeks, F.E. \& Lotter, G.A., 2014, 'Possible "mentoring" and discipleship in the New Testament - A proposition', Journal for Christian Scholarship 50(3), 191-212.

Freeks, F.E., Strydom, C. \& Bartlett, E., 2015b, 'Die impak van afwesige vaders op adolessente dogters se psigososiale welstand', Health SA Gesondheid 20(1), 45-58. https://doi.org/10.1016/j.hsag.2015.03.002

Galli, M., 2015, 'A church welcome for the tired, the poor: How the refugee crisis makes a beautiful gospel witness', Christianity Today, November, pp. 33-34.

Gilkes, C.T., 1989, 'Mother to the motherless, father to the fatherless: Power, gender, and community in an Afrocentric biblical tradition', Semeia 47, 57-77.

Groody, D.G., 2009, 'Crossing the divide: Foundations of a theory of migration and refugees', Theological Studies 70(3), 638-667.

Groody, D., 2015, 'Migrants and refugees: Christian faith and the globalization of solidarity', Theological Studies 70(3), 638-667. https://doi.org/10.1177/ 004056390907000306

Hans, B., 2008, 'Local children left fatherless', News24 Witness, viewed 30 June 2018, from https://www.news24.com/witness/archive/local-children-leftfatherless-20150430.

Holscher, D. \& Bozalek, V.G., 2012, 'Encountering the other across the divides: Regrounding social justice as a guiding principle for social work with refugees and other vulnerable groups', British Journal of Social Work 12, 1093-1112. https://doi.org/10.1093/bjsw/bcs061 
Hoogeveen, J.G. \& Ozler, B., 2005, Not separate, not equal: Poverty and inequality in post-apartheid South Africa, The William Davidson Institute at the University of Michigan, Ann Arbor, MI.

Human Science Research Council (HSRC), 2010, 'Tsireledzani: Understanding the dimensions of human understanding and the dimensions of human trafficking in Southern Africa', viewed 07 December 2018, from, www.hsrc.ac.za/en/ research-data/ktree-doc/8277.

Koop, I.I., 2005, 'Refugees in church asylum: Intervention between political conflict and individual suffering', Journal of Peace and Psychology 11(3), 355365. https://doi.org/10.1207/s15327949pac1103_8

Langmead, R., 2014, 'Refugees as guests and hosts: Towards a theology of mission among refugees and asylum seekers', Exchange 43(1), 29-47. https:// doi.org/10.1163/1572543X-12341301

Makou, G., Skosana, I. \& Hopkins, R., 2017, 'Factsheet: The state of South Africa's prisons', Africa Check, viewed 13 August 2018, from https://africacheck.org/ factsheets/factsheet-the-state-of-south-africas-prisons/.

McGee, R.S., 1993, Father hunger: In the hearts of many men and women is a hollow place: We long for the blessing that only a father can give, Servant Publications, Ann Arbor, MI.

McLellan, J., 2015, 'Religious responses to bereavement, grief, and loss among refugees', Journal of Loss and Trauma 20, 131-138. https://doi.org/10.1080/153 25024.2013.833807

Munroe, M., 2001, Understanding the purpose and power of men: A book for men and the women who love them, Whitaker House, New Kensington, PA.

Munroe, M., 2008, The fatherhood principle: Priority, position, and the role of the male, Whitaker House, New Kensington, PA.

Naja, W.J., Aoun, M.P., Khoury, E.L., Bou Abdallah, F.J. \& Haddad, R.S., 2016, 'Prevalence of depression in Syrian refugees and the influence of religiosity', Comprehension Psychiatry 68, 78-85. https://doi.org/10.1016/j.comppsych.2016.04.002

Namli, E., 2011, 'Identity and the stranger: A Christological critique of refugee politics', Political Theology 12(6), 813-829. https://doi.org/10.1558/poth. v12i6.813

Neumark, H., 2004, 'Church for refugees', Christian Century, 13 January, p. 9.

Nyberg, R., 2003, 'Bringing order from chaos: Churches help with refugees, hunger, and the lasting trauma brought on by war', Christianity Today 47(11), 39-41.

Perrin, P.B., Baker, J.O., Romelus, A.M., Jones, K.D. \& Heesacker, M., 2009, 'Development, validation, and confirmatory factor analysis of the father hunger scale', Psychology of Men \& Masculinity 10(4), 314-327. https://doi.org/10.1037/ a0017277

Polak, R., 2014, 'Migration als Ort der Theologie', in T. Kessler (ed.), Migration als Ort der Theologie, pp. 1-20, Verlag Friedrich Pustet, Regensburg.

Porobic, S., 2012, 'Resilience and religion in a forced migration context. A narrative study of religiousness as a resilience factor in dealing with refugee experiences 
from a post-migration perspective of Bosnian refugees in Sweden', Prikazi, Migracijske 'etnicke teme 28(3), 317-330. https://doi.org/10.11567/met.28.3.4

Ratele, K., Shefer, T. \& Clowes, L., 2012., 'Talking South African fathers: A critical examination of men's contributions and experiences of fatherhood and fatherlessness', South African Journal of Psychology 42(4), 553-563. https:// doi.org/10.1177/008124631204200409

Richter, L., Chikovore, J. \& Makusha, T., 2010, 'The status of fatherhood and fathering in South Africa', Childhood Education 86(6), 360-365. https://doi.or $\mathrm{g} / 10.1080 / 00094056.2010 .10523170$

Richter, L., Desmond, C., Hosegood, V., Madhavan, S., Makiwane, M., Makusha, T. et al., 2012, 'Fathers and other men in the lives of children and families', paper presented at the Strategies to Overcome Poverty and Inequality 'Towards Carnegie III' conference, University of Cape Town, Cape Town, 03-07th September, viewed 30 June 2018, from http://carnegie3.org.za/docs/ papers/231_Richter_Fathers\%20and\%20 other\%20men\%20in\%20the\%20 lives\%20of\%20children\%20and\%20families.pdf.

Robertson, L., 2018, 'Illegal immigration statistics', Factcheck.org, viewed 13 August 2018, from https://www.factcheck.org/2018/O6illegal-immigrationstatistics/.

Shore, M.H., 2016, 'Jesus as a refugee', Journal for Preachers, 40, 1-8.

Soares, D., Lotter, G.A. \& Van der Merwe, S.J., 2017, 'The missio Dei as context for a ministry to refugees', In die Skriflig 51(1), a2101. https://doi.org/10.4102/ids. v51i1.2101

Stringer, D., 2009, Hope for a fatherless generation: Rebuilding our foundations, Destiny Image, Shippenensburg.

The Herald, 2002, 'EC-mayor concerned over fatherless kids', The Herald, 18 April, p. 8.

Vick, K., 2015, 'The great migration', Time. Special Report. Exodus. The Epic Migration to Europe \& What Lies Ahead, pp. 26-34, October 19, 2015.

Warr, S., 2010, 'Counselling refugee young people: An exploration of therapeutic approaches', Pastoral Care in Education 28(4), 269-282. https://doi.org/10.108 O/O2643944.2010.481307

\section{Chapter 8}

Bevans, S.B. \& Schroeder, R.P., 2004, Constants in context: A theology of mission for today, Orbis Books, Maryknoll, New York, NY.

Bosch, D.J., 1991, Transforming mission: Paradigm shifts in theology of mission, Orbis Books, Maryknoll, New York, NY.

Burger, C., 2017, 'Why we need the missional conversation in South Africa now', in C. Burger, F. Marias \& D. Mouton (eds.), Cultivating missional change: The future of missional churches and missional theology, pp. 20-34, Bible Media, Wellington. 
Cape Town Commitment, 2010, A confession of faith and a call to action, The Luasanne Movement, viewed n.d., from https://www.lausanne.org/content/ ctcommitment.

Clark, D., 2015, Breaking the mould of Christendom: kingdom community, diaconal church and the liberation of the laity, 2nd edn., Fastprint, Peterborough.

Keum, J., 2013, Together towards life, World Council of Churches, Geneva.

Knoetze, J.J., 2012, 'Missionary diaconate: Hope for migrated people', Missionalia 40(3), 40-52. https://doi.org/10.7832/41-1-20

Mogensen, M.S., 2016, 'A missiology of sharing for the evangelizing and serving church', in R. Dowset \& I. Phiri (eds.), Evangelism and diakonia in context, Regnum Edinburgh centenary series, vol. 32, pp. 46-58, Regnum Books International, Oxford.

Myers, B.L., 2017, Engaging globalization: The poor, Christian mission, and our hyperconnected world, Baker Academic, Grand Rapids, MI.

Newman, B.M. \& Nida, E.A., 1980, A translator's handbook on the Gospel of John, United Bible Societies, London.

Niyonsaba, F., 2018, 'Mission is not only about preaching', International Review of Mission 107.2(407), 458-471. https://doi.org/10.1111/irom.12243

Ott, G. \& Strauss, S.J., 2010, Encountering Theology of mission, Baker Academic, Grand Rapids, MI.

Rooms, N., 2017, 'Missional anthropology', in C. Burger, F. Marias \& D. Mouton (eds.), Cultivating missional change: The future of missional churches and missional theology, pp. 306-319, Bible Media, Wellington.

Stiller, B.C., 2005, Preaching parables to postmoderns, Fortress Press, Minneapolis, MN. Wright, C.J.H., 2006, The mission of God, InterVarsity Press, Downers Grove, IL.

\section{Chapter 9}

Anon, 1990, 'South Africa's new era; Transcript of Mandela's speech at Cape Town City Hall: "Africa It Is Ours!", The New York Times, viewed 12 February 2018, from http://www.nytimes.com/1990/02/12/world/south-africas-new-era-transcript-mandela-s-speech-cape-town-city-hall-africa-it. html?pagewanted=all.

Bruce, F.F., 2008, Zondervan Bible Commentary, Zondervan, Grand Rapids, MI.

Calvin, J., 1845, Commentaries on Matthew, Mark and Luke by John Calvin, transl. W. Pringle, vol. 1, Printed for the Calvin Translation Society, T. Constable, Geneva.

Canda, E. \& Furman, L., 1999, Spiritual diversity in social work practice: The heart of healing, Free Press, New York, NY.

Du Plessis, A.L., 2018, 'The zone of non-being: When belonging becomes more important than being', In die Skriflig/In Luce Verbi 52(1), 1-8. https://doi. org/10.4102/ids.v52i1.2364 
Heyns, L.M. \& Pieterse, H.J.C., 1990, A primer in practical theology, Gnosis, Pretoria.

Jean, F., 1997, 'The plight of the world's refugees: At the crossroads of protection', in J. Groenewald \& E. Porter (eds.), World in crisis: The politics of survival at the end of the twentieth century, pp. 42-57, Doctors Without Borders, Routledge, London.

Johnson, T.M., 2005, 'Christianity in global context: trends and statistics', Pew research, viewed 08 February 2018, from https://www.pewresearch.org/wpcontent/uploads/sites/7/2005/05/051805-global-christianity.pdf

Kearney, R., 2010, Anatheism: Return to God after God, Columbia University Press, Chichester.

Louw, D.J., 2016, 'The refugee dilemma and migrant crisis: "Charity begins at home" or "being home to the homeless"? The paradoxical stance in pastoral caregiving and the infiltration and perichoresis of compassion', HTS Teologiese Studies / Theological Studies 72(2), 1-23. https://doi. org/10.4102/hts.v72i2.3267

Louw, D.J., 2017a, 'Ekhaya: human displacement and the yearning for familial homecoming: From Throne (Cathedra) to Home (Oikos) in a grassroots ecclesiology of place and space: Fides Quaerens Domum et Locum [faith seeking home and space]', HTS Teologiese Studies / Theological Studies 73(4), 1-11. https://doi.org/10.4102/hts.v73i4.4484

Louw, D.J., 2017b, 'Practical theology as life science: Fides Quaerens Vivendi and its connection to Hebrew thinking (Hālak)', In die Skriflig 51(1), a2239. https:// doi.org/10.4102/ids.v51i1.2239

Niebuhr, H.R., 1952, Christ and culture, Harper Collins Publishers, New York, NY.

Paas, S., 2016, Christianity in Eurafrica: A history of the church in Europe and Africa, Christian Literature Fund, Wellington.

Shawgrass, W., 1997, 'Protection of civilians in conflict', in J. Groenewald \& E. Porter (eds.), World in crisis. The politics of survival at the end of the twentieth century, pp. 1-15, Doctors Without Borders, Routledge, London.

Sills, M.D., 2015, Changing world, unchanging mission: Responding to global challenges, InterVarsity Press Books, Downers Grove, IL.

Van der Walt, B.J., 2003, Understanding and rebuilding Africa, Institute for Contemporary Christianity in Africa, Potchefstroom.

Van Hook, M., 2013, 'Resiliency and spirituality: A framework for assessing and helping', paper presented at the NACSW Convention, Atlanta, GA, 17-20th October.

Vorster, N., 2018, 'Reformed theology and "decolonised" identity. Finding a grammar for peaceful coexistence', HTS Teologiese Studies / Theological Studies 74(4), 1-21. https://doi.org/10.4102/hts.v74i4.4915

Wilson, B.R., 2018, 'Jew-Gentile relations and the geographic movement of Acts 10:1-11:18', The Catholic Bible Quarterly 80(1), 81-96. https://doi.org/10.1353/ cbq.2018.0004 


\section{Chapter 10}

Barton, G., 2019, 'Christchurch attacks are a stark warning of toxic political environment that allows hate to flourish', Abc.net, viewed 24 March 2019, from https://www.abc.net.au/news/2019-03-17/christchurch-attacks-stark-warningof-toxic-hate-flourishing/10909394.

Bosch, D.J., 1980, Witness to the world: The Christian mission in theological perspective, John Knox Press, Atlanta, GA.

Bromiley, G.W., 1995, The international standard Bible encyclopedia: Vol. Q-Z, Reprint edn., William B. Eerdmans, Grand Rapids, MI.

Brown, G. (ed.), 2016, The Universal Declaration of Human Rights in the 21st century: A living document in a changing world, Open Book Publishers, Cambridge.

Carter, W., 2000, Matthew and the margins: A socio-political and religious reading, Sheffield Academic Press, Sheffield.

Chester, T., 2011, A meal with Jesus: Discovering grace, community, and mission around the table, Crossway, Wheaton, IL.

Coalson, R., 2019, 'Christchurch attacks: Suspect took inspiration from former Yugoslavia's ethnically fueled wars', RadioFreeEurope RadioLiberty, viewed 24 March 2019, from https://www.rferl.org/a/christchurch-attacks-yugoslaviatarrant-inspiration-suspect-new-zealand/29823655.html.

Denton, R.A., 2018, 'Faith and South African realities in practising forgiveness', HTS Teologiese Studies/Theological Studies 74(4), 1-9. https://doi.org/10.4102/hts. v74i4.5176

Derrida, J., 2003, 'Autoimmunity: Real and symbolic suicides', in G. Borradori (ed.), Philosophy in a time of terror, pp. 87-136, Chicago University Press, Chicago, IL.

Derrida, J., 2005, On cosmopolitanism and forgiveness, Routledge, London.

Enright, R.D., 2011, Forgiveness is a choice: A step-by-step process for resolving anger and restoring hope, American Psychological Association, Washington, DC.

Enright, R.D. \& Fitzgibbons, R.P., 2000, Helping clients forgive: An empirical guide for resolving anger and restoring hope, American Psychological Association, Washington, DC.

Enright, R.D., Freedman, S.R. \& Rique, J., 1998, 'The psychology of interpersonal forgiveness', in R.D. Enright \& J. North (eds.), Exploring forgiveness, pp. 46-62, University of Wisconsin Press, Madison, WI.

Enright, R.D. \& North, J., 1998, Exploring forgiveness, The University of Wisconsin Press, Madison, WI.

Fozdar, F. \& Hartley, L., 2013, 'Civic and ethno belonging among recent refugees to Australia', Journal of Refugee Studies 27(1), 126-144. https://doi.org/10.1093/ jrs/fet018

Fuller, G., 1995, 'The next ideology', Foreign Policy 98, 145-158. https://doi. org/10.2307/1148963

Giddens, A., 1990, The consequences of modernity, Polity Press, Cambridge. 
Global Extremism Monitor (GEM), 2017, 'Violent Islamist extremism in 2017', Tony Blair Institute for Global Change, viewed 12 April 2019, from https://institute.global/ sites/default/files/inline-files/Global\%20Extremism\%20Monitor\%202017.pdf.

Hall, S., 1992, 'New ethnicities', in J. Donald \& A. Rattansi (eds.), 'Race', culture and difference, pp. 252-259, Sage, Newbury Park, CA in association with The Open University, London.

Henry, H.M., 2012, 'African refugees in Egypt: Trauma, loss, and cultural adjustment', Death Studies 36(7), 583-604. https://doi.org/10.1080/07481187.2011.553330

Hook, J.N., Worthington, E.L., Utsey, S.O., Davis, D.E., Gartner, A.L., Jennings, D.J. et al., 2012, 'Does forgiveness require interpersonal interactions? Individual differences in conceptualization of forgiveness', Personality and Individual Differences 53(5), 687-692. https://doi.org/10.1016/j.paid.2012.05.026

Huyse, L., 2003, 'The process of reconciliation', in D. Bloomfield, T. Barnes \& L. Huyse (eds.), Reconciliation after violent conflict: A handbook, pp. 19-33, International Institute for Democracy and Electoral Assistance, Stockholm.

Klaasen, J., 2016, 'Identity, race and faith: The role of faith in post-apartheid South Africa', HTS Theological Studies/Teologiese Studies 72(2), 1-5. https://doi. org/10.4102/hts.v72i2.3861

Knowles, M.D., 2004, 'Pilgrimage imagery in the returns in Ezra', Journal of Biblical Literature 123(1), 57-74. https://doi.org/10.2307/3268549

Kristjánsdóttir, E.S. \& DeTurk, S., 2013, 'Cultural insiders to cultural outsiders: Structure, identity, and communication in the adaptation of domestic, involuntary migrants', The Howard Journal of Communications 24(2), 194-211. https://doi.org/10.1080/10646175.2013.776340

Langmead, R., 2014, 'Refugees as guests and hosts: Towards a theology of mission among refugees and asylum seekers', Exchange 43(1), 29-47. https:// doi.org/10.1163/1572543X-12341301

Lerche, C.O., 1998, 'The conflicts of globalization', International Journal of Peace Studies 3(1), 47-66.

Louw, D.J., 2016, 'The refugee dilemma and migrant crisis: "Charity begins at home" or "being home to the homeless"? The paradoxical stance in pastoral caregiving and the infiltration and perichoresis of compassion', HTS Teologiese Studies/ Theological Studies 72(2), 1-11. http://dx.doi.org/10.4102/hts.v72i2.3267

Louw, D.J., 2017, 'Ekhaya: Human displacement and the yearning for familial homecoming. From throne (Cathedra) to home (Oikos) in a grassroots ecclesiology of place and space: Fides quaerens domum et locum [Faith seeking home and space]', HTS Teologiese Studies/Theological Studies 73(4), 1-11. https://doi.org/10.4102/hts.v73i4.4484

Magezi, V., 2017, “"Glocal” and integrated churches within a practical theological imagination of "home away from home": Towards a ministry of migrants and refugees in diaspora', Stellenbosch Theological Journal 3(1), 227-250. https:// doi.org/10.17570/stj.2017.v3n1.a11

McCullough, M.E., Fincham, F.D. \& Tsang, J.A., 2003, 'Forgiveness, forbearance, and time: The temporal unfolding of transgression-related interpersonal 
motivations', Journal of Personality and Social Psychology 84(3), 540-557. http://www.ncbi.nlm.nih.gov/pubmed/12635915.

Namli, E., 2011, 'Identity and the stranger: A christological critique of refugee politics', Political Theology 12(6), 813-829. https://doi.org/10.1558/poth. v12i6.813

Neufeld, D., 2005, 'The rhetoric of body, clothing and identity in the vita and genesis', Scriptura 90, 679-684. https://doi.org/10.7833/90-0-1058

Nyamnjoh, F.B., 2006, Insiders and outsiders: Citizenship and xenophobia in contemporary Southern Africa, Zed Books, London.

Oberdorfer, B., 2010, 'Human dignity and "image of God”', Scriptura 204, 231-239.

Phillips, D.J., 2000, 'The need for a nomadic theology', International Journal of Frontier Missions 17(2), 25-33, viewed 11 April 2019, from https://www.ijfm.org/ PDFs_IJFM/17_2_PDFs/nomadic_theology.pdf.

Rebelo, M., Fernández, M. \& Achotegui, J., 2018, 'Mistrust, anger, and hostility in refugees, asylum seekers, and immigrants: A systematic review', Canadian Psychology 59(3), 239-251. https://doi.org/10.1037/cap0000131

Scott, J.J., 1995, Jewish background of the New Testament, Baker Books, Grand Rapids, MI.

Soares, D.R., Lotter, G. \& Van der Merwe, S.J., 2017, 'The missio Dei as context for a ministry to refugees', In Die Skriflig/In Luce Verbi 51(1), 1-7. https://doi. org/10.4102/ids.v51i1.2101

Sonn, C.C., 2010, 'Engaging with the apartheid archive project: Voices from the South African diaspora in Australia', South African Journal of Psychology 40(4), 432-442. https://doi.org/10.1177/008124631004000406

South African History Online (SAHO), 2018, 'Xenophobic violence in democratic South Africa', viewed 16 April 2019, from https://www.sahistory.org.za/article/ xenophobic-violence-democratic-south-africa.

Taylor, J.E., 2017, 'Jesus was a refugee', Biblical Archaeology Society, viewed 24 February 2019, from https://www.biblicalarchaeology.org/daily/peoplecultures-in-the-bible/jesus-historical-jesus/jesus-was-a-refugee/.

Thesnaar, C.H., 2014, 'Seeking feasible reconciliation: A transdisciplinary contextual approach to reconciliation', HTS Teologiese Studies/Theologica/ Studies 70(2), 1-8. https://doi.org/10.4102/hts.v70i2.1364

Tidwell, A. \& Lerche, C.O., 2004, 'Globalization and conflict resolution', International Journal of Peace Studies 9(1), 47-59. http://www.gmu.edu/programs/icar/ijps/ vol9_1/Tidwell\&Lerche_91IJPS.pdf.

Tony Blair Institute for Global Change, 2018, 'Violent Islamist extremism: A global problem', viewed 27 March 2019, from https://institute.global/insight/coexistence/violent-islamist-extremism-global-problem.

UN General Assembly, 1948, 'Universal Declaration of Human Rights, Resolution 217 A(III)', viewed 26 March 2019, from https://www.un.org/en/universaldeclaration-human-rights/. 
United Nations High Commissioner for Refugees (UNHCR), 2019a, 'Population statistics database', viewed 25 March 2019, from http://popstats.unhcr.org/en/ overview\#_ga=2.170108643.2123346368.1553523512-1607783344.1553523512.

United Nations High Commissioner for Refugees (UNHCR), 2019b, 'UNHCR global appeal 2019 update', viewed 07 April 2019, from http://reporting.unhcr.org/ sites/default/files/ga2019/pdf/Global_Appeal_2019_full_lowres.pdf.

Viljoen, F.P., 2015, 'The double love commandment', In Die Skriflig/In Luce Verbi 49(1), 1-11. https://doi.org/10.4102/ids.v49i1.1869

Volf, M., 1996, Exclusion and embrace: A theological exploration of identity, otherness, and reconciliation, Abingdon Press, Nashville, TN.

Vorster, J.M., 2011, Menswaardigheid, versoening en vergifnis, Potchefstroomse Teologiese, Potchefstroom.

Vorster, J.M., 2017, Ethical perspectives on human rights, Potchefstroom Theological, Potchefstroom.

Vorster, N., 2007, Restoring human dignity in South Africa: Christian anthropology in a new dispensation, Potchefstroom Theological, Potchefstroom.

Walvoord, J.F. \& Zuck, R.B., 1985, An exposition of the scriptures by Dallas seminary faculty (The Bible knowledge commentary: Old Testament), Victory Books, Auckland.

Ward, V., 2019, 'Brenton Tarrant: The "ordinary white man” turned mass murderer', The Daily Telegraph, viewed 24 March 2019, from https://www.telegraph.co.uk/ news/O/brenton-tarrant-ordinary-white-man-turned-mass-murderer/.

Worthington, E.L., 2001, Five steps to forgiveness: The art and science of forgiving, Crown, New York, NY. 



\section{Index}

A

accept, 58-59, 86, 101, 104, 120, 229

acceptance, 10, 47, 50, 166-167

Africa, 1, 4, 13, 20, 31, 37-38, 41, 48, 51-60, 62-68, 70-72, 74, 76, 78, 80, 82, 84-85, 103-109, 112-117, 123, 125-126, 129-134, 136-138, 140-142, 144, 146-148, 151-158, 160-161, 163-164, 171-172,

174-176, 178-184, 186, 189, 193, 199, 207, 213, 216

African continent, 31-32, 37-38, 48, 66, 193

African, 4, 13, 20, 31-32, 34-35, 37-38, 40-46, 48-50, 54-57, 59-68, 71-72, 84, 90, 103-128, 132-134, 137, 140-143, 145, 153-155, 157, $163-164,175,180,193,215$

age, $37,132,134,156$

agencies, 112, 164-165

agency, 35-37, 110, 235

AIDS, 118, 122, 125

analogy, 171-172, 174, 176, 184

anxiety, 4, 10, 40, 61, 118, 126, 214, 224

awareness, 11, 28, 61, 99, 202, 209, 219

\section{B}

behaviour, 56, 91, 97, 122, 142, 155-156, $159,168-169,194-195$

Bible, 75, 99, 109, 114-115, 118, 120-121, 124, 127, 169, 172, 191, 194, $198-199,219-220$

birth, 8, 86, 91, 114, 141

business, 21, 42, 56-57, 63, 125, 179

C

care, 2, 7, 24, 28-29, 32, 42, 45, 65-66, 68-69, 72-74, 79,
81-82, 84-85, 87-88, 90, 94-96, 98-99, 116, 118, 134, 137-138, $140,142,144-145,161,166,170$, $175,185,190,201,203-205,212$, 218-219

challenges, 3, 8, 11-12, 31-32, 36, $38-42,45,47-54,56,58$, 60-62, 64-66, 68-70, 72-76, 78, 80-84, 86-87, 90, 94-95, 99-101, 103, 105, 111, 114-116, 118-121, 125-126, 129-131, 134-135, 137, 142-143, 148, 154-155, 168 , $170,176,185-186,190-191,197$, 208, 211, 213-214, 220, 222, 224 , 227-228

change, 11-12, 14, 17, 22, 33, 39-40, 110, 114, 178, 191-192, 197-198, 200, 203, 208, 210

character, 2, 19, 44, 115, 159, 185, 203

characteristics, 68, 116, 183

child, 12, 82, 132-133, 136, 141-145, $147-148,166,220$

children, 39, 61-62, 123, 129-149, 152, 154-157, 160-162, 165, 169, 181

Christ, 25-27, 73-74, 82, 89, 93-95, 98-99, 115, 124, 145, 149, 167, 177, 183, 187, 190, 193, 195-196, 200 , 203, 205, 218-219, 222, 228

Christian, 4, 8-10, 12, 21, 23-24, 27, 29, 43-44, 46-50, 70, 72, 83, 93, $95,97,99,101,109,113,115-116$, $120,125,131,135-136,140,146$, $148,169-170,173,175,186,196$, 200-201, 211, 216, 218-219, 222, 227

church ministry, 54, 190

church, 1-10, 12, 14, 16, 18, 20, 22, 24-28, 30, 41, 43, 49-54, 83-86, 
88, 93, 95, 99-101, 104, 108, 110, $112,115-125,127,131,135-142$,

144-146, 148, 164, 166, 171-174, 176-186, 190-194, 196-197, 200-202, 205

citizenship, 87, 94

city, 90, 138, 164, 197

coexistence, 18-21, 23, 223

community, 19, 27, 32, 40-44, 48-50, $60,64,66,68-71,80-81,83,88$, 91-92, 95, 99, 105, 108, 117-118, 137-138, 140-141, 144-146, $148,154,158,167,170,175-176$, 178-180, 182-186, 196, 209-211, $213,220,227$

compassion, 2-3, 10, 12, 15, 17, 21-22, 28-29, 41-42, 48, 50, 67-69, 72, 79, 81, 84, 88-89, 96, 166-167, 187, 201, 203-204, 207-208, 210, 212, 214, 216, 218-220, 222-224, 226-229

complex challenges, 51-53, 73, 84 composition, 203, 216 concept, 20-21, 33, 52-53, 65-76, $80,83-84,103,130,137,159$, 202-203, 216-218, 222

conception, 56, 59, 70, 81, 90 context, 24, 31-32, 37, 41-45, 53-54, 60-61, 65-66, 68, 71-75, 77, 82, 84, 86, 88-90, 92-95, 100-101, 104, 111, 126, 130-131, 155, 159, 161, 174-180, 182, 186, 189, 192, 196, 200, 209, 211, 213-214, 218, 225,228

contextual, 53, 86, 95, 100, 116, 130-131, 148

create, 3, 13-14, 19, 22-24, 28, 43-44, 49, 56-57, 72, 92, 148, 160, 183-184, 196, 204-205, 208, 219,227

creating, $5,14,18,20,23,26,34,47$, $56,69,151-152,154,156,158$, $160,162,164,166,168,170,193$, 208 creation, 56, 113, 144, 183, 185-186, 193, 202

culture, 22, 27, 64, 68, 73, 90-92, 99, $113,131,143-144,148-149,181$, 191, 197, 200, 209-210, 215-218, 224, 226, 228

\section{D} death, $8,34,74,104,114,142,178,187$, 191

defined, 6, 26, 66-67, 69, 81, 87, 109, 112, 130-131, 203, 210, 215, 224

democracy, 7, 116, 132, 155

design, 4, 11, 13, 15, 22, 24, 26, 29, 216 determination, 182, 185

develop, 19, 36, 50-53, 73, 84, 96, 98, 100-101, 125, 157

developing, 65, 84, 99-100, 197, 213

development, 18-19, 41, 62, 85-86, 95, 100-101, 103, 105, 116, 118, 125, 130, 133, 136, 144-145, 157, 160, $168,170,181,210$

dignity, 7-8, 29, 66, 68, 99, 120, 127, $136,151-152,154,156,158,160$, $162,164,166,168,170,193,202$, 204, 212-213, 215, 219, 222, 224, 226

displaced, 2, 4, 12, 15, 25-27, 32, 34-39, 41-46, 48-50, 86-87, 94, 101, 104, 117, 121, 126, 132 , 139, 148-149, 151-152, 154, 161-170, 189-191, 203-205, 208, 211-214, 218-222, 227-228

displacement crisis, 2-3, 16-17, 25, 29, 31, 162, 207, 212, 223

displacement, 1-4, 7-13, 16-17, 19, 22-23, 25, 28-29, 31-42, 45, 48-49, 51, 85, 87, 94, 101, 103-105, 129-130, 134-136, 143, 145-146, 148, 151-152, 161-163, 165-167, 171, 189, 197, 201, 205, 207, 212-213, 219-221, 223, 228 divine infinition, 190-191, 201-204, 206 


\section{E}

economic, 21, 33-34, 38-40, 49, 52, 100, 106-107, 110, 118-120, 125, 127, 134, 137, 162, 166-167, 179, 214-215, 221, 224, 226

education, 39, 49, 59, 61, 117, 124, 134 , 140-141, 157, 164, 182, 212

embodiment, 47, 67

enemies, 42, 77, 173-174, 195

environment, 45, 50, 59, 87, 95, 141, 214, 222, 224, 227

eschatological home, 86, 94, 96, 98, 101

eschatological, 86, 88-89, 93-98, 101, 173-174

eschatology, 86, 93-97

ethical, 7, 14, 24, 89, 95, 101, 117, 124, 136

ethics, 58, 67, 83, 95-97, 99, 121, 125, 229

Europe, 37, 40, 112, 163, 197, 213

exclusion, 60, 86, 143, 186

exploitation, 25, 40, 49, 57, 118, 145

\section{F}

faith community, 32, 41-44, 48-50, 117, 176

families, 34, 39, 72, 114, 125, 139, 141, 148, 154-155, 158, 160-161, 166, $169-170$

family, 26, 42-44, 49, 58, 71, 81, 91, 100, 121, 139-145, 147, 151-152, $154,156,159,161-162,168-170$, $175,185,213,219-220$

father absence, 152, 154

father, 139, 148, 151-152, 154-157, 159-161, 167, 169-170, 172-173

fatherhood, 151-152, 154-155, 157-161, 168-170

fear, 2, 6, 8-10, 14, 16, 19, 25, 34, 61,

$63,77,118,139,165,191,196$, 208, 210-211, 214-216, 224, 226, 228-229

flourish, 160, 256 foreigner, 2-3, 13, 52-53, 84, 134, 183 , 192, 212, 216-218, 221-222

forgiveness, 68, 89, 207-208, 210, 212, $214,216,218,220,222-228$

G

Genesis, 82, 195, 197, 219

globalisation, 44, 172-173, 197, 208-210, 213, 226, 229

God, 4, 22-24, 26-27, 43, 52-53, 73-77, 79-80, 82-84, 89, 93, 95, 97-98, 109-112, 117-120, 122, $124,127,136,138-139,143-146$, $152,157,161,166-167,169-170$, 172-178, 180, 182-187, 190-196, 201-205, 219-223, 227

Good Samaritan, 51-54, 65-66, 73-75, $77-78,80,82-84$

gospel, 74, 83, 89, 112, 115, 117, 120, $127,136,161,166,174,176-177$, 183, 186-187, 191-192, 198, 200, 202, 205

governance, 117, 123, 125

government, 34, 52, 55, 62-65, 71, 107-108, 116-117, 123, 126, 134, $165,178-179$

grace, 77, 120-121, 138-139, 161

Greek, 21, 27, 45, 93, 194

growth, 48, 104, 145, 168-169, 192, 197

\section{H}

healing, 11, 13, 17, 22, 29, 104, 109, 112-113, 115, 117, 119, 122, 167, 186, 191, 222-223, 225-227

health, 40, 49, 95-96, 98, 113, 115, $117-118,156,160$

heaven, 94, 117

hermeneutics of listening, 130, 136

hermeneutics, 9, 11, 14, 29, 94, 130, 136, 198, 202, 205

holistic, 42, 54, 114-115, 117, 147, 185

Holy Spirit, 109, 113, 202, 204

home away from home, 85-86, 139 
home, 1-2, 4, 6-10, 12, 14, 16, 18, 20, 22, 24-28, 30-34, 36, 38-51, 71, 85-94, 96-98, 100-101, 103, 105-106, 129-149, 151, 156, 161-162, 165, 171, 174, 182, 189, 194, 196, 207-208, 213, 216-217, 219-220, 227-229

hope, 7-8, 23-25, 34, 47, 118-119, $125,151-152,154,156,158,160$, 162-164, 166-170, 173, 177, 179-180, 204

households, 157, 161

human dignity, 7-8, 66, 99, 136, 222, 226

human displacement, 1, 3-4, 8, 10, 22, 32-35, 37, 41, 45, 48-49, 197, 201, 205, 207, 212-213, 223, 228 human rights, $70,86,122,132,166$, 211-212, 215-216

human, 1-10, 14-15, 20-22, 24-25, 27-28, 31-35, 37-42, 45, 48-49, $51,54,66-70,73,75,82-83$, 85-86, 90-91, 94-95, 97, 99, 103-104, 110, 113-114, 120, 122, 129-130, 132, 135-136, 141, 143-149, 151, 157, 162-163, 166, 170-171, 173, 178, 181, 183-185, 189-191, 195, 197, 201-205, 207, 211-213, 215-216, 219, 222-223, 226, 228

humanity, 7, 20, 52-53, 66-68, 81, $83-84,99,145,149,157,175,182$, 186, 196, 201, 203, 205, 222

\section{I}

Identity, 5, 7, 14-15, 18, 39, 44, 47, 50, 78, 81, 91-92, 97, 99, 134, 144, $148,151,157,162,165-166,168$, 184, 192-193, 204, 209-210, 213, 216, 218, 220, 223, 226

Imago Dei, 82, 222, 228 implementation, 99, 107 implications of, 183, 185 importance, 37, 122, 124, 131, 155, 178,193

inclusion, 5, 96, 131, 143 inclusive, 4, 27, 68, 86-87, 201

influence, 91, 95, 114, 119-120, 125, 155, 159, 173, 197-198, 225

injustice, 70, 113, 185, 222

integrity, 18, 88, 146

interpret, 53, 95, 118, 127, 186

interpretation, 21-22, 95, 121, 136, 175-176, 225

investigation, 62, 95

Israel, 75, 77, 79, 118, 173, 220-222

J

Jerusalem, 74, 78-79, 174

Jesus, 27, 52, 73-82, 89-90, 93, 97-98, 113, 143-144, 147, 149, 161, 166-167, 175-177, 180, 186, 193-195, 201, 218, 220, 222-223, 228

Jewish, 74, 77, 80, 167, 192

justice, $68,117,124,136,166,218,222$, 226-227

K

Kingdom of God, 74-75, 89, 93, 97, $122,174,176-177$

kingdom, 74-75, 77, 86, 88-90, 93-94, 96-98, 101, 113, 117, 122, 166, 173-174, 176-177, 179-180, 182-186, 190

L

language, 60, 73, 82-83, 93, 105-106, $140-142,148,198,210,217,228$

laws, 35-36, 41, 54, 58, 217, 221

leadership, 12, 106, 121, 123-125, 135 , 180,220

liberation, 120, 179, 184, 186, 193, 198, 222

listening, 21, 130, 136, 149, 198 love, 9, 25, 27, 72-73, 75-77, 79-83, 137-138, 140-141, 144-146, 148-149, 154, 161, 167, 184, 186-187, 195-196, 201-202, 218-219, 223, 226-228

Luke, 52-54, 65, 73-84, 89, 178, 192, 222 
M

Mark, 25, 122, 203, 217

media, 6, 44, 48, 63, 65, 113

mercy, 21, 23, 80, 138, 161, 203, 219-221

metaphor, 43, 48-49, 95, 99

migrants, 4-7, 10, 26, 29, 34-35, 37, $40,45-48,50-56,58,62,65$, 73, 83-88, 90-101, 105-108, 117-120, 124-127, 133-134, 138, 147, 162-165, 171-186, 213-214, $218,221,224$

migration, 2-3, 5-7, 11, 22, 32-38, 40, $48,51-52,54,56-58,60,62$, $64-66,68,70,72,74,76,78,80$, 82, 84, 86-88, 91-94, 99-100, 105, 107-108, 118, 130-133, 136, 143, 146-147, 149, 151, 162-163, $165,172-173,177-178,180$, 182-184, 186, 207-208, 211-214, 219-220, 223, 228

mission, 74, 103, 112, 114, 172-174, $176-178,182,185,196$

missional church, 172, 183

moral, 3, 10, 17, 25, 66-67, 69, 109, 116, $120,163,225$

morality, 25, 119, 193

N

narrative, 41, 46, 50, 52-53, 55, 73, 78, $80,82,84,135,138,178,192-193$, 219-221

nature, $62,89,97,105,108,114,176$, $195,202,223,225$

need, 13, 23, 39, 51, 53, 73, 75, 77, 79, 81-82, 87, 89-90, 98, 101, 111, 113-115, 118, 120, 127, 169, 177, 180-181, 183-186, 203-204, 218, 226

neighbourliness, 52-54, 65-66, 73-75, 80, 83-84

neo-pentecostal churches, 109, 115-117, 124-125

neo-prophetism, 104, 111-112, 114, 117, 121, 124-127

network, 9, 42, 201, 211 nostalgia, 31-32, 34, 36, 38, 40, 42, $44-48,50$

nurture, 142, 146, 167

0

Old Testament, 75-76, 166, 173-174, 202

operative ecclesiology, 2, 24-25, 30, 85-86, 93

orphans, 137, 169, 221

P

paradigm, 4, 11, 18, 32, 42-43, 48-49, 131, 174, 178, 190, 198, 202, 206

parent, 145, 161

parents, 61, 132, 134-135, 140, 144-145, 148, 156-157, 161

participation, 16, 19, 23-24, 119, 121, 123, 136, 169, 181, 186, 221

pastoral care, 32, 42, 45, 94-95

pastoral encounter, 189-192, 194, 196, 198-200, 202, 204-206

peace, 18-19, 71, 91, 97-98, 113, 117, 137-138, 141, 148, 191, 209, 226

people, 3-4, 6-7, 11, 13-14, 16, 20, 23-25, 27, 29, 33-39, 44, 46, 48-49, 52-59, 61, 63-69, 71-83, 86-87, 89-101, 106-107, 111-115, 117-118, 120, 124-127, 130-132, 138-140, 144, 146-149, 154, 156, 161-167, 169, 172-175, 179-181, 183-184, 186, 190-191, 197, 199, 204, 208-215, 219-229

philosophy, 66, 139

politics, 9, 12, 20, 34, 119-121

poor, 2, 34, 62, 82-83, 106, 108, 111, 118, $122,125-126,156-157,165-166$, $168,173,179,218,222-223$

population, 105, 112, 115, 118, 152, 158 , 197, 214, 228

poverty, 107, 113-115, 117, 120-121, $125,133,155,163,165,198$, 213-214, 224

power, 14, 110-111, 113-114, 117, 120, 134, $136,143,178,185,217$ 
practical theology of home, 130, 132, 135-136, 142

Practical Theology, 1, 23, 31, 51, 70, 85, 95, 103, 129-132, 135-136, 142-143, 145-148, 151, 171, 189-190, 203, 207

praxis, 11, 18, 41, 131, 202, 204

prayer, 120, 169

prison, 151-154, 156-159, 161, 168, 199, 223

process, $11,14,18,35,46,79,99-100$, 113, 136, 152, 174, 193, 198-199, 204, 218, 223, 225-227

prophecy, 103-104, 106, 108-118, 120, $122-124,126,128$

prophetic, 109-113, 119-123, 125, 128, 222

prophets, 27, 97, 104, 109-113, 115, 117-120, 122-127

protection, 15-16, 35, 123, 134, 138, 142, 144, 154, 165-166, 213, 215, 221-222, 224

purpose, 73-74, 88, 91, 95, 105, 110, 144-146, 157, 159, 173, 191, 226

\section{$\mathbf{R}$}

reciprocal, 88, 216, 224, 228

reciprocity, 68,146

recognition, $13,47,50,82,88-89,97$, 146, 178, 202, 205, 229

reconciliation, 207-208, 210, 212, 214 , $216,218,220,222-228$

refugee, $2-3,6,9-10,18,28,32,35-37$, 44, 130, 132-135, 137, 142-143, 147, 151-152, 161-167, 194, 197, 212, 214, 216, 218, 220, 228

refugees, $4-7,10,12,18,32,34-35$, 37-38, 40-41, 44-45, 48, 86-87, $105,107,118,124,126,132,134$, 136, 138-140, 161-167, 169, 173, 189-191, 196, 205, 207-208, 211-216, 218-220, 222-225, 227-228

relation, $67,130,137,146,173,192$, 200, 219, 223

relational, 14, 18-19, 67, 82, 139, 141, $144-145,225$ relationship, 44, 69, 78, 82, 87, 97, 111, $124,145-146,160,168,176,182$, 200, 208, 225

representation, 108, 216

research, 2, 5-6, 35, 39, 44, 54, 70, 76, 103, 105-106, 111, 118, 125 , 133-135, 137, 139, 154, 156-157, 159, 168, 190-191, 205, 215

resilience, 152, 168-169, 190, 200, 202-205

resources, 19, 38, 40, 92, 99-100, 107-108, 131, 142, 179, 190, 205, 209, 215, 224

responsibilities, 89, 146, 186

responsibility, 16, 57, 97, 117, 120, 127, $140,145,168-170,177,222$

rhetoric, 198, 211

rights, 35, 41, 61, 70, 86, 107, 122-123, 132, 136-137, 143, 166, 211-212, 215-216, 224

risk, 11-12, 61, 100-101, 118, 126, 139, 157, 194, 198, 217-218

Roman, 27, 104, 109, 192

Romans, 180, 203

\section{S}

salvation, 68, 74, 77, 104, 113-114, 227

school, 61-62, 123, 139, 153, 160, 181-182

scripture, 75, 121, 202-203

separate, $86,135,146$

services, 107, 115, 123, 131, 142-143, 152-153, 158, 160-161, 168-169, $175,179,215,224$

$\sin , 79,89,157,161$

social relations, 42, 208, 224

societies, 3, 9, 20, 68-69, 71, 82, 120, $125,163,208-210,212,215,223$, 226, 229

society, 2, 7-9, 12, 20, 30, 39, 66-68, $88,103,108,113-114,116,131,136$, 148-149, 152, 154-157, 160, 166, $168,170,172,174,181,185,190$, 195, 208, 216, 222-224, 226-229

socio-economic, 118-119, 125, 162

solidarity, 11-12, 15-17, 19, 23-24, $29-30,68,97,121,185$ 
soteriology, 115, 117

soul, 21, 23-24, 76, 185

South Africa, 1, 13, 20, 31, 41, 51-60, $62-68,70-72,74,76,78,80$, 82, 84-85, 103, 105-109, 116, 126, 129-134, 136-138, 140-142, 144, 146-148, 151-158, 160-161, 163-164, 171-172, 174-176, 178-184, 186, 189, 193, 199, 207, 213, 216

space, $8,10,13-16,18-20,22,25$, $43,88,95,137,139,141,143$, 146-148, 151-152, 154, 156, 158, 160-162, 164, 166, 168, 170, 178, 180, 183, 196, 204-205, 211-214, $218,221,223,228-229$

spaces, 40, 42-44, 49, 63, 131, 136, $147,149,180,182,186$ status, $6,27,34-36,83,123,134,136$, 145-146, 149, 152, 167, 218

stigmatisation, 214, 223

stories, 19, 66, 167, 199

story, 53, 65, 73, 77-78, 81-83, 90, 135, $173,176-177$

stranger, 7-8, 12, 26, 41-42, 48-50, $138,165,189-192,194-196$, 198-206, 208, 211-212, 216, 218, 221-223, 227

streetwise ecclesiology of home, 2 , 26, 28

suffer, 21, 40, 57, 60, 62, 154, 228 suffering, 3-4, 6, 19-22, 26-27, 116, $138,152,185,187,218-219$ sustainability, 23, 28

\section{T}

temple, 79, 220

theological theory, 51-52, 54, 73-75, 80,84

theology, 1-3, 9, 11, 21-25, 31, 51, 70, 72-73, 85, 88-89, 95, 103, 109, $115,127,129-132,135-136,142-143$, 145-148, 151, 158, 171, 185, 189-191, 198, 203, 207, 219, 227 transformation, iv, 4, 90, 94, 124-125, $127,148,177,218,224$

\section{U}

Ubuntu, 20, 44, 48, 50, 52, 54, 65-73, 84, 117

unaccompanied migrant children, $129-136,138,140,142,144-146$, $148-149$

urban, 61, 105, 146-147, 174, 197

\section{V}

value, $8,32,39,44-45,69,123-125$, 131, 146, 166, 182, 201, 203-204, 209

values, 10, 14, 18-19, 40, 66, 68, 72, 114-117, 140-141, 144, 146-147, $168,183,201,209,226$

violence, $6,8,13,19,35,37,39-40,59$, $61,64-65,107,125,138,156,160$, 163-164, 181, 210-212, 226, 228

virtue, $26,70,94$

vulnerable, 3, 34-35, 39-40, 49, 63, $114,124,162,165-166,169,175$, $178,221,223,228$

\section{W}

well-being, 9, 23, 90, 97, 114-115, 118, $136,144-145,147-148,156,210$, 221

wisdom, 21, 23, 180, 203, 220

women, 39, 155, 157-158, 164, 179

written, 74-75, 111, 122, 162, 171-172

\section{$\mathbf{x}$}

xenophobia, 2, 4, 8, 10, 15, 23, 25, 28-29, 40, 49, 56-57, 61, 64, 103-108, 116-120, 125-127, 139, $142-143,152,163,175,179,184$, 196, 208, 210, 212, 214-216, 228

Y

youth, 124, 142, 156, 160 

This scholarly collected work is written by practical theologians who see Africa as their home and who are enthused to participate in the academic discourses related to the phenomenon of displacement and migration. The authors approach their research with an empathetic compassion for affected people. They link their scientifically based pastoral approach to operative ecclesiologies seeking solutions to the trauma of displacement and migration. The book represents a valuable attempt at a practicaltheological and also a critical-theological reflection at the intersection of the Christian faith and those who find themselves without a home and without hope.

\section{Prof. Dr lan Alfonso Nell, Department of Practical Theology and Missiology, Stellenbosch University, Stellenbosch, South Africa}

In this book, social responsive theological research converges in order to provide practical theological and ecclesiological perspectives on the growing human dilemma of displacement. The book presents the research of practical theologians, a missiologist and a religious practitioner whose work pertain first and foremost to the (South) African context. The book engages the critical questions of what kind of church would be relevant in today's world and what kind of care should the church provide in the face of the growing predicament of human displacement. The theological and theoretical principles uncovered in the different chapters are functional for academic exploration and use by theologians from multidisciplinary research areas focusing on communities that are challenged with the growing realities of strangers on their doorsteps and in their pews.

\section{Prof. Dr Andries G. van Aarde, Commissioning Editor, AOSIS Scholarly Books, Cape Town, South Africa}

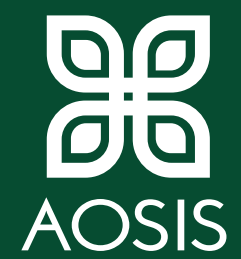

aosis.co.za

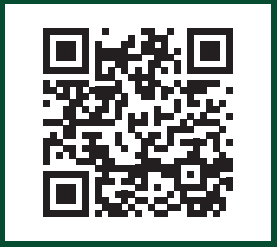

Open access at https://doi.org/10.4102/ aosis.2020.BK198

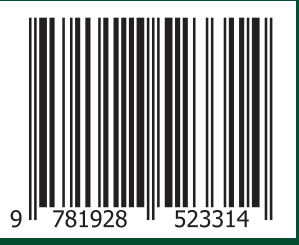

ISBN: 978-1-928523-31-4 